\title{
UMASS/ARHERST
}

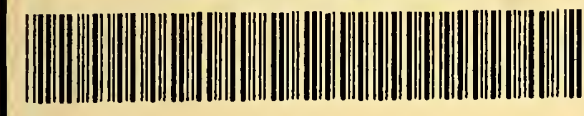

312066005858556

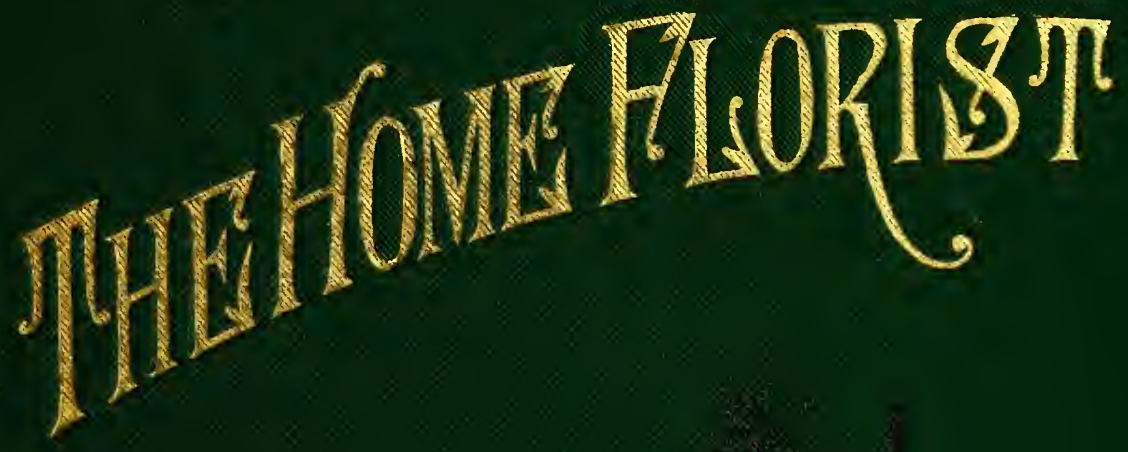




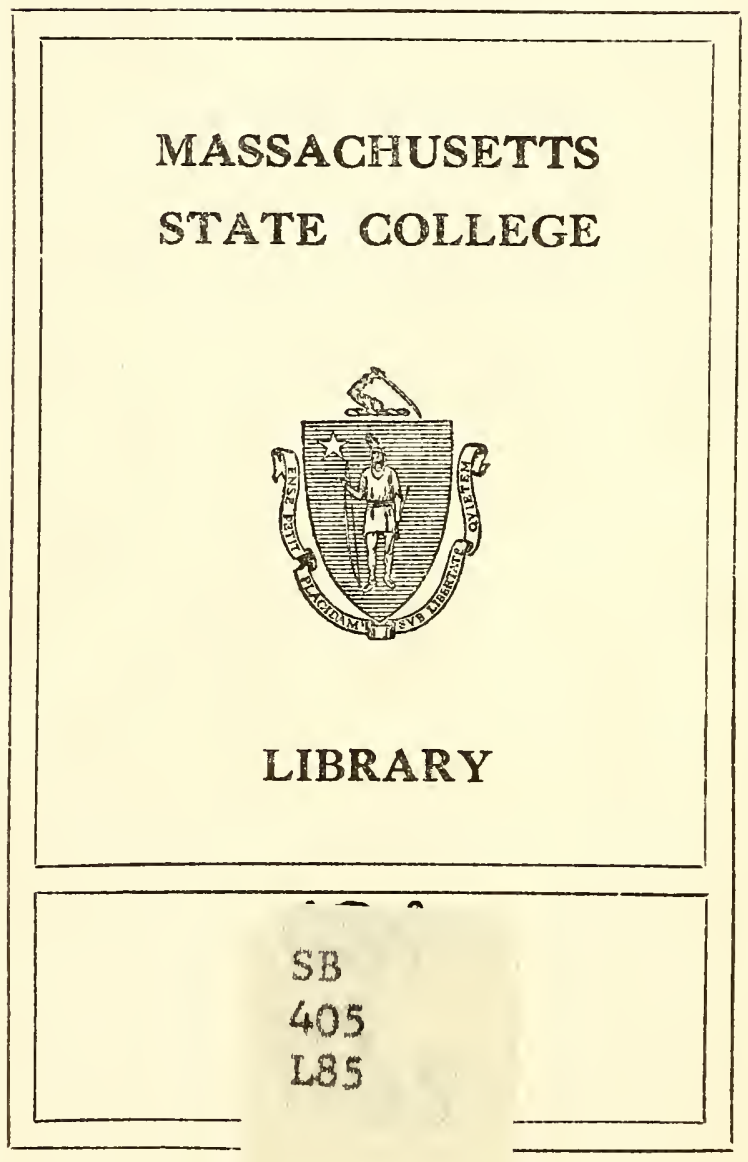


This book may be kept out

\section{TWO WEEKS}

only, and is subject to a fine of TWO CENTS a day thereafter. It will be due on the day indicated below.

OC' 171955 







\section{HOME FLORIST:}

A TREATISE ON THE

CULTIVATION, MANAGEMENT AND ADAPTABILITY

OF

\section{FLOWERING AND ORNAIIENTAL PLANTS,}

DESIGNED FOR THE USE OF

\section{AMATEUR FLORISTS.}

BY ELIAS A. LONG,

Author of "Ornamental Gardening for Anericans."

REVISED AND ENLARGED.

ILLUSTRATED.

SPRINGFIELD, OHIO.

CHAS. A. REESER, SEedsian and Florist, PUBLISHER.

1885. 


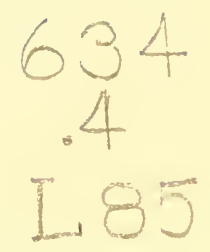

ENTERED ACCORDING TO ACT OF CONGRESS, IN THE YEAR 1885, BY C. A. REESER,

IN THE OFFICE OF THE LIBRARIAN OF CONGRESS, AT WASHINGTON.

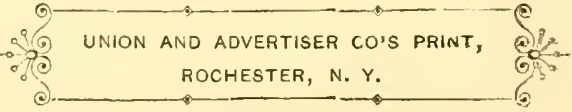




\section{N D EX.}

Abelia.................. $\quad$ I 24

Abutilon.................... 125

A ca!ypha.................. 120

Achania.................... 127

Achillea ................... 127

Achimenes................. I27

A chyranthus................... I27

Acroclinium................. I 28

Adam's Needle .................... 308

^.gapanthus.... $\quad \ldots \ldots \ldots \ldots \ldots \ldots$ 128

Agave .................... 129

Ageratum.................. 129

Agrostemma................. I30

Airing House Plants........... 47

Akebia....................... I30

Allamanda................. I $\mathbf{3}^{\mathbf{1}}$

Aloysia ................... I

Alternanthera................. I32 $^{3}$

Althea...................... I 32

Alyssum .................... I 33

Amaranthus...$\ldots \ldots \ldots \ldots \ldots \ldots \ldots$........ 1 33

A mary'lis.................... 134

Amateur's Conservatory........... 55

American Pampas.............. I92

Ammobium.................. I 34

A momum ....................

A morphophallus................ I 35

Ampelopsis ..................... I35

Anemone................... 136

Animated Oats................. I 37

Anthericum ................. 137

Antirrhinum ................... 337

Annuals described................ 122

Aphis or Green Fly............ 47

Aquilegia................... 139

Ardisia..................... 1 39

Aristolochia.................. 139

A rmeria ...................... 1 39

Artillery Plant................ 281

Asclepias .................... 139

Aspidistra.................. r 40

Astiıb...................... 142

Aster........................... r40

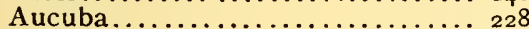

Azalea.................... I42

Balm... .....................

Balsam.................... I 42

Banana...................... 259

Begonia .................... I 44

Showy Leaf............. I 49

Tuberous rooted... ..... I 50

Beginners, advice to ............. 7

Bellis perennis............... J 87

Biennials, what are $\ldots \ldots \ldots \ldots \ldots$...... 23

Bignonia...................... 150

Bonapartia................... I 50

Bougainvillea..................... 150

Boussingaultia................. I I $^{\mathrm{I}}$

Bouvardia ...................

Browallia ....................... I 53

Brugmansia...................

Bryophyllum ................. I54

Bulbs, autumn planting of ......... 32

Buttercup.................... ${ }_{286}^{52}$

Cacalia........................ 54

Cactus................................... 155

Cactus Dahlia................. 186

Caladium ......................... 155

Calandrinia................... I 55

Calceolaria........................ 156
PAGE.

Calendula.................. 557

California Poppy.............. I93

Calla....................... I 57

Calla, Spotted ................... 288

Calliopsis................... I 58

Calycanthus.................. I 59

Camellia................... I 59

Campanula................. I60

Campsidium ................ r $6 \mathrm{r}$

Campylobotrys ............... I6r

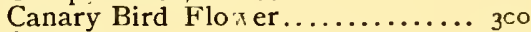

Candytuft $\ldots \ldots \ldots \ldots \ldots \ldots \ldots \ldots$ r 6 I

Canna...................... I

Cape Marigold.... . . .......... I 57

Cape Jasmine................ 245

Cardinal Flower............. 253

Carnation ................... 162

Carpet Bag Flower............ r ${ }_{56}^{6}$

Castor Oil Bean................... 288

Celosia.................... I65

Centaurea .................... 165

Centradenia................. I 66

Century Plant................. 129

Cereus ................... 166

Cestrum.................... 167

Cherianthus..................... 307

Chorozema.................... 167

Chrysanthemum................ I 68

Cigar Plant................ $18_{2}$

Cineraria.................. I7

Cissus Discolor ............... I 7 I

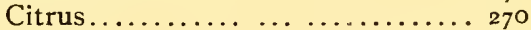

Clarkia................... I7

Clematis.................... I72

Clerodendron ................ I73

Cocoloba.................... I74

Cockscomb ................. r $6_{5}$

Coix Lachryma................ 229

Coleus...................... I74

Columbine................... I39

Cold Frames................ 28

Cold Pits for Winter............ 34

Convolvulus................ I77

Conservatory, Amateurs.......... ${ }_{56}^{6}$

Heating .............. 57

Plans with cost........... 57

Small.................. 59

Summer Management........... б. ó

Winter Management...... . 6r

Convallaria ...................25

Comparative Value of Plants...... I24

Coral Tree..................... I93

Coreopsis.................... I 58

Crape Myrtle................. 245

Crocus .................... I 8

Crotons ........................ 179

Crown Imperial................ 182

Crowfoot.................... 286

Cuphea............................ 82

Cups and Saucers.............. ${ }_{28}$

Cuttings, Propagation from....... 35

Cyclamen................. I 82

Cyperus..................... 183

Cypress Vine................. 239

Cytisus..................... 184

Daffodil.......................262

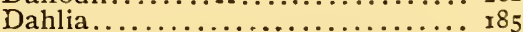

Daisy........................ I8

Daphne......................... 18

Deutzia.................... I 89

Delphinium................... Is 
Devil-in-a-bush............... ${ }_{26} 66_{4}$

Dew Plant................... 256

Dianthus.................... I 89

Dicentra................... Igo

Dieffenbachia................ Igo

Digitalis. ................. I00

Dracena.................... I

Drives..................... I9

Dutchman's Pipe................ I 39

Dwarf Morning Glory........... I77

Easter Lily.................. I 34

Echeveria.................. IgI

Eranthemum ................ I 92

Epiphyllum................. I 55

Erianthus.................... I 92

Erysimum ................... I93

Erythrina................... I 93

Escholtzia .................. . 193

Ethiopian Lily ............... . . 57

Eucharis................... I93

Eulalie...................... I93

Euonymus.... ................ . . I94

Eupatorium.................. I95

Everlasting Flowers.......... I95, 230

Evening Glory ............... . 234

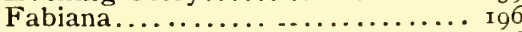

Farfugium.................. Ig6

Ferns..................... I96

Feather Grass............... 229

Fertilizers for pot plants........ 49

Ferneries................... 5 I

Feverfew................. I97

Ficus..................... I 8

Fittonia .................... 229

Flora's Paint Brush.............. I 54

Floriculture, open air.......... 2 I

Floriculture, work of each week... 3 Io

Flower Beds, locating............ I I Beds for constant cutting... 24

Designs for............. 20

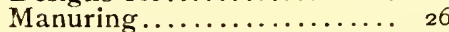

Mixed borders............ 24

Planting in masses......... 2 I

Ribbon beds............. 23

The soil................. 25

Flower de Luce... . . . . . . . . . 239

Flowering Maple............. I 25

Forget-Me-Not ............. $260^{\circ}$

Forsythia ..................... 198

Fountain Plant............... I 34

Four O'Clock................ $25^{8}$

Fox Glove.................. r go

Fritillaria................... 182

Frozen Plants, how to treat....... 5 I

Fuchsias ................... Ig9

Double varieties......... 20 I

Single varieties.......... 200

Winter-blooming ........ 203

Funkia................... 203

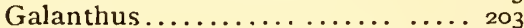

Gardenia .................242, 245

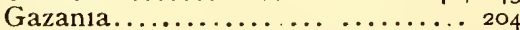

Geraniums.................. 205

Doubie ................ 211

Golden Bronze............ 223

Golden Tricolor........... 218

Ivy-leaved.............216

Lady Washington ......... 274

Scerted and Cut-leaved..... 222

Silver-leaved ............. 220

Single or Horseshoe....... . 206
PAGE.

Gesneria.................... 225

Gilyflower ................. 295

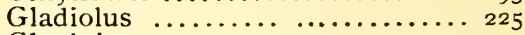

Gloxinias .................. 227

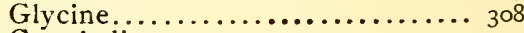

Gnaphalium .................. 227

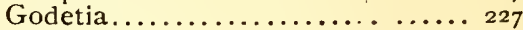

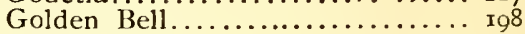

Gold Dust Shrub . . . . . . . . . . . 228

Golden Feather............... I98

Goldfussia.................. . . 228

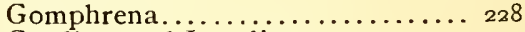

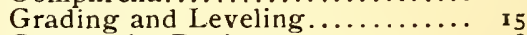

Grasses for Drying... ........ 228

Gymnostachyum.............. 229

Gynerium...................229

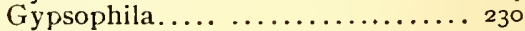

Habrotliamnus.............. 230

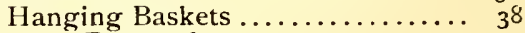

Plants for.............. 40

Heart's Ease................ 272

Hedera ................... 240

Helianthus................. 230

Helichrysum ................ $23^{\circ}$

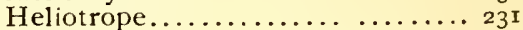

Helipterum................ 232

Hesperis.................. 232

Heterocentron ............... 232

Hibiscus... . .............. 232

Hotbeds... .............. 28

House, Plant culture about the .... 42

Hollyhock .................. 234

Honeysuckle................ 234

Hoya ............. ..... 235

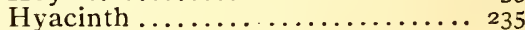

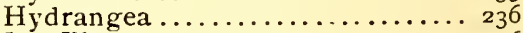

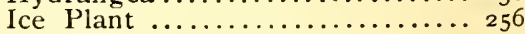

Impatiens . . . . . . . . . . . . . . 237

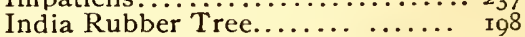

Insects................... Angie Worms........... 49

A phis or Green Fly $\ldots \ldots .47,6_{3}$

Injurious to Roses.......... I 17

Mealy Bug ..........47, 64

Red Spider............47, 64

Scale................ . 49,64

Introduction ................. 6

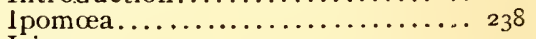

Iris....................... 239

Isolepsis................... 240

Ivy . . . . . . . . . . . . . . . 240

Ivy, German or Partor........... 293

Ivy, Kenilworth............. 252

Ixora... $\quad \ldots \ldots \ldots \ldots \ldots \ldots \ldots 2^{2}$

Japonica $\ldots \ldots \ldots \ldots \ldots \ldots \ldots$. 59

Japanese Chrysanthemum ....... . I69

Japanese Maize.............. 242

Jasmine .................. 242

Jerusalem Cherry... . . . . . . . . . . 294

Jessamine.... ... ............ 242

Job's Tears................... 229

Jonquil ...................... 262

Joseph's Coat................. I34

Justicia .................. 245

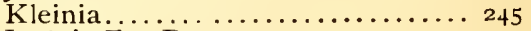

Lady's Ear Drop................ I99

Lady in the Green ............ 264

Lady's Slipper................ I 42

Lagerstromia .............. 245

Landscape Gardening, Notes of ... 9

Breadth................ Io 
Landscape
Beds, designs for... ... Flower Beds, locating........ I Grading and Leveling...... I5 Planning the Work......... I The Lawn .............. I 7 The House.............. Io Things to be avoided........ I2 'Tree Planting............. I7

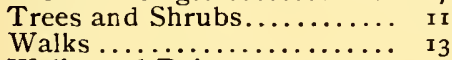
Walks and Drives........... Ig What is desirable in a place.. 9

Lantana.................... 245

Lathyrus..................... 297

Laurestinus. . .............. 247

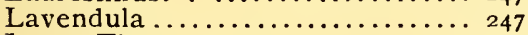

Lawn, The............... . I 7

Seeding down ............ 18

Sodding..................

Layering, Propagation by ........ $3_{3}^{6}$

Lemon...................... 270

Lemon Verbena.............. I $3^{\mathbf{I}}$

Leptosiphon .................... 247

Libonia...................... 248

Litting Plants.................... $32, \quad 33$

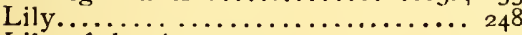

Lily of the A mazon............... 193

Lily, Calla or Ethiopica.......... I 57

Lily of the Valley .............. 251

Lily, Water....................... 264

Lilium ...................... 248

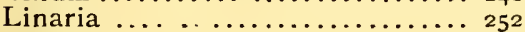

Linum...................... 252

Lobelia....................... 252

Lonicera...................... 234

Lopezia..................... 253

Lophospermum................. 253

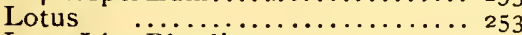

Love Lies Bleeding............... 190

Lupine....................... 254

Lupinus........................... 254

Lychnis........................... 254

Lycopodium ....................... 202

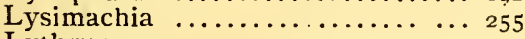

Lythrum ................. 255

Madeira Vine.................

Maherni $\ldots \ldots \ldots \ldots \ldots \ldots \ldots \ldots \ldots . \ldots 255$

Maize........................ 242

Manettia ................... 255

Manuring Flower Beds.......... 26

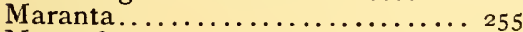

Marıgold.......................... 256

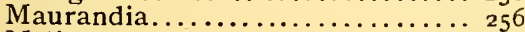

Melissa ...................... 1 44

Mesembryanthemum $\ldots \ldots \ldots \ldots \ldots 256$

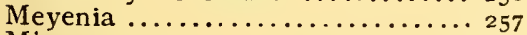

Mignonette.................... 257

Mildew.................... 64 " On Roses.................

Mimosa....................... $22^{2} 8$

Mimulus....................... 258

Mirabilis........................ 258

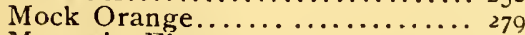

Moccasin Flower.................. ${ }_{15} 6$

Moisture, Maintaining............ 47

Moneywort........................ 255

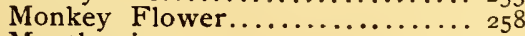

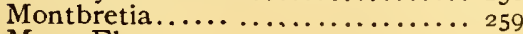

Moon Flower................. 239
Morning Glory............... PAGE.

Mourning Bride................... 2QI

Musa..................... 259

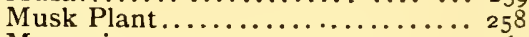

Myosotis.......................260

Myrsiphyllum............... 260

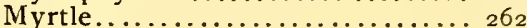

Myrtus.................... 262

Narcissus......................... 262

Nasturtium .................... 299

Nemophila....................... $26_{3}$

Nierembergia................ $26_{3}$

Nerium................... 265

Nigella................... 264

Night Blooming Cereus.......... . I66

Nymphæa.................. $26_{4}$

Olea....................... 265

Oleander................... 265

Olive...................... . 265

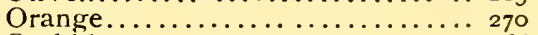

Orchids.................. 266

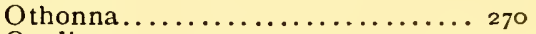

Oxalis..................... 27

Paconia..................... 27

Palms.................... 271

Pampas Grass................ 229

Pampas, American ............ I92

Panicum................... 272

Pansy.................... 272

Papaver.... ............... 284

Passion Flower................ 274

Passiflora.................. . 274

Pea Flowering............... 297

Pelargonium..............205, 274

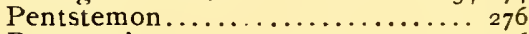

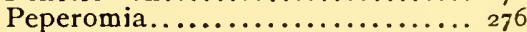

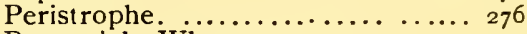

Perennials, What are............ I23

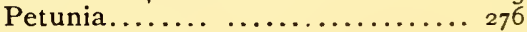

Philadelphus................. 279

Phlox..................... 279

Pilea........................ $28 \mathrm{n}$

Pilogyne..................... 281

Pinks.. ...................

Pittosporum............... 282

Planting Roses, a new method of.. Izo

Plants, House, managing, etc..... 42

Description of ......... 40, I 22

Do Plants poison the air of rooms............... 55

Frozen, How to Treat...... 5 I

Keeping clean............ 49

Planning Gardens ............... I $_{3}$

Plantain Lrly ............... 203

Plumbago...................... ${ }_{28}$

Poinsettia................... 282

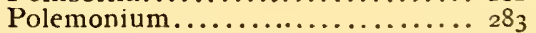

Polyanthus $\ldots \ldots \ldots \ldots \ldots \ldots \ldots \ldots .283$

Polyanthus Narcissus... .......... 262

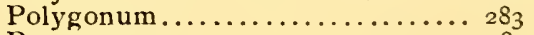

Pomegranate ......................... $28_{3}$

Pond Lily.................... $26_{4}$

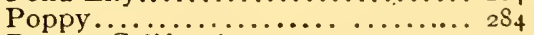

Poppy, Californian .............. I93

Portulaca................... $28_{4}$

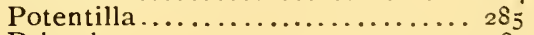

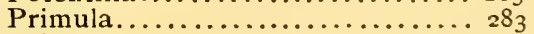

Primula...................... 285

Prince's Feather.................... I34

Propagation......................... $\sigma_{3}$

Protection for House Plants....... $4_{46}^{6}$ 
Protection for Roses........... II Pruning House Plants.... .... 49 Pruning Roses .. ............. I 7 Pyrethrum................. I97 Ragged Robin................. 254 Ranunculus.................. 286 Reineckia................. 287 Removal of Matured Flowers..... $3^{I}$

Reseda................... 257

Rhodanthe................. 287

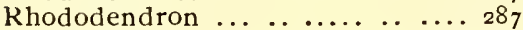

Rhyncospermum....... ..... 288

Richardia.................... 288

Ricinus ...................... 288

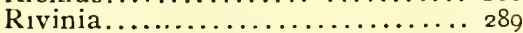

Rondeletia................... 289

Rose Garden, the ............... II6 For Pot-culture and Winterblooming ............ 12I Insects Injurious to ........ II 7 Mildew and Rust on......... r 18 New method of Planting..... I 20 Protection during Winter.... IIg Pruning ............... I I 7

Rose of Sharon................ 132

Roses, Cultivation and managem'nt 116 Roses, Pot Fertilizer for .. ...... 50

Roses....................... $6_{5}$ Bourbon ............... 85,87 Bengal or China........85, 9o Climbing............68, 79

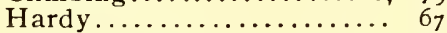
Hybrid Perpetual.......67, 68 H৮brid Tea...........86, I 10 June or Summer........68, 82 Moss ... ..........68, 80 Noisette.............86, I07 Polyantha ............ 87 , I 4 Prairie................. 70 Tea-scented .......... 85, 92 Tender-Monthly......... 84

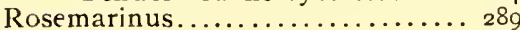

Rosemary..................... 289

Ruellia..................... 289

Russelia ..................... 289

Rust on Roses................. . . п 8

Salvia..................... 290

Salpiglossis ..................... 289

Sanchezia ...............291

Saucer System of Propagation... . . 38

Saxifraga.................. 291

Scábiosa................... 291

Schizophragma .............. 237

Scuttelaria................... 29I

Sea Pink.................. I39

Sedum. ..................... 292

Seed-beds .................... ${ }_{2} 8$

Seeding down Lawns............

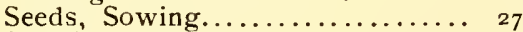

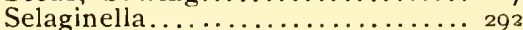

Stlection of Plants.... ......... 44

Sempervivum................ 293

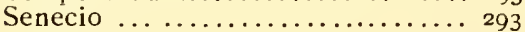

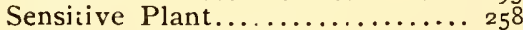

Slips, Propagation from........... 35

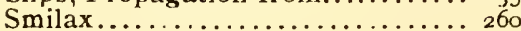

Snapdragon...................... I 37

Snowdrop.................. 203

So 1 ding.................... I9

Soil The; Preparation and Treatm't 25 Trenching
PAGE,

Solanum.................... 293

Sowing Seeds...............27, $3^{\mathrm{I} 2}$

Spirea ...................... 294

Spirea Japonica................ I $42^{2}$

Stephanotis.................. 294

Stevia.. .................... 294

Streptosolen .................. 297

Stock...................... 295

Summer Culture.............. 30

Summer Watering.............. 30

Summer Management of Conserva-

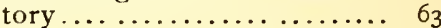

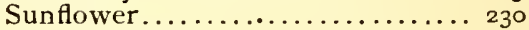

Sweet Alyssum................ I33

Sweet Pea................... 297

Sweet-scented Shrub............ I59

Sweet William.............. 190

Tabernæmontana............. 298

Tagetes......................256

Tecoma...................... 298

Temperature ................ 44

Thunbergia................. 298

Thyme ................... 299

Tiger Flower................. . 299

Tigridia .................... 299

Torenı.................... 299

Tradescantia................ 299

Transplanting..................... 30

Trees and Shrubs, locating.......... I I Planting............... I 7

Trellises, Plants for............ 40

Trenching....................... 26

Tritoma.................. 302

Tropæolum.... ............. 299

Trumpet Creeper.............. r 50

Tuberose.................. 30 I

Tulip..................... 300

Vallota...................... 302

Vases, Garden... ............... $3^{8}$ Plants for.............. 40

Verbena....................... $30_{3}$

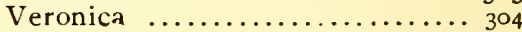

Viburnum................... 305

Viola Tricolor.................. 272

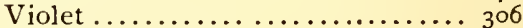

Virginia Creeper................ ${ }^{1} 35$

Virginian Stock, ............. 305

Walks .................... 19

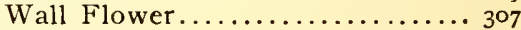

Wandering Jew.................. 299

Wardian Cases................. $5 \mathrm{I}$

Watering, Summer................. 30

House Plants............. 47

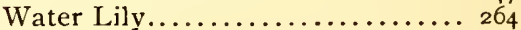

Wax Plant................ $\quad 235$

Weigela.... . ............. 307

Window Boxes.............. 43

Window Plant Culture.......... 42

Winter-blooming, Roses for........ I2 I

Winter Culture of House Plants, .. 44

Winter Flowering, Preparing plants for.............. 31

Winter Managm't of Conservatory 6r

Winter Plant Quarters, the. ..... 44

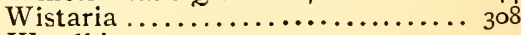

Woodbine.................... 234

Work arranged by weeks ........ 3ro

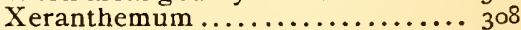

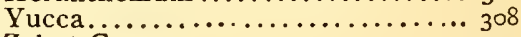

Zebra Grass...... . ........... r94

Zinnia......................... $3^{208}$ 


\section{Preface to the Revised Edition.}

When the HoMe Florist was written, ten years ago, I did not realize that it was destined to fill the useful place in the gardening literature of our country, which it has done by the kindness of a most forbearing public, towards its many and conspicuous shortromings. The original work was written hastily in snatches of time between the pressing duties of a complicated business, and was always far from satisfactory to me, owing to its many faults, mostly due to hasty composition. In the present revision pains have been taken to make amends for past defects, while considerable new matter has also been added. The work now goes forth in the belief that it will more fully than it ever could in the past, meet the demand for information on the subject of flower growing about the home, and adapted to the wants of amateurs.

Elias A. Long.

Buffalo, N. Y., July 19, 1884. 


\section{INTRODUCTION.}

THE cultivation of plants for the sake of their beautiful flow-

ers, and other attractions, has from the earliest ages received attention wherever civilization has made some progress. Floriculture as an art, however, is so susceptible to influences of climate, soil, heat, cold and other conditions, that, notwithstanding it may claim antiquity, anything like general progress in all lands has been impeded by reason of this very fact. Whatever knowledge may have been gained in the art, during one age or in one country, when applied to another, is found to be practically useful only to the extent in which it finds a state of adaptability in the other. Hence. it may be said that in each nation the practice of Floriculture is peculiar, and differing from that of every other nation.

In our own country the cultivation of plants and flowers has only of late years received any great degree of attention. While from the first it was, of course, realized that the practice must be somewhat distinct from that of other countries, now after some years of practical schooling, we may claim to have adopted a system which is entitled to be considered in the fullest sense, as American. It has been only about twenty years since a general manifestation of interest in Floriculture, by the masses of people, has been apparent, but from a preceptible awakening, about that time, there has been a continual and rapid increase, until now, when we find nearly everybody devoting more or less attention to the culture of flowers.

What is felt to be the greatest need of the day in the further promotion of Floriculture, is the more general dissemination of correct knowledge concerning the kinds of plants and flowers most suitable for the American cultivator, and also regarding their culture, all brought down to such a simple matter as to be adapted to the wants of inexperienced amateurs. It is with an appreciation of such a need that the author and publisher of the present work take pleasure in presenting it to the public, as a book 
of instruction, relative to the proper means of managing many kinds of plants used for the adornment of American homes. It is designed to aid all classes of cultivators, but especially those who aspire to the rearing of a choicer class of plants and flowers than are common in perhaps the majority of homes where Floriculture is now receiving attention; aiming to carry those who adopt its teachings over obstacles which tend to cause failure and discouragement, and to promote an interest in every plant that is cultivated.

A good indication of progress in amateur Floriculture is shown at the present time, in the fact that the people are learning that more than only seeds, or bulbs, or plants alone, are required for beautifying gardens and homes with flowers; that in the best kept gardens judicious selections of some of each should be used for producing the finest results. No matter, scarcely, to how limited an extent the culture of flowers is engaged in, it can be better done, and becomes more interesting, by including in the stock cuitivated, perennial greenhouse plants, hardy bulbs, tubers and seed-grown plants-than by limiting the stock to varieties of any one class. Even where the stock must be purchased from the florist and seedsmen, this rule will hold good, no matter how small is the amount to be invested. I have seen gardens where none but annuals and other seed-grown plants were employed, which were beautiful during the entire summer season, and I always advise persons who expend but little for floral decorations to depend largely on these for their flowers. But where richness of color, exquisite fragrance, and strong contrasts in foliage are sought, some green-house plants and bulbs are also required. Planting even a few scarlet Geraniums, Lantanas, Gladiolus, Heliotropes, Hyacinths and other hardy bulbs, monthly Roses and others along with the seed-grown kinds, will add to the grounds a brilliancy of coloring and afford an abundance of bloom daily from early in the spring until October, and with many, eren in November, which would be impossible with seed-grown things alone. It is also a great feat to nicely stock a hanging basket, vase or window box without the use of green-house plants.

New beginners sometimes have over-ambitious ideas in regard to selecting stock for their first attempts. It is a poor plan for such to invest largely in all kinds of stock found in the catalogues as a first step. Let them begin by selecting sorts that are known 
to be easily grown, and then gain all the information possible relative to treatment, soil, time of sowing, etc., and be sure to devote to these their best attention the season through. Thus it: will be found that even a few choice plants, besides the product from half a dozen packets of flower seeds will give far more real enjoyment to the cultivator than a hundred things in a neglected condition, through ignorance of what they need. And let me warn even the most careful new beginners that they must expect to meet with some little difficulties and drawbacks, which, by unpropitious weather, or other causes, always will attend flcricultural operations. In these the young florist who has a love for the work and its fruits should find no cause for being discouraged. The most skilful florist has always something to learn; and no mistake will be made but you will be wiser for it, and the better prepared for future emergencies. Success, gained at the expense of slight failures and inconveniences, will be enjoyed the more for them afterwards. After each succeeding season's experience you will see the safety of striking out more boldly in purchases and plans, and each year will place you higher up that scale to perfection which every cultivator of flowers aspires to.

Buffalo, N. Y., October, 1874.

E. A. L. 


\section{THE HOME FLORIST.}

\section{Notes on Landscape Gardening.}

As being somewhat distinct from laying out large grounds, parks, etc., the present chapter is devoted to that more limited branch of rural adornment about homes, in which the majority of people outside of the crowded parts of large cities are interested, and the planning of which usually devolves upon the owners or occupants. That a marked degree of incongruity and dull ness exists in the ground improvements of the majority of American homes cannot be denied, but this perhaps arises oftener from lack of useful information, ignorance of correct principles, and through not fully realizing the importance of thoroughly executing work of this nature, than from any real want of appreciation of what is tasteful and elegant in ornamental gardening in the minds of the people.

What is Desirable in a Place.-To be most delightful, a place of residence should be surrounded with ground of sufficient area to devote some parts to a fine lawn, others to flower beds, shrubbery, trees, etc., in groups or singly, and then the necessary walks and drives, besides it may be arbors, fountains, a conservatory, rockeries, fern gardens, lakelets, etc. The area need not be very extensive to allow of some or all of these and be rendered very attractive, provided the arrangement is in good taste, and all operations which contribute to the improvements are thoroughly performed, and the after care is what it should be. 
In all cases of improving grounds the house should be considered as the chief feature with which we have to deal, and the chief point of vision in a place. When the house is already present, and the grounds have been improved in a measure, perhaps all that may be desirable will be to introduce some new improvements, or to remove or alter any features which are found to be objectionable. With homes that are still in contemplation, there is the advantage of being able to arrange the various features at will, giving to each and all ample study and forethought, and then finally deciding upon such a plan as combines the greatest number of excellencies.

Largeness of extent is no doubt very desirable in ornamental grounds, but the fact that everything connected with construction and maintenance requires a good deal of labor and expense, must never be lost sight of. In every'instance it would be better to decide upon a retraction of area, than to attempt work on a large scale with too small an outlay. Surroundings consisting of a fourth of an acre of land, improved in the most perfect manner, will be infinitely more satisfactory and enjoyable to the owner than a half or whole acre, with the same amount of labor and expense bestowed upon the improvements. There is such a thing, too, as augmenting the appearance of extent in a place, be it large or small.

A garden of any size will always look more limited in breadth without a good open piece of lawn, and one broad glade of grass at least should stretch from the best windows of the house to within a short distance of the boundary at the farthest point, with as little interruption from walks, trees or other objects as possible. Harmony of parts and simplicity of arrangement also maintain the idea of size, for where everything is linked together to form a united whole, there will be none of that division of interest which tends to make a place appear still smaller. A place that is laid out in a formal manner-in the geometrical stylewhere all walks, flower beds and plantings are arranged with a degree of regularity, in which the various lines and parts bear a geometric relation to each other, will, unless very extensive, always look smaller than it really is, and very much less than one treated in a more irregular and natural way. Where the space will at all justify it, the walks, shrubs, flower beds, etc., should be so disposed of as to afford as many different views as possible. 
Walks, in which graceful and easy curves are introduced, are more pleasing than if made entirely straight, especially ix small places, as straight walks or any straight lines reuuire length to show them to advantage.

Trees and shrubs are always more effective if arranged largely in groups,making the planting heaviest next the boundary fences -in preference to the style of planting in straight lines, parallel with the street, straight walks, etc. The projections, made by curves in winding waiks and the points formed by angles, are suitable for accommodating groups, having these extend back from the walk somewhat, but the inner points should be limited to such a distance as will keep the centre of the grass plat open. It will be allowable, however even in a small place, to plant here and there some what centrally, small, irregular groups or single trees or shrubs of fine form and appearance, while in large places stronger groups may be set with a view to breaking the distance and opening new scenes or parts in the grounds.

Flower beds are most effective if located in outward bends, formed by walks, or in chaste, well-balanced designs, thrown across the line of a walk or opposite a bay or other window of the dwelling. They may also come in as borders or in the shape of numerous small beds of round or other forms, on each side of walks, or be located at distant points on the lawn, to be viewed from the dwelling or street. Sometimes an excellent effect is created by making a compound bed in the line of the walk, with the walk passing on each side and through it, as shown in Fig. 14.

Where there is an opportunity of connecting a lawn with a closely fed meadow or pasture lot, which is almost on the same level, separating the two by means of a wire fence or one constructed in a depression, either natural or artificial, a place, may be enlarged in appearance. If some groups of trees were to be planted in such a meadow, they might be made to impart to it quite a park-like character.

It is frequently possible to keep some object outside the grounds in view from a principal window or garden seat, and where, from its attractiveness, it may seem desirable to do so, the planting of trees should be done to effect this. It may be a neighboring village, a distant mountian peak, or a steeple, or some edifice possessiag an air of romance, and perhaps the plantings may be so ar- 
ranged as to give it a beautiful setting between the trees. By Fig. 1 , it will be seen how, if a desirable view is in the direction of $A$ the trees should be planted on each side of the line of vision, to keep the object in sight. Sometime an object in some direction possesses an offensive appearance, making it desirable to shut it from sight. In the same figure we will suppose such is the case in the direction of $B$. It is plainly noticeable how trees can be thrown across the line of vision to entirely hicie the object. For this latter purpose, evergreens are to be pieferred, because of their being continually in foliage.

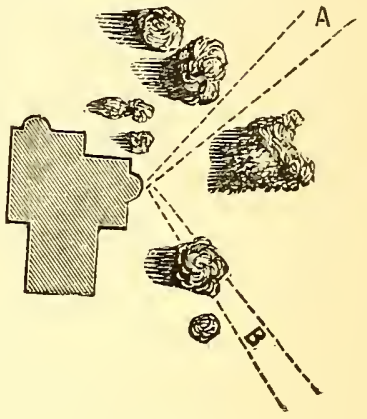

Fig. 1.

Things to be Avoided.-In the first place let me say, avoid attempting too much by applying the labor and expense necessary to put a place of a certain size in order to one of twice or three times the size, and consequently doing the work onehalf or one-third as well.

Simplicity is a prime element in beauty, and nothing can be more objectionable, in small places especially, than intricacy of design, or the prevalance of an air of ostentation. Avoid crowding numerous flower-beds or groups of shrubs or trees about the lawn, especially if it be a small one.

In deciding upon a plan for your place, avoid the two extremes of exposing it too much, or of rendering it too secluded by planting too many, especially of large growing trees. Errors are frequently committed in planting Hardy Evergreens and Deciduous trees, by not taking " one long look ahead." Many instances have come under my observation where Norway Spruce, Pines, or other trees, which, with age, grow to large size, have been planted while small close to walks, or perhaps the fence, house, or other trees, in groups, without calculating for their future growth or spread. Such mistakes are not so evident to the planter while the trees are young, but after some years of growth, and after it is too late to remedy the matter, they encroach upon the walks or house or injure other trees, which it is now also noticeable where planted too close.

Planting ornamental trees is a work requiring forethought. It is not altogether for the present immediate effect that it is done, but for time far distant as well, and one needs to have the full- 
grown form, size and appearance in his mind's eye at the time of planting, if he would avoid making blunders which never can be corrected.

Never locate walks and drives unless there is either a real or apparent need of them. Walks may lead to a flower bed in the lawn or to a seat or a:bor, or be carried through the outskirts of the grounds, but there should always be a meaning connected with their existence-some objects of interest in close proximity to them, or to be seen from various points along their course. A writer of note has well said that "a walk leading nowhere and ending in nothing is never satisfactory." A practice which should never be allowed in walks and drives is for two bays or two projections on the same side to be seen at once. Use curves, as many as may be desired, but no serpent-like twistings. Avoid, however, making the curves too short ; they should be fair and continuous, and reasonably direct, otherwise in a roadway a horse drawing a carriage would be likely to shave projections and avoid the indentations, and the track of the wheels would soon show the fault of the design.

In this country, where we are subject to severe dry spells almost every Summer, terraces (earth thrown up above the common surface, and made uniformly level, usually), should, as a rule, be avoided, unless means are at hand for watering the grass growing upon them whenever necessary. The same might be said of rockeries, unless they can be constructed in a shady situation, or where they can be readily sprinkled in dry weather.

The introduction of miscellaneous ornaments about gardens, such as statuary. groups of stones, artificial basins of water, or other objects of similar nature should be undertaken with caution, for although there are places in which these may be desirable, yet it is easy to have more than are compatible with correct taste. A vase filled with vigorous plants seldom appears out of place.

Planning the Work. - The best time to avoid the bad effects which naturally arise from a poor arrangement of ornamental grounds, is before the work is commenced. How this may be done, is, by making an outline plan of the grounds to be improved upon paper, locating existing objects, such as the dwelling, outhouses, trees that may be standing on the grounds, the highway, etc., in their correct position on the map, and then with 
a pencil, do the planning throughout upon this, until a satisfactory plan has been arrived at, which can be transferred to the grounds in parts, as the work of improving goes on. It does not require much skill to draw the necessary map for this purpose, as the grounds or their outlines serve to guide the making of it. With a pencil, rubber, and foot-rule (with the inch and the divisions of the inch marked upon it) you can get along well enough, as regards drawing instruments. First measure each boundary with a measuring tape-or a ten-foot pole will do (land surveyors would use a Gunter's chain), representing each in its relative position on the paper by a line reduced to a certain scale-say an inch to represent sixteen or thirty-two feet on the ground; then measure the distance the house and other objects are from the boundary line and from each other, locating these correctly on the map by the scale adopted. Being such objects as well as the boundary lines will not be changed in the design, their outlines may be drawn with ink on the map, to prevent erasure subsequently. The map is now ready for locating the various features to be introduced into the plan ; this should be done with a lead pencil, to allow of erasing and changing as often as may be necessary, until a plan is found which suits the place and the taste. Every object to be introduced should be drawn by the adopted scale of measurement and located in its correct position, so that it can easily be transferred to the ground by measuring when operations are under way, Occasionally, as the work of planning progresses, each feature should be viewed from various directions by holding the upper surface of the paper nearly in line with the eye; to get a better view of them, as they will appear on the grounds. The reason of this is obvious, when we consider that objects upon a landscape or garden are viewed in this way, the beholder standing upon the level of the grounds and not above them.

It is well to make several maps and draw a different plan upon each, thus securing the means of making comparisons and choosing the one which combines the greatest number of good points. Fac-similes of the first map are easily produced for this purpose by laying this one on top of half a dozen or less papers of the same size, and then running the point of a sharp instrument down through the papers at the corners of all angles and the various points on the map. This will mark each paper to guide the drawing of lines for making fac-similes of the upper one. 
Too great care cannot be taken in making various plans and in finally deciding upon one, for any inconsiderateness in these respects may be the source of regret afterwards. This is work for the leisure hours of Winter, and it should be engaged in early enough, so that each and all distinct features that suggest themselves may be deliberately pondered over and studied in their relation to the whole design, for, bear in mind, when a plan is once fully decided upon and the work of completion executed, it is done for a long time distant in the future, and will stand as a monument, pointing either to the wise and deliberate or to the reckless action of the projector.

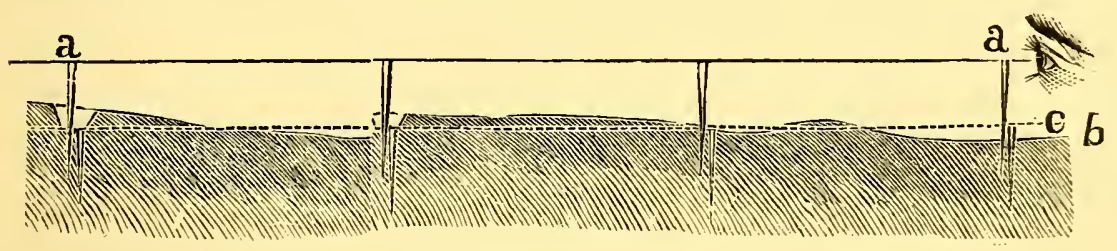

Fig. 2. Arranging Stakes to Facilitate Grading.

Grading and Leveling.-After the plan has been completed, the work of grading the surface-generally more or less uneven, is first in order. Grading is one of the distinguishing features of a complete garden, and if nice and evenly done, does more to give to grounds, otherwise well improved, a finished appearance than any other one operation. The lawn if properly made will then present the appearance of a carpet of velvety green, and flower beds, shrubs and trees will stand in delightful relief above the surface. The propriety of preserving natural undulations, or attempting artificial variety of surface in moderatesized or small grounds is always questionable; although in large grounds planted in irregular style these, if softly and appropriately finished off, may be made to improve the general appearance of the grounds.

The work of grading is commenced by passing over the grounds and leveling, being guided only by the eye; all elevations should be plowed up and the ground from them should be hauled or scraped into the depressions which may exist. It should, howerer, be observed, that at least six inches of good soil overlay the whole in all places, and where any considerable hills are remored sufficient subsoil is also to be removed to be replaced with topsoil to this depth. Wherever walks and drives are to come the ground 
may now be excavated to a proper depth for filling in with the road material and be used in low places. When this rough grading is completed, drains should be laid wherever necessary, after which the work should be planned for finishing the grading to a nicety. To do this it will be necessary to set guide stakes in rows across the grounds, driven down so that the heads be in line, and exactly marking where the new surface is to come. How to accomplish driving the guide stakes so that the heads will be in line I shall presently explain. If a heavy rain can be had on the grounds before the work at this stage is advanced, it will be all the better, otherwise it will become necessary, with the finishing work, to leave the ground sufficiently elevated wherever filling in of low places was done, to allow for perfect settling.

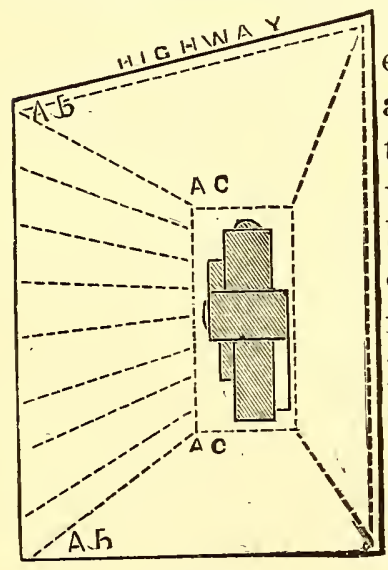

Fig. 3.

In Fig. 3 we will suppose the ground on each side of the dwelling slants away towards the boundaries. The first step to take towards setting the stakes for guiding the work of final grading is to pass along the boundary and drive a stake at each corner of the Iot to a depth so that its top will represent the desired new grade in each place. Then similarly drive four corresponding stakes around the dwelling, seteach far enough from the corner to enable sighting from it to the next one to it on all sides of the house. After this, stakes are to be set in rows across each section or slant of the grounds to guide the leveling; but, as this can only be done over one part at a time, we will illustrate how to proceed by directing the reader through each step of setting the stakes on the wide plot of ground laying to the left of the house in Fig. 3. Let us suppose that the line $b$ in Fig. 2 represents the surface between the corner stakes driven at $A b$ and $A c$ in the upper part of Fig. 3, and that the stakes shown at each end of this sectional cut, with their heads to line $C$, are these two corner stakes $(A b$, $A$ c, Fig. 3). Now drive a new stake at the side of each of these stakes, but with the heads, we will say, exactly 18 inches above them. These stakes are for the purpose of sighting over to place three or fire or more stakes between the two corner ones. One person should sight while another drives the stakes; the former observing and directing the depth they are to be driven. This 
sighting is illustrated in Fig. 2. After these intermediate stakes are set, another stake should be driven at the side of each, with the top 18 inches lower than top of the sighting stake, which it is obvious will bring the heads of them in line with the corner stakes just driven, as is shown by dotted line $C$ in Fig. 2, which is the line of the desired grade. If the surface is wanted slightly crowning in the center between the corner stakes, by keeping the lower stake at the center less than 18 inches below the top of the sighting stake and gradually increasing the measure between the top of the upper and lower stake as you proceed towards the corner, this may be easily done. We next proceed with the sighting and staking operation along the boundary, from the upper corner stake $A b$, to the lower corner stake $A b$, and also from $A$ $c$ to $A c$, driving the same number of stakes on each, although line $A b A b$ is much longer than the other. The distance they are to be apart on each line may be arrived at by guess, as it is not material that they be exactly alike. A good way is to set one at what would be taken as half way between the corner stakes, and then dividing the distance to the corner on each side in the same way, and so on until enough have been placed, being cer. tain, however, that the same number are on each line After this is done, crosslines of stakes are to be run from each stake in line $A b$ $A b$ to the corresponding stake in line $A c A c$, in the manner described in my reference to Fig. 2 , commencing at one end of the plot. The other quarter sections around the house are each in turn to be laid out in the manner I have described, after which the work of leveling may finally be completed. With these stakes at ten, fifteen or twenty feet apart each way, it is easy to grade the earth evenly between them. With the completion of grading and the removal of the stakes, we are brought to making walks and drives, and sowing the lawn.

The Lawn ; Tree Planting.-A good lawn, clean and well kept, one which presents a lively green appearance, from early in the Spring until cold weather, is a sight worth witnessing, and one well worth expending a good deal of labor and money upon to obtain. After the ground is shaped to the desired grade, as described above, then the whole should be trenched or plowed, a sub-soil following in the wake of the common plow to deeply pulverize it. The soil from the first furrow made in plowing will be thrown above the common level, and after the piece is overturned this should be drawn or wheeled into the open 
furrow left by the plow in finishing, that all may become even again. A heavy harrow should then be applied until the surface is thoroughly fined down. It may now be noticed by the careful eye that slight undulations still exist here and there about the grounds; these can be leveled with a shovel or hoe. All stones, roots, etc., should also be removed, so that a smooth surface may be obtained ; these will be found useful for filling, in making walks and drives. To facilitate the work of tree planting, which next should receive attention, small stakes should be set at the points marked on the plan ; the planting should be done carefully and without unnecessary digging or disturbing the graded surface. After this the harrow or, better yet, the rake may again pass over the surface, with afterwards the roller, and the lawn is ready to be sown. For small plats, of course, digging, trenching and raking must be done, instead of plowing, sub-soiling and harrowing. Do not fall into the common error of using seed sparingly. Four bushels to the acre is the proper quantity. The Red Top or Blue Grass are about the best, or the "mixtures" of desirable kinds that are furnished by reliable seedsmen. It is well to add a pound or two of Sweet Vernal grass to the acre for the delightful fragrance it emits after being cut; also a quantity of White Clover, say one or two pounds to the acre. These are usually included in the mixtures prepared by seedsmen.

When the seed is sown, a light harrow or rake should be applied, and after that a thorough rolling given, so that the surface may become as smooth as possible. The seed may be sown in the Spring, during April and early May, or even earlier at the South, and will form a good lawn by August, if the preparation has been good. If not ready to sow before June or July, a sprinkling of oats should be sown at the same time, so that the shade given by the oats will protect the young grass from the sun. But rather than sow during the hottest weather, I prefer to put it off until September, which is one of the best of times for the work. Frequent mowing of the grass and the weeds, let me add, should be attended to from the first, The weed seed lying dormant in the ground at sowing time, may spring up thickly with the grass, but will finally succumb to the frequent use of the lawn mower or scythe, and some hand digging later, while the grass will improve in strength and appearance with each cutting. Mowing every week or two will not be too often. The grass, if it is very heavy, should be raked off 
after each mowing with a lawn rake. Lawns are frequently sown during the Fall months with excellent results.

Sometimes after a good sod has formed on the lawn, it is desirable to remove a tree or shrub from one part of the ground to another, or to plant a new one. In fig. 4, I show how this can be done, without mutilating or otherwise injuring the sod. Four cuts are made, two or three feet in length, away from the tree, and the sod is rolled back while taking up or planting the tree, and again unfolding it into its original position after the soil has been properly leveled. With a little care this operation may be so nicely done as scarcely to leave marks.

Sodding.-The edges of grass-sown lawns, bordering on walks, drives, flower-beds, etc., should for protection, be sodded one foot wide. Sodding is best

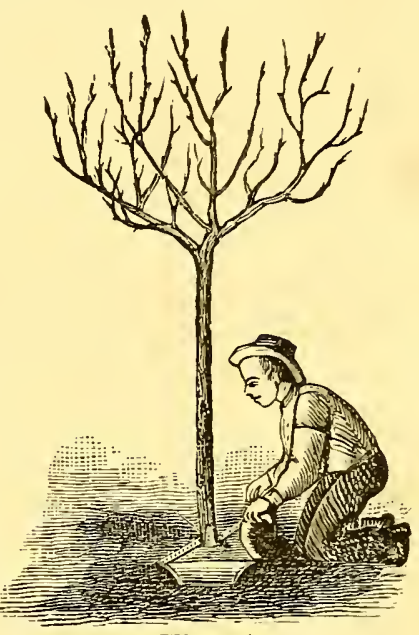

Fig. 4. done with turf obtained from an even grassy spot in the meadow, where no weeds are growing. In taking up the sods they should be cut into squares of about one foot by one foot, or into lengths of five or six feet and one foot wide, which can be conveniently rolled up for handling them, cutting them about an inch and a half thick. In putting down the sods they should be laid closely and compactly together, beating them smoothly with the back of the spade, so that there will be no crevice between the cut portions or beneath them. This work is best done early in the Spring or late in the Autumn.

Walks and Drives.-Good dry roads or walks should be aimed at for about the home, and these when well made and finished impart character and finish to any grounds. The ordinary method of securing the curves which have been decided upon, is by measurement or by setting small stakes on the line of the road, and moving them until the curve seems graceful and pleasant to the eye. We find a very good plan in J. Weidemann's work on Landscape Gardening, published by the Orange Judd Co., for accomplishing this. In the engraving it will be readily seen how, by mcans of a stout cord and stakes, the curve is secured. After the desired course and width of walks and drives 


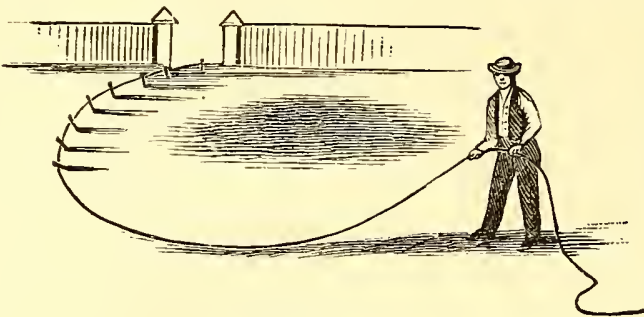

are decided upon, the work of making may commence. Excavate from one to two feet, fill in with large stones, upon these put smaller ones, diminishing the Fig. 5 . size as the surface is reached, and using coarse gravel on top of the stone, and then finish with a coat of finer gravel at the top. Roll well all during the process of construction, and there will be a road that will seldom if ever need mending, and be fit to travel on in any kind of weather.
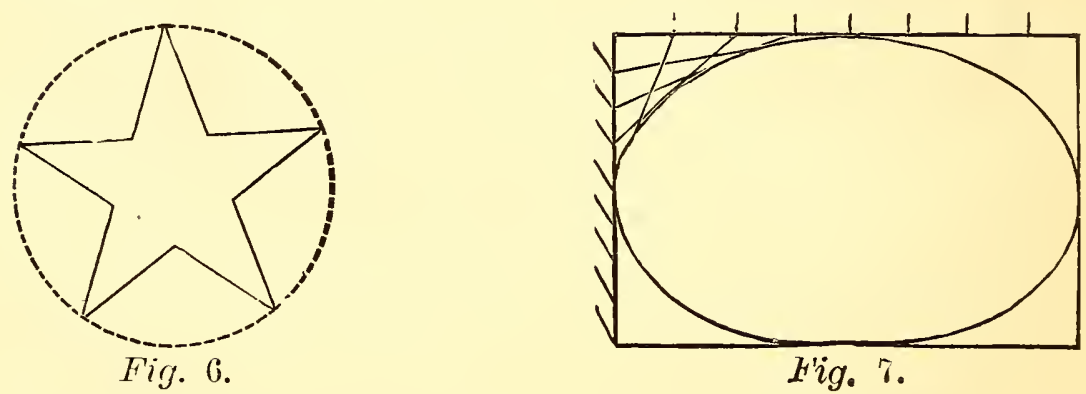

Designs for Flower Beds on the Lawn.-With a tenfoot pole, two stakes eighteen inches long, and a cord to connect then, and several dozen small stakes for defining outlines, the following designs may easily be made. In figure 6 , ascertain the

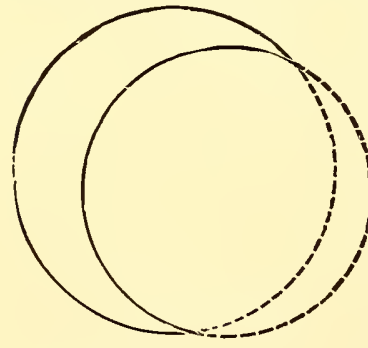

points of the star by setting five stakes at equal distance from each other on the circle, lay the ten-foot pole from each stake to the second one from it both ways, and mark with a pointed stick. For the moon make one large circle for the outside, and another smaller one with the center a little moved to give the inside shape. To make an oval, first Fig. 8 lay out an oblong square of the desired size, placing stakes at the corners. Then set five, seven, or any like number of stakes, on each side, as is shown in figure seven. Now lay the pole against the middle, long-side stake, and the first stake from the corner on the short side, and draw a mark; then 
move it to the stake next the middle on the long side and stake number two on the short side, and draw another mark, proceed in this manner around the entire square, and a well-proportioned oval will finally result. Triangular and other forms are readily made with the pole, stakes and line.

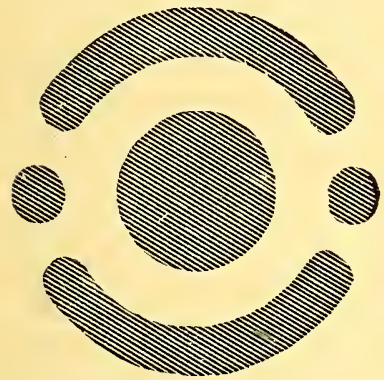

Fig. 9.

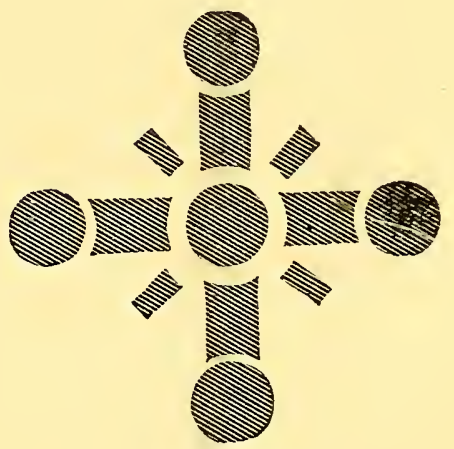

Fig. 10 .

Designs of Compound Flower Beds.

\section{OPEN AIR FLORICULTURE.}

Planting in Masses of Color.-This style of adornment with plants and flowers is one of the most effective that can be adopted for ornamenting the grounds about the home, and it possesses the merit of being simple. It consists of planting beds which are cut in the lawn, or otherwise located, with a single kind of plant, or with various kinds, grouped so thickly that the ground will become entirely concealed, thus forming one or more distinct masses of bloom or color. Or the beds may be of compound form, consisting of separate parts, each planted with a distinct color. Sometimes an edging of any beautiful low plant may be set around these masses with good advantage. Certain plants are better than others for masses, these being such as are free bloomers, or that have attractive foliage. Several designs of beds suitable for this style of work are represented herewith, and the reader is referred to the article on "Laying Out Flower Beds in the Lawn," for others.

It should not be inferred that beds in the massing style need be either large or costly to be effective. Beds three, or even two 
feet across, if cut in the green lawn, and planted with such valuable plants for this purpose, as scarlet, or any bright-bedding Geraniums, Coleus or others, say five well-established plants for the smaller, and eight for the larger-sized beds, will become amazingly attractive and appear complete in any grounds. Those trying one or more beds in massing could scarcely fail to be pleased with the result. Fig. 12 is a perspective representation of a round bed planted in three different colors, as shown by the dark and light parts. The centre is occupied by a distinct color, somewhat taller than the others. Fig. 9 represents a compound bed of circular outline. The centre bed may be divided into four equal parts, each planted with a distinct color of Phlox Drunmondi, or only two colors, as white and scarlet, each color occupying two opposite quarters. The small outside beds might be planted with mixed Pansies, and the large ones respectively with crimson and rose-colored Portulaca. Fig. 10 is a very easily-planned compound bed, more elaborate than the last one described, but, like it, is well adapted for any fair-sized grounds. The former may be about twelve feet in diameter, from outside to outside, and the latter twenty to thirty feet across between extreme points. A star, the body of which is planted with Achryanthes Verschaffelti, and the points with Alternanthera Versicolor, a plant of the same color, makes a very attractive bed. We have often planted round beds with the dark and other colored Cannas, placing a row of White Centaureas around the elge with satisfactory results. There is really no limit to the varied arrangements which may be adopted with pleasing effects in this style of planting. To render the present article on this subject more complete, I give a list of the plants best suited to this purpose. The reader is referred to the description of each kind, which will be found in other parts of the work.

Ageratum, in variety. Abutilon Thompsoni. Achryanthes, various Colors. Alyssum and Thyme,variegated Alternantheras, various colors. Artemesia Stellaris.

Candytuft, various colors.

Cannas, various colors.

Centaurea Candida, and Gymnocarpa.

Coleus, in large variety.

Dwarf Convolvulus.
Geraniums, in large variety. Golden Feather Feverfew. Heliotrope.

Leptosiphon, various colors, Lobelia.

Pansies, various colors.

Petunias, various colors.

Phlox Drummondi, var. colors. Portulaca, various colors.

Stocks, various colors.

Sedums in variety.

Verbenas, various colors. 
Ribbon Gardenirg.-This method

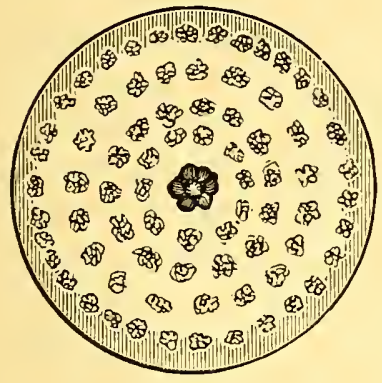

Fig. 11.

A Circular Ribbon

Bed. of planting consists of setting piants with contrasting color of flowers or with showy foliage, in lines on round, oval or square beds, to produce an effect resembling a ribbon, when viewed from a distance. To give a correct idea of this matter I illustrate in Fig. 11 the placing of the plants in position in a circular bed; it will be seen that the work of planting may be guided by striking circles, with a line attached to a stake in the centre. I have found in practice that in planting circular or oval ribbon beds it is best to plant the largest or outside circle first; then commence in the center and finish at the second line from the outside. Fig. 13 represents a long ribbon bed planted with five lines of plants of various colors. A large oval bed, 12 by 18 feet in diameter, might be planted, with the first row next to the grass, with Varigated Sweet Alyssum, eight inches apart, the second from the edge

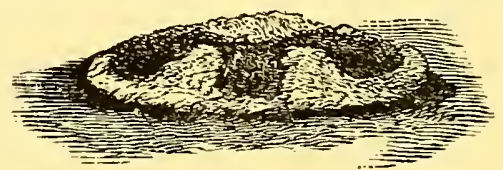

Fig. 12. Planting in masses of color. with Alternantheras ten inches apart ; third, Centaurea Candida, fourteen inches apart ; fourth, Coleus Verchaffelti, sixteen inches

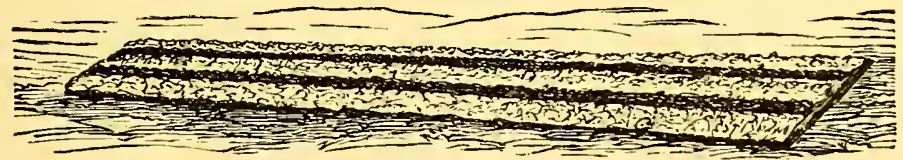

Fig. 13. A Long Ribbon Bed of Plants.

apart ; fifth, Caladium Esculentum, a foot and a half apart ; sixth, Abutilon Thompsoni, fifteen inches apart; the center with large Cannas, intermixed with Gladiolus. Such a bed is bound to be exceedingly beautiful for months, provided that the soil and the quality of the plants set out are the best. It will be noticed that the tallest plants occupy the center, while each circle toward the edge contains plants of less height. Where smaller beds are desi.:ed, a less number of circles or lines will be necessary ; one might be made with a large scarlet Geranium, Gladiolus or double Zinnia, for the center, with white Feverfew, Centaurea, or white Phlox Drummondi next, and surrounding these, Larkspur, Heliotrope, or other blue flowers, with yellow Calceolaria 
or Dwarf Nasturtium next, and outside of all a circle of Variegated Thyme, Sweet Alyssum, Mignonette, or other low-growing plant. A very pretty, long-ribbon bed is made by taking different colors of the same flower, like Phlox Drummondi, Portulaca, Verbenas, Stocks, and others described as being suitable. With care in sudying descriptions of plants, so that good selections may be made, and then a little experience, the work of arranging these beds becomes easy and interesting.

Planting Mixed Borders and Beds.-A very common arrangement of flower beds, and one of the best of all, consists in making borders along the walks four or more feet wide, large beds in the lawn, or a center bed in the vegetable garden, and planting promiscuously with a general variety of all kinds and seasons of flowering. Be careful, in planting such beds, to place the tallest growers, such as Hollyhocks, Ricinus, Dahlias, etc., in the background or in the center if the beds are circular, and then setting the smaller growers in front of such. Plants and flowers of different colors should be set to show to the best advantage by contrasts and those flowering at different times, to make the display continual throughout. Fig. 14 illustrates a plan for flower beds in a walk bordered with shrubbery.

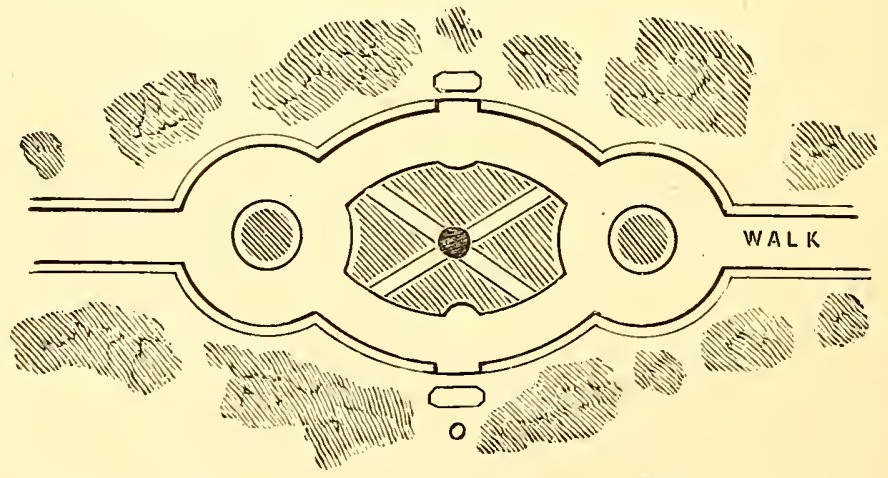

Fig. 14. Flower Beds in Walk.

Flower Beds for Constant Cutting.-Many flowers will perhaps be wanted for the table, bouquets, or to give away. For such purposes it is better to have a bed or mixed border near at hand, planted with free blooming varieties that are desirable for fragrance and brilliant colors, especially for this use. These will bloom ali the more constant for having the young flowers cut as fast as they open, and it is surprising to see what an amount of 
flowers can be daily cut from quite a small bed. Such a bed should be planted largely with annual Phlox Drummondi, Sweet Pea, Zinnia. Stocks, Candytuft, Mignonettes, besides Heliotrope, monthly Roses, Gladiulus, Dahlia, double, single and scented Geranium, Verbena, Pansy and others. An abundance of green should be provided for, a matter which is too often overlooked. Nothing can be cultivated to supply this better than the Rose and other scented Geraniums, varieties of which valuable family of plants are easily propagated by every one, and which grow with great vigor if taken from the pots and planted in fertile soil. A few plants of each will afford a large supply of delightful foliage, and many clusters of flowers all Summer. There are several varieties of so-called Rose Geraniums, all differing somewhat in fragrance and appearance, most of which are inferior to the true rose-scented variety. Then, some plants with beautiful foliage, such as Abutilon Thompsoni, Centaurea Gymnocarpa, or the Achryanthes, Amaranthus, etc., should not be overlooked. These will furnish a variety of material for intermixing with and edging flowers in bouquets, baskets and other arrangements, that is very desirable along with green. Smilax is a plant with finer foliage than the Geraniums alluded to, but it is not so good for constant cutting, being a climber, and hardly available until it has made a growth of six feet, as the vine with leaves attachea are too succulent for use, unless several months old. Another plant deserving of more general use for this purpose is the Lemon Verbena (Aloysia Citriodora), which is of easy culture, and a favorite wherever its delightfully fragrant leaves are known.

The Soil : Its Preparation and Treatment.-To be successful in cultivating flowers, it is of the greatest importance under all circumstances that we give plants a deep, fertile and well-drained soil to grow in. That attempts at floriculture may prove to be failures from other causes, is possible; but I freely assert that lack of attention to securing the requisites named is the direct cause of nearly every failure to produce fine flowers in abundance. This is a point that should be well observed by beginners. Not a season passes but in July, August and September, flower beds are to be seen which were laid out and planted with much taste and expense perhaps, that contain at this season only poor, unthrifty, flowerless plants, an eye-sore to the beholder, and a testimonial to the one fact, that the soil was unsuitably prepared for flowers. Few soils are so stubborn that with perfect 
drainage, either natural or artificial-and this well done once will last a lifetime-with being trenched eighteen inches or two feet deep, and annually supplied with a dressing of manure, together with being well tilled, will not produce flowers in abundance.

Trenching is an operation which consists in working the soil deeply with the use of the spade. It serves to promote the growth

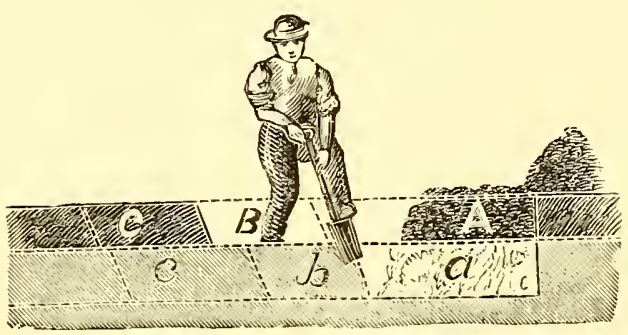

Fig. 15. Trenching. of vegetation, by giving to the roots ample room for extension; besides, with retaining moisture the entire depth to which the soil is stirred and broken, it prevents injury to plants in severe drouths, where they might be badly effected by drying, were the soil only worked to a shallow depth. In ordinary culture the surface soil only is overturned or stirred by the plow or spade, leaving the subsoil underneath, which is usually hard and compact, untouched; but with trenching the operation is conducted to work up the latter as well as the former, keeping each part by itself, the surface soil above and the subsoil, which is of a sterile nature, underneath. The annexed cut, representing a section of soil to be trenched, shows how this is accomplished. The surface soil shown in section $A$, to the width of aboutsix feet across the bed, is first thrown out entirely and the subsoil underneath $(a)$ is turned with the spade, moving it only enough to facilitate the work; a section of surface soil about four feet wide, represented in the cut by $B$, is next thrown over in the space $A$, on subsoil $a$, and the subsoil now turned to light is overturned $i_{2}$ like manner as that represented by $a$ was. The soil in section $C$, to the width of about four feet, is in turn thrown into space $B$, and the subsoil underneath is overturned. The operation is continued in the same manner across the bed or lot, and the opening remaining at the end after the other side has been reached, can be filled up with the surface soil first thrown out.

Manure should be applied to flower beds in the Fall, after severe frosts have finally cut down the plants, and annual bulbs and tubers are removed. This should be spread evenly over the surface, and incorporate well with the soil by spading up thoroughly and deep, leaving the clods unbroken as they leave the spade. Always have a supply of manure in some corner for such pur- 
poses. Those who keep a cow or horse will of course have enough. If you manage to have it twelve or more months old before using, it is best, although some fresher from the stable will answer the purpose. Those who cannot get stable manure readily may hare to depend on artificial fertilizers, even though they are not so good on the whole. In some places a compost heap night be made to a good purpose by gathering up a store of leaves in the Fall and leaving them lay until Spring, when they should be piled up in alternate layers with a cartload of sods from some meadow or roadside to rot, giving the heap a weekly soaking of soapsuds on washing days. Throw on, during the Summer months, rakings and scrapings from the garden, and once in a while add a shovelful of lime and a barrow load of black earth from the street, and by early Winter you will have a mound of rich, black crumbly loam, of fine fertilizing quality.

Where hardy plants, shrubs, or Roses that remain in the ground from year to year, are growing in the beds, care should be taken not to cut or spade so near them as to injure the roots at the annual Fall spading. These are benefited by receiving a dressing of coarse hay or strawy manure over their roots late in the season, which should be raked off again in the Spring. In Spring the beds are tu be lightly worked over again with the spade or digging-fork. If the manure worked in in the Fall appears to have been ample, none need now be applied. We take exception, however, to new beds to be planted for the first time; better give these another moderate dressing before spading. In no case do spading in the Spring until the soil is dry. Imprudence in this respect will cause most land to become rough and cloddy, a state wholly unfit for flowers, and which cannot be remedied during that season. After nicely raking up the beds, always leaving the middle slightly elevated, you can carry out your plans-which should have been perfected before planting time-by setting out the hardiest plants first, finishing with the more tender kinds in May.

Sowing Seeds.--Some flower seeds, like those of Candytuft, Convolvulus, Escholtzia, Larkspur, Mignonette, Poppy, Portulaca, Sweet Pea, etc., do better to sow directly where they are to bloom. As soon as the ground becomes warm and friable, say in April and May, open, neat, shallow drills-not too deep-and drop in the seed; draw in fine earth and beat it down a little with the hoe or spade. Where many flowers of a single kind of seedgrown plants are wanted the seeds may be sown broadcast, corering 
with light sandy soil, sprinkled on with the hand or through a fine sieve, or a careful raking, if the soil is fine, may answer the same purpose. I may say, however, that on the whole, sowing in drills, even if flowers are grown on a large scale, is the better way. Never cover seeds of any kind too deep. Failurcs often arise from this cause alone. I consider the old rule of covering twice the depth of their own diameters to be reliable, and applicable to any kind of sowing. As soon as seedlings have devcloped their second leaves they should be thinned. Pansies, Hollyhocks, Delphiniums and many other hardy perennial plants should be sown in August and September, and most of these will then flower the next year and earlier than if their sowing is deferred until Spring. These should be slightly covered over the roots at the approach of cold weather. For further remarks on time of sowing various seeds, see Weekly Classification of Work for May, June, July, August and September.

Most other seed-grown plants, besides those named above, are benefited by being transplanted, and should be started in a prepared seed-bed, hot-bed, or a box in the house. In either case, a light, sandy loam should be used, as with plants intended for removal when they have attained a certain size, an abundance of fibrous roots is of importance, and these can never be obtained if the seedlings are brought forward in a soil of a hard, "baked" character. Decomposed grass sods from a sandy meadow mixed with some old manure that is finely separated make an excellent soil for all such purposes.

Hot-Beds, Cold-Frames and Seed-Beds._Every family possessing a garden ought to have a hot-bed, even if it be a small one, in which to start seedling plants, Dahlia roots, Tubcrose bulbs, etc., and also to root cuttings. Tender annuals and vegetables of all kinds for planting could be had three or four

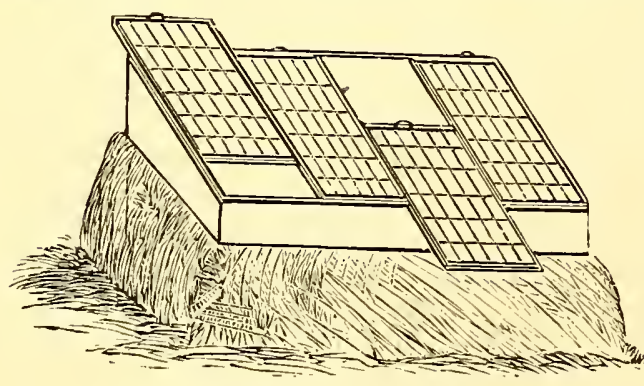

Fig. 16.-Hot Bed. weeks earlier than if the seeds were sown in the open ground, thus advancing their season of maturity. A hot-bed is made by forming a pile of fresh strawy horse manure some three feet in height, slightly elevated at what is to be the back end of the 
bed. $\Lambda$ s a number of loads will be required for an ordinary sized bed, it may be necessary to gather up manure for the purpose for some time previous to using it, in which case the accumulations should be kept from the wet under cover, and be frequently overturned to check its heating before needed. The bed may be sunk a foot or eighteen inches in the ground if the soil is well drained, and should be a foot larger each way than the frame which is to be used. The manure should be well trodden down to prevent settling when finished. Lying thus causes it to ferment, which fermentation produces the lasting bottom heat that warms the soil and renders the bed essentially a miniature greenhouse. After the manure is in shape, the frame, which should be made of $1 \frac{1}{4}$ or $1 \frac{1}{2}$ inch plank, 18 inches wide, can be placed on at once and filled in with about four or five inches of light soil well enriched with fine manure. Banking up over the projecting portion of the manure on the outside with ground will tend to confine the heat to the inside of the frame, and will also improve the appearance of the bed by hiding the manure. Keep the sash closed until the heat has warmed the soil well. Then better wait a day or two before sowing the seed. Sow in drills, about two or three inches apart, running across the bed. Care is required in clear weather to prevent the heat rising to an injurious temperature, giving abundant air when the sun shines, by moving the sash up or down. The safest way is to be governed by a thermometer, which should be placed where the sun's rays will not strike it; keep the temperature as near sixty degrees in the shade as possible. When the mercury indicates higlier than that point, give air; when below-as it will in frosty nights-cover with mats. By being attentive in this matter, seeds that were sown in March or $\Lambda$ pril will have become thrifty, well-tempered plants by Маy.

The principal advantages of a hot-bed may be secured by what is called a Cold-Frame. This is formed without manure, by plac. ing the hot-bed frame upon a bed of soil in some shelted place in the garden protected from cold winds. Do not start the cold frame until the latter part of April in this latitude, as we depend wholly on the sun for heating it. It requires much the same care with reference to airing on sunny days, and protecting with mats in cold nights as does the hot-bed. Both must be watered occasionally as the soil demands it.

Many can have neither of these conveniences. By starting a a week or two later, seeds may be sown in a bed of mellow soil 
in some warm, sunny spot about the house with good results. On the east or south side of a building is the bcst place, as here the sun's rays reflected on the building will cause the bed to be some degrees warmer, consequently earlier than if made out in an open space. All secds will come up sooner for having the ground shaded with shutters, mats, or perhaps, better than all, a little scattering of fine hay, until the shoots have reached the surface, when the covering must be removed at once.

Transplanting.-This with seedling plants should be done with a dibble or pointed stick, and pot-grown plants with a garden trowel just before or after a shower. But sometimes transplanting must be done in a dry spell. The best way then is to plant carefully towards evening of the day, leaving a depression in the soil around each plant, which should be filled with water and allowed to settle away until the soil is thoroughly saturated. Next morning the earth should be drawn in, to prevent the wet soil from baking.

Simmer Culture.-In Summer the earth between the plants should be frequently stirred, after each rain at least, to keep it properly mellow, and for destroying all weeds. Thorough culture is also one of the best remedies against the bad effects of drouth, as an open soil absorbs moisture from the atmosphere in the night-time to a great extent. Some things, like Lilies, Carnations and Rhododendrons, it is well to mulch with a coat of straw. Beds are better if so arranged that flowers or plants can be reached in cultivating or picking without treading on the ground.

Watering in Summer-Whenever it becomes necessary to resort to watering in dry weather, it is much better to apply sufficient water to thoroughly soak the soil while about it than to apply a small quantity day by day, a custom very prevalent among cultivators. In watering plants, first draw the soil away from the base of the stalk in order to form a sort of basin in which to pour the water; fill this up and let it settle away repeatedly until a plenty has been applied, then draw the earth again to the plant, which will prevent the soil from baking in the sum. A thorough watering of this kind ought to answer for several weeks in the dryest time of Summer. When entire beds are to be watered the soil should be opened by thrusting a digging-fork into it here and there before sprinkling; then the beds should be passed over again 
and again with the pot and sprinkler until there is enough. The next day the surface of the bed should be mellowed up with the rake or hoe.

This rule of watering very thoroughly each time it is needed, and then not again until really necessary, applies quite as well to watering plants in pots at all seasons of the year, either out of doors or in the house and conservatory, as in the open ground. $\mathrm{Be}$ on the guard to not over-water pot plants, however, as it is contrary to the nature of most of these to thrive in a heavily saturated soil.

The Removal of Matured Flowers._Every experienced cultivator of plants and flowers probably knows the good effect that the removing of flowers, as soon as they are fully developed, or before the petals fall, causes to a plant, by increasing its general productiveness, and the size of the future flowers. A study of vegetable physiology discloses, and practical observation fully confirms the fact, that the young flower or bud taxes the vitality of a plant to but a slight degree, as compared with the hardening: of the flower stem, which causes the petals to drop, and precedes the ripening of the seed. This is important to observe, particularly in cultivating Roses, Verbenas, Pansies, Dahlias, Zinnias, Mignonette, Sweet Pea, Double Petunias, etc. I will add that some plants, like Mignonette, which are usually treated as annuals, will live and continue to increase in beauty for years if not allowed to seed.

The flowering season of many things like Verbenas, Geraniums and Dahlias may be lengthened almost erery Autumn, by corering the plants with mats, etc., on cool nights to protect from the first September frosts. After some quite sharp frosts the weather usually comes off warm and pleasant for some time yet, and it is well to have the benefit of this on the plants.

Preparing Plants for Winter Flowering - It should be borne in mind that in plant culture either in the window or the conservatory in the Winter the natural conditions of heat sunlight, and the lessened length of the days, are adverse to the profuse growth of vegetation, and particularly the production of flower buds; for this reason it is of the greatest importance to have at the outset for this purpose, good plants of strong vitality. When plants pass into the Winter quarters in a weakened condition from any cause they will be apt to remain weak all Winter. 
Tlic bcst way of securing plants for Winter flowering, especially rapid growing kinds, is to start with young ones the Spring previons, and prepare them during the Summer by giving them a favorable opportunity for making a healthy growth in the open air, either in pots plunged to their rims in soil, refuse hops or other material, or by being bedded out. During this time, and until within a month or two of cold weather, practice a system of heading them in to cause a compact stocky growth, and also to prevent the exhaustion of plant force by flowering, which, if allowed, would be detrimental to the crop in Winter. For special remarks on the culture of all suitable varieties, see the direction accompanying each kind.

The plants that were bedded during Summer, such as Carnations, Violets, etc., should be taken up and potted in September, in order that they may fully recover from the effects of the operation before cold. weather sets in. With plants grown for the beanty of their foliage, it is needless to adopt this course of Summer treatment, further than to hare them healthy and of fine form, whether they be large or small. Some small pots containing pretty plants, placed among the larger ones of a collection will enhance appearances greatly. In the Fall avoid taking plants into their Winter quarters too soon, but gradually inure them to the confined air of the room or bay window by keeping them inside during cold nights or cool weather, allowing them to be fully exposed to the air in partial shade, as under the piazza, or at the side of the house during fine weather. In the case of having a conservatory the plants may be placed in it at once, but an abundance of air should be allowed to circulate through the structure at all times when the outside temperature will allow. The plants grown in pots should receive their final shift into the pots or boxes they are to occupy during Winter, in September or October. We find that a soil made of two or three parts of decomposed turf. and one part of well-rotted stable manure, with the addition of a little clean sand, is suited to nearly every plant grown, and is better than " chip ground," so commonly used.

Autumn Planting of Hardy Bulbs. - Were the bulbs which are known as the Hardy or Dutch Bulbs grown by planting in the Springtime of the year with the Gladiolas, Tigridia, etc., their culture would be more common, and collections of the choicer varieties, such as are conspicuous for their beauty and 
grandeur, wonld be less rare. Planting at the approach of Winter is rather contrary to the general rule of garden management, and we are inclined to neglect this only means for securing the flowering of Hyacinths. Tulips, Crocus, etc., early the following Spring, or for improving the collections that may already be growing in our gardens, which consist far too often of inferior varieties, considering the trifling outlay which is necessary for obtaining a better collection.

The planting of the hardy bulbs may be done at any time during the months of September, October and November, or even later. provided the ground remains unfrozen later, which is sometimes the case. To be entirely safe, it is best, perhaps not to defer the work much after October. Bulbs will succeed in any good garden soil ; in order, however, to secure the highest degree of success in their culture, it is necessary to plant in a soil that is well drained and enriched with thoroughly decayed manure. Hyacinths require a richer soil than any others. When all plantings have. been completed, and before Winter sets in, corer the beds with several inches of leares, straw or other coarse litter, to prevent severe freezing from injuring the bulbs. In situations exposed to the wind, a few brush or sticks thrown on will prevent its being blown off. Early in the Spring this Fall covering should be removed. Where beds planted with hardy Spring-flowering bulbs are required for Summer flowers, Hyacinths, Tulips, etc.. may be safely taken up to prepare for planting the coming Fall, as early as two weeks after the flowers have disappeared, prorided the precaution of covering the bulbs with soil, to allow the foliage to become gradually ripened, is observed.

Taking up Plants in the Fall.-Many kinds of bedding plants, such as Geraniums, Veronicas, Stocks, Salvias, Ageratums, Roses, Carnations, etc. can be taken up from the flower-beds at the approach of frosts, and transferred into pots, or eren packed thickly in boxes of soil, for use another year, by taking care to have some earth adhering to the roots, and by keeping in a rather dry and cool cellar, or in a good cold pit through the Winter. It must, however, be done at the sacrifice of much autumnal beauty, as all such plants should receive when lifted a severe cutting back of at least onethird or one-half of the shoots. But this is gain after all, for plants like these kept orer, in most cases, make a better show the next year than the plants of the present season's striking. Give the plants one thorough watering when potted ; after which 
they should be kept rather dry till Spring, when, after new growth commences, water may be given every few days apart in increased quantities as they commence making a new growth,

Cold Pits for Winter Protection.-A cold pit, made by excavating the soil in some dry spot in the garden, to the depth of $t$ wo feet and upwards, and of a size suitable to be covered with glass sash, forms one of the most inexpensive and efficient appliances that can be introduced into the flower garden. It will answer the purpose of wintering tender Roses, Carnations, and many other plants, much better than a cellar, especially if the latter is too dark, too damp or too warm. A pit also provides the means for keeping up a succession of flowers of Alba Fimbriata and other Pinks, Roses, Deutzia, Iberis, Violets, Lily of the Valley, etc., during the Winter in the house or conservatory, by carefully taking these up from the garden, and after potting, storing them in the cold pit, until they are brought into the heat and better light, which may be done at intervals during the Winter and Spring. Indeed, a conservatory can hardly be considered completeiy equipped without a cold pit near at hand to serve this purpose. The sash used to cover the pit may be similar to those made for hot-beds, an ordinary size being six feet long, by three and one-half feet wide. The sides against the soil should be boarded up or walled up with brick or stone, which should run a foot above the surface at the rear, and nine inches above it on the front side, the top of the end walls having a regular slope from rear to front, and all finished to give support to the sash. Bank up the part of the wall that projects above the surface, and scatter an inch or two of coal ashes or gravel in the bottom of the pit, on which to place the plants. About all the attention a pit requires after the plants are in, is to ventilate when the weather will allow, and to cover the glass with shutters or mats of straw or other material, sufficient to keep out hard frost in severe cold weather. Aside from one thorough watering when the plants are potted, water should be sparingly given to them during the Winter. 


\section{PROPAGATION.}

Many plants that do not bear seed freely, or which cannot be increased by division of the roots, are best propagated from cuttings or layels of the young growing shoots. The florist finds propagation from cuttings about the only practical means of increasing the majority of that class of plants commonly known as green-house and bedding plants, in which may be included such valuable house plants as Tender Roses, Geraniums, Fuchsias, Carnations, Heliotropes and many others of equal importance as outdoor decorative plants. As the two methods here alluded to are quite distinct, I shall treat each separately, commencing with that of propagating from cuttings, as this is the more commonly employed of the two.

The principal conditions essential to propagation from cuttings are nearly the same with all plants susceptible of being thus perpetuated. These are first, the proper condition of the cutting: second, that it be rightly pruned before putting in; third, that it receive suitable treatment while rooting ; and fourth, that after it is rooted the transplanting from the cutting-box or bed to soil be done at the right time, and then finally, that it be properly attended until it becomes a well-established plant.

With the generality of kinds the ends of newly formed shoots make the best cuttings, anc are much better than old hardened growth. There is a certain time and condition in the growth of plant shoots in which, if a cutting be taken. it will strike root and make a plant better than at any other time. To ascertain this condition, and how far back it extends from the growing terminal bud, let us bear in.mind that there are different degrees of hardness present in the wood-the yougest part being the softest, while toward the base of the shoot it is likely quite hard and fibrous. $\mathrm{By}$ taking a cutting off, down in this hardened portion of the shoot, it would be found to root slowly, and in some piants not at all, and at best would make a plant of inferior quality ; while with adopting the opposite extreme, making a short cutting of the succulent young growth only, it would be still less likely to root. if not quickly decay. Now the right place to cut the shoot is at the furthest point in from the end where it is somewhat hardened, 
and yet sufficiently brittle to snap off with a clean break instead of bending without breaking, or parting with a rough break with the fibers of the bark protruding. Practice will demonstrate that in the difference of one joint there is considerable variation in the hardness of the growth; it is always better to break or cut at a point which is rather soft than at one that has become too hard. A little experience will put the careful operator in the way of determing the right place with scarcely a failure.

To rightly prune or trim a cutting requires that the superfluous leaves be removed, and that the base be cut away with a sharp knife. Cuttings of some plants will callus and form roots at the

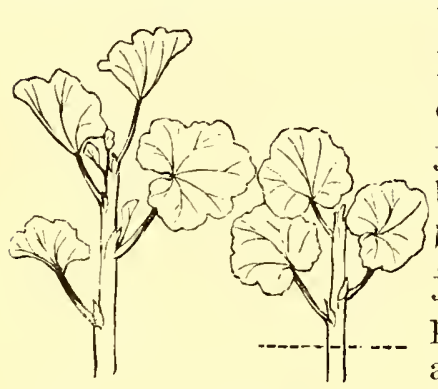
base, no matter whether it be just below a leaf joint or not, while others seem to root best from the leaf joints, and these should accordingly be cut off just here. It would be best, perhaps, for amateurs to cut all just below a joint, as with limited experience they have little opportunity for assertaining which varieties do, and

Fig. 17. Branch and which do not, require it. Fig. 17 repreCutting of Geranium. sents a Geranium shoot as taken from the plant, and also a cutting ready for striking made from it. A point below the fourth leaf, counting from above, was found right for cutting, and here the cut was made close up to the joint. The fourth leaf was removed, and also parts of the largest remaining leaves were nipped off to admit air and light to the cuttings, where many are put in close together. This cutting away the tips is well with all varieties having large leaves, as it also prevents an unnecessary absorption of moisture from the material in which the cutting is placed to root.

Clean sand is the best material in which to strike cuttings. Whether placed in a propagating house where, in cold weather, the sand may be heated from below to be fifteen degrees warmer than the air in the house, or in a box or pan, it should be about three inches deep, and be underlaid by broken pots or other material for drainage. According to their size, cuttings are put into the sand at various depths and distances apart, from an inch for long-jointed ones to a third or half inch for small ones, and at such a distance that the leaf points just touch. Water thoroughly 
when the cuttings are first set, and then daily or erery other day as they require it, only guarding against allowing the surface to become dry. Outside of a regular propagating bed, a bright, sunny place in the window, where some air can be admitted, is the best place for the cuttings, but whenever the sun shines shade with paper.

From one to three or four weeks is the usual time required for cuttings to root, depending upon the condition of the cutting or on the kinds, some rooting much sooner than others. It is better to pot them off as soon as the roots can be seen than to wait until they become an inch or two long, which endangers their being broken off. Their state may be easily ascertained while they are yet in the sand by drawing some out for examination, which can be replaced again. The callusing process always directly pre. cedes the formation of roots, this being an irregular growth which forms upon the base or along the side of a cutting, and its presence is a healthy sign that roots will quickly appear. After potting off, much the same care should be given the cuttings as regards shading and watering, as they received in the cutting bed, for the length of a week, or until the roots have started new growth in the soil. Never put the most common plant in a dirty pot. Never fill a pot so full of soil but that it may receive and hold water enough to go through; every pot should have half an inch or more of vacancy above the soil.

Some plants, like Carnations, Roses and many of the hardy shrubs and vines are best propagated by layering, especially if there is no convenience 'f a green-house propagating bed at hand. Layering consists in bending a growing branch into a depression

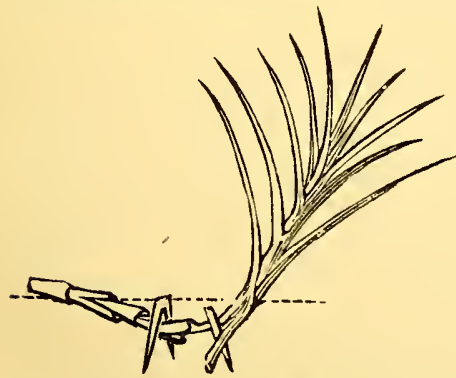

Fig. 18. Layering the Carnation.

at the sicle of the plant, covering it with soil to induce rooting, and allowing the growing extremity to extend out of the soil to form a new plant. Fig. 18 represents a Carnation branch prepared for layering. In preparing the layer, at the lowest point of the bend an oblique cut is made from the under side, about half or two-thirds way through the branch. This is done for the purpose of prerenting the free return of the sap to the plant which tends to the formation of roots. To keep the layer in place it should be pegged down 
as shown in the cut. A small bit of wood or other substance should also be inserted in the cut to keep it from growing together. The separation from the parent plant is not effected until the layer is sufficiently provided with roots, which will usually be in from six to twelve weeks, although layers of some hard-wooded plants require a year or two to become rooted, but these are rarely in the line of plants which amateurs propagate.

The "saucer" system of propagating cuttings is an excellent one for amateurs. It consists of placing these close together in a saucer or dish containing several inches of sand, and then keeping the sand thoroughly saturated with water untıl the cuttings are rooted. There is no need of shading the cuttings from the sun, and the saucers may be kept constantly in the sunlight, provided sufficient water is at all times present.

\section{HANGING BASKETS AND GARDEN VASES.}

The plants of drooping, trailing and climbing habits are always interesting and attractive, if planted where their peculiar growth can be accommodated. The proper place for these is found in hanging baskets, garden rases, window boxes, etc., and these with judicious planting, form very effective means of adornment. Hanging baskets are indeed very popular, because they are so easily given a place, even about houses that afford no room for a flower garden, accommodating themelves to positions like under a piazza or tree, or a trellis on the side of a house, or in front of a window, and thus enabling thousands of plant admirers to possess a luxuriant growth of plants and flowers, who but for them would be deprived of the pleasure. Another recommendation for the hanging basket is its slight cost, which, indeed, need be very little aside from the cost of necessary plants, where a person possesses any skill at construction. A piece of strong wire, shaped and fastened into a circle, and several yards of lighter wire attached to it and woven into a sort of basket or dish-shaped structure, which, with being mosslined, will answer for holding soil, is all that is necessary for producing the most beautiful effect. The manufactured earthern hanging pots, rustic and wire baskets, if of tasty design, are beautiful for this purpose, but where their expense might be an objection, 
such a home-made basket will do quite as well and is preferred by most people. Those who are unacquainted with plants in selecting some for this purpose should discriminate between droopers and climbers, and the upright growing plants which are to be used as the body of the display, such as Begonia, Centaurea, Geranium,

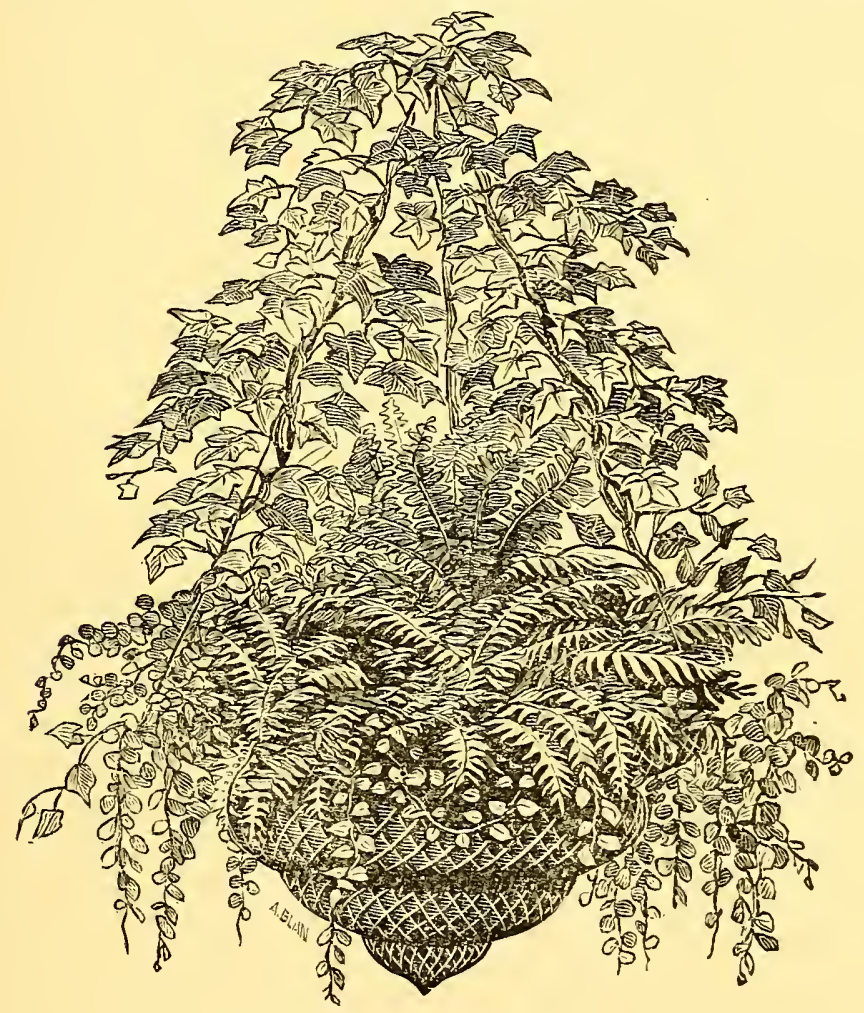

Fig. 19. A Hanging Basket of Plants.

Cuphea, etc. By carefully reading the descriptions of plants giren in this work, there will be no need of failure in making a suitable selection. I will suggest that it is scarcely possible to stock a hanging basket, much less a garden vase, well, with plants grown from seed, as every cultivator wl.. has made the attempt could testify. The trouble is, that seed-grown plants cannot be reared strong enough by Spring to make any show; and are not permanent enough in the attractiveness of individual plants; besides, only a few are strictly suitable, Sweet Aḷssum, Thunbergia, Petunia and Maurandia being the best that can be recommended and for this purpose the seeds should be sown rery early. 
For adorning the lawn or the garden, nothing can be finer than a vase of chaste design, of iron, stone or earthenware, planted with droopers at the edge, and Geraniums, Heliotropes, Fuchsias, Caladiums, Cannas, or other attractive flowering and showy plants in the centre. Vases if made of iron, are usually somewhat costly, but by removing them into a shed or outhouse at the approach of Winter they may do service for a lifetime, on which account they do not prove so expensive after all. Many people prefer a rustic vase and these need not be costly to most persons, as they are readily made with the use of a few tools, from material procured from the woods.

Managenent.-The management of vases and hanging baskets and window boxes is nearly identical. I desire to impress upon the minds of those who have their care in hand, the importance of supplying them with an abundance of water as needed. Especially during hot weather water should be given to them in sufficient quantity to thoroughly moisten every portion of soil every time it is required, and this in dry weather will be pretty often. This is about the only matter in which vases and baskets need attention after they are once established, and the difference between their being well grown or poorly grown, nine times out of ten, may be directly ascribed to the amount of attention or neglect they receive in this respect. (Temperature $32^{\circ}, 45^{\circ}, 80^{\circ}$, except where noted or elsewhere described). See Temperature, under head of Plant Culture in and about the House.

TRAILERS FOR BASKETS, VASES, TRELLISES, ETC. Alternantheras. See description of varieties in general list of plants.

Colisettm Ivy, a rapid growing drooper, forming a dense mass of long, dark green foliage.

Deeringia variegata, a beautiful variegated plant of climbing habit. $\left(35^{\circ}, 50^{\circ}, 80^{\circ}.\right)$

Ficus repens, an admirable plant for baskets, etc., having small, almost round leaves, and wiry stems; distinct and beautiful. $\left(40^{\circ}, 50^{\circ} \cdot 80^{\circ},\right)$

Gazanias. See description of varieties in general list of plants. Geraniums. See descriprion of Iry-leaf section in special article. German Ivy (Senecio Mikanoides), not an ivy at all, but so-called because of its ivy-shaped leaves; one of our most rapid growing rlimbers, always healthy, beautiful and attractive; very desirable. $\left(33^{\circ}, 45^{\circ}, 75^{\circ}\right.$.) 
Isolepsis gracilis, one of the grasses, forming a dense plant of gracefuily-drooping round blades of lively green color, each bearing a small tuft-like bud at its end. $\left(35^{\circ}, 50^{\circ}, 90^{\circ}\right.$.)

Ivies. See description of varieties in the article on Iries.

Lobelias, exceedingly valuable droopers; see description of varieties in general list of plants.

Lonicera curea reticulata, a pretty climber; the foliage is distinctly netted with gold upon green; rery desirable for trellis culture; the root is hardy, with slight protection.

Lophosphernum scandens, a climber, with attractive heart-shaped foliage. $\left(34^{\circ}, 50^{\circ}, 80^{\circ}.\right)$

Madeira Vine, well-known as an excellent climber for both Summer and Winter culture, with beautiful thick, glossy foliage; excelient to train up the window and for trellis; a tuberous plant, very easily grown. The dry tuber should be kept in a warm, dry place in Winter. (For forcing, $35^{\circ}, 50^{\circ}, 90^{\circ}$.)

Mahernia odorata, a beautiful plant, with finely-cut foliage, covered in Spring with very many sweet-scented, bright yellow flowers of bell shape; excellent in pots. $\left(34^{\circ}, 50^{\circ}, 75^{\circ}.\right)$

Maurandia Barclayana, a superb climber of rapid, dense growth, producing many flowers of fox-glove shape; among the best of plants for covering trellises in the open ground. It is readily grown from seed, which should be sown early. $\left(34^{\circ}\right.$, $50^{\circ}, 75^{\circ}$.)

Mesembryanthemums. See description of varieties in general list of plants.

Mimulus moschatus, the Musk Plant, the leaves of which emit a genuine, yet delicate, musky odor; of compact, drooping habit; very attractive as a pot plant. It can be propagated either from seed, cuttings, or by dirision of the roots in the Spring. The plant may be kept in a half dormant state cluring Winter. (This and the following one, $34^{\circ}, 45^{\circ}, 89^{\circ}$.)

Mimulus triginoides, a variety producing exceedingly beautiful golden and orange flowers of tubular shape, with the richest maroon spots and blotches, Both delight in moisture.

Moneyvine (Lysimachia nummelaria', one of our most valuable droopers; has handsome, dark green, chain-like foliage: its rapid growing shoots will fall over the edge of a rase or basket, and grow to the length of three or more feet; flowers beautifully in June. 
Moneyvine, Golden (L. nummelaria aurea). This is a variety quite similar to the above, in form of foliage and habit, but the color of the leaves is nearly golden yellow; not so rapid a grower.

Poa trivalis, another fine grass, with narrow white and green variegated leares. $\left(40^{\circ}, 60^{\circ}, 80^{\circ}\right.$.)

Saxifraga sarmentosa (Strawberry Geranium), a running strawberry-like plant of curious and interesting growth, with striped and mottled foliage.

Torrenia Asiatica, a pretty drooping plant; will not bear much cold; flowers blue, of lovely tint and shape, and extremely beautiful; excellent for pot culture in a warm place. $\left(40^{\circ}\right.$, $60^{\circ}, 80^{\circ}$.)

Tradescantia Vulgaris (Joint Plant-Wandering Jew), an oldfashioned drooper of the easiest culture, with beautiful dark glossy foliage. It is quite certain of giving satisfaction.

Tradescantia repens vittata. The leaves variegated, as shown in the engraving; are of a clear, waxy white and whitish yellow color, on bright, glossy green ground. Like all Tradescantias, it is particularly recommendable for home cultivation, either in baskets or pots, as it will thrive in a temperature either high or low, in a moist or dry atmosphere, and is not at all particular as regards light, in this respect being almost equal to the Iry.

Tradescantia zebrina, a variety with finely-striped green and reddish leaves.

Variegated Thyme, very desirable as a drooper and bedder, the foliage being distinctly variegated.

Vinca minor variegata, one of the best and most attractive droopers in cultivation; the leaves are from one to two inches in diameter, and distinctly variegated; a rapid grower.

Other plants suitable for hanging baskets, vases, etc., are described throughout the general list.

\section{PLANT CULTURE IN AND ABOUT THE HOUSE.}

There are many persons so restricted in their surroundings as regards room for flower growing that they have to content themselves with cultivating plants only in and about the house, con- 
verting a sunny or bay window into plant quarters in Winter, and moving their plants under the veranda, or into the open air when warm weather approaches. This, with the planting of outside window boxes in Summer, the growing of hanging baskets, Ferneries, or Wardian cases, and Ivies for permanent, are about the limit to which they dan indulge in plant-decorations. It is, however, a pleasure to know that even under such circumstances it is not a very difficult matter, by going about it rightly, to have a beautiful show of plants and flowers continually throughout the year, without any great outlay of trouble and expense.

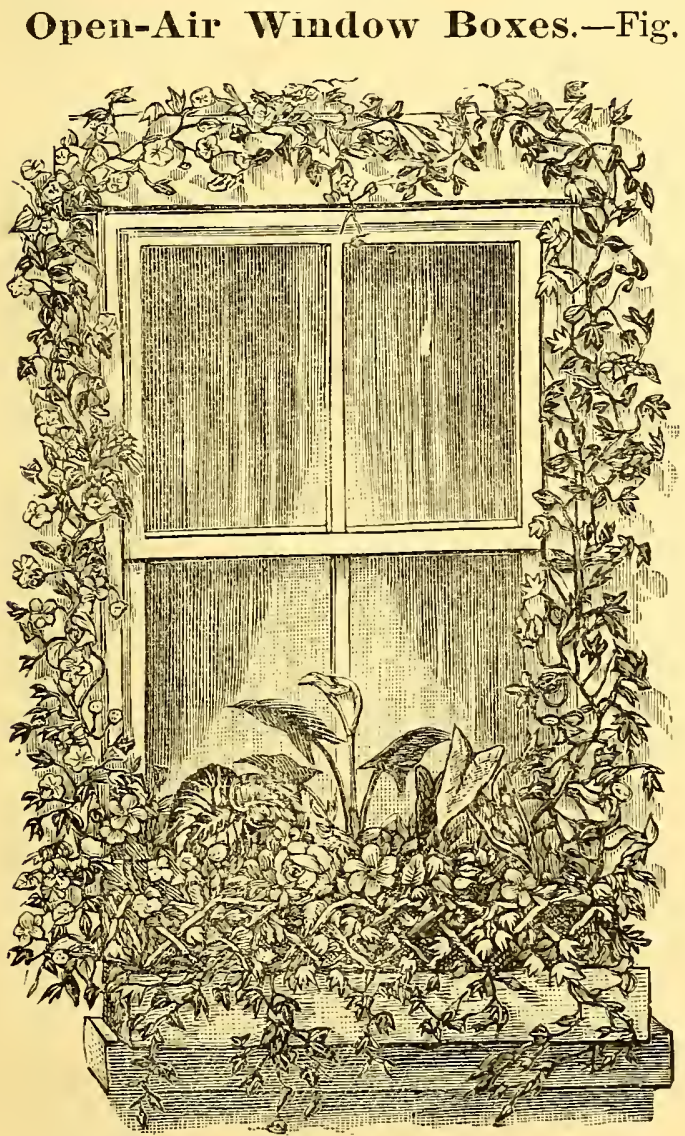

Fig. 21. Open-Air Window Box. the use of Open-Air Window Boxes as a ready means of growing plants and flowers, and which is adapted for ornamenting the windows of any room, either inside or out, be it in the first or fifth story of a building, as many rooms in the cities are. These are simply boxes made to fit the window casing or sill, and planted with Scarlet Geranium, Mignonette, the pretty blue Lobelia, Verbena.Roses, and in fact about all kinds of plants suitable for the open air. Morning Glory, Iry, Madeira Vine, or other climbers are suitable for planting at the ends of such boxes to be trained on wires up and around the windows. 
Plant Culture in Winter.-To learn what can be done at plant forcing in winter, under farorable circumstances, it is only necessary to see the large crops of flowers that are daily cut, and also the beautiful foliage plants grown at this season, in the commercial greenhouses. I would not encourage the thought that plants can be grown as well in the dwelling as in the florist's wellappointed structures, yet very satisfactory results can be obtained here by nearly every one if only the matter is properly entered upon and executed. Sometimes those whose efforts in growing flowers in the open air are well rewarded, find disappointment attending similar undertakings in the Winter to their surprise. No doubt the cause of this lies more frequently in the fact that the necessary course of treatment is not sufficiently understood, than that the conditions of light, heat, etc., which the dwelling affords, are unfavorable to plant life. Such conditions have their infuence surely, but, then, the adaptability of plants is so varied, that at least a number of varieties may be found which will thrive under any circumstances that are likely to exist in our dwellings. Under the head of "Open-Air Floriculture" are given directions for preparing plants for Winter flowering.

The Winter Quarters.-Next to a conservatory, built expressly for plants, a bay window, off from the living-room, and from which it will receive sufficient warmth, is the best place for cultivating plants in Winter, although a window facing east, south, or west, answers the purpose very well. Should we be even less fortunate and have only windows with a northern exposure, and no sun in Winter, there is no need of being entirely deprived of the beauty of plants and flowers, because the Ivies, Begonias, Enonymus, Callas, Tradescantias, Achryanthes, etc., and, perhaps, most imporiant of all, the entire list of Hardy Bulbs, all of which will readily dispense with direct sunlight, will thrive beautifully here with fair conditions of heat, air and moisture. But these last named things are essential to plant growth under any other circumstances as well.

Temperature, Selection of Plants, Protection, etc. -The amateur, who, for the first time might want to engage in plant culture in the window, would naturally ask, what plants can best be grown in my house? The answer to this question is not a very difficult one to arrive at in each case, provided first, that the temperature which can be maintained in the plant quarters to be. 


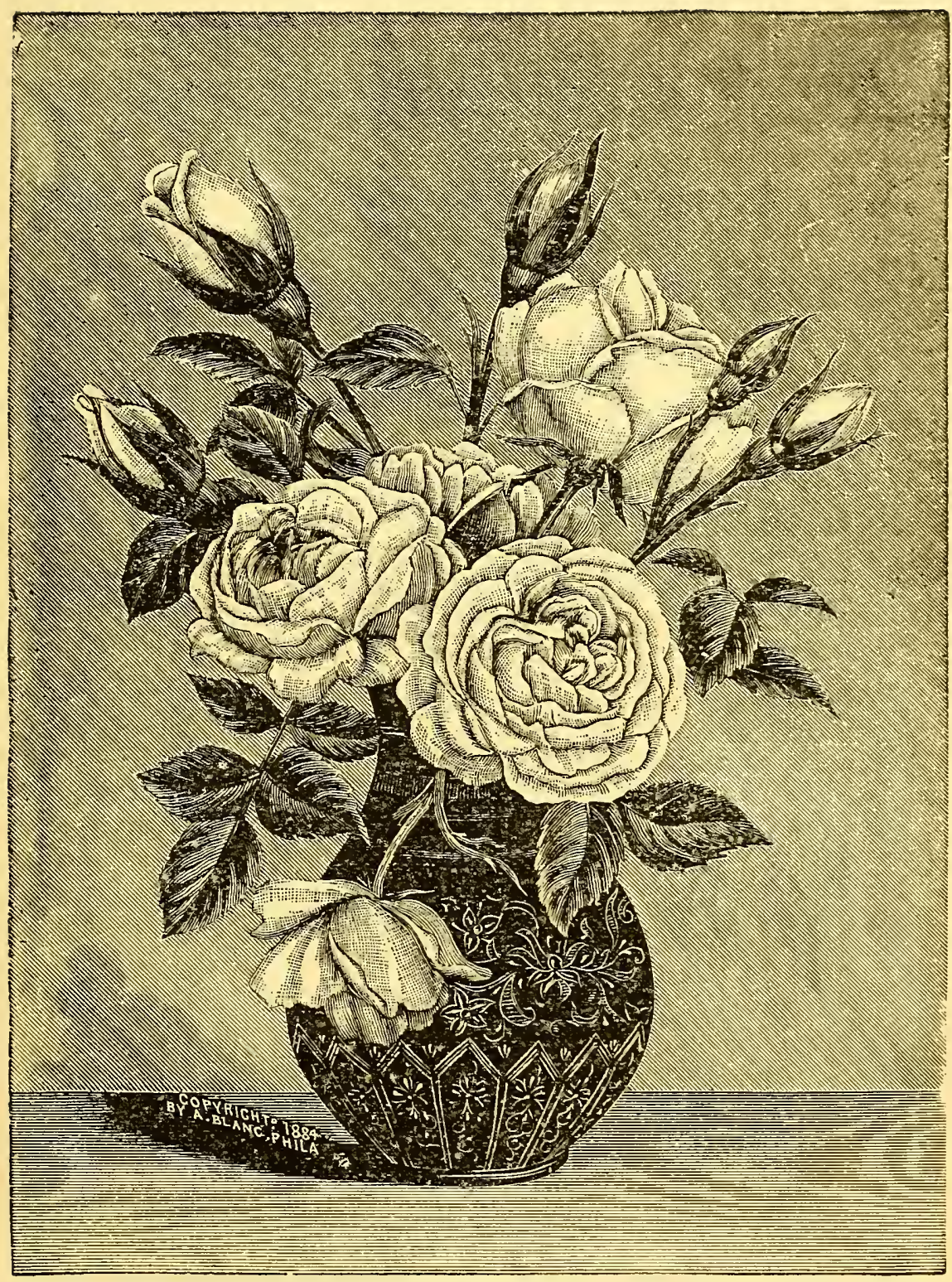

Tea Rose White Bor Silene 
is known, and then also the degrees of temperature which the various plants suited to Winter culture will best thrive in respectively, Recall to your mind the lowest temperature of previous seasons, as indicated by the thermometer, or if you were without this almost indispensable instrument to the plant grower, recollect whether it ever fell to $32^{\circ}$-the freezing point-and allow this knowledge to guide you as to the lowest extreme. Now for guidance in making selections suited to your temperature, observe the figures and degrees in parenthesis which have been placed in connection with the names of all the plants described throughout this work as suitable for window culture. These figures indicate the extremes of temperature that every plant described will bear. and also the intermediate degree most congenial to its growth as a night temperature. To render tlis more clear, let us take as an instance the Abutilons. described on the 125th page. The descriptions and cultural directions of this family are preceded by (33. $\left.45,85^{\circ}\right)$, which indicates that the plants will bear a temperature of $33^{\circ}$ as one extreme and $85^{\circ}$ as the other, for some time without injury, while $45^{\circ}$ is best suited to the plant as a night temperature; ten to twenty-five degrees above this is to be considered nearest right for their growth in the daytime.

It should be understood in this connection that plants can be

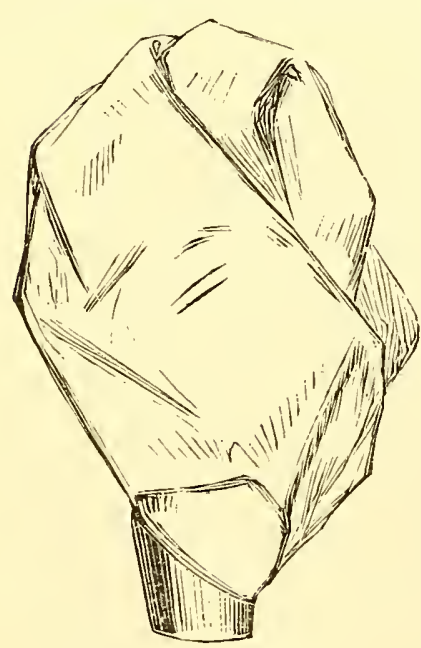

Fig. 22. Protection. safely kept through several additional degrees of cold than indicated by the first temperature figure (lowest extreme) by protection, and it is safe to calculate somewhat on this for the few excessively severe nights of each Winter, by giving the more tender ones especial care at such times. Simply pinning several thicknesses of newspaper over a plant, as shown in the annexed cut, would protect it sufficiently for remaining a number of hours in a temperature from five to ten degrees lower than it would otherwise bear. Ordinarily where danger from frost is apprehended from leaving plants next to the window, they can be romoved to the middle or further side of the room, which is sure to be several degrees warmer. By setting them close together it is easy to protect the lot by spreading newspapers on them and 
throwing a blanket over all. It really does not seem necessary to mention that to correct too high a temperature in the plant quarters air should be admitted from the outside.

The various varieties of the Ivy family possess so many desirable qualities as house plants, thriving under such widely varying conditions, that they are recommended to all cultivators as a class with which failure is scarcely possible.

Indoor Plant Management.-Airing.-As often as the weather, from its mildness, will allow of introducing air among the plants from the outside, it should be done, but be careful to avoid a strong, direct draft of wind upon them. Cold air striking on Roses is the common cause of mildew. Maintain a temperature as nearly uniform as possible, endeavoring to keep it at a degree best suited to the majority of the plants in the collection, being guided in this respect by the figures in parenthesis which accompany the descriptions of plants.

Moisture and Watering.-One difficulty amateurs have to contend with in growing plants in the living room-especially if heated with anthracite coal stoves and furnaces-is dryness of the atmosphere. This can in a measure be obviated by nailing a narrow strip of board on the front and back edges of the plant-stand shelves, or false bottom of the window sill. and filling up with three-fourths of an inch of sand, upon which the pots are to be placed; keeping the sand quite wet. The moisture escaping counteracts the dryness of the air. It will improve appearances to cover the surface between the pots with moss. Sprinkle the foliage of all growing plants occasionally, and whenerer the surface of the earth shows signs of dryness, water so that the soil is saturated and no more. Too much water passing through imporerishes the soil and does the plant no good. As a rule, in the Winter, do not allow water to stand in the saucers continually, as it tends to sour the earth.

Insects.-If any plants become infested with Aphis or Green$f y$, take a handful of tobacco stems, steep in water until it looks like strong tea, and wash the affected foliage, or else fumigate the plants by burning tobacco stems in a close apartment or even a large box in which they have been placed. The presence of the minute Red Spider on the underside of the leares of plants, and causing them to turn brown, indicates too try an atmosphere where they are. Any plants affected should, sereral times claily. receive a thorough sprinkling or washing with water. Mealy 


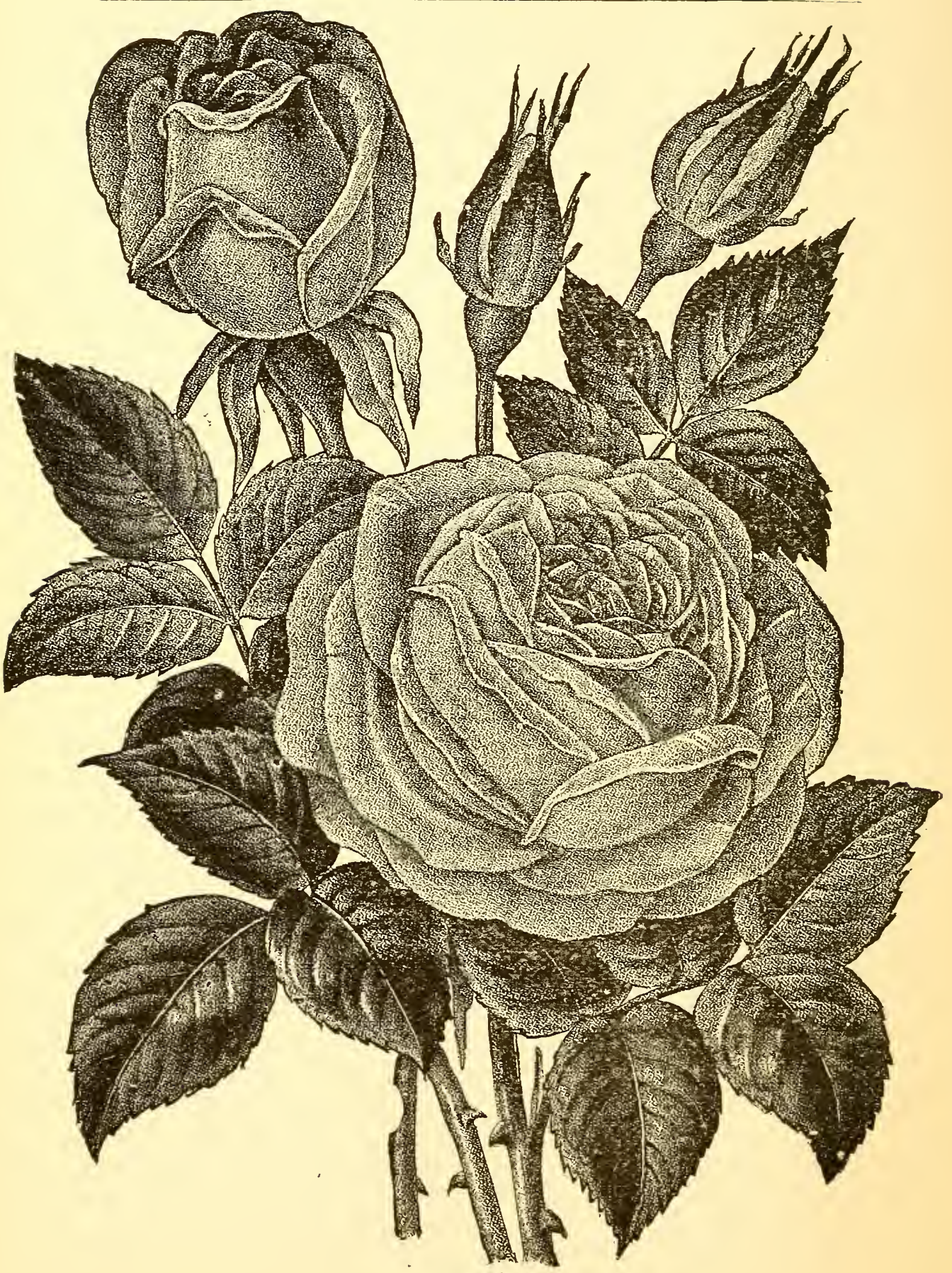

Sunset. 
Bug and Scale, if they appear, may be exterminated by washing and brushing the affected part of the plant with warm soapsuds. To remove Angle Worms, plants should be tapped out of the pots and the worms picked from the ball of earth.

Improving Plants by Pruning.- "How shall I grow my plants compact and symmetrical in form?" is a question frequently asked by amateur florists. It is a simple matter, and is accomplished by jud cious pruning and cutting. In nearly all flowering plants, exce ting those grown from bulbs, also in trees and shrubs, buds are formed at the axis of the leaves along the stem or branches, while the growth usually proceeds from its termination. This, in tender perennial plants, if not checked, continues to grow, and may cause a tall or unshapely form, but by cutting off at any point, or pinching out the terminal buds, new shoots start out at the leaf-joints below the cut, or if already started, commence to grow with increased vigor, and will, in due time, result in a better-shaped and more bushy plant or branch. Pruning or pinching should be more generally resorted to than it is, for, by observing the principle of growth alluded to, and varying the pruning to the habit of the kind, it is just as easy to have your plants, either in the house, conservatory or garden, of fine form, as to have them otherwise, and they are so much more rewarding and agreeable to work among. Little danger exists of cutting away too much; persons who resort to pruning frequently err in cutting too little. Old plants with long, leafless branches may be entirely reshaped by severe pruning.

Keep the Plants Clean.-To be healthy a plant must have clean foliage, and it is necessary to go over the window collection occasionally, and wash the leaves by the use of a sponge, otherwise, with the dust from the room accumulating upon them, they will in time receive injury. It is a capital plan to throw a sheet of cloth over the plants when sweeping and until after the dust has settled, but even then an occasional sponging is useful. In the case of bay windows, glass doors or curtains should be provided, which can be closed during sweeping.

Convenient Fertilizers for Pot Plants.-The gargardener who would derive profitable returns from his land for years in succession, learns the need of providing the soi! with an equivalent in fertilizing matter-plant food-for each crop that 
has been taken from it. In this is involved a principle that will apply to any kind of husbandry, and as well to plant culture in pots as in the open ground. With the treatment young, thrifty plants receive of being repotted occasionally as their growth adrances, and each time receiving a belt or layer of new fertile earth, the principle we have referred to may appear and to an extent is exceptional while this goes on. But as plants attain considerable size, it is well not to shift them so frequently as when small; one reason being that the smaller the pots can be kept, the more conveniently they are managed, and then the plants should receive some artificial stimulant at times. It may be said also that generally, it is better to keep all plants in the smallest pots that will answer for them, and such a course also necessitates providing the soil with fertilizing matter of some kind as plant food. Some suitable article in a concentrated or liquid form, is most convenient to apply, but it must be done with caution by the inexperienced cultivator, else it may be too strong, or if given in an overdose, injury to the plants result. For general porposes a garden shovelful of rotten cow or horse manure-that taken from an old hot-bed is excellent-put in a barrel of water and stirred up with a stick, and then left to settle before applying to the plants, will have a good effect upon their growth if applied freely, and it will not be strong enough to injure them. I hardly care to encourage the use of liquid manure made from guano, except by skillful hands. It is usually prepared in the proportion of one large tablespoonful to one gallon of hot water, aud stirred until it is dissolved. This may be applied once a week, taking care not to touch the plant or leaves. Hen manure may be substituted and used in about the same quantity. A safe liquid fertilizer is obtained by dissolving a tablespoonful of prepared bone, ground sufficiently fine to be soluble, in a gallon of warm water. This may be applied in sufficientquantity to soak the entire ball of earth, and will have a remarkable effect upon plant growth.

An excellent liquid fertilizer, for Roses in pots may be prepared by dissolving a tablespoonful of soot in two quarts of warm water. By giving the plants a small portion of this each week they will make rapid adrances. A solution of ammonia, made by dissolving a $\frac{1}{2}$ ounce of the crystal in two gallons of water, will improve the growth of plants if freely applied. One distinction between rain water and water obtained from wells is the presence of a 
small quantity of ammonia in the former. which may be taken as an explanation for the usually accepted belief, that rain water is better for plants than that drawn from wells or springs.

How to Treat Frozen Plants. - The disastrous effects which tender plants that have become frozen are subject to is generally known to cultivators; but how or why freezing produces the effect it does upon plant life is not so well known. In practice it is found, that the length of time, and the degree of cold to which plants are exposed, affect them in proportion to the duration and intensity of these conditions, which points, therefore. to the speedy restoration of a suitable temperature as the best means of restoring plants that have been unfortunately exposed to frosts. But the thawing out should, in all cases, be gradual, and one of the best things to do when plants have beconre frozen, either in the dwelling, conservatory or in the open air, is to sprinkle the foliage with cold cistern or well water, as the temperature turns to rise. In the dwelling or conservatory, however, it will be necessary to start the fire in the stove, furnace or flue the first thing of all, to give the temperature an ascendency, but it should for several hours not be allowed to rise above an ordinary suitable degree. Some adrocate shading the plants from the sun and light for some length of time, but the policy of so doing has nerer been apparent to me, while I have frequently had strong proofs to the contrary; that, the sun's rays striking upon the plants with gradually increasing heat, in a great measure aids their recovery. There is a great difference in plants, as regards their ability to resist cold, and while some the slightest frosts will injure beyond cure, others will bear various degrees, and even alternative freezing and thawing again and again with impunity. Aroid handling plants in a frozen condition as much as possible, as the injury to them will be heightened should the leares become bent or be roughly brushed orer. To restore flowers that have become frozen, place them in cold water until they have thawed out.

Ferneries or Wardian Cases. - Lorers of plants and flowers should not overlook the advantages presented by these novel and successful appliances, for growing plants in "the dwelling at any time, but particularly in the Winter. Dryness of atmosphere and dust are among the detrimental influences which we meet in Winter plant culture, but by adopting the Wardian case 


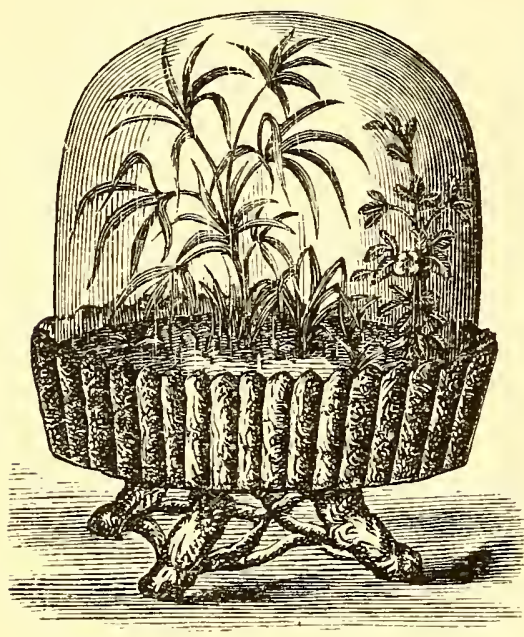

Fig. 23. Round Fernery.

principle of growing plants, these are entirely avoided, and, instead, a uniformly moist atmosphere is gained, which is altogether congenial to plant growth, no matter how dry the air outside in the drawing-room or parlor may be. A glass case or shade is the principal agent employed. This is placed over plants growing in a vase or stand, to which it is fitted, and completely surrounding them. The glass retains the moisture of the atmosphere, and constantly returns it to the bed, thus also making frequent watering unnecessary. Usually plants with striking foliage are employed in Fernery culture, the Ferns and Lycopodiums being especially prized for the purpose, although all mentioned for this purpose in the descriptions, including the flowering Begonias, are quite suitable. After planting the Fernery, the only care necessary to its management is to prop up the glass on one side, or entirely remove it for a shori time daily after the morning dusting, and to pick out all decaying flowers and foliage. Water should be given only when the surface of the soil becomes dry, which will not be often.

Culture of Bulbs in Glasses, etc.-Taking advantage of the peculiarity of the Dutch bulbs to grow and flower freely in any medium capable of retaining moisture, we find it easy, with a little forethought, to have a profusion of bloom in the house or conservatory during the Winter, and the presence of their brilliant colors among the various pot plants is very desirable for adding to the attractiveness of collections. Whether bulbs are grown in glasses of water or in pots, vases or other holders, they should, to make a complete success of the undertaking, be removed after planting, to a cellar, or a cool, dark place, to remain six or eight weeks, for the purpose of causing a growth of roots before the leaves and flower stems start up. From here they can be brought directly into the parlor or conservatory where they are to flower. The difference of a week or two between the periods of starting 


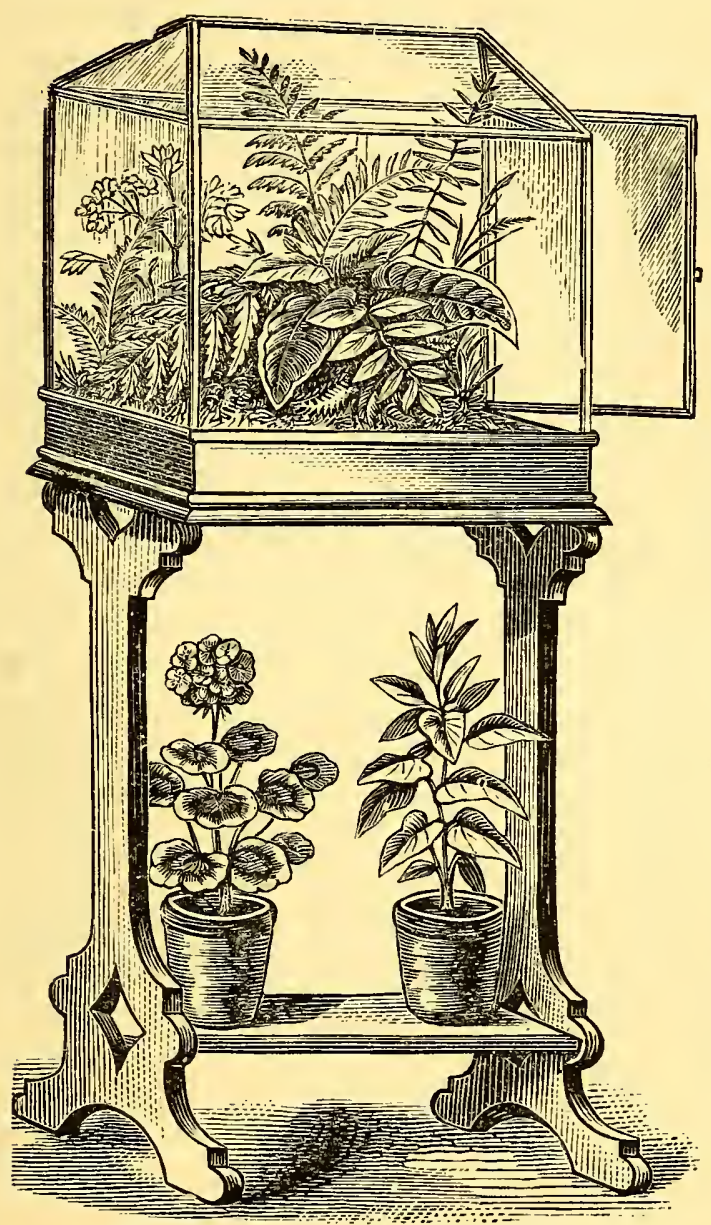

Fig. 23. Square Fernery.

will produce a corresponding difference in the periods of bloom. When growing Hyacinths or Crocus in the glasses made for the purpose, see that the base of the bulb, only, touches the water; also, after admitting to the light, the water should be changed occasionally. In pot, box or vase culture, bulbs should be planted onethird or one-half of their heights in the soil or other material employed, moderately pressing the same around the bulb and applying enough water to soak thoroughly before placing into the dark as above alluded to. Bulbous plants of any kind should never le allowed to suffer for lack of water while in a growing state. A very good course to pursue in managing bulbs in glasses, is by first starting them in clean sand in some cool place, and after they have become well rooted, transferring them to the glasses, first washing all sand from the roots. Dark colored glasses are preferable to clear ones for bulb culture. Any attempt at forcing the hardy bulbs will be quite certain of being attended with successful results. The flowers will develope most beautifully in a rather cool place, but where the theremometer never reaches a freezing point, for, although a slight freeze will not destroy them, it will lessen the beauty of the flowers. 
Do Plants Poison the Air We Breathe-There is a notion somewhat prevalent that growing plants in rooms are detrimental to a healthy atmosphere by their giving out poisonous carbonic acid gas in the night time. It has been demonstrated that growing plants do exhale an almost imperceptible quantity of carbonic acid gas, which, in rery small proportions, is necessary in the air we breathe. But it is also shown that the quantity exhaled at night is but the one-sixteenth part of what the same plants absorb from the atmosphere during the day, and convert into nearly its own weight of oxygen, thus rendering a poisonous gas, that derives its origin from various sources, into one of the principal elements of pure air.

If carbonic acid gas is emitted from plants in dangerous quantities, it certainly would exist largely in the night atmosphere of a close greenhouse heated to a tropical temperature, and crowded from floor to rafter with the rank vegetation of thousands of plants. Yet, no florist, to my knowledge, has ever found the slighest ill effects to attend night work in greenhouses, or even from making the warm houses sleeping quarters of a night, or for an entire winter, practical proofs that the notion is a fallacy. The fact that perhaps no healthier class of men can be found anywhere than greenhouse operators, who work constantly in an atmosphere where plants are growing, would go to show that living plants exert altogether a very beneficial influence upon the air we breathe. 


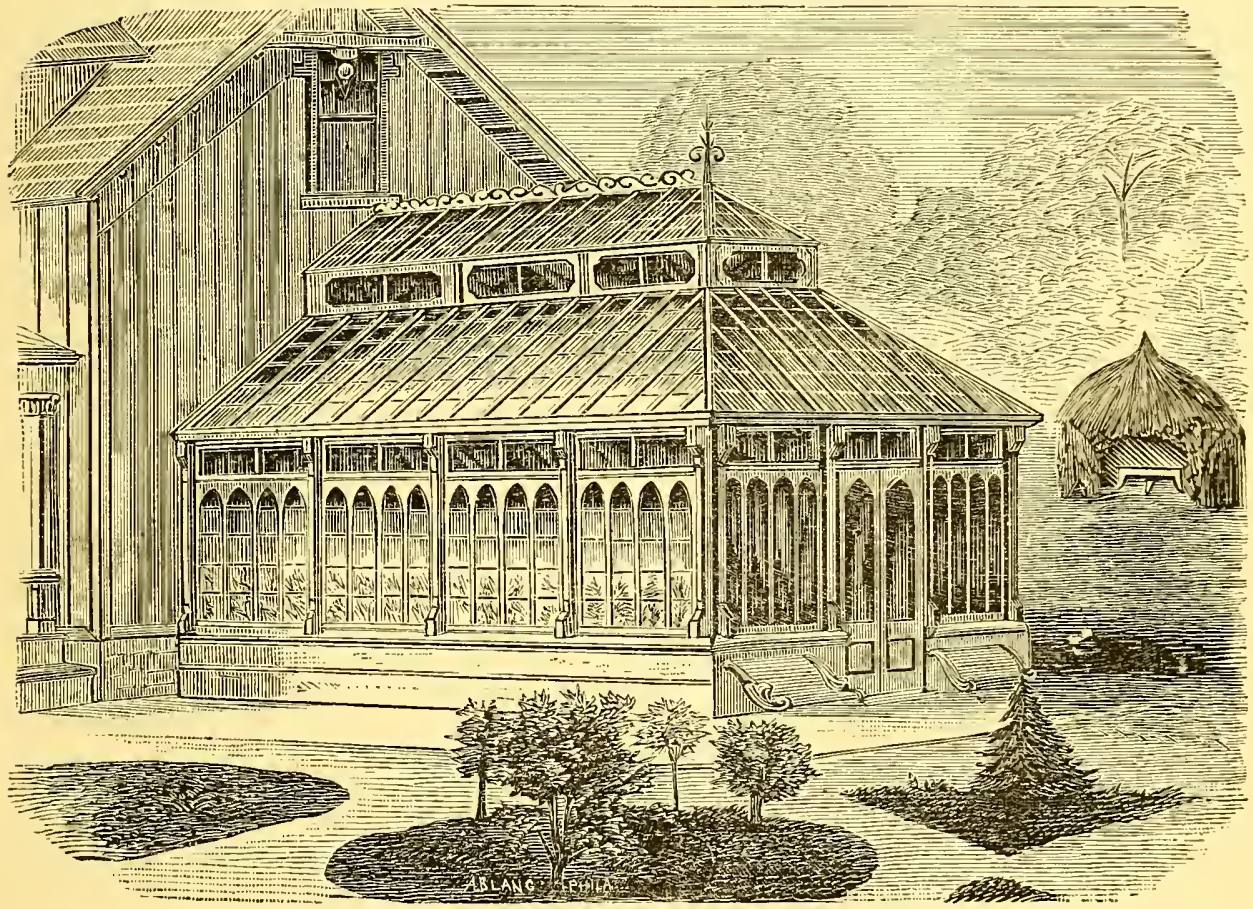

Fig. 25.

\section{THE AMATEUR'S CONSERVATORY.}

A well-managed Plant Conservatory opening from the living room, and accessible at all times, is perhaps, the most beautiful and ever-changing source of recreation that can be introduced in connection with the home, and in consideration of the attractive features it possesses is comparatively an inexpensive source of gratification, particularly if the duties connected with its management are discharged by the patrons of its innumerable stores of interest.

The subject of conservatories for amateurs in America is, at 
the present time, comparatively new and undeveloped. This is especially true outside of our large cities, and doubtless many have given the subject of possessing one some consideration, only to finally drop it in the belief that, however desirable one might be, its erection for a moderate amount, and the after management of it, would for them be out of the question.

It is my desire to present such facts and suggestions relative to building, stocking and managing home conservatories as my experience points out as being applicable to the wants of amateur florists, hoping by these means to remove erroneous impressions, and enable the reader to riew the matter in a practical light.

Utility of a Conservatory. - With the erection of a suitable structure, cut flowers for bouquets and other uses can be grown almost as well in the winter as in the open ground in the summer, thus affording a continuous season of flowers all the year. Besides this, beautiful and rare decorative plants may be grown to great perfection, and young plants for the flower garden, hanging baskets and other purposes cari be raised without additional expense, while vegetable and flower seeds of all kinds may be started. These various last-named items, with the growing of flowers, which would otherwise be bought at the florist's in winter, might be made to go far towards balancing the expense and investment account. Besides, in most small towns, where no regular florist is located, or in the rural districts, the home conservatory, aside from serving the purpose for which it was mainly intended, might readily be made self-supporting, and more, if those who have the management in hand would desire to engage in growing a stock of plants and some extra hanging baskets, and offering them for sale at a reasonable price. They would be surprised to see how eagerly neighbors and friends would purchase all their surplus in the spring, when the plants would be in full flower. And were more cut flowers and foliage grown, than would be needed at home by letting it be known, a demand could easily be created for them at paying prices, to be used for decorating at wedlings, parties, etc. I make these suggestions in the belief that in thousands of localities throughout our country persons might combine profit with pleasure in cultivating plants and flowers in the conservatory with the most pleasing results. Ladies and young people, especially, would find this a fascinating employment for spare moments and one free from heavy toil. 


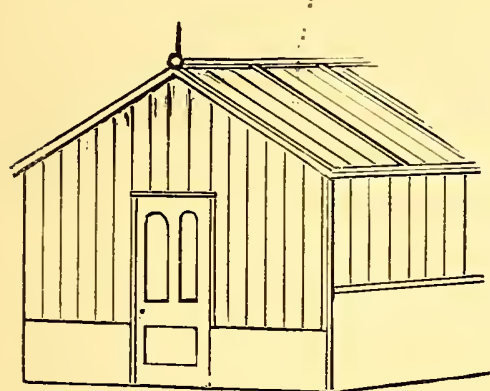

Fig. 26. End View of a Cheap can call to mind structures of this Conservatory. kind, on private places, that have cost various figures, from $\$ 2,000$ or $\$ 3,000$ each, down to $\$ 100$ and less. One very simple structure in this city, which is heated by an ordinary base-burning coalstove, and in which at all times can be seen a fine growth of plants, hanging baskets and flowers. has pleased me so much that I have had an engraving made of the ground plan of it as shown in figure $2 \%$. The building is ten by twelve feet, and is seven feet to the rafters at the lower end, being a lean-to agăinst a dwelling. The beds or benches are two and a half feet high, and nearly two feet wide. On the floor at the sides and ends of the aquarium, are placed tall plants, such as the side benches will not accommodate. In case an aquarium were not wanted, a plant bench might be built up a foot or more from the floor in its stead. The sides of the house from the benches upward are of glass, and at a height allowing the heat to the ventilators are fixed in the roof. it; $C$, aquarium or plant bench; $D$, The plant bench; $E$ water barrel or $^{-}$ The rafters support a number of fine sink; $F$, entrance from dwelling. growing hanging baskets, and altogether the house is quite complete, and cost the owner, perhaps, inside of $\$ 60$.

The large view of a conservatory, Fig. 25, represents a house. size sixteen by twenty-four feet, the cost of which would be $\$ i 00$ and upwards, if heated in the most approred style, with hot water boiler, and one hundred and fifty to two hundred feet of fourinch cast iron pipe. The same sized house might, however, be built in plain, durable style, similar to Fig. 26, for about half that figure and be precisely as vaiuabie for plant growing, while by employing a cheaper means of heating, which is much used by flor- 
ists, namely, the brick furnace and Hue, the cost might again be lessened $\$ 150$, which would bring the entire cost down to $\$ 200$, and perhaps even less, for what would be quite a large-sized house. By building of smaller dimensions the cost could be again reduced. In a house like the one represented in Fig. 2.5, the ventilators for admitting fresh air consist of the side sashes, of the raised portion of the roof; these are hung by hinges from above, and are worked by means of pulleys or rods from the interior. The roof of Fig. $\cong 6$ is built more simple, and the ventilators consist of sashes, which reach either from the plate board to the ridge piece, or else a part of this distance, starting from the centre $\mathrm{f}$ the house. These ventilating sashes by being hinged at their lower ends, are raised and lowered by means of a light iron bar eighteen inches long, with holes in, attached to the top of the sash, and which is caught on a round nail in the ridge piece. Fig. 28 represents the cross section of this house, showing the internal arrangement of the beds and walks, and also the brick flues for heating, which are unde: the side beds. The walks should be two and a half to three feet wide, and extend from the dwelling entrance to the outside door on each side of the middle bed. The cross section $A$ shows a bed in a house, heated by two four-inch hot water pipes. The brick furnace or the hot water boiler for heating might in many cases be placed to be fed with fuel, from the basement of the dwelling.

In heating with a hot water boiler and pipes the heat is imparted to the interior by the hot water pipes from the boiler

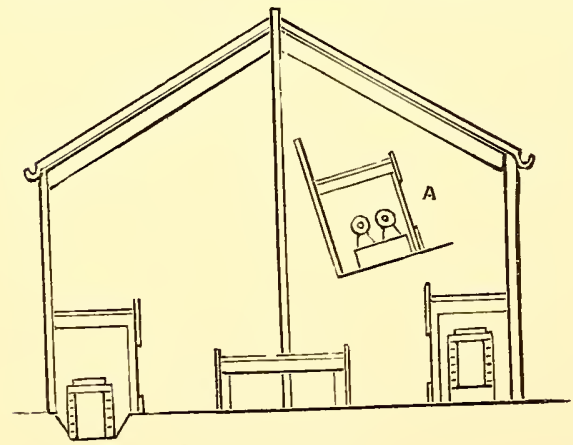

Fig. 28. laying in one continuous line throughout the building, under the beds, and returning to the boiler again. In some cases the smoke from the boiler might be conducted to the chimney of the dwelling. Through these pipes the water circulates, continually flowing from and returning to the boiler for heat. With furnace and flue heating it is different; here the heat is distributed directly from the latter, which is built to pass nearly around the house, uncler the side beds, with a gradual ascent the entire distance, to give draft, opening into a chimney built at the side of the con- 
servatory near the further end. At the outside cloor it will be necessary to cover the pipes or flue with a low platform raised six or more inches above them. The sides and ends of a conservatory, up to the glass, should be built by boarding against the studs with matched flooring, the tongue side up, both in and outside: by lining with tarred building felt or boards against the studs, the structure will be rendered much warmer. After the wood work is finished it should receive several coats of paint, white being the color generally preferred.

In a recent number of the Ohio Farmer, Mr. Mijton Mansfield gives some excellent points on the construction of small glass houses that may be found useful in this place. He says that small greenhouses for raising bedding plants, as well as regetables, can be either built with fixed or movable roofs, the latter being the better, using sash which can be taken off during summer, when not required. If good white oak posts can be secured, get them six feet long, and sufficient in number to put into the wail every six feet. The house can be made any length up to 50 feet, if it be heated with flue. Let us allow the house wanted to be thirty feet long and ten feet wide, inside measurement; for six feet long sash this makes the best width. It will require 13 posts, 6 for each side and one for centre of end. Sink the posts into the ground $2 \frac{1}{2}$ feet, allowing $3 \frac{1}{2}$ feet abore the surface of the ground, allowing the posts to be four inches in diameter; set them $10 \frac{2}{3}$ feet from outside to outside. Line up with common pine lumber, having the upper edge level with the top of the posts. Cover this with roofing paper, fastening it down with strips half an inch thick, which affords an air space between the paper and the next lining, which may be of same kinds of boards as the first, or may, if it cannot be banked up with soil, either core or cap siding, but it is the better way if convenient for this kind of house to bank up with soil; it keeps the house warmer and requires less fuel to keep up the necessary temperature. On the top of the posts put on a plank $1 \mathrm{x} 6$ inches, surfaced on upper side to rest the rafters on. Joists $2 \times 3$ inches, haring one corner bereled off to the same pitch of the house for the end of the sash to rest on; spike this down one inch from the inner erige of the 6 -inch plank, which affords a rest for the end of the rafters. The rafters being also $3 \times 2$ inches, are made and fitted so that the upper edge of them, where the sash rests, shall be flush with the bereled edge of the joist; then the sash lies close at the bottom and tight to the 


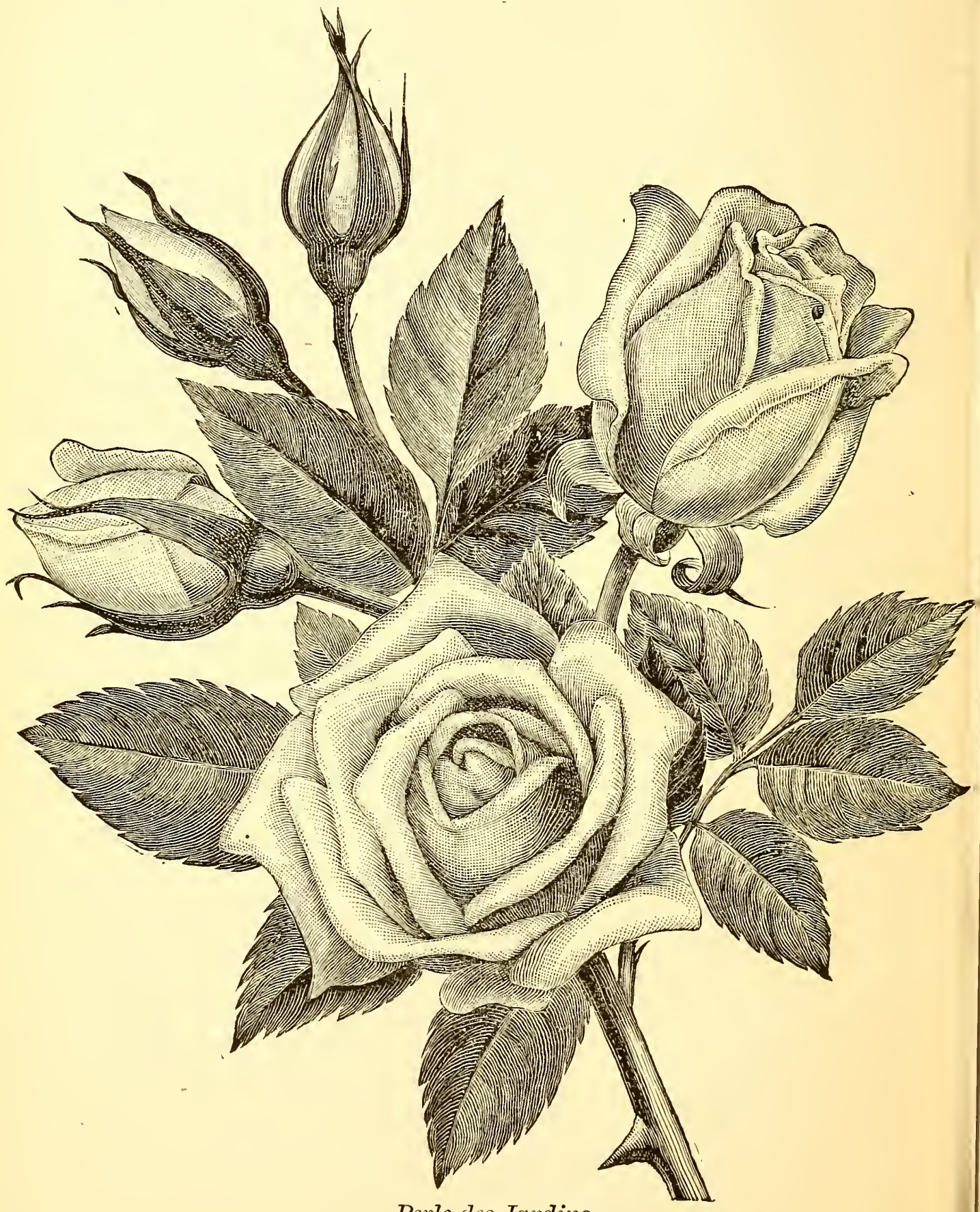


rafters. For a ridge, $6 \times 1 \frac{1}{2}$ inches is the most suitable, to which nail the rafters, which should be 3 feet apart from centre to centre. Bevel the upper ends of the sash so that they shall fit neatly against the ridge. Make every alternate sash so that it can be raised to admit of thoroughly ventilating the house. The other sash screw tightly down at the top and bottom.

The flue should be built of brick and terra cotta pipes, using brick for about 12 feet next the furnace, as if the pipes are placed too near they are liable to break from the intense heat. They are better, however, than brick at the further end, being easier warmed, and being smooth inside, the draft is much better; 8-inch sewer pipe answers very well. Sink the furnace pit so that there be a rise of about one foot in $1^{n}$ to the bottom of the chimney.

A house this size (10 feet wide) can have benches four feet wide on each side of the path, which for all practical purposes is wide enough at two feet. If the house is to be used for raising vegetable plants, have the bottom of the benches about 4 inches from the glass at the lower side; this allows plenty of head room for the plants after about 4 inches of soil is placed on them in which to grow them. If for single bedding plants, they may be kept nearer the glass, and instead of soil on benches, have an inch or two of sand or finely sifted coal ashes. It is better to have something on the boards of this nature, as it prevents drying out of the plants too rapidly, which is the case when set on the bare boards.

Winter Management.-The conservatory in winter should be kept at as uniform a temperature in the night time-that is one night with another-as possible, and at a figure adapted to the requirements of the majority of the collection. I say night time because the inside atmosphere is not then affected by influence of sun and clouds, which renders it easier thus to give and observe directions, besides in the day time a uniform temperature is undesirable, as plants in the conservatory require more heat when it is sumny than in cloudy wheather. This is a point that should be carefully observed by erery inexperienced operator. A thermometer is indispensable to indicate the temperature. Throughout the descriptions of plants in this book, the temperature best suited to each is indicated to guide their management in the conservatory. In most cases three figures indicating temperature are given, the first one showing the lowest point of cold each plant will bear, the last the highest degree, with the most 


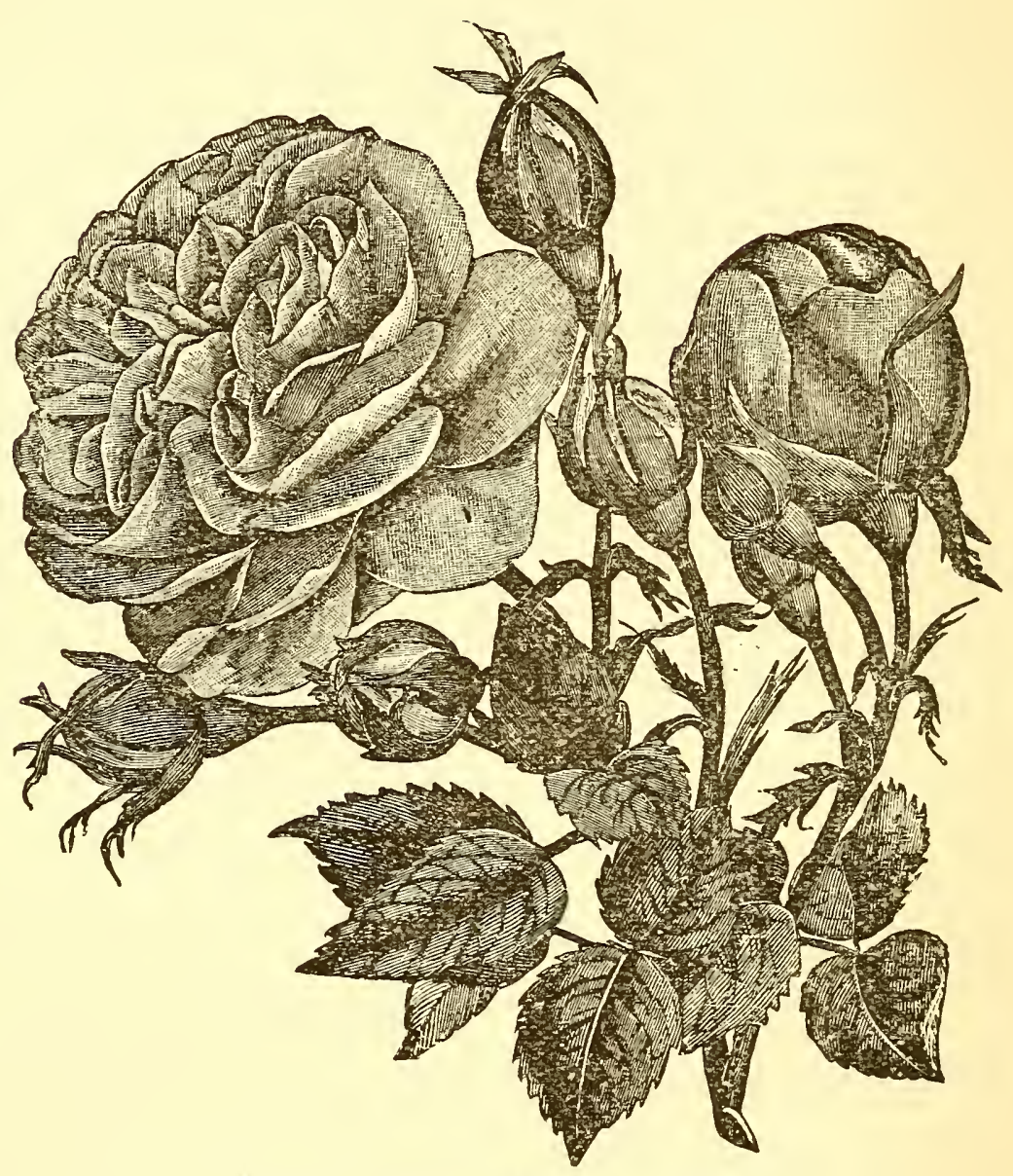

Bourbon Rose-Queen of Bedders.

generally suitable night temperature shown by the middle figure. A temperature of $70^{\circ}$ or even above, will suit any kind of plants when the sun shines, provided some air is admitted at the same time, while in cloudy days more than $10^{\circ}$ above a suitable night temperature is not desirable and should be guarded against by checking the fire if necessary or admitting air. When airing do not open the ventilators so much at once as to greatly lower the temperature suddenly. A little air at least is desirable every day in the year when the weather is not too severe, while in warm spring, summer and autumn weather the rentilators may be liept wholly or partially open all the while. When the surface of the soil in pots indicates dryness, water should be freely applied with 
the pot hose, as plants are soon injured by becoming over dry. Looking over the collection every second day in winter, and daily in spring, watering profusely where it is required, is none too often; in a house heated with the flue, it may be necessary to water several times daily orer the hottest part of the flue. Water occasionally syringed or sprinkled over all the plants renders the air humid in a way that will be beneficial to all kinds of plant life. The matter under the head of a Classification of the Amateur's Work for Every Week in the Year, contains much other information that bears on conservatory management in the winter as well as summer.

Summer Management.-If the glass roof be whitened on the outside with a thin wash made either of quicklime and water, or else of turpentiue or naphtha and a little white lead mixed up so as to appear like thin milk, the home conservatory can be made a most delightful place all summer. But if this or some kind of shading is not done the scorching rays of the summer sun will cause heat of sufficient intensity to hurt many kinds of plant life in the building; this wash should be applied about the first of June. Then, with doors and rentilators open, by dashing water.on the walks, and profusely sprinkling and watering the plants, etc., the atmosphere may be kept agreeable and hanging baskets and all kinds of plants will thrive amazingly, particularly if abundant pot room has been afforded the latter. With the return of August and the two following months, the securing of plants from the open ground will require attention, and fire heat may be started a'little in cool nights, but during the day, as late as possible in the season, the rentilators should be kept open. It is well always to have an inch of sand on the benches where pots are set.

Propagation of all kinds of plants may be successfully done at most any season of the year in the conservatory. The bed in which the cuttings are struck shonld be boarded up on the sides, underneath, to cause the heat from the pipes or flue to rise up through the sand, for imparting the desired bottom heat to the bed. See special article on the subject of Propagation.

Insects, etc.-Aphis or Grcen-fiy are very common intruders in the greenhouse; these may be destroyed, and also prevented, by dampening ore-fourth or one-half pound of dry refuse tobacco or stems from the cigar maker, and after placing 
it on a handful of shavings or live coals, on the ground or stone floor, burning to ashes. The smoke thus produced may be strong enough to be very uncomfortable indeed to human lungs and senses, without affecting plants. The presence of Red $S_{i}$ inder indicates too dry an atmosphere, and this should be corrected by dashing water about the house very freely. Any plants affected by this insect should daily receive a thorough sprinkling or washing of water. Mealy Bug and Scale may be exterminated by washing and brushing the affected part of the plant. To remove Angle Worms, plants should be tapped out of the pots, and the worms picked from the ball of earth. Should mildew at any time put in an appearance, scatter a little flour of sulphur over the plants after the foliage is wet from watering and keep the nouse closed for a day or two.

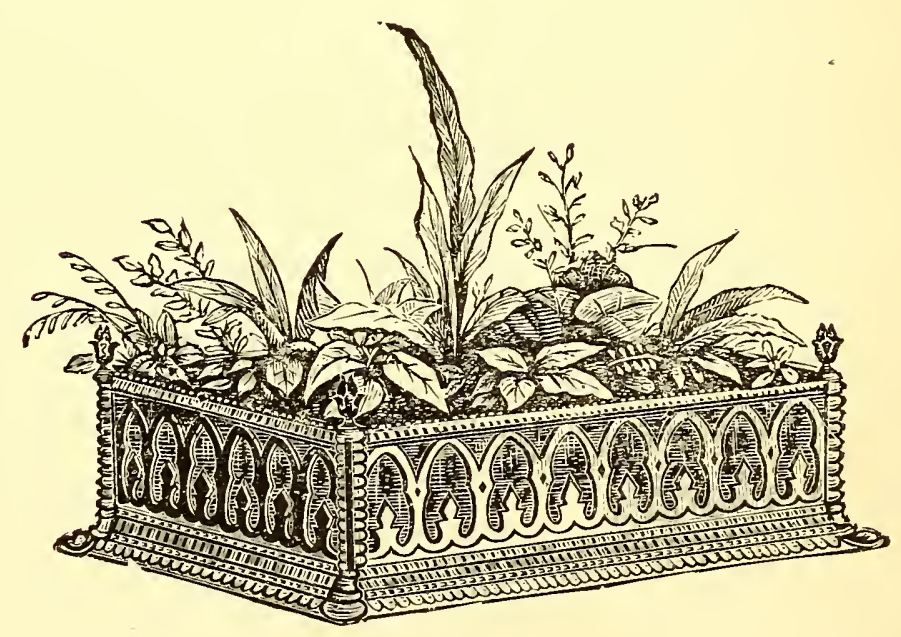




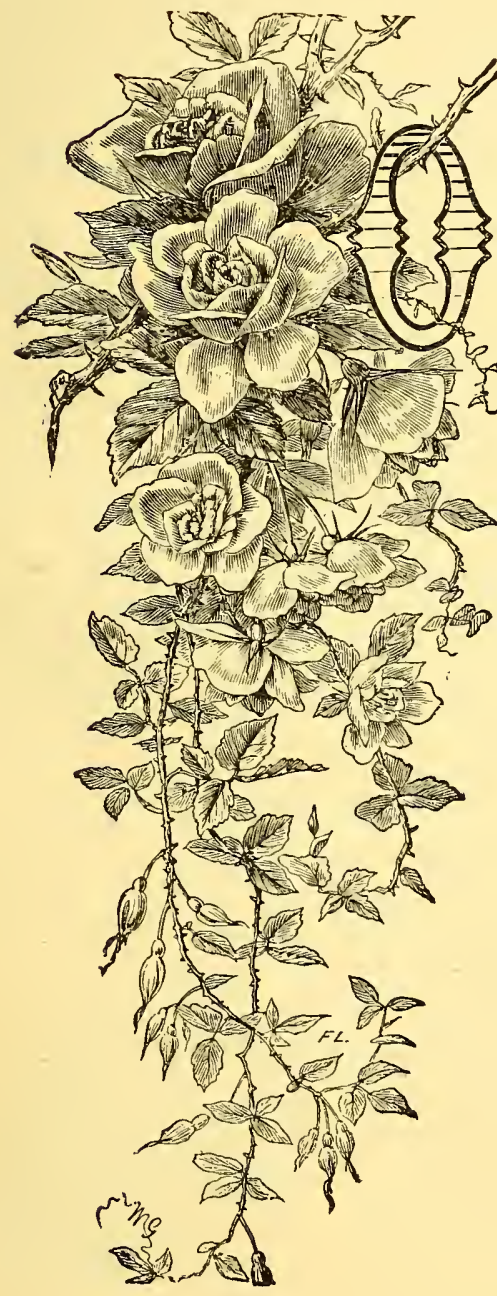

\section{ROSES.}

II, the queen of all the roses, it can never be cenied,

Is the heavy crimson rose of velvet leaf !

There is such a gracious royalty about her vivid bloom,

That among all charming kindred she is chief !

Then the fainter shaded roses, in their balmy damask pride,

Group like satellites about one central star

Royal princesses, of whom we can discover at a glance

What aristocrats the dainty creatures are !

Then those tender gauzy roses, clustered closely on their vines.

They are gentle maids of honor, I am told; But the pompous yellow roses, these are sneered at, it is said,

For so showing off the color of their gold!

And the roses that are powerless to boast of any tint,

Unsullied as the snow itself in hue,

These are pious nuns; I fancy, who perhaps may murmur prayers

Very softly upon rosaries of dew!

But the delicate pink roses that one meets in the quiet lanes,

Gleaming pale upon a background of clear green,

Why, these are only peasant girls, who never go to court,

But are loyal little subjects of their queen!

\section{THE ROSE FAMILY.}

As a rule experienced cultivators are ready to admit, I think, that Roses are no more difficult to rear, in proportion to their value, than any other family of plants in cultiration; and yet there is scarcely a subject connected with floricuiture, in which amateurs generally realize so great a lack of knowledge, as on the subject of the different kinds of Roses and their management. 


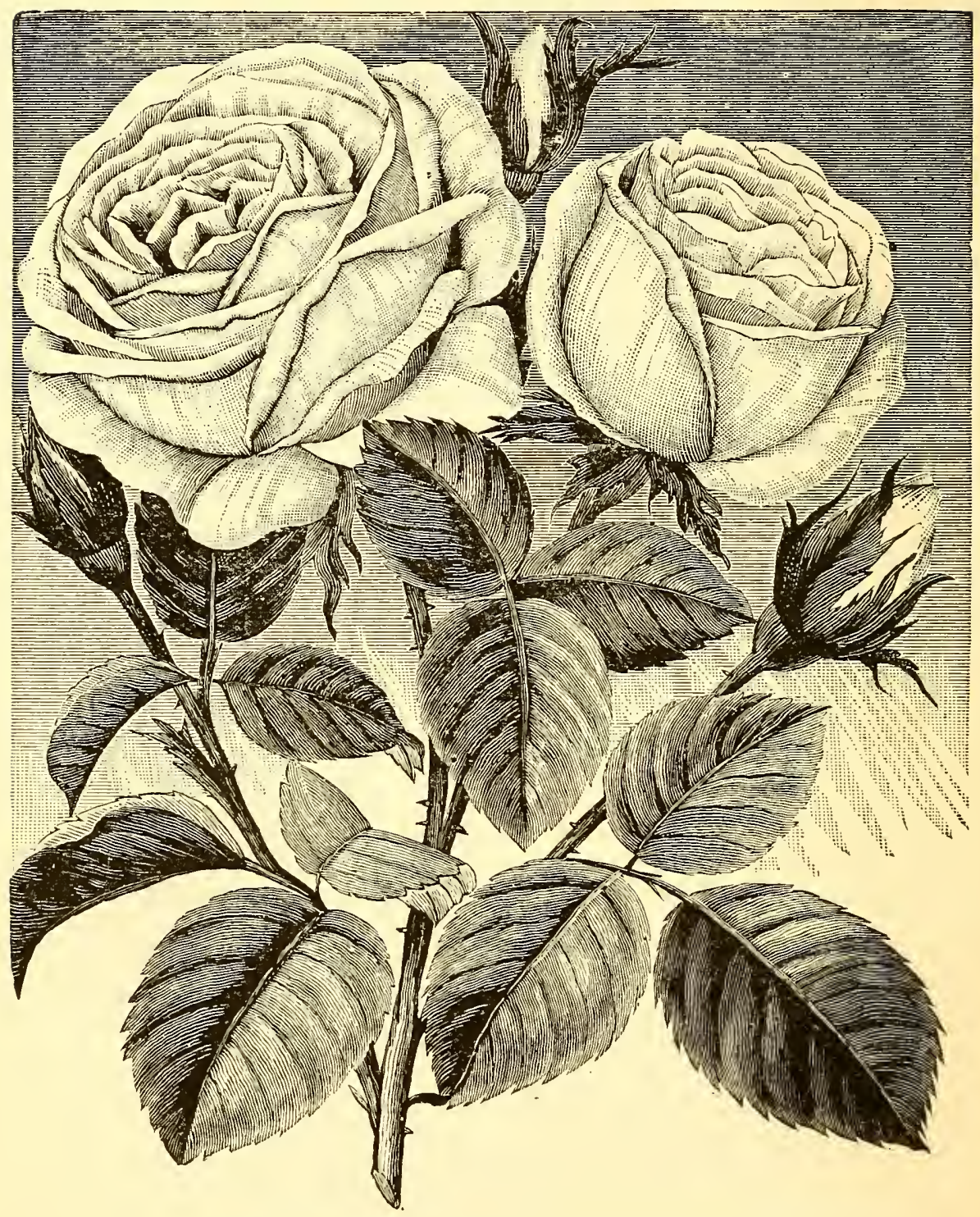

Hybrid Perpetual Rose-Coquette des Alps.

This can be accounted for by the fact that the family is extensive and diversified, and consequently not so easy to fully comprehend and gain an acquaintance with as some others are. The right way to proceed for becoming familiar with the entire subject is to carefully discriminate at all times between the various 
classes into which the family is divided, bearing in mind the distinct habits, adaptability and treatment of each. By such a course there need be no more difficulty in becoming familiar with all the classes and every branch of the subject, than to master an acquaintance with the same number of different kinds of other plants. In the present work there are for instance eight different classes of roses described. By proceeding on the plan suggested, the distinct characteristics as well as the management of all these ought to be as easily mastered as would be the same with any eight different other flowers described in the book. Being desirous of rendering all possible aid in this matter, I have paid due attention to simplifying it, firstly, by presenting the Hardy and Tender divisions of the family separately, and then describing the classes that are included in each, following up with directions for managing the different kinds in summer and winter.

\section{HARDY ROSES.}

This division of Roses includes the classes known as the Hybrid Perpetual Roses, June or Summer Roses, Climbing Roses, Moss Roses, etc., all of which are noted for their hardiness and easy culture.

HYBRID PERPETUAL ROSES. - This is by far the most desirable class of hardy Roses for general cultivation, being vigorous and robust in habit and producing flowers, usually very fragrant, and which for immense size, perfect form and gorgeous colors are unequaled. This class is of more recent introduction than some others, having originated from shybridizing the June or Summer Rose with the ever-blooming section. Although the name would indicate the quality of blooming perpetually, onlysome varieties are strictly deserving of the name, for as a rule they flower freely but once in early summer, after which they cancot be depended upon for more than a few flowers; but as an ofiset to such mis-application of the term "perpetual," the flowers of these more shy-blcoming varieties are likely to be possessed of more than ordinary perfect form, fragrance or color. The more prolific varieties, however, not only produce a wealth of flowers in June and July, but again at intervals during the summer, with usually an increase toward autumu. Although this class is comparatively hardy in this latitude, it is always best to protect with straw in winter. The remarks elsewhere relative to removing 
matured flowers apply with particular stress to Hybrid Perpetual Roses.

JUNE OR SUMMER ROSES. - The varieties of this class are all perfectly hardy, free growers. producing an abundant crop of flowers in June or early summer, and will thrive in any soil and under almost any circumstances. Specimens of this class are to be found in nearly every old garden in the country. Many of the improved varieties are very desirable. The Hybrid China, Damask and Provence sections belong to this class.

HARDY CLIMBING ROSES - This class, of which the Prairie Roses are the principal sorts, are generally vigorous growers with strong thorns and most admirably adapted to covering walls, trellises, arbors, etc. They are well known for their perfect hardiness, rapid growth, fine foliage and beautiful and finely-shaped flowers, comprising many different colors.

MOSS ROSES. - An elegant and well-known class of Roses, in most varieties producing large clusters of buds, that have individually their calyx and sepals entirely covered with a delicate, mossy growth which renders them the perfection of beauty while in a bud or half open state.

\section{HYBRID REMONTANT, OR HYBRID PER- PETUAL ROSES.}

If delicacy describes the Teas, grandeur is the appellation peculiarly appropriate to the beauty of the Hybrid Perpetuals. Their flowers are much larger than those of the tender Roses and the prevailing coloring is darker and richer than any found among the Teas. In growth they are also decidedly stronger and more vigorons. Their habit is erect and stiff rather than bushy and branching, and they are perfectly hardy in all parts of the country. Although requiring no protection against the cold, it is well where in every way convenient, to throw loose branches of trees over them in winter as a shelter from heavy winds. There appears to be an idea somewhat prevalent among amateurs, that these roses are only suitable for planting at the north, or that they are not worthy of being grown, where the Teas can be wintered over without protection. The notion is wholly erroneous. Their attractions are entirely different, and a collection that lacks them, exhibits but half the beauty of the rose. It should be 
well understood that these roses do not as a rule, bloom continuously. In May and June they present a magnificent appearance, the plants being fairly loaded with large, double flowers; a burst of bloom seldom seen on any of the dwarf Teas. July, however, witnesses the last of them until September and October, when most of the varieties, under good treatment, produce a second crop, not nearly so liberal as the first one, but often including individual flowers of greater perfection. Some kinds bloom almost as constantly as the Teas and Bourbons, but they are few.

Abbe Bramerel-Crimson, shaded with velvety purple; a grand rose, full and very double.

Abel Carriere-Velvety crimson, with fiery centre; large, full flowers; fragrant,

Achille Gonod-Rosy carmine, full form and large size.

Admiral Nelson-Bright crimson, double, cupped form.

Alfred Colomb-Carmine crimson, very large, of fine globular

form, extremely fragrant. This is truly a magnificent sort. Alfred $K$. Williams--Carmine red, changing to magenta.

Alphonse Fontaine-Bright carmine, shaded with rich, ruby scarlet; a charming sort, large and full.

Amelie Hoste-Pink, reverse of petals; darker, large and full, fragrant and beautiful.

Amelie Plantier-Flowers are a coppery yellow, color changing to yellowish white; medium size and full form. Anna Alexieff-Bright rose, large and double; free flowering. Anna de Diesbach-Bright rosy carnine; a fine large, showy variety.

Antoine Mouton-Bright, glossy pink, reverse of petals, silvery white; flowers of extraordinary size.

Auguste Mie-Clear, waxy rose, large and finely cupped; very fragrant; an excellent rose.

Baron de Bonstetten-Velvety maroon, shaded with deep crimson, almost black, fragrant and fine.

Baroness Rothschild-Light, clear pink, large cupped form, very symmetrical; much prized as a garden rose.

Baronne de Maynard-A very pretty white rose, edge of petals shaded blush.

Baronne Prevost-Pure rose, very large and full, free bloomer, fragrant and hardy. 
Beauty of Waltham-Bright, rosy crimson, large and fragrant; a free bloomer.

Belle Normande-Clear rose, shaded and clouded with carmine and lilac.

Boieldieu-A bright cherry red, circular flower of great size; blooms freely; vigorous.

Boule de Neige-Pure white, medium-sized flowers of perfect form. Captain Christy-Delicate flesh color, deepening toward centre. A most lovely sort.

Cardinal Patrizzi-Dark velvety crimson, very attractive; a superb rose.

Caroline de Sansal-Clear, brilliant rose, merging into rosy lilac, edged with bronze.

Catherine Bell-Deep rose color, reverse of petals, silvery pink, full and sweet; a vigorous grower.

Charles Darwin-Crimson with violet shadings, very beautiful and distinct.

Charles Lefebvre-Brilliant crimson centre, deep purple, large, very full and fragrant; a noble rose.

Charles Margotten-Fiery red, shaded with crimson, large, full flowers; an excellent distinct rose.

Climbing Jules Margotten -Flowers same as "Jules Margotten," highly commended as a useful pillar rose.

Comtesse Cecile de Chabrilliant-Satiny pink, medium size, full and fragrant: a lovely rose.

Comtesse de Choiseuil-Color vermilion, lighted with velvety scarlet, large, full, imbricated form; vigorous grower; superb.

Comtesse de Serenye-Beautiful silvery pink, blush centre, sweet and perfectly formed, of great beauty.

Coquette des Alps - Shell tinted white, of delicate appearance and beautiful color.

Coquette des Blanches--One of the finest whites, large and full; fragrant.

Countess of Oxford-Carmine red, tinged with lilac; a valuable variety.

Crown Prince-Bright purple, crimson centre; a fine variety.

Dean of Windsor-Clear rich rermilion, flowers large and very. attractive; free and constant.

Dr. Andry-Rich, rosy crimson, large flowers, fine, smooth petals; superb. 
Doctor Hogg-Deep violet, erenly shaded with purple.

Doctor Sevell-Bright crimson, tinged with purple; large and full. Duke of Edinburgh-Rich, velvety crimson, large, full and of good symmetrical form.

Duke of Teck-Bright crimson scarlet, clear and distinct in its vividness of color; flowers large and very full; pointed, globular shape.

Duke of Wellington-Beautiful velvety red, shaded scarlet crimson; very fine.

Earl of Beaconsfield-Cherry rose, medium size, beautiful form. Earl of Pembroke-Velvety crimson; a most beautiful rose.

Elise Boelle-White, delicately tinged with pink; medium size; a lovely rose.

Empress of India-Dark violet crimson, velvety, globular and fragrant; an imperial rose.

Eugenie Verdier-Silvery pink, tinged with fawn; one of the best of the type.

Fanny Pitsold-Bright rosy flesh, shaded and edged with riolet. Felicien David-Deep rose, tinged with purple; full and sweet; very large.

Felix Genero-Beautiful lilac rose, large globular flowers, double and deliciously fragrant.

Ferdinand de Lesseps-Bright crimson, large and full; very free flowering: a lovely rose.

Fisher Holmes--Dark, rich scarlet, elegantly shaded with deep velvety crimson; brilliant and beautiful.

Fontenelle-Large flowers of a rich, dark velvety crimson; a good rose.

Francois Levet-Soft pink, delicately shaded carmine and blush; delightfuily fragrant.

Francois Michelon-Deep rose tinged with lilac, very large, full of fine globular form; fragrant and free blooming.

Gabriel Tournier-Dark rose, large, full and fine shape; a free bloomer.

General Washington-Brilliant, dazzling crimson, approaching vermilion; free and constant bloomer; flowers are large and perfectly double.

George Moreau-Bright red, shaded with vermilion; very large; full, opening well.

Giant of Battles-Deep, fiery crimson, very brilliant and rich medium size, full, well formed, handsome. 


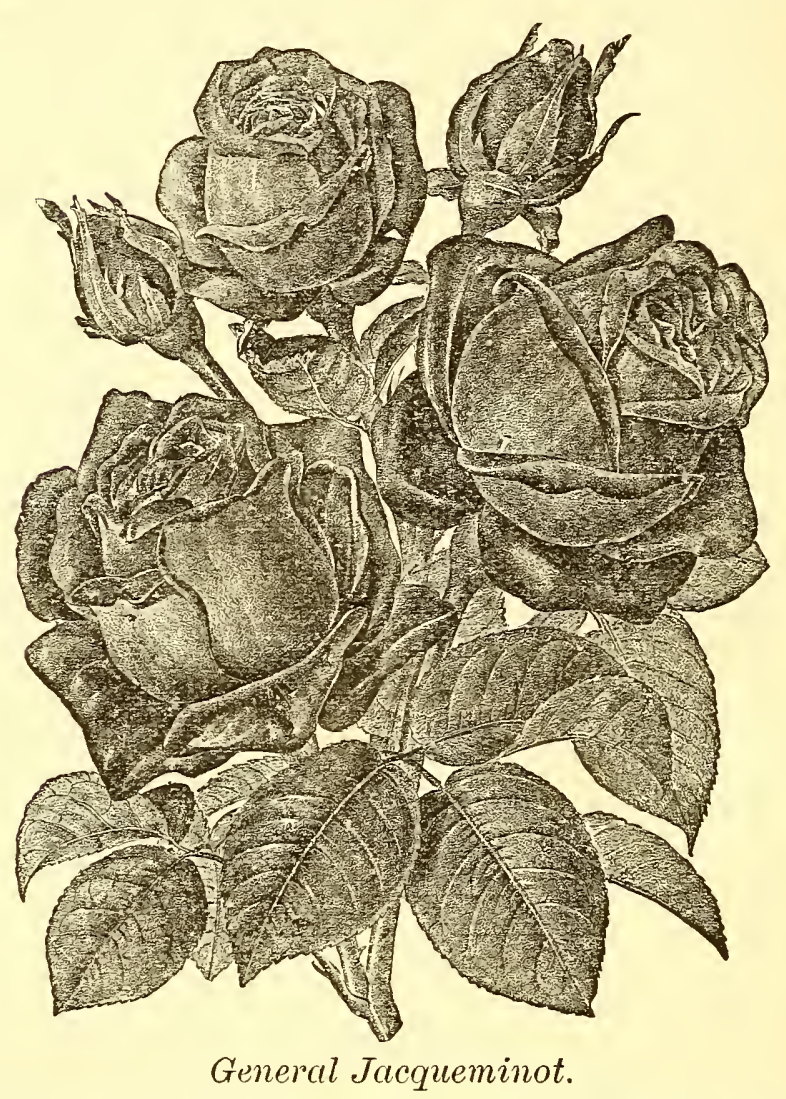

General Jacqueminot-Brilliant crimson scarlet, very large and attractive; an abundant bloomer; one of the best of the class.

Gloire de Ducher-Flowers very double, beautiful brilliant scarlet, deepening to dark maroon; fragrant, handsome and desirable.

Gloire de Paris-See "Anna de Diesbach."

Glory of Cheshunt-Rich crimson, double, very effective; a decided acquisition.

Grand Duke Nicholas--A magnificent ruse, color dazzling crimson, brightly flamed with intense scarlet, exceedingly fragrant, double and of perfect form.

Gustave Thierry-Cherry red, large, full and very double; very fragrant; a good variety.

Harrison Weir-Deep velvety crimson, brightenes with brilliant scarlet; very double and fragrant. 
Heinrich Schultheis-A grand new rose, flowers very large, of good form, full and very sweet, color very delicate, pinkish rose; a grand show rose.

Helen Paul-White, sometimes shaded with pink, large globular flowers, full and sweet.

Hippolyte Jamain-Bright rosy carmine; a handsome flower. large, double and globular.

Horace Vernet-Crimson, illumined with scarlet, large, double and beautiful. Few roses have such lovely form.

Jacques Lafitte Carmine rose, edged silver rose, reverse of petals, light.

Jean Liabaud-Crimson maroon, illuminated with scarlet, very dark, rich and fragrant; a lovely rose.

Jean Soupert-Fiery crimson, shaded with black; a richly-colored sort.

John Bright -. Color a pure glowing crimson, very bright, perfect form, with large even outer petals, sometimes recurved.

John Hopper-Deep rose, with carmine centre, large and full, semi-globular; a free-blooming standard sort.

Jules Cretien-Flowers large and finely-formed, color brilliant, fiery red, shaded with light purple.

Jules Margottin-Brilliant carmine, somewhat imbricated; a very fine rose, being large and attractive, fragrant and a free bloomer.

Julius Caesar Dark cherry red; a free and constant bloomer; large, full and fragrant.

La Reine-Beautiful, clear bright rose, fine, full form, large and fragrant; a favorite old variety.

La Rosiere-Very deep, velvety crimson, large and full; a good rose of splendid color.

Lady Emily Peel-A charming rose, medium size and full form, very sweet, color white, sometimes tinged with blush.

L'Enfant du Mont Carmel-Deep crimson, purple shading, free and constant; very fragrant.

Leopold Premier-Deep red, shaded crimson; a fine large rose, very full and sweet.

L'Esperance-Cherry red, large, full flat form, fragrant; a good rose.

Lord Macaulcy-Fiery crimson, large, double, well-formed flowers; fragrant; a good rose. 
Lord Palmerston-Carmine red, tinged with vermilion; double, well formed; a good variety for the garden.

Lord Raglan-A lovely shade of crimson; full and well formed; an old sort much esteemed.

Louis Dore-Strong, vigorous growth; flowers well formed and produced freely; color bright cerise red, shaded purple.

Louis XIV.-Rich crimson, double and full, large and fragrant; a beautiful shade.

Louis Van Houtte-Crimson maroon; full, globular form; free blooming; a decidedly fine crimson variety.

Ludoric Letauld - A fine large rose of vigorous growth, color beautiful pale rose; very double and fragrant.

Mabel Morruson -Flesh white, changing to pure white, sometimes tinged with pink; a useful garden sort.

Madame Alfred Carriere-Flesh white, shaded with salmon yellow at base of petals, of climbing habit; good size and very sweet.

IMadame Alfred de Rougemont-Pure white, delicately shaded and tinged with rose; double, good size, very sweet and pretty.

Madame Alice Dureau-Fine bright rose, clear and glossy; a handsome globular flower, large and double.

Madame Charles Wood-Brilliant crimson, shaded with purple; large and double; a free bloomer; very fragr int; profuse.

Madame Eugene Verdier-Satiny rose; very large, full, globular; a most beautiful variety.

Madame Francois Pettit-Pure white, very full and double; flowers produced in clusters; a good white rose.

Madame Gabriel Luizet-A beautiful shade of pink; fragrant, large, cupped shape; an elegant sort.

Madame Gustave Bonnet-Pure white, sometimes slightly tinged with rose; medium size, very double and full.

Madame Laffay-Rose color, large, double, cupped form; an old and much esteemed rose.

Madame Louis Caricques-Rosy crimson, double, full and fragrant; very fine; a good rose.

Madame Louis Leveque-Carmine rose, large, very full, flat form and fragrant; good in the fall.

Madam Masson-Velvety crimson; very bright and full; a fine sort for bedding. 
Madame Noman-White, sometimes shaded centre, medium size, full, globular; a rose of exquisite beauty.

Madame Oswald de Kerchove-White, tinged with fawn: full, with imbricated form; a lovely sort.

Madame Thevenot-Beautiful, bright violet red, very showy and handsome, flowers large, finely formed, double and sweet.

Madame Trotter-A strong, vigorous grower; very hardy; flowers bright brilliant red, full and sweet.

Madame Victor Verdier-Rich, bright cherry red, changing to satin rose; large, full and fragrant; a superb rose.

Mademoiselle Marie Rady-Vermilion red, shaded with crimson; large, very full, of splendid globular form; very fragrant; altogether a most valuable sort.

Magna Charta-Bright, clear pink, suffused with carmine; very large, full and globular form; a fragrant, excellent variety. Marechal Vaillant-Crimson, large, full, well formed and fragrant; a fine rose.

Marguerite de St. Amand-Bright rose, very beautiful in the bud state; flowers produced in great profusion; excellent.

Marie Baumann-Crimson vermilion, shaded carmine, large, full, of exquisite color and form; very fragrant; a charming sort.

Marquis de Bocella-Creamy white and flesh color; centre rosy blush; double and fragrant; a free bloomer.

Marquis de Castellane-Carmine rose, a bright and permanent shade; very large, very full and effective; a valuable sort. Marquis of Salisbury-Coppery rose, shaded with crimson; large, globular form; distinct.

Marshall $P$. Wilder-Vigorous growth, with healthy foliage; flowers large, semi-globular, full and well formed, color cherry carmine, fragrant, one of the most constant bloomers of the class; beyond question a rose of great merit.

Maurice Bernardin-Bright crimson; large, full and fragrant; a very prolific sort; one that is growing in favor.

May Quennell-Brilliant magenta carmine, shaded with crimson;

large, full, globular form; a handsome rose.

Merveille de Lyon-Flowers very large, full, well formed, pure white centre, satiny rose; a magninicent new rose.

Monsieur Eugene Delaire-Velvety crimson, lighted with fiery red; large, full, extra. 




Marshall P. Wilder.

Monsieur $E$ Y. Teas-Carmine crimson; large, fine, globular form, highly scented; a superb rose.

Mrs. Harry Turner-Dazzling crimson scarlet, with rich maroon shading; very brilliant; large and full; beautifully imbricated.

Mrs. Laxton-Bright, rosy crimson of the most perfect globular form; very fine.

Olga Maria-Pure white, delicately shaded with amber and blush; large, full flowers, very double and sweet; a free bloomer.

Oxonian-Rosy carmine flowers, very large, cupped, very sweet; a free autumn bloomer. 
Poenia-One of the finest old roses, very large, full, fragrant; a free bloomer; color clear bright red; a good garden variety. Paul Jamain--Velvety crimson, slightly tinged with violet red; large, full and double; a grand rose.

Paul Neyron-Deep rose; very large, very full, somewhat fragrant; free bloomer; the largest variety known, and a very desirable sort for the garden.

Paul Ricaut-Bright rosy carmine, darker towards the centre; sweetly fragrant and cup-shaped; a free bloomer.

Peach Blossom-Mottled pink, shaded with a beautiful tinge of delicate peach; an elegant color; large and full.

Penelope Mayo-Brilliant carmine red, large, well-shaped flowers of great substance.

Pierre Notting-Deep crimson, tinged with violet; large, fine globular form, highly scented; a most beautiful dark rose Pius the Ninth-Purplish red, changing to violet rose; flat form; very full, free flowermg and very hardy.

President Lincoln-Scarlet and crimson, shaded with purplish vermilion; very full, fine form; beautiful and fragrant.

President Thiers-Flaming red, large-sized flowers, full and globular in shape; one of the darkest colored in the type.

President Willermoz-Bright rose, shaded lighter; large and doubie, fragrant; very beautiful.

Prince Albert-Dark red, very fine form, good bloomer; a muchesteemed sort.

Prince Camille de Rohan-Rich, dark velvety crimson; large and fine; a good rose of splendid color.

Prince de Portia-Velvety vermillion; large, full, well formed; one of the most fragrant; a splendid varicty.

Prince Humbert-Brilliant, fiery crimson; full, large, well-formed; excellent.

Prince of Wales-Satiny pink; a delicate and lovely shade; very İarge and double.

Prince Paul Demidoff-Satiny rose; very full, fine form, and very sweet; a good garden rose.

Prince Antoinette Strozzio-Flowers large, full and very double; delightful perfume; soft, rosy pink, shaded crimson.

Princess Louise Victoria-Salmon pink, medium size, fine globular form; a splendid rose.

Princess Mathilde-Burgundy crimson; a lovely shade, medium size, double; valuable. 
Queen of Queens-Pink edges, elegantly tinged with blush; large and full, and of perfect form; grows and flowers freely.

R. Dudley Baxter-Flowers deep maroon crimson; very rich in color, extra large, full and cupped, free and hardy.

Red Dragon-Brilliant crimson, very bright and striking; large, double and finely cupped flowers.

Rev. J. B. M. Camm-Carmine rose, large, semi-globular form; one of the most fragrant and free blooming roses; a superb sort.

Rosy Morn-Peach pink, shaded darker; fine large flower of good form and finish; very sweet and full.

Royal Standard-Satiny rose, tinged with lilac; a large, wellformed, globular flower.

Senateur Vaisse-Crimson carmine; elegant, large form; free bloomer, highly scented.

Sir Garnet Wolseley-Vermilion, shaded crimson; large and full; a splendid sort.

Souvenir de Charles Montauld-Dark, rich, crimson maroon; velvety; a bold and striking flower; full and good.

Souvenir de la Reine d'Angleterre-Bright rose; very large and double; a much admired variety.

S. Reynolds Hole-Maroon, flushed with scarlet crimson; medium size, full and well formed; a rose of great beauty.

Star of Waltham-Carmine crimson, medium size, semi-globular; full and fragrant; a good rose.

Sultan of Zanzibar-Blackish maroon, edged with scarlet; full and well-formed; medium size.

Sydonie-A charming old variety, much esteemed, rose color; very large and full; a constant bloomer.

Thomas Methiven-Red, tinged with velvety crimson; good size, well formed; a fine rose.

Thomas Mills-Rosy crimson, very large and double; a good variety for the garden.

Triomphe de l'Exposition-Reddish crimson; very bright and beautifully shaded.

Triomphe des Beaux Arts-Metallic rose, flamed with scarlet; large, very fragrant and full; splendid.

Victor Trouillard-Bright crimson, shading to purple; large, full and fragrant; a good old sort.

Victor Verdier-Bright rose with crimson centre; globular form, good size; a most beautiful rose. 
Vulcain-Rich crimson, double, well-formed; a rose of splendid color.

White Baroness-Pure white; large cupped form, very symmetrical; except in color identical with Baroness Rothschild. Xavier Olibo-Flower's large and double, of excellent form, color velvety black, shaded with fiery red; a superb rose.

\section{PRAIRIE ROSES-HARDY CLIMBING.}

These are the only ciimbing roses that are perfectly hardy everywhere, and are consequently of the greatest value. They can be readily trained to the height of twenty or thirty feet, as they grow with great vigor. They bloom only in June and July, but are then objects of the greatest beauty. We have seen Baltimore Belle growing all over the side of a house, where its thousands of blooms formed a complete mass of white. At least one of these hardy climbers should be found in every rose garden north of Tennessee. The flowers are produced in large clusters. When $\mathrm{i}$ is desired to cover walls, unsightly buildings, etc., with Roses, none will be found to do the work so efficiently as varieties of the Prairie Rose.

Baltimore Belle-Pale blush; variegated carmine, rose and white; very double; flowers in beautiful clusters, the whole plant appearing.a perfect mass of bloom; one of the very best of the type.

Bennet's Seedling-An Ayrshire or Scotch rose and a vigorous runner; flowers are white, very double and fragrant and borne in great profusion.

Caroline Goodrich-This new hardy-climbing rose has finelyformed flowers; very double, and its fragrance is most delicious. The color is the same as that of the well-known General Jacqueminot. It makes a growth of from twelve to fifteen feet in a season; flowers freely till fall; constant; also known as "Running General Jacqueminot."

Champney-A hardy rose, quite double and very fragrant; flowers deep rose, changing to pale rose; desirable.

Dundee Rambler-Scotch rose; growth is slender and rapid; flowers small, semi-double.

Gem of the Prairie-Light shade of crimson, large, perfectly beautiful form; the flowers are borne on trusses, numbering from ten to twenty buds on each. 
Greville or Seven Sisters-Flowers in large clusters; varies in color from white to crimson.

Mrs. Gunnell-Soft, rosy blush, becoming almost white; large clusters; full and double; much admired.

Mrs. Hovey-Blush, changing to white; resembles Baltimore Belle, but is hardier; a valuable climbing rose.

Prairie Queen-Flowers very large and of peculiar globular form; bright, rosy red, changing to lighter as the flower opens.

Pride of Washington-Brilliant amaranth, shaded rose centre; large clusters; very double and fine.

Russell's Cottage-Dark velvety crimson; very double and full; a profuse bloomer, strong grower; desirable.

Tennessee Belle-Flowers bright, beautiful pink; is more slender and graceful in growth than either of the other varieties.

Triumphant-An excellent variety; flowers large, very double and compact; color deep rose, changing to pale carmine; beautiful, shaded and variegated.

\section{MOSS ROSES.}

The beautiful mossed buds of these Roses have placed them higher in the popular estimation than any other rose, or indeed than any other flowers, and they have furnished a theme for so many poets that they are familiar to everybody. The bushes are not very prepossessing in appearance, forming large, rugged masses, and set with irnumerable small thorns; most of them bloom only in the spring, but sometimes produce a few flowers in the fall. They are as hardy as an oak; no garden is complete without some of these charming roses.

Alice Leroy-Fine, clear pink; extra large flowers; fragrant. Aphelis Purpurea-Violet purple; large, fine form, well covered with moss.

Blanche Moreau-Flowers are produced in clusters; large, full and sweet; color pure white. The buds have an abundance of lovely deep green moss.

Captain John Ingraham-Brilliant carmine; large, full flowers, very double and mossy.

Common Moss - The finest of all the moss roses; color pale rose; very beautiful in the bud; a grand rose for the garden .

Comtesse de Murinais-Flowers white, sometimes tinged with flesh color; large, double, cupped; one of the best moss roses. 


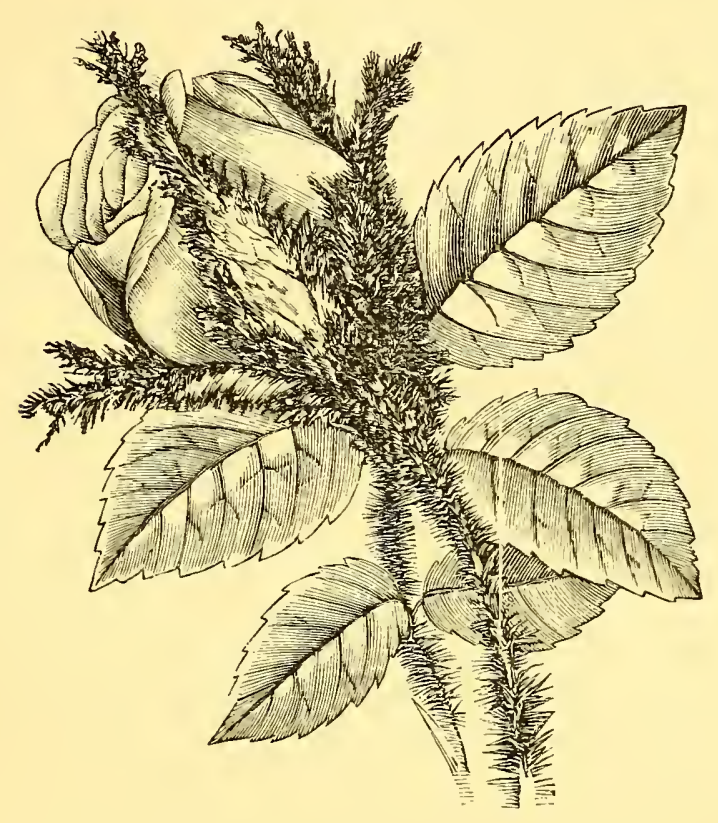

Mos.s Rose.

C'rested Moss-Deep, pink-colored buds surrounded with a mossy fringe and crest; a fragrant and very beautiful rose.

De Luxembourg-Bright crimson scarlet; large and double; very sweet and mossy.

Elizabeth Roue-Bright, satiny pink; very large and double; fragrant and finely mossed.

Etna-Crimson, tinged with purple; delightfully fragrant; very mossy.

Glory of Moss-A magnificent moss ross; very large and double: color deep rosy varmine; very mossy and fragrant; one of the best of the type.

Gracilis-Deep pink buds, surrounded with delicate fringe-like moss; a magnificent and elegant sort: very prolific.

Henry Martin-Rich, glossy pink, elegantly tinged with crimson; large, globular flowers, very full and sweet: finely mossed.

Hortense Vernet--Fine, rosy carmine; large, full and sweet: buds beautifully mossed. 
Laneii-Large, bold flowers, very double; full and fragrant; color rich crimson, delicately shaded with rosy purple; very mossy.

Little Gem-A miniature sort; color bright crimson; very small and full; desirable.

Madame Moreau - Flowers extra large, perfectly full and double: color rich carmine with crimson centre; petals beautifully edged with white; buds are finely mossed.

Perpetual White Moss-Buds very mossy, color pure white. medium size and borne in large clusters; fragrant.

Princess Adelaide-One of the best, extra large flowers, very double and fragrant; very mossy; color bright, rosy pink.

Purpurea Rubra-Violet purple; large, full form; very double and fragrant; buds beautifully mossed.

Raphael-Beautiful mossy buds; color pinkish white, shaded with rose; large, full and sweet,

Soupert et Notting-Rose color, very large, very full, globular form, highly scented, nicely corered with beautiful moss; a charming sort.

White Bath-Pure white, in clusters: attractive in bud and open flower; free blooming and very mossy.

\section{SUMMER AND MISCELLANEOUS ROSES.}

\section{BLOOMING IN JUNE AND JULY,}

In this class we place all the varieties of Summer Roses and other roses that are not described in our classifications. The list embraces many that are valuable and highly esteemed, especially the old garden varieties.

Beanty of Glazenwood (Erergreen-See “Fortune's Double Yellow."

Blanchefleur. (June)-White, tinged with blush; medium size, flat, very full, highly scented; very profuse bloomer; a valuable garden rose.

Bridal Rose-See "Rubus Grandiflora."

Cabbage Rose, (June-Old fashioned)-See "Centifolia."

Cameliae folia, (evergreen)-Leaves deep, shining green; is an evergreen species from Japan: handsome in or out of flower; the flowers are single and white.

Celine, (June)—Cupped̄ rose, large and fine; suitable for pillars. 
Centifolia, (June)-Rose color, large, full, globular form and fragrant; a very desirable garden variety; the old fashioned Cabbage Rose.

Centifolia Cristata, (June)-Large, pink flowers, fragrant and good.

Charles Lauson-Light rose color, very fragrant; large and full; useful for pillars.

Chenedolle, (June)-Bright red, double, very large; a valuable sort.

Cherokee Rose, (evergreen)-Large, single flowers, pure white; very fragrant.

Comte d' Espremesnil-Vigorous flowers; lilac, semi-double and very fragrant; it is highly esteemed, is perfectly hardy; belongs to the Rugosa family.

Coupe d' Hebe, (June)-Dark pink, large size, cup form; a rery distinct rose.

Double Margined Hep, (June)- A beautiful lose, white, tinged with pink; flat form; full and good.

Fortune's Double Yellow, (evergreen)-Bronzed yellow or copper and fawn centre; very pretty and sweet.

Harrison's Yellow, (Austrian)-Golden yellow, medium size,semidouble.

Madame Hardy, (June)-White, large, very full, flat form, very fragrant; a very beautiful sort.

Madame Lxcharme, (June)-White, tinged with pink, medium size, full and of globular form; very hardy.

Madame Plantier, (June)-One of the June roses, at which time it is literally covered with pure white, perfectly double, fragraut flowers, which hang on for a long time: makes large, dense bushes. We have seen plants five feet in diameter with hundreds of blooms open at a time; as hardy as an oak; a beautiful cemetery rose.

Madame Zoetman, (June)-Delicate flesh, changing to white; large, very full, flat form, fragrant; a splendid white variety.'

Mademoiselle Emma Hall, (June)-Carmine rose; globular form, of good size and very fragrant; an excellent summer rose.

Paul Verdier, (June)-A beautiful shade of bright red, globular flowers; a splendid sort.

Persian Yellow, (Austrian)-Bright yellow: small, full, well-formed flowers; must be pruned sparingly. 
Queen of Ayrshire, (Ayrshire)-Violet crimson, semi-double, small flowers; a fine garden rose.

Queen of the Belgians, (Ayrshire)-Pure white, double and sweet. Rubus Grandiflora-Large, double, pure white flowers; very showy and desirable; known as the bridal rose.

Rubus Roscefolius Coronarius-A new dwarf Rubus; rose-colored flowers.

Rugosa Alba-Single, pure white flowers, highly scented.

Rugosa Rubra-Rosy red, tinged with violet; single and fragrant. The Rosa Rugosa are splendid shrubs for borders. The three varieties we name in this list are highly commended.

Stanwell Perpetual, (Scotch)-Blush, medium size, double, delicately scented.

Sweet Briar or Eglantine, (evergreen)-The delicious fragrance of the leaves of this old favorite keeps it in demand; fine for hedges.

White Banksia, (Banksia)-Pure white, very small, very full and double; blooms in panicles; has the delicious fragrance of the violet; somewhat tender; splendid for the south.

White Microphylla, (evergreen-Alba Odorata)-Medium-sized flowers; very double, white and sweet scented; bright, glossy leaves.

Yellcw Banksia, (Banksia)-Like White Banksia, except the color, which is clear yellow; it too is a most grand and charming acquisition for cultivation in a southern clime.

\section{TENDER ROSES-MONTHLY.}

In the division of Tender Roses certain characteristics are found that render the various classes of them, perhaps, the most desirable of all Roses for ordinary cultivation. They are natives of warm countries, like China, Bengal, the isle of Bourbon, etc., and although all the varieties will bear considerable freezing, and some are almost entirely hardy, even in the north, their natural propensities to grow and flower, more or less, continually-monthly, as it is termed-remains unchanged with being removed to our climate, and with proper treatment and a suitable temperature in winter, in the window or conservatory, they may be had to flower almost the year through. In the mild climate of our Southern States they continue to grow and bloom in the open air with little interruption. By suitable protection at the approach 
of cold weather, or by wintering in a cold pit or cellar, they are easily managed to thrive in the open air in our Northern States, and produce an abundance of bloom from June until October and November.

BOURBON ROSES. - This is the hardiest class of this division, being nearly, but not quite, hardy in the latitude of Buffalo. Although some of the varieties do not flower as frequently as do those of other classes of tender rcses, the flowers are produced in large clusters, are of large size, well shaped, bright and varied in color, fragrant and lasting, for which reason they are always found very satisfactory to grow. Some, among which the Hermosa stands prominent, are unequaled for their free flowering qualities, in the open air, and nearly so for pot culture and winter flowering. All are vigorous growers, with rich, luxuriant foliage, and are quite certain of giving satisfaction to cultivators.

BENGAL OR CHINA ROSES-The varieties of these throughout are free flowering, of thrifty growth and rather compact form, and while the flowers probably do not average as large as those of the Bourbon and other sections, the plants, if bedded out, are certain to be covered with a larger number of buds and flowers of their characteristically brilliant colors than any other class cultivated. They require to be well protected during winter in the north. Very desirable for pot culture. The Agrippina, a well-known type of this class, is unequaled as a fine rose for growing in pots and for summer bedding.

TEA-SCENTED AND FORCING ROSES.-Of these beautiful, sweet Roses, it may be said, with mild justice to their many good qualities, that while the Rose finds deroted cultivators, they will rank high among fine kinds in many respects This is particularly true of the exquisite, deliciously fragrant, bud varieties, which, in the estimation of cultivated tastes, are lovely and attractive above the majority of flowers in our collection, and many of them remarkably suitable for pot cultivation, in the window or conservatory, being of fine habit and rery productive. In our own experience in cultivating these in greenhouses, where the varieties Marchal Niel, Perle des Jardins, Safrano, Isabella Sprunt and Bon Silene are grown largely for our cut-flower trade, the plants never fail to produce a constant daily supply during the winter, and almost continually through the year besides. To show their appreciable value, I will state that these find ready purchasers all through cold weather, at the uniform price of fifteen 
to forty cents per bud, just as cut from the plants, which is nearly twice the money realized for other Roses at the same time. The entire class is perhaps more susceptible to injury from cold than most other Roses, but nevertheless their general habit is healthy and vigorous, and when growing in the open ground some of them are prolific of buds and flowers all during the summer. By carefully lifting such plants in October and giving them protection in a first-class cold pit during winter, returning then to the open ground in spring, they will thrive from year to year bedded out the same as any other class of tender Roses. Some of the Teascented Roses are too double to be classified as bud varieties-a few of which are not fully double when open. These produce large flowers of the unapproachable tints, shades and colors, and possessed of the exquisite fragrance for which this class is peculiar.

NOISETTE ROSES. - This class, although quite limited in number of varieties, is of great value for permanent planting in the soil of a greenhouse or conservatory, as on account of their free climbing habits they can be permanently trained to the rafters and trellises. Plants, after having spread to some distance, produce immense crops of beautiful, fragrant and fine colored flowers at short intervals. Severe pruning of the young shoots is necessary to secure the best results. By keeping the leading branches well cut back, numerous varieties of this class are excellent for growing as ordinary pot roses and for bedding in summer.

\section{HYBRID TEA ROSES.}

The New Hybrid Tea Roses, lately introduced from Europe,are so distinct and beautiful, and are attracting so much attention, that we class them by themselves. These splendid varieties represent an entirely new and distinct type or class of Roses, the result of a cross between varieties of the Hybrid Perpetual or Remontant Roses and the Teas. The great advantage claimed for them is, that they combine the hardiness of the Hybrid Perpetuals, with the constant blooming qualities. rich and delicate coloring, and delightful fragrance of the Tea Roses. Most of them are probably hardy in the Middle States, and they are well worthy of extensive and thorough trial by all who love rare and beauti. ful Roses. 


\section{POLYANTHA ROSES.}

This is an interesting group from Japan, of comparatively recent introduction. The foliage and flowers are both very small, the latter being produced in panicles. The original varieties are non-remontant, but are crosses or hybrids, natural or artificial, between the singled-flowered Polyantha and varieties of other classes, Teas, etc. They are ever-blooming, of slender growth, and will probably prove more hardy than most of the Teas Their character of blossoming in panicled clusters gives them a distinctive interest, and they are much esteemed by those who have seen them.

\section{BOURBON ROSES.}

They are not quite hardy, but a very slight protection suffices them. They are continual bloomers, mostly of rapid growth, with rich, luxuriant foliage, and are the most beantiful in the autumn. The flowers are for the most part, produced in clusters, and generally of a light color, well shaped and somewhat fragrant. Some of the freest and most constant blooming Roses are contained in this section, Hermosa and Malmaison having bui few e, uals for freedom and continuity.

Abbe Girardin-Vigorous, flowers large, full and well formed, color satiny rose, deeper in the centre; very distinct and free.

Alfred Aubert-A vigorous grower and profuse bloomer; flowers as well shaped as "Hermosa," of a bright red color.

Apolline-Delicate rose, heavily shaded with pink, exceedingly sweet, very large, full and double; one of the best.

Bouquet de Marie-Deep rose, tinted, and veined silver white; free bloomer; very fragrant.

Comtesse de Barbantine-Flesh color, changing to white; beautiful cup-shaped flowers.

Comtesse de Rocquigney-Color white, delicately tinted with rosy salmon: full, globular form, fragrant and desirable.

Duchess de Thuringe-Beautiful silver rose, finely cupped, full and sweet; free bloomer.

Edward Desfosses-Carmine rose, medium size, full and double, very sweet and a most excellent variety.

Emotion-Rose, tinged with lilac, changing to blush and clenr rose, full and fragrant. 


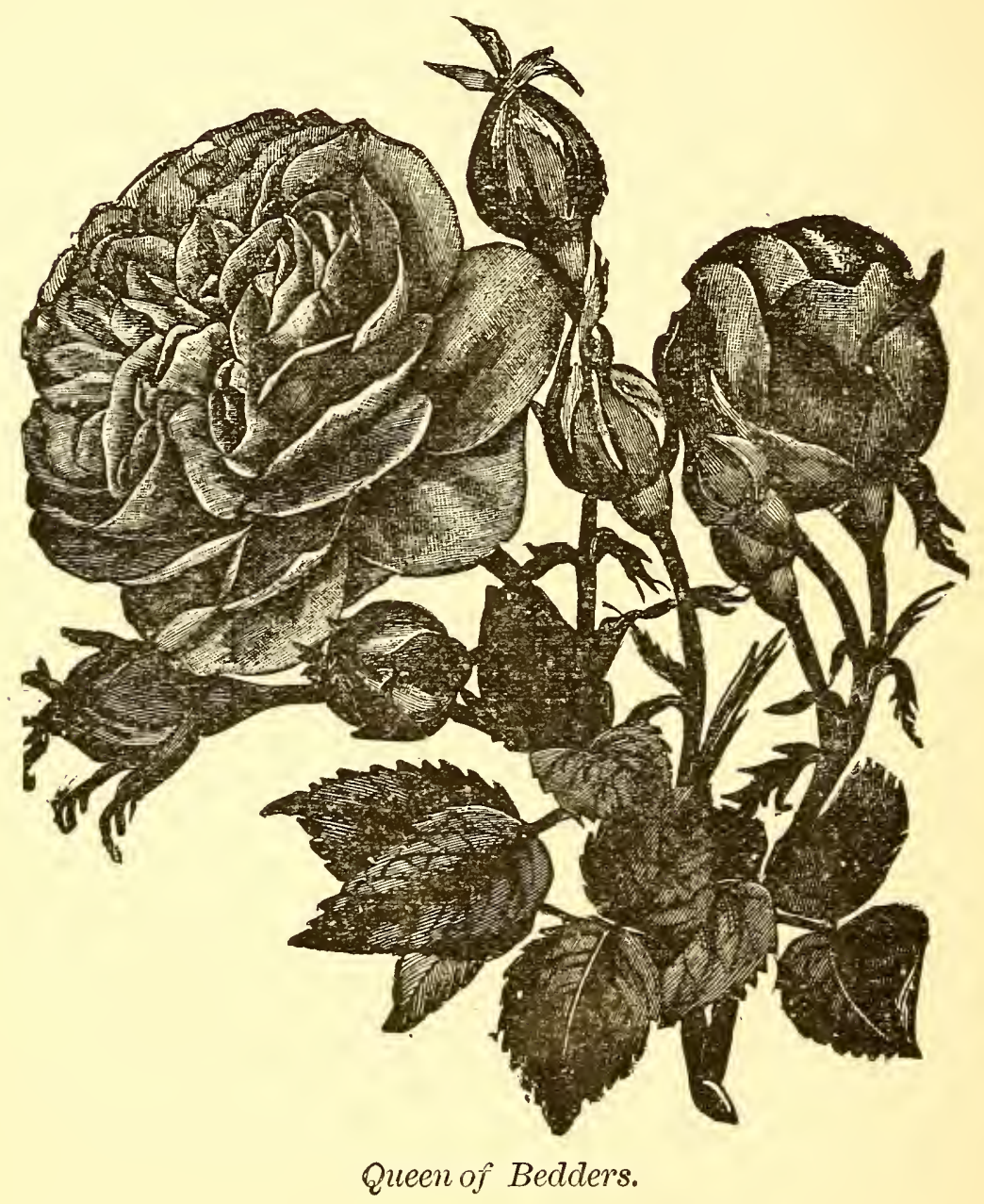

George Peabody-Rosy crimson, medium size, full, well formed, fragrant; one of the best Bourbons, highly commended.

Gloire des Rosomanes-Vigorous growth, brilliant crimson, semidouble, but very effective; fragrant.

Henri Plantier-A charming sort, color clear rose, medium size, very sweet and blooms in profusion.

Hermosa-Always in bloom and always beautiful. The flower is cupped, finely formed and full; color the most pleasing shade of pink, soft but deep; very fragrant; a standard variety, 
Imperatrice Eugenie-Silvery rose, large, very full and fragrant; a most excellent sort.

Leveson Gover-Deep rose, tinged with salmon. This variety is very scarce and much sought after as a companion for "Malmaison."

Louis Odier-Another old variety of great merit, bright rose, medium size, full, well formed, hardy.

Madame Bosanquet-A fine old variety, much esteemed; pale flesh, shaded with deep rose, large size, very double and sweet.

Madame Isaac Pereire-Carmine red, very large, full, free blooming; a charming new rose.

Madame Jeanne Joubert-Fine, rich crimson; a solid and brilliant color; flowers large, compact and full; fragrant.

Madame Pierre Oger-Beautiful flesh color, the exterior of petals marbled with soft, rosy lilac, double flowers of cupped form; a fine and distinct rose.

Madame Rivouy-A companion rose for Sombreuil. except in color, which is of a beautiful rich crimson scarlet, very large, fine form; very fragrant.

Malmaison a fleur Rouge-Said to have all the good qualities of Souvenir de la Malmaison, which sort it resembles, except in color, which is a bright clear red; extra fine.

Marquis de Balbiano-Splendid soft, rosy blush, edges and reverse of petals, silver rose, full and sweet.

Monthly Cabbage-Deep rose red, large, globular shape; good bloomer; fragrant.

Peerless-Rich crimson; blooms in clusters; very sweet.

Perle d'Angers-Flowers very large, color glossy flesh white, very delicate; a magnificent rose.

Pierre de St. Cyr--Bright rose, large and double, full and sweet; a vigorous grower.

Pink Daily-Bright pink; flowers produced in clusters in the greatest profusion.

Queen of Bedders-Very rich, dark, velvety crimson; very free blooming: flowers compact and full; one of the best crimson bedders; a grand sort.

Queen of Bourbons-A splendid rose, large, fine form, full and sweet, color clear carmine, changing to cleạr rọse; petals edged with white.

Red Malmaison-See "Malmaison a fleur Rouge." 
Robusta-Very large, double flowers, full and sweet, clear carnation red, shaded and reined with rosy crimson; very beautiful.

Sir Joseph Paxton-Deep red, slightly tinged with violet, medium size, full and well formed.

Sombreuil-A strong grower, pushing up long, heavy shoots, each bearing a cluster of flowers. large and full, creamy white, often tinted with pink; a valuable sort for culture in the open air.

Souvenir de la Malmaison-A noble rose. The flower is extremely large and double to the centre; color flesh white, clear and fresh; has been considered the finest Bourbon rose for 40 years. Its great beauty in the fall makes it one of the finest of all roses at that season; a flower that is universally popular and will always be so.

\section{CHINESE OR BENGAL ROSES.}

The China or Bengal Roses are dwarf and flower with the greatest profusion all through summer and fall, makiug excellent edges for beds of other roses and fine pot plants. Their flowers are not equal in size and fragrance to those of the Teas, but they consist chiefly of rich, dark colors, which are scarce in the other sections of the Ever Blooming Roses. They make grand bedders. Abbe Mailand-Dark, rosy crimson; large, full, vigorous.

Admiral Rigney-Rich, carmine rose, large flowers, full and handsome; constant and profuse.

Agrippina-Rich crimson, specially valuable for its fine buds; useful for bedding out; the best of the class brought from China about 1789; much esteemed.

Arch Duke Charles-Brilliant, rosy crimson, rery full and extremely sweet; a splendid rose; heary foliage.

Beau Carmine-Fine carmine red, very rich color, good size, double, fragrant and desirable.

Cramoisi Superieur-Rich, velvety crimson, double, fine in the bud; a good bedding variety.

Crimson Bcdder-Bright, fiery red, velvety; its habit and blooming qualities combine to make it the best scarlet bedding rose for massing, etc.; recommended.

Dougluss-Dark, rich crimson; buds of good shape; very free flowering, highly recommended; a valuable variety for house culture. 
Eugene Beauihamais-Beautiful crimson, illumined with fiery red; a good variety.

Green Rose-See "Viridi flora."

La Ploœnix-Red, shaded crimson; free bloomer, flowers medium size and double; delicious fragrance.

Louis Philippe-Rich dark, velvety crimson, full and beautiful; one of the best for bedding.

Lucullus-Beautiful dark crimson maroon, large, full and fragrant; a constant and profuse bloomer; extra good for outdoor culture.

Madame Julie Lassean-Flowers large and full, free and constant; color a deep rose.

Madame Lawrence-Pink b'itton rose, about the size of a ten-cent piece; double and fragrant; the growth, foliage and flower are all miniature.

Madame Laurence-Crimson button rose, same as preceding, but deep crimson color.

Nemesis-Splendid full, double flowers of dark relvety crimson; especially fine for massing when rich, dark colors are wanted.

President d' Olbecque-Bright, purplish crimson, large, full and fragrant; a profuse bloomer.

Purple China-Rich, purplish crimson; velvety; one of the most constant and free blooming in the class.

Queen of France-Fine, brilliant red, shaded with dark crimson; good size flowers, full and very profuse.

Queen's Scarlet-Dazzling crimson scarlet; has beautiful buds, which are much prized for cut flowers; sweet scented, hardy.

Roi de Cramoisi-Bright, purplish crimson, full and very double; good size, free and fragrant; a charming rose.

Sanguinew-Brilliant crimson, good size. This variety is much prized, both for pot culture and for massing in beds: one of the best.

Souvenir de David-Fine, rich crimson; good grower; large, full and fragrant; constant bloomer.

Viridiflora-The flowers of this variety are pure green, quite double; a great curiosity, both in bud and flower. 


\section{TEA ROSES-EVER-BLOOMING.}

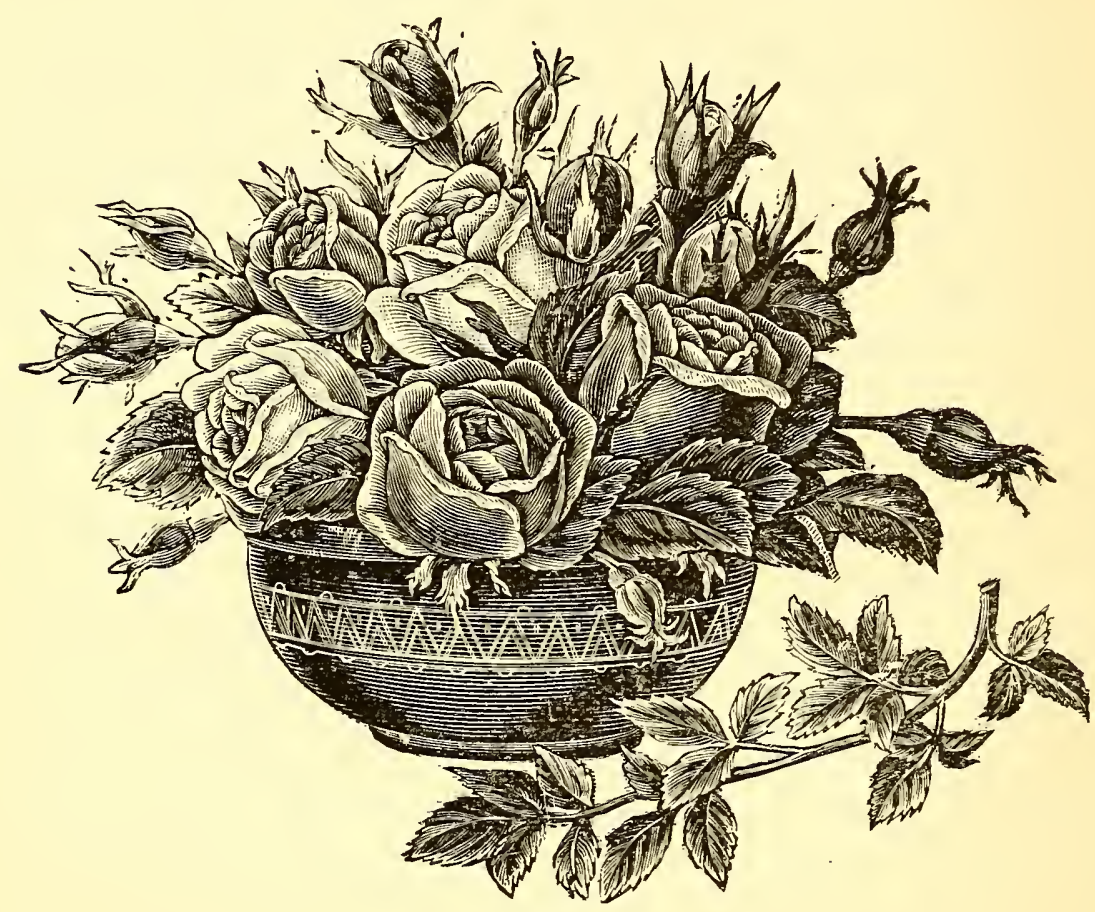

Tea Rose.

Tea Roses are celebrated the world over for their delicious fra grance and the exquisite forms and rich, charming tints of thei= flowers, and may well be taken as a synonym for all that is delicately beautiful. What refinement of color; what subdued, yet powerful fragrance do they possess ! They may be justly called the sweetest of all roses. The flowers, many of them are large and very delicate in their shades of color, such as white, straw, salmon, and various tints of rose combined with them. While, as a rule, they are inferior to the Hybrid Perpetuals in brilliancy of color and fullness of flower, the distinctions between varieties are marked, and for bouquets and cut flowers they excel all other flowers. Like other tender roses, their flowers improve in quality as the season advances, and reach perfection in the autumn. In judging the merits of a Tea Rose, we do not consider fullness of flower a requisite. A Hybrid Perpetual is nothing if not at least moderately double; but many of our most ralued Teas have but very few petals, and are comparatively single. All these have 
exquisitely-formed buds, and are therefore prized as invaluable. The Teas are more tender than any of the other classes and need a little more care in their protection. They form the largest and most popular section of the Ever-Blooming Roses, producing an endless succession of flowers in a favorable climate, and even at the north blooming from the time they are planted until stopped by freezing weather. Teas should be planted in a rich, warm soil, where they will be kept constantly growing, for they bloom as they grow. Where they continue to grow year after year, without being checked by hard freezing, they form immense masses of foliage covered with flowers of the largest size and produced in the greatest abundance.

Abbe Roustan-A splendid variety; large, full, globular flowers, very sweet; color beautiful creamy white; elegantly shaded rosy blush.

Adam-Bright fresh salmon rose, extra large size, double and full; free bloomer; delicious tea scent; a lovely rose.

Adrienne Christople-A beautiful rose, very full and double and tea scented; color a lovely shade of apricot,citron and fawn, tinged with soft rosy pink.

Alba Rosea-Beautiful creamy white with rose-colored centre; petals shaded with blush; rery double and fragrant.

Aline Sisley-Flower is large and full, double and full; color a rare shade of violet rose, brightened with crimson maroon; a fruity, pleasant fragrance.

Amazone-Yellow, reverse of petals, veined with rose; long, wellformed buds; a charming rose.

American Banner-The flowers are bright red, distinctly striped and marked with pure white. The colors are well defined and every bud and flower are deeply striped. It is fragrant and a profuse bloomer when full grown; a rose of merit.

Andre Schwartz-Beautiful crimson free flowering variety, pretty buds; new and distinct.

Anna Ollivier-Lovely creamy blush, shaded with deep carmine, tinged add edged with silver; rose fragrant, large and full; a superb rose.

Arch Duchess Isabella-Large, full form, delightfully fragrant; white, shaded with rosy carmine, changing to amaranth: makes lovely buds; a constant and profuse bloomer.

Baron de St. Triviers-Flowers very large. full, and of fine form, color a delicate flesh rose; fine winter bloomer; rigorous 


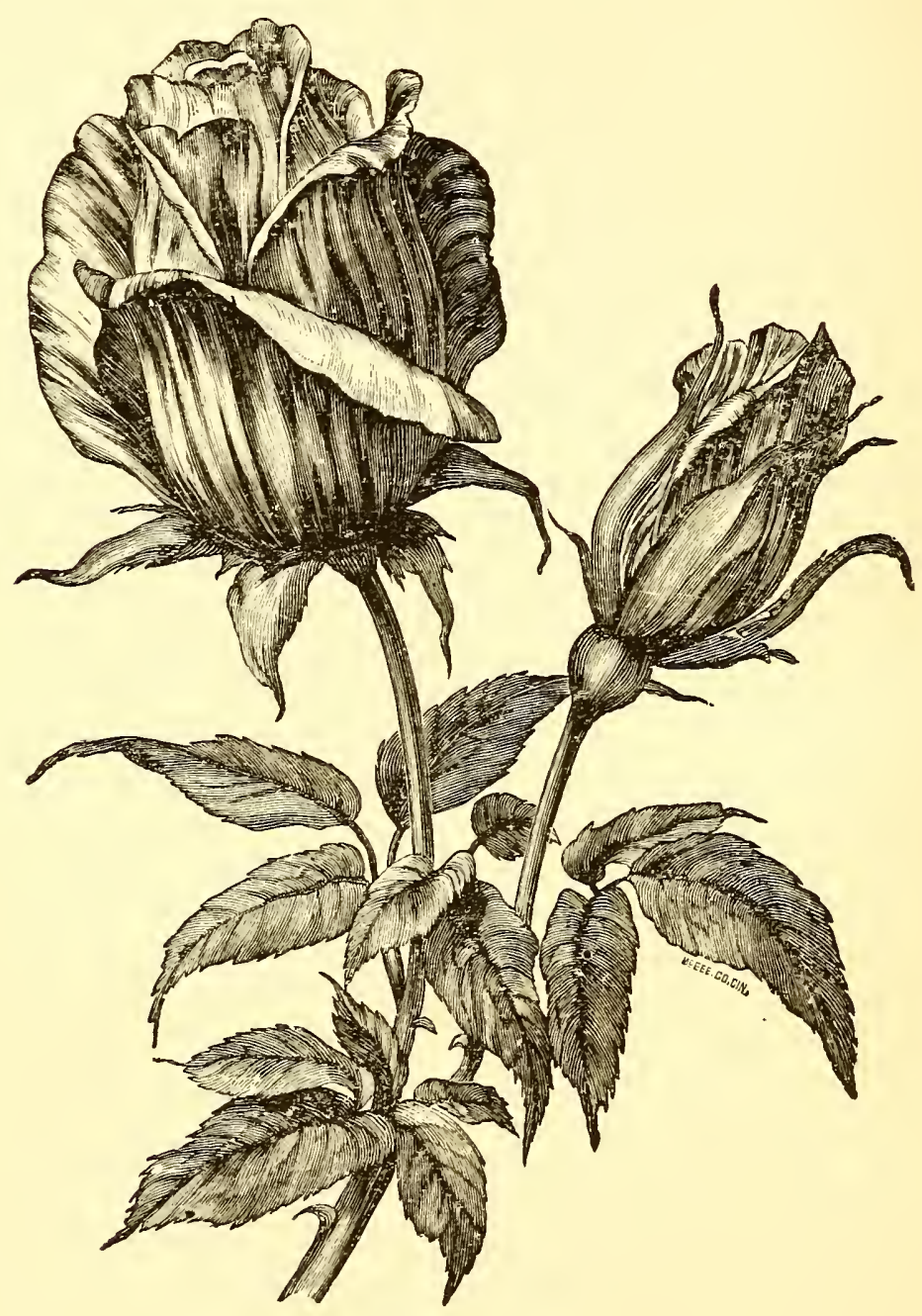

American Banner.

Baron Alexander de Vrits - Beautiful pale blush rose, de"icately tinged with carnation red; flowers are borne in clusters, are large, fuli and very fragrant.

Baronne Sinety-Color deep yellow with darker centre, outer petals slightly shaded pink, of good form; a charming sort. Bella-Pure snow white; splendid, long-pointed buds, tea scented; large size, full and double; an excellent sort.

Belle Maconrise-Pale, salmon rose; buds orange fawn; large, full and fine form; vigorous. 
Belle Fleur d:Anjou-An elegant rose, large, full and double, delightfully fragrant; color beautiful silver rose; beautiful, large, pointed buds; a good sort.

Binaqui-White, shaded with flesh color; a distinct, beautiful rose, full and fragrant.

Blanche Nabonnand-Habit vigorous; flowers very large, double and of very fine shape, imbricated; color pure white; a continuous bloomer.

Bon Silene-Grown by every florist for its highly-colored buds, dark carmine rose, often changing to crimson. The buds are very handsome and produced in great profusion; a strong, healthy grower; one of the best for pot culture.

Bougere-Bronzed pink, tinged with lilac; large and full, thick petals; one of the handsomest; an old variety, yet one of the most desirable.

Canary-Light canary yellow, beantiful buds and flowers, very fragrant; an old and much-esteemed variety.

Caroline-Rosy flesh, deeper towards centre, prettily-formed buds, highly tea scented; very free flowering.

Catherine Mermet-A beautiful, clear flesh color, with the same silvery lustre seen in La France: large, full, well formed, very beautiful in the bud; when the flowers expand they exhale a delightful perfume; the finest of all the Teas.

Cels-Multiflora-A fine old variety, much valued; flowers in clusters, medium size, full and double, pale flcsh, deepening to rose.

Charles Covelli-A charming tea rose; large, globular flowers, full and sweet; color a lovely shade of brilliant carmine, changing to silver rose.

Clara Sylvain-Creamy white, good, full form, very double and fragrant; a splendid variety.

Clement Nabomand-Charming buds and beautiful flowers; color coppery rose, tinged with purplish crimson; a constant and profuse bloomer; very sweet.

Comte de Paris-Beautiful clear silver rose, shaded with rosy flesh: large, full flowers, sweet, an old rariety, much esteemed.

Comtesse de Labarthe-Few roses equal this in freedom of flowering; none surpass it in fragrance. The Howers are cupshaped; color a rich pink shaded with carmine and amber; pretty in bud and flower; a grand rose. 
Comte Taverna-Pure white with lemon-yellow centre and shading, deliciously scented; a beautiful sort.

Comtesse Alban de Villenenve-Extra large, full and regular; color a peculiar shade of rosy peach, faintly passing to silvery white; very pretty and sweet.

Comtesse de Nadaillac-Coppery yellow, illumined with carmine rose; large, full, distinct and effective; highly esteemed.

Comtesse Riza du Parc-Flowers very large, full, double and sweet; color bright coppery rose, tinged and shaded with soft violet crimson; a strong grower and profuse bloomer.

Coquette de Lyon--Flowers canary yellow, medium size, sometimes called the "Yellow Hermosa" on account of its freedom in flowering. The plant has a charming effect covered with its beautiful yellow blooms; very constant and free.

Cornetia Cook-See "Cornelie Koch."

Cornelie Koch-This beautiful rose is now in great demand for its magnificent buds, which are of immense size and of lovely form. The color is pure white; delightful tea fragrance, known as "Cornelia Cook."

Curt Schultheis-Large, full flowers; color a rosy salmon or coppery yellow, tinged with rose; very distinct and beautiful; sweet and a free bloomer,

David Pradle-An old and much-esteemed variety; very large size, full and sweet; color lilac rose.

Devoniensis-Magnolia rose, beautiful, creamy white, with rosy centre; large, full, and delightfully sweet; tea-scented; one of the finest roses.

Doctor Berthet-Beautiful silvery pink and dark carmine, passing to rosy crimson; cup shaped, very double and sweet.

Duc de Magenta-Flesh, shaded with fawn, thick petals, full, very large; a splendid tea rose.

Duchesse de Brabant-See "Comtesse de Labarthe."

Duchess of Edinburgh-A splendid rose, in great demand for its lovely buds, and remarkable for its beautiful color, which is the most intense glowing scarlet.

Edward Gontier-Full, fine-shaped flowers, quite double and of good size; pure white, with a deep yellow centre, occasionally tinted with pink; constant bloomer; superb.

Elise Sauvage-Orange yellow, medium size, full and double; an excellent sort. 
Empereur de Russia-Beautiful pinkish scarlet; good form and habit; free bloomer; fragrant.

Enfant de Lyon-Creamy pink centre, rosy blush; an excellent bloomer; its fragrance is quite distinct from that of any other rose; not unlike sweet Anise; desirable.

Etendard de Jeanne d'Arc-Flowers fine, well formed and of good substance; color creamy white, passing to pure white; one of the finest of the class; robust grower.

Etoile de Lyon-Beautiful chrome yellow, deepening at the centre to pure golden yellow; flowers very large, very double and full, and deliciously fragrant; a grand bedding variety. Eugene Patete-Color violet crimson with rose and yellow; a strong, vigorous grower; very fine.

Flavescens-Light yellow, long, fine buds; fragrant; introduced from China about 1824; of delicate habit, commonly known as "Yellow Tea."

Flora Nabonnand-Canary yellow, edged with rose; a most charming sort; large, full and exquisitely sweet.

General Schablekine-Rich, glowing crimson, large, well-formed flowers, highly tea-scented; esteemed for its constant winter-blooming qualities.

General Tartas-Deep mottled rose, sometimes tinged with buff; beautiful buds; good habit; an excellent rose.

Gerard Desbois-Bright glowing red of good form; one of the hardiest and most useful of the class.

Helvetia-Salmon, with peach rose in the centre; large, very full; an extra fine tea.

Homer-Flowers very beautifully formed and handsome in bud; color soft clear rose with a salmon shade; a good garden rose; extra fine.

Honorable Edith Gifford - Flowers large, of heary texture, very fine, both in bud and open flower; color flesh white or cream, with very distinct light pink centre; an exquisite rose.

Ida-A lovely rose, medium size, full and double; pale canary yellow; fine buds.

Isabella Sprunt-Well known as one of the most useful kinds: grows luxuriantly and literally lavishes its long lemon-yellow buds from early spring till frost in the fall.

Janne d' Or-Fine coppery yellow, full, globular form; rery double; highly tea-scented; one of the sweetest in the class. 
Jean Ducher-Bronzed rose; large, very full, globular form; very beautiful.

Jean Pernet-Light yellow, suffused with salmon; beautiful buds; a magnificent variety.

Jeanne Abel-Above medium size: flowers of the purest pink, the centres of a deeper rose tint; habit compact and rery free flowering.

Jules Finger-Elegant and valuable; flowers large and finely formed; very full and sweet; color bright rosy scarlet, beautifully shaded with intense crimson; free bloomer.

Julie Mansais-Creamy white, large and full; very sweet-scented; very beautiful.

Ketten Freres-Of vigorous habit; flowers very large, double and of fine form; imbricated; remarkable for its beautiful color; a grand rose.

La Chamoise-Bright orange vellow: a peculiar shade in roses, of delicate habit; flowers are single, but pretty in the bud.

La Fl,rifere-Deep salmon rose, large and showy; very free flowering and vigorous.

La Grandeur-Beautiful lilac rose, tinted with pale riolet purple; large, full flowers, deliciously scented.

La Jonquil-Brilliant Jonquil vellow, semi-double, sometimes single, medium or small-size; the most intense yellow rose extant; pretty buds.

La Nuancee-Fine salmon rose, tinged with fawn and coppery yellow; charming buds; an elegant variety.

La Princess Vera - One of the finest tea roses; very full and double; immense buds, which are prettily shaped and quite distinct: color pale flesh, changing to salmon rose, shaded with carmine; very sweet; tea scented: a magnificent sort.

La Sylphide-Blush, with fawn centre; very large and double: a grand rose.

La Tulip_Creamy white, tinted with carmine; full and fragrant; beautifully formed; a vigorous grower.

Lady Warrender-Pure white, sometimes shaded with rose; medium size; very fragrant: a very pretty rose.

Laurette-Delicate creamy white, shaded with rose: flesh-colored centre, fine, full form; fragrant; sometimes finely dotted with dark rose.

Le Mont Blanc-Pale lemon yellow, growing lighter as the flowers expand; very charming buds. 
L'Elegante-Of medium size; full, good shape; color rivid rose, centre yellow, shaded and striped with white; very free blooming; truly an elegant variety.

Le Nankin-Pale yellow, shaded with coppery yellow; pretty buds.

Le Pactole-Very free flowering, elegant buds; color pale sulphur yellow; much esteemed.

Letty Coles-Soft, rosy pink, deeply shaded with crimson; extra large, full form, exceedingly sweet; superb.

Louisa de la Rive-Habit vigorous; flo sers large, double, and of fine form imbricated; color flesh white, inclined to rose in the centre; a constant winter bloomer.

Louis Richard-Rich, coppory rose, changing to carmine; large size, full form; tea scented.

Ma Capucine-Nasturtium yellow, beautiful buds; a rery distinct rose of very delicate habit.

Madame Adelaide Ristori-A good bedding variety; color deep blush; large and full.

Madame Amadieu-Flowers brilliant carmine with white centre; reverse of petals silver rose edged with purple; large and fragrant.

Madame Angele Jacquier-Light, silvery rose, shaded throughout with coppery yellow; flowers large and of distinct form; free flowering; one of the finest new tea roses.

Madame Azelie Imbert-Large, full form, double; color rosy buff with peach shading; fragrant.

Madame Barthelemy Levet-Canary yellow, medium size, full and sweet.

Madame Bernard-Coppery yellow, medium size, very free flowering; quite a distinct and grand rose.

Madame Bernoit Derroches-Dark, glossy pink, prettily tinged with yellowish buff; base of petals white; flowers large, sweet and full.

Madame Bravy_Canary white, large, full and very symmetrical form and great fragrance; one of the most beautiful tea roses.

Madame Brest-A splendid dark colored rose, shading to crimson: flowers very large and double, and handsome when fully open.

Madame Camille-Delicate rosy flesh, changing to salmon rose, shaded and suffused with deep carmine; tea fragrance; a magnificent variety. 
Madame Caroline Kuster-Bright, lemon yellow, very large and handsomely shaped: one of the finest roses; very free flowering.

Madame Chabaud de St. Mandrier-Extra large, full flowers; color coppery or buff rose, elegantly tinted and shaded with golden yellow; pretty and fragrant.

Madame Chedane Guinoisean-Sulphur yellow, shaded canary; a very free flowering sort: valuable.

Madame Cusin-Violet rose tinged with yellow: a profuse blooming variety; extra.

Madame Damaizin-Beautiful salmon rose, changing to amaranth and bright pink; a magnificent flower.

Madame Dennis-Wax white centre, fawn and flesh; flowers large, full and cupped; a distinct and fine rose with beautiful musk scent.

Madame de St. Joseph-Fawn, shaded salmon; large, full, sweetscented; highly esteemed.

Madame de Vatry-Red, shaded with salmon, of good form, both in bud and flowers, and well scented; a very choice old sort.

Madame Devaucoux-Beautiful clear canary yellow; delicious tea fragrance; very double and full; a beautiful sort.

Madame de Watteville-White, shaded with salmon; outer petals edged with bright rose: large flowers, but not coarse; of peculiar odor; petals evenly arranged.

Madame Dubroca-Growth vigorous; flowers large and double; of fine shape; has a perfect habit; color delicate rose, shading to yellow at base of petals; a new color.

Madame Elise Stchegoleff-Silvery white, beautifully clouded with crimson and tinged with pale yellow; large, fine flowers; very full and sweet.

Madame Eugenie Verdier-Very large, finely-formed flowers of good shape; color dark salmon yellow; lighly comme:ded.

Madame Falcot-Fine, apricot yellow with beautiful buds; tea scented; a constant bloomer; much esteemed.

Madame Francois Janin-Orange yellow, smail size; buds of exquisite shape; very distinct, both in color and its peculiar fragrance.

Madame Francois Levet-Beautiful, creamy yellow, tinged with rosy blush; very large and doukle; commended. 
Madame Hippolyte Jamain-Large and very double, fine cup form, white with yellow centre, delicately shaded with pink. tea fragrance, extra fine.

Madame Joseph Halphin-Salmon pink, with yellowish centre; an elegant rariety.

Madame Joseph Schwartz-White, flushed with rose, changing to flesh white, flowering in clusters; full and well-formed buds.

Madame Jules Margottin-Bright pink with crimson centre; large and double; very sweet; full and fine.

Madame Jure-Lilac rose, good size and substance, fragrant; a very pretty and desirable sort.

Madame Lambard-A fine large rose of elegant form, very full and sweet; color a peculiar shade of silver bronze; buds bright cherry red; a valuable variety.

Madame Leon de St. Jean-Carmine and orange, changing when open to blush rose tinted with fawn and citron; exceedingly fragrant; an excellent rose.

Madame Leone Ferrier-Growth vigorous; fllowers large and full; buds perfect and of fine form; color flesh white; excellent. Madame Margottin-This is a great rose, always a favorite; very large, perfectly double flowers, elegantly perfumed; beautiful citron yellow with coppery centre; bright foliage.

Madame Maurice Kuppenheim-Flowers of elegant form, large and full; color pale canary yellow, faintly tinged with pink, shaded with coppery rose; sweet, handsome and desirable. Madame Melanie Willermoz-Creamy white, thick petals, large, full and fragrant; an excellent sort for out-door culture.

Madame Pauline Labonte-Salmon rose, large and full: good in the bud; will give the most bloom planted out of any tea; an old and excellent sort.

Madame Remond-Medium size, handsome form, color yellowish white, centre darker; very fragrant.

Madame Welche-Very large, double and beautifully formed: soft, pale yellow, shaded in the centre with orange and copper; blooms freely: one of the finest teas.

Mademoiselle Cecile Berthod-A grand rose, extra large size, very fragrant, very double; color deep clear yellow.

Mademoiselle Lazarine Poizeau-Bright daffodil; a very distinct color in roses; prettiest in bud; of delicate habit. 
Mademoiselle Marie Armand-Elegant canary yellow, changing to white, with reddish buff centre; large, full and fragrant; rare and elegant.

Mademoiselle Marie Burton-Pale yellow; very free flowering; full and very double; fragrant, a magnificent sort.

Mademoiselle Marie Morean-Pale, silvery white, elegantly flushed with crimson and yellow; large, finely formed flowers, full and sweet.

Mademoiselle Rachel-A lovely tea rose, pure snow white; the purest white tea rose; makes beautiful buds; a most charming variety; deliciously fragrant.

Marcelin Roda-Pale lemon yellow, deepening toward the centre to golden yellow; lovely buds and flowers; an esteemed sort. Marechal Robert-White, the centre shaded with flesh; very large and full; a fine sort.

Marie Ducher-Salmon rose, large, very full; a free blooming kind of excellent habit.

Marie Guillot-White, faintly tinged with yellow, large, full and splendid form; one of the most beautiful teas. This rose combines perfection in both shape and form.

Marie Parc-Beautiful rosy flesh, delicately shaded red, with rich crimson centre; large, full flowers; very sweet.

Marie Sisley-An elegant rose, full and double; delicious tea scent; color an exquisite shade of pale yellow, broadly margined with bright rose; superb.

Marie Van Houtte-Pale yellow; edge of petals often lined with rose, well formed; of good habit, and in every respect a most charming sort. The finest tea for ont-door culture.

Marquis de Sanima - Large, globular flowers, very double and sweet; deep coppery yellow with rose centre.

Melville-Bright pink, changing to silver; rose good form; full and fragrant.

Monsieur Furtado-Yellow, medium size, well formed, very full; an excellent sort, of good habit; not nearly so much grown as it deserves.

Nina-Silvery white, colored with rosy blush; medium size, full and sweet; a good rose.

Niphetos-An elegant tea rose, very large and double; deliciously sweet; color pure, snow white; highly valued for its lovely buds, which are very large and pointed and borne on long stems. 


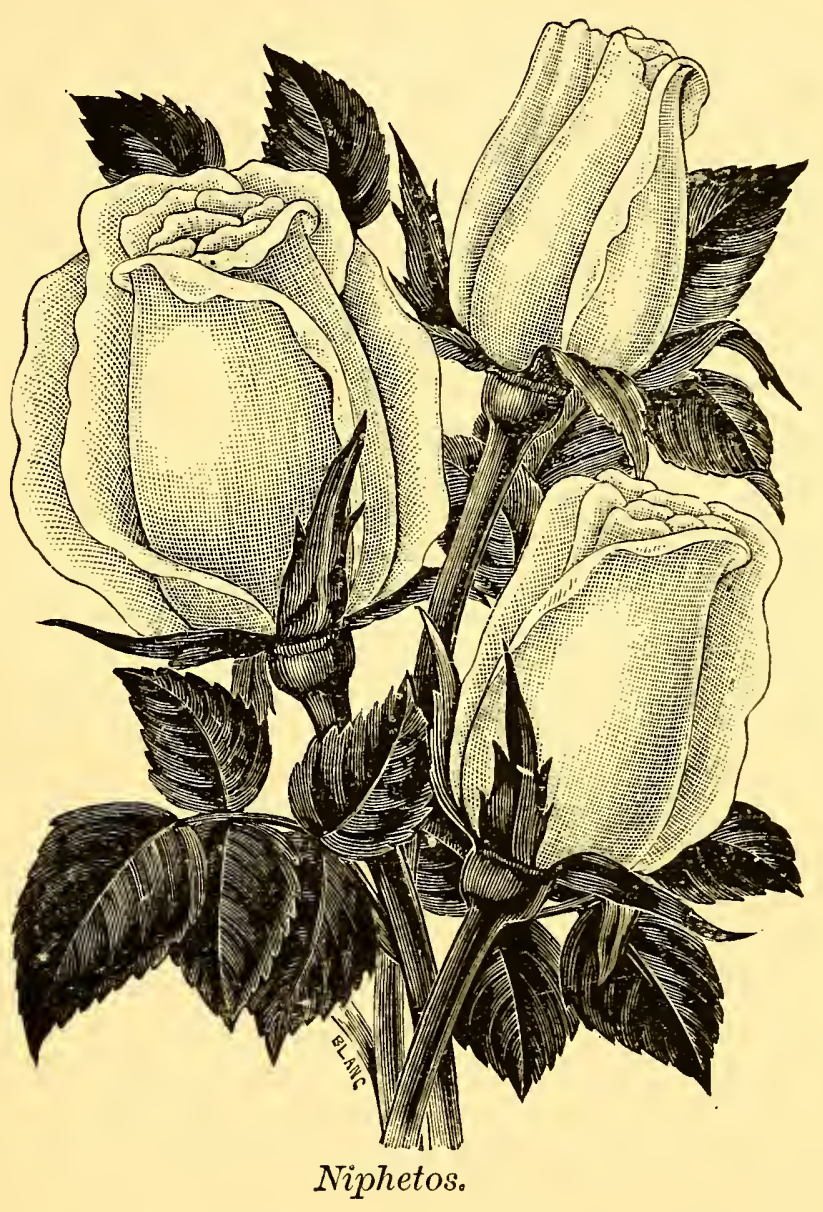

Odorata-Carmine, changing to blush; large flowers, good in bud; one of the most fragrant.

Olympe Frcesney-White, shaded yellow; full and large; free bloomer and very sweet.

Ophelia-A charming variety with very pretty cream-white flowers, changing to pure white when open; fine in bud.

Papa Gontier-Growth vigorous; flower large and full; vivid rose shaded with vellow, reverse of petals, purplish red.

Paul Nabonnand-An elegant shade of satiny rose, large and 1ull; a charming free-blooming sort.

Perfection de Monplaisir-Canary yellow, medium size, full, very free flowering; a splendid garden rose. 
Perle des Jardins-Canary or golden yellow, large and beautifully formed buds, handsome in every stage of development, from the smallest bud to the open bloom; without doubt the finest dwarf yellow rose cultivated. The plant grows freely and the foliage is a picture in itself, being exquisitely edged with pink. The flowers have a delicious tea fragrance and are borne in great profusion; in every respect a superb and charming rose. See figure.

Perle de Lyon-Yellow, with saffron centre; large, full and very fragrant; a rose of fine quality.

Premium de Charrissiens-Extra large, full and sweet; bright carmine rose with fawn centre; splendid buds; a good garden rose.

President-Splendid large flowers and buds; color soft rosy crimson, changing to brilliant carmine; very fragrant and beautiful.

Princess of Wales-Color a rich rosy yellow, the centre deeper yellow; very chaste and waxy in appearance; long, pointed buds; very desirable.

Red Safrano-See "Safrano a fleur Rouge."

Regulus -Large, perfect form, full and fragrant; color brilliant carmine with purple and rose shading; good for both house and garden; a splendid rose.

Reine de Portugal-Coppery yellow, blending with rose; large, very full; an eminently distinct sort.

Reine des Massifs-A low, bushy grower and profuse bloomer; flower medium size, full and sweet; color fine salmon yellow.

Reine Emma des Pays Bas-Bright yellow shaded with reddish salmon; large, full flowers, very fragrant; an elegant variety.

Reine Marie Pia-Splendid large, full flowers, bright scarlet rose, with rich crimson centre; very fragrant and beautiful; lovely buds.

Reine Olga de Wurtemburg-Large, full and fine; color rosy flesh, delicately tinged with salmon yellow; petals margined with crimson; blooms in clusters.

Rosalie - A distinct and charming miniature rose, very pretty in bud; open fiowers of good substance; very free flowering; color a deep pink.

Rosa Nabonnand-Growth vigorous; flowers very large; double and imbricated; delicate rose, vivid in centre; extra fine. 
Royal Tea-White, faintly tinged with yellow; long, beautiful buds; medium size; full and sweet.

Rubens-Rosy flesh, deeper at centre; large, full, well formed; fine in the bud; an excellent variety.

Safrano-Saffron and apricot yellow, exceedingly beautiful in the bud; very free flowering; "much esteemed; deliciously tea scented.

Safrano a fleur Rouge-Flowers bright salmon red, shaded with coppery red; semi-double; has a peculiar scent.

Shirley Hibbard-A charming rose of medium size: full and double; color real Nankeen yellow; very distinct; extra fine.

Souvenir d'Elise Vardon-Flesh color shaded with rosy salmon; large, full and sweet; highly esteemed.

Souvenir de Georges Sand-Elegant and valuable; fine, large, full flowers; bright carmine buds, changing when open to reddish amber, veined with crimson; very fragrant.

Souvenir de Germain de St. Pierre-Growth vigorous; flowers large and full, with very large petals; purplish red; unique color in this class; very abundant bloomer.

Souvenir de Madam, Pernet-Beautiful soft silvery rose, underlaid with yellow; large, full flowers; very handsome when in bud.

Souvenir de Marie Tetrey-An elegant rose; large size, full, regular form, very double and sweet; color pure white, flushed and tinted with soft, rosy crimson.

Souvenir de Paul Neyron-White, beautifully tinged with clear, golden yellow; petals edged with rosy crimson; very distinct and fine tea-scented.

Souvenir de Theresa Levet-Color fine scarlet, shaded darker; flowers large and freely produced; a charming new rose.

Souvenir d'un Ami-Fine delicate rose, shaded with salmon; very large, full and exquisitely fragrant; free bloomer; a rose that will please the most exacting.

Sunset-A beautiful, highly-colored rose of great merit. The color is a rich, tawny shade of saffron and erange, similar to, but deeper than the coloring of Safrano or Md. Talcot. In size, vigor and productiveness, it is the same as "Perle des Jardines." The young foliage is of a rich crimson, which contrasts admirably with the orange-tinted safron flowers; exquisitely sweet and in all respects a superb rose. See figure. 
Sulphureux-Sulphur yellow, medium size; fine in the bud; fragrant and profuse.

Therese Loth-Fine carmine red, with deep rose shading; full and very sweet; free flowering: a good sort.

Triomphe de Milan-White, suffused with pale yellow; large, full, well-shaped flowers; a handsome variety.

Triomphe du Luxembourg-Rosy carmine, finely nerved and shaded with salmon; the buds are very handsome; free in growth and flower; one of the best old sorts.

Unique-White ground flamed with rose and purple; a beautifully colored rose.

Vallee de Chamounix-The coloring of this rose is simply exquisite; the base and back of petals is a bright yellow; the centre highly colored with glowing copper and rose.

Vicomtesse de Cazes-An exceedingly lovely rose, very sweet, very free flowering; color clear copper yellow in centre, changing to lighter on reverse of petals.

White Bon Silene-This is a sprout from the old Bon Silene, possessing the same vigorous growth, the same free flowering qualities, and as hardy in constitution as the parent. The flowers are of pearly whiteness, and it is like gilding refined gold to say more in its favor than that it is a counterpart of the red Bon Silene. See figure.

White Catherine Mermet-Identical with "Catherine Mermet," except in color, which is of a pure pearly white; excellent.

White Daily-Pure white, medium-sized flowers, which are borne in great profusion; constant: also known as White Tea.

White Tea-See "White Daily."

Irilliam Francis Bennett-This new rose is expected to fill a long felt want by taking tho place of the old favorite, "General Jacqueminot," which rose it resembles in color, being a deep, rich crimson. Its bud in shape is long and slender, like "Niphetos," its size that of "Marechal Niel," its fragrance like "La France," and is beyond doubt the most delicious of any rose extant. In the superlative sense it possesses size, color, shape, fragrance, vigorous growth and freedom in blooming; will undoubtedly become popular.

Yellow Tea-Sẹe "Flạvescens," 


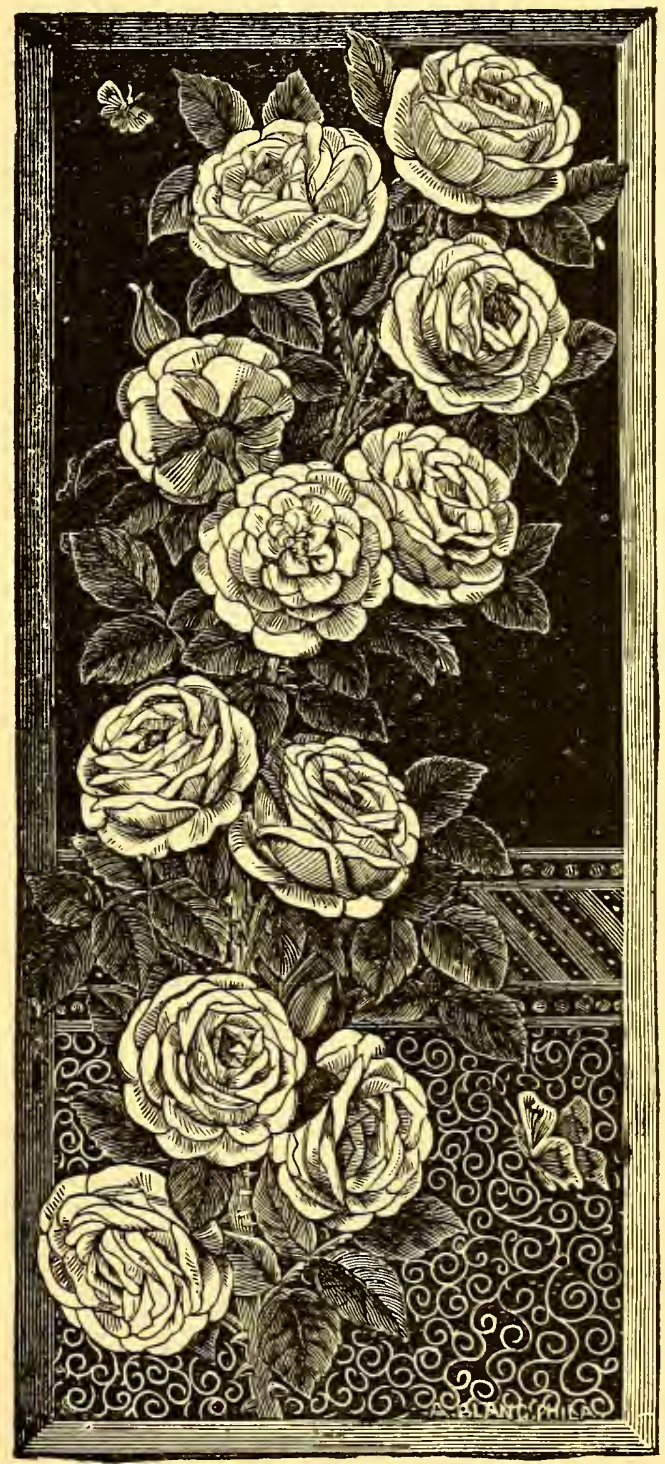

Noisette.

NOISETTE OR EVER-BLOOMING CLIMBERS.

This group is naturally of vigorous growth, nearly hardy, and produces large clusters of flowers freely throughout the summer and autumn. In fact, their distinguishing characteristic is their 
cluster-blooming habit; in a mild climate they become magnificent climbers; nothing can be finer than a wall covered with Lamarque, Solfaterre, or Cloth of Gold. Those in the South and California wishing climbing roses should plant them freely.

Aimee Vibert, (Scandens)-Pure white, small, double flowers, produced in large clusters; nearly hardy.

America-Fawn yellow, changing to coppery yellow; large, full flowers. Augusta-See "Solfaterre."

Beaute de l'Europe-Deep yellow, reverse of petals, coppery yellow, flowers very large, full and well made; superb.

Beauty of Greenmount-Rosy red, medium size, hardy and vigorous.

Belle Lyonaise-Pale lemon yellow; large globular flowers, very full; a fine sort.

Boquet d'Or-Orange yellow, with coppery centre; large, full and fine.

Caroline Marniesse-Creamy white, small and full; hardy; much esteemed.

Car mine Schmitt-Blooms in clusters; flowers full and regular, color coppery rose, passing to buff and white; very pretty and fragrant.

Celine Forestier-Pale yellow, deepening towards the centre; hardy; one of the finest in the class.

Chromatella-See "Cloth of Gold."

Claire Carnot-Buff or orange yellow, with peach-blossom centre; delightful tea scent; pretty and desirable.

Climbing Devoniensis_Same as tea rose "Devoniensis," except of climbing, vigorous habit; one of the finest of the class.

Climbing Hermosa-See "Setina."

Cloth of Gold-Deep golden yellow, with sulphur edges; large, full flower; a grand rose for the South.

Estella Pradle-Lovely pure white buds; flowers medium size; full and sweet; profuse bloomer.

Euphrosyne-Pale yellow, orange tinge. a free bloomer; good grower; very fine sort.

Fellemberg-Rosy crimson; strong, vigorous grower; hardy.

Gloire de Dijon-In color a combination of rose, salmon and yellow; flowers very large, very full; good globular form; a very useful rose. 
Isabella Gray-Deep, golden yellow, old and much esteemcd.

James Sprunt-Deep velvety crimson; large flowers, full and very double; a grand rose.

Lamarque-White, with sulphur centre; sometimes pure white; very large, full flowers, fragrant, and makes beautiful buds; an excellent rose.

Lily Metschersky-Flowers double and well formed; color violet red; vigorous habit; very free flowering; a charming rose.

Madame Berard-A first-class variety; clear salmon pink, beautifully shaded, crimson and rose; large, finely-formed buds and flowers; full and sweet.

Madame Celina Noirey-Extra large, very double, full and sweet; color soft, rosy blush, beautifully shaded with deep red; a splendid sort.

Madame Louis Henry-Pale, silver rose, elegantly shaded with buff and salmon; large and full; very fragrant.

Madame Miolan Carvalho-Deep, sulphur yellow, large and full; very double and sweet.

Madame Trifle-Fawn and yellow; very large and full; a good sort.

Marechal Niel-One of the largest, most beautiful roses grown; flowers deep golden yellow, very large, very full, globular form, delightfully fragrant; the finest of all the yellow roses. The buds are of immense size; a rose of great merit: highly esteemed.

Marie Levelley-Habit extra vigorous; flowers large, full and of fine form; color vivid rose, shaded and lined with white; a splendid new rose.

Musk Cluster-Creamy white; medium size; flowers in large clusters, with a delicate musk flavor; vigorous grower; excellent.

Ophirie-Nasturtium yellow, suffused with coppery red; good size; double; a very distinct sort.

Phaloe-Soft, creamy white, deepening to rosy buff; amber centree, very fragrant; large, double and fine.

Pumila-Salmon rose, tinged with coppery red; large, full, sweet and very free bloomer.

Reine Marie Henriette-Flowers large, full and of fine form; color beautiful cherry red; a pure shadr, rery double, very sweet; an extra fine sort; sometimes called red flowering "Gloire de Dijon." 
Reve dOr-A beautiful pillar rose, being a strong climber; color orange yellow or rosy buff; good size, full and sweet; known also as "Golden Chain."

Setina-Identical with Hermosa, except being of a vigorous climbing habit; recommended.

Solfaterre-Fine, clear sulphur yellow; large, double, full and fragrant; an excellent climbing rose; valuable.

Stephanie et Rodolphe-Flowers medium size; petals prettily imbricated; full, sweet, color orange yellow, flusherl with rosy crimson.

Therese Genevay-A lovely rose, beautifully cupped form, full and double; very fragrant; color peach blossom and fawn, shaded crimson.

Triomphe de Rennes-Canary yellow, the centre tinged with salmon; large, full and good.

W. A. Richardson-Branches strong and spreading; flowers of good size, full, of fine form; color orange yellow; a new shade of Noisettes.

Washington-Medium size, pure white; blooms in large clusters; strong grower; splendid.

Woodland Marguerite-Delicate pure white, sometimes tinged with flesh; medium size; free bloomer; an excellent rose.

\section{HYBRID TEA ROSES.}

This is a new group, produced from crossing Teas with Hybrid Perpetuals. It is yet in an incipient state. Within a few years there will doubtless be a great many varieties introduced. No group attracts more attention than this, and it is certainly destined to attain great popularity. La France, the oldest variety of the class, is probably more highly-prized by connoiseurs than any other rose, and though none of the new varieties in this division have proved her equal, there will yet be found some worthy companions among them. They are, in fact, indispensable, as neither the rosarian nor amateur can have a complete collection without them, embracing as they do a delicacy of color and perfume found in no others.

Antoine Verdier-A beautiful variety; flowers bright silvery rose, shaded and tinged with a very rich carmine; a very free bloomer. 


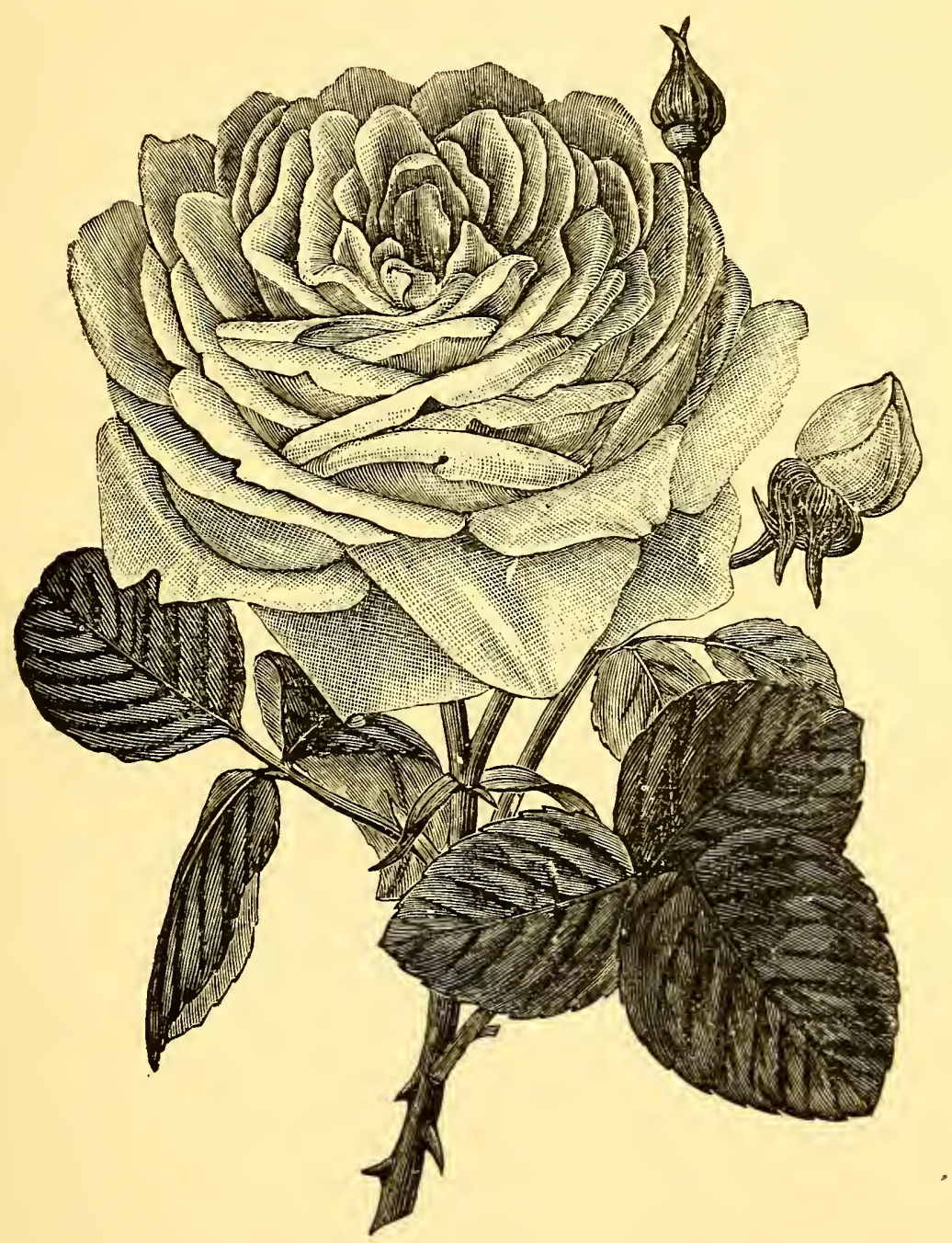

Hybrid Tea Rose.

Antoine Mermet-Very large, full and of fine shape; the color is a rich, dark carmine pink, slightly shaded with pink; an elegant rose.

Beauty of Stapleford - Deep rosy red, centre dark purplish. rose large and double, very handsomely formed; a richly-colored and beautifully-shaped flower.

Camoens-Large flower, of a bright silvery pink color. shaded with yellow; a very profuse bloomer; superb. 
Cannes La Coquette-Very large, full flowers of perfect form; a new color, reddish salmon, with a shade of brick red.

Cheshunt Hybrid-Cherry carmine with a shade of violet: flowers large, full, slightly fragrant; distinct and fine.

Countess of Pembroke-Flowers large and of exquisite form; very full and highly scented; color soft satiny pink, elegantly shaded with rosy peach; very sweet and distinct.

Distinction Mauve color, shaded with reddish amber; very pretty and highly scented.

Duchess of Connaught-Large, very full and finely-formed; color delicate silvery rose, with bright salmon centre; a charming rose of excellent quality; highly-scented.

Duchess of Westminster-Satiny pink, shaded with rose, sometimes carmine rose; large, full flowers; fragrant.

Duke of Connaught. Rosy crimson, large, full, well formed; has charming buds; a fine rose.

Hon. George Bancroft-Flowers very large, full and regular; color bright rosy crimson, elegantly tinged and shaded violet very beautiful.

Julius Finger-Salmon pink, large and full form and habit perfect; a magnificent variety.

La France-One of the most beautiful of all roses, and is unequaled by any in its delicious fragrance; very large, very double and superbly formed. It is difficult to convey an idea of its beautiful coloring, but the prevailing color is light silvery pink, shaded with silvery peach. It flowers continuously throughout the season, often blooming so freely as to check the growth of the plant, in which case a portion of the buds should be removed; stands first among the roses of our climate.

Lady Mary Fitzuilliams-Flowers extra large and globular; quite full and regular; very fragrant and beautiful: color delicate flesh, elegantly tinged with amber.

Madame Alexandre Bernaix--Salmon rose, edged with blush; full globular form; fragrant; very beautiful.

Madame Etienne Levet-Cherry red, with a copperv shade; a good clear color, well-shaped buds, freely produced; agreeably perfumed.

Madam Julie Weidman-Flowers extra large; color clear silvery rose, tinged with coppery yellow, reverse of petals; violet crimson; a beautiful rose. 


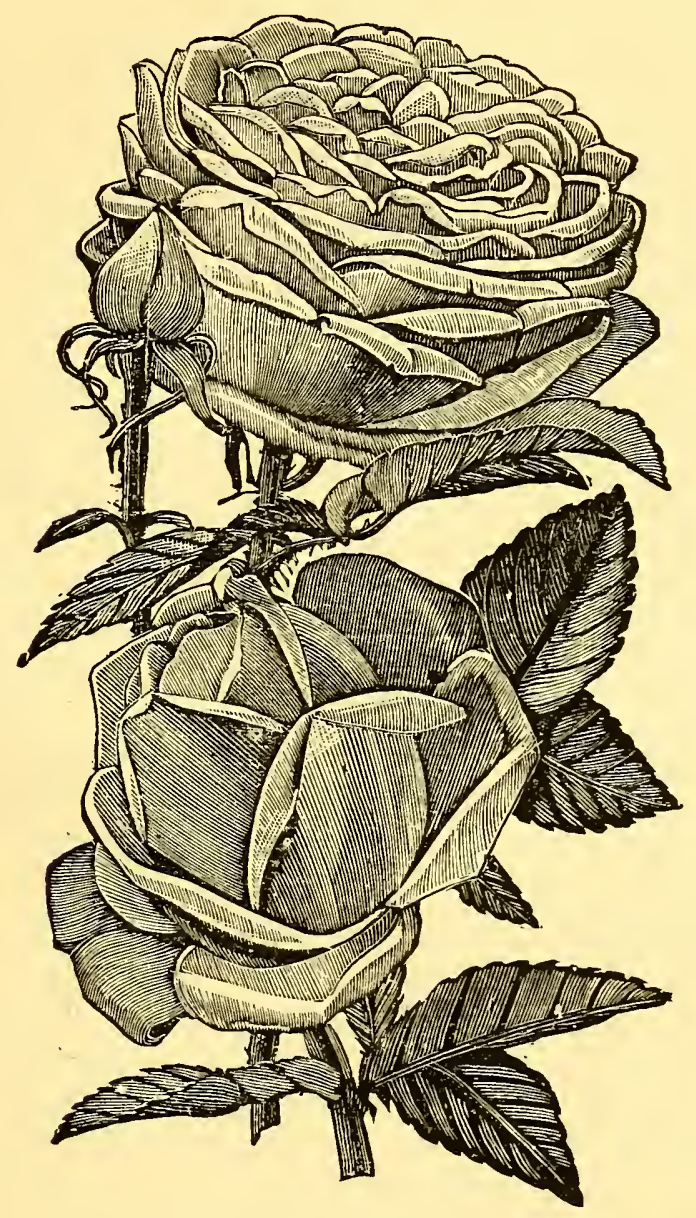

La France.

Mademoiselle Brigitte Violet-Pale rose shaded with violet: flowers large and full; a pleasing sort.

Michael Saunders-Rose, shaded with coppery red; medium size: very full, finely formed; fragrant; a very distinct and pleasing sort.

Nancy Lee-Satiny rose, of a very delicate and lovely shade; beautiful buds, of medium size and highly perfumed; a very beautiful rose.

Pearl-Rosy flesh, medium size, full; has very pretty buds: in every respect an elegant sort.

Pierre Guillot-Bright, dazzling crimson; flowers large, very double and sweet; a charming variety. 
Triomphe d'Angers - Bright, fiery red, changing to darkest relvety crimson, tinged with purple; large, full flowers; double and extremely fragrant.

Viscountess, Falmouth-Bright, shining rose: back of petals bright carmine; flowers extra large and full; of splendid form; very distinct and beautiful.

\section{POLYANTHA ROSES.}

A delightfully unique class of Roses. The original Polyantha Rose is a hardy Japanese species with single flowers, and blooms only in the spring. Its seedlings however, have shown a remarkable tendency to vary from the character of the parent, and among them are the kinds described below, which produce double flowers and bloom continuously from early spring until winter. In habit they are most peculiarly distinct, being the dwarfest of all roses, with graceful, slender branches and delicate foliage. They might be called Fairy Roses, with their miniature and beautiful-shaped flowers, which are borne in immense panicles or clusters, elevated considerably above the foliage. It is not unusual for one shoot to bear dozens of flowers; altogether a new departure among Roses and an invaluable one. They will no doubt prove to be comparatively hardy in nearly every section of the country.

Anne Marie de Montravel-A beautiful, pure white, fairy-like rose, very double, perfect flowers, about the size of a 25cent piece; delightfully sweet-scented and borue in such large clusters that the plant frequently seems to be a mass of flowers. It blooms profusely from early summer until late fall.

Mademoiselle Cecile Brunner-One of the most beautiful and lovely in the class. The flowers are salmon pink, with deep salmon centre, borne in large clusters and deliciouslv perfumed; an exquisite miniature rose for floral work, bouquets, etc.; a vigorous grower and a constant and profuse bloomer; splendid bedder.

Mignonette-One of the most lovely and beautiful miniature roses; the flowers are full and regular, perfectly double, borne in large clusters, and deliciously perfumed; color clear pink, changing to white, tinged with pale rose; it is a vigorous grower, and a constant and profuse bloomer. We 


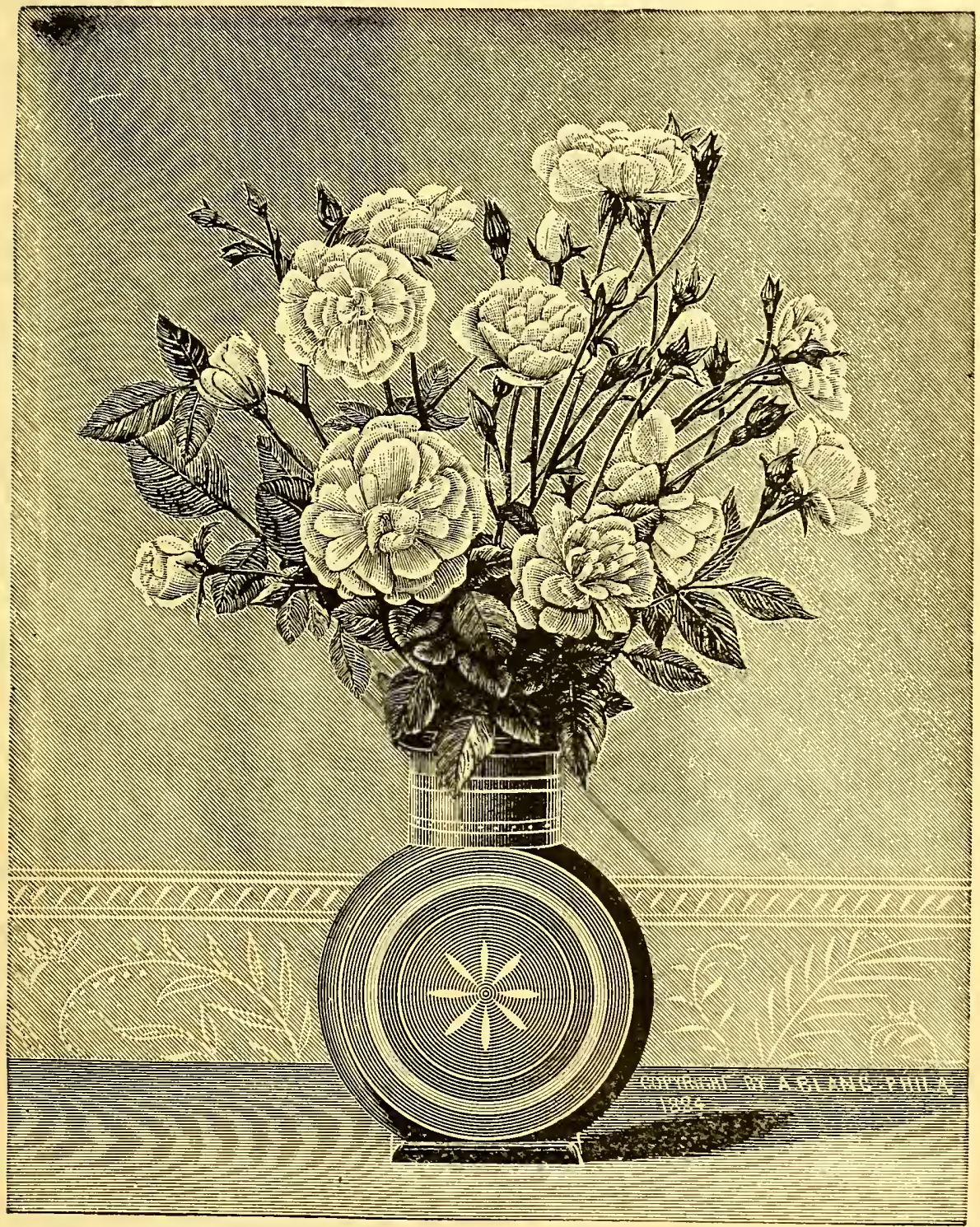

Polyantha Rose. 
have seen as many as 150 flowers on this variety at one time. It has also survived a temperature of 20 degrees below zero without any protection.

Paquerette-We consider this variety the best of all the Polyantha Roses. The flowers are pure white, about one inch in diameter, flowering in clusters of from five to fifty blooms; very full, prettily formed, recalling blossoms of the double flowering cherry, and fully equals the double white Primrose in profuse blooming during the winter. It has a peculiarly delicious perfume that is exquisite; altogether a rose of charming beauty and great merit.

Perle $d^{\circ} \mathrm{Or}-$ This is a new and striking rose, similar in character and habit of growth to Anne Marie de Montrarel. The flowers, however, are larger, and if possible produced in still greater number than those of that valuable variety, but the great difference lies in the color, which is a beautiful light canary yellow, deeper in the centre, with small,white edge; blooms in clusters, numbering often sixty to sixtyfive flowers each; medium size, of fine form and texture; petals are slightly imbricated and overlap each other, giving the flower a very double appearance; growth bushy, rarely attaining over fifteen inches in height: regarded as one of the finest, most distinct and valuable of the class.

\section{CULTIVATION AND MANAGEMENT.}

The Garden.-Roses, to be most effective, should be planted in a bed by themselves, where it is possible to do so. A dozen Roses scattered about the garden lose their individuality, and are not nearly so attractive as when planted in masses of any shape the grounds may allow or fancy suggest. Any fair, well-drained garden soil will answer for them, although where a choice can be had, a loamy clay is preferable; but whatever its character may be, to attain anything like perfection in their culture it should be dug two spades deep and have plenty of rotted stable manure thoroughly incorporated with it. During summer the surface of the soil should be kept loose by cultivation. In planting the hardy varieties, including Hybrid Perpetuals, which are to remain permanently in the beds, do not plant so close that they will become crowded after attaining to some size; three to four feet is about right for this division. although the tender sorts will 
do some nearer. Roses will not thrive in a situation much shaded and like many other plants they do better if not exposed to sweeping winds.

Pruning.-Usually the most pleasing form for the Rose is a symmetrical, bushy one, and this can be produced by judicious pruaing. The proper time to prune those that are entirely hardy is late in the fall, while the varieties that are liable to be frozen back in winter should have the operation deferred until early spring. All strong shoots of the last season's growth should be cut back to three or four eyes, making the cut with an upward slope from directly above an eye: weak growths should be entirely removed. This treatment will cause a vigorous growth of young wood, and tends to increase the size and beauty of the flowers. In pruning climbing Roses, only such shoots as may appear superfluous, and all old wood that can be spared, should be cut away. The varieties of the tender division, the growth of which is almost continual, require pinching back of the strongest new shoots during the season to keep the plants shapely, and all branches after flowering should be cut back sufficiantly to induce from three or four new flowering shoots to start into growth from the buds which remain.

Insects Injurious to Roses. - The most troublesome insect enemies of the hardy Roses are the Rose Saw-fly, especially in its caterpillar state-then known as the Rose Slug-and the Rose Chafer or Bug. As the depredations of each of these sometimes assume a serious form, I will endeavor to describe them so that they may be known at their first appearance, and proper remedies be applied in time to check their ravages. During the last two weeks of May, and until the middle of June, the Rose Sawflies make their appearance upon the plants, pair and lay their eggs in the incisions made with their saws in the leares. They are of a shiny black color, about one-fifth of an inch long. and will be found mostly on the under side of the leares, or flying around from bush to bush. The first young slugs hatch out in a few weeks after the flies appear, usually showing themselves about June 1st, and increasing in number during the month. These are of a pale green color and have an almost transparent, jelly-like appearance. They feed upon the leaves, which soon look as if they had been burned, and drop if the slugs are not destroyed. Dry slacked lime scattered orer the leaves while wet with dew is the most convenient remedy for destroring them, 
and will often prove effectual; but a more destructive one may be had in frequently syringing the plant with whale oil soap dissolved in water in the proportion of one pound to eight gallons of water. Many of the female insects in their beetle state-being more sluggish than the males-can be destroyed with this solution if thoroughly applied by sprinkling or with a syringe every day as they first appear. No pains should be spared to lessen the number as much as possible by this means. The Rose Chafer is a small insect with a slender body, which tapers before and behind, measuring near three-eighths of an inch in length, and entirely covered with ashen-yellow down. They usually appear towards the middle of June, sometimes in large numbers, and remain from four to six weeks, also feeding on some other plants beside the Rose. The usually efficacious remedies employed in destroying other insects, scarcely effect these at all; and about the only way of destroying them is to pass over the plants daily, shake or brush them into tin vessels containing water, or they may be gathered on sheets and burned. Red Spider and Green-fly are the most common insects met with in cultivating Roses in the window and conservatory, and directions are given for preventing and destroying these in the articles on "The Amateur's Conservatory," and "Plant Culture in and about the House."

Mildew and Rust,-Mildew is a fungoid growth which shows itself upon the leaves and small twigs of Roses and other plants, both indoors and out at times. It has a gray, mold-like appearance, and seems to be invited by anything that causes the growth of the plant to be suddenly checked. Roses making a vigorous growth in the window or conservatory, if exposed to a strong draft of cold air from the outside, will frequently be troubled with mildew, or by allowing the soil to become dry enough to cause the leaves to droop generally affects them similarly. In Rose culture all such unfavorable causes must be strictly guarded against. The ordinary agent, and undoubtedly the best, for eradicating and also preventing midew is flour of sulphur, which may be applied by dusting it upon the leaves after wetting down the foliage, every few days, until it is no more to be seen. Rust frequently troubles Roses in the garden by appearing upon the leaves. The best way to deal with it is to cut off and burn the infected branches, although if badly affected it may necessitate the sacrifice of the greater part of the plant. 
Protection During Winter.-Wherever it is possible, by means of protection, to keep Roses in the open ground during winter, I advocate the plan of so doing. There will be little use of attempting to winter any but the most robust varieties, however, unless the ground is thoroughly drained, and when the rosary is in such condition, little loss need occur in leaving out many of the tender varieties, if well protected. One of the best ways of protecting tender kinds, is to bend the plant to the ground and completely cover with fine soil from six to ten inches deep. If the Roses are in a bed, the plants should all be bent_in one direction, and the entire bed covered to the same depth. Another good way is to remove the top and bottom from a barrel or box, and placing it over the plant, fill loosely with leaves or straw. An amateur cultivator in Pennsylvania informs me that she succeeds in wintering tender Roses by laying them flat on the ground and covering them with a board. Where the winters are very severe and it is not considered desirable to risk tender kinds out of doors, they may be carefully taken up, pruned slightly, and placed in a cold pit until spring. By admitting an abundance of air in sunny spring days and warm weather they may be planted into the beds again by May 1st in this latitude. They should however, be pruned again before planting out.

In cut on next page, taken from the Rural New Yorker, is shown a new method of treating tender and half-hardy roses and other plants, lately described in that excellent paper, and which enables the owner to remove them easily to a place of safety in the falland replant them in the spring, with but very little disturbance of the roots. For roses, take an ordinary 12 -inch pot and drill or bore a number of holes one inch in diameter through the sides, as shown at Fig. 1. The pots would be better if originally made with these holes, and the sides of the pots all about them thickened, as shown in the cut; this thickening would add greatly to the strength of the pot. The bush is to be planted in the pot, using good rich soil for the purpose. The rose grounds should be made very rich with well-rotted manure, and a liberal use of charcoaldust adds much to the health of plants and beauty of the flowers. At the proper season set the pot and plant in place where desired, as shi,wn at 3; this puts the pot entirely beneath the surface and out of sight, which, in ornamental grounds, is very desirable. As the growth progresses, the roots emerge from the pot in all directions, penetrating the soil, and the bush grows as vigorously as 


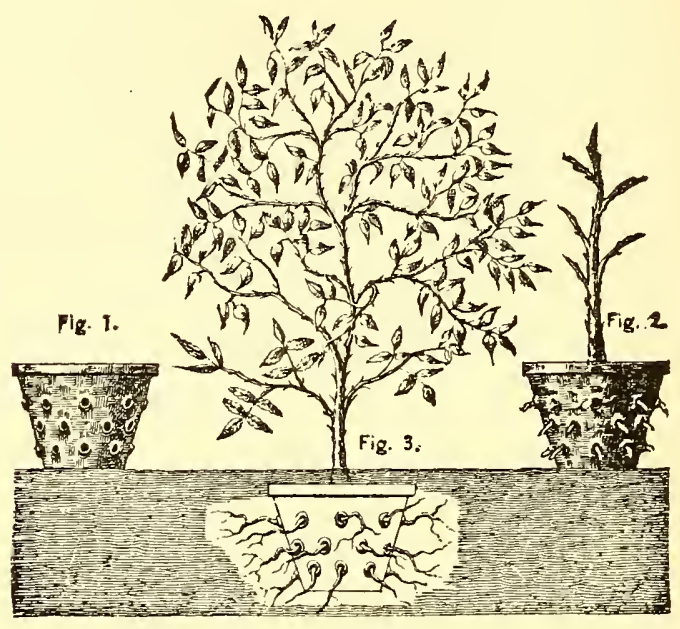

A New Method of Planting.

though planted in the open soil. After severe freezing in the fall, the pot and plant are raised, those roots within the pot being, of course, entirely undisturbed, and can be stored in a cold cellar or other convenient place where, entirely protected from the sun's rays, and from too severe freezing, the pot and protruding roots should be covired with damp sand or earth. Fig. 2 shows the plant ready for replanting, with roots and top cut back, as should be done each spring, and then planted out as before as soon as danger of severe freezing is passed. The grounds should be enriched each year, and being very rich, the plant at once commences a rapid growth, which is essential to an abundant bloom. Fach succeeding fall it is to be taken up and treated in the same way, and can be kept many years in good health and vigor. In place of the pot, any wooden box, having numerous holes in its sides may be used, but, of course, it is not nearly as durable or desirable, for in the damp, warm soil, it decays rapidly, and is liable to become full of insects.

Most varieties of Hybrid Perpetual Roses will survive the coldest winters unprotected, if growing on drained ground. It is, however, a wise policy, to cover all the plants with straw late in autumn, as this is but little trouble, and they generally flower better, while they are sure to winter safely with such treatment. This may be done by driving a stake firmly into the ground to each plant, and tying it nicely and rather close to it; then some straightened straw is placed around the entire length of the 
plant-..it need not be very thick--completing the operation by binding twine or straw bands around the whole in several places throughout its length. An application of stable manure or leaves around the base of the plant will afford all needed protection to the roots. All roses, including the most tender kinds, will stand some freezing without injury, and it is as well to defer protecting them until quite late in the fall, say in November. In the spring, as soon as the frost is out of the ground and growing weather is at hand, all protection should be removed.

Roses for Pot Culture and Winter Blooming.-The tencler monthly roses are nearly all suitable for pot culture and winter flowering, the Tea-scented section. with its unapproachable bud varieties, being usually preferred. Plants designed for winter blooming should be grown in pots during the previous summer. These should be plunged to the rim in earth or coal ashes, in order to prevent their drying out. Roses under any circumstances are quite susceptible of being injured by becoming too dry, and the condition should always be guarded against in pot culture. In the remarks on page 31, entilled "Preparatory Treatment of Plants designed for Winter Flowering," directions are given which apply to summer treatment of roses grown in pots for this purpose. In August the plants should be shifted into larger-sized pots, or planting them into a box will answer quite as well. If they are to be grown in the window, they should now be gradually inured to the changed light and heat by keeping them in confinement only a part of the day, in the intervening time giving them an airy exposure under the piazza or at the side of the house, lessening this by degrees as the season advances. If to be forced in the conservatory, this means of acclimation is unnecessary, provicied plenty of air is allowed to circulate through the structure after they have been taken in. Their winter position should be as much exposed to sun as possible, and the temperature kept at between $55^{\circ}$ and $60^{\circ}$ at night, with an increase of $15^{\circ}$ higher during the day. Syringe the plants frequently and never allow them to suffer from dryness at the roots.

Before dismissing this subject, I will explain how, by means of a cool greenhouse or a cold pit, the Hybrid Perpetual and many other hardy roses, besides all tender ones, may be taken up and made to do a kind of double duty, safely, and with little tronble, by flowering profusely in the house or conservatory in Narch or later, and after being returned to the garden thrive there as 
usual. For this purpose any of the plants growing and flowering during summer are suitable without extra treatment. Dig them carefully late in October in this latitude, and prune away the old straggling wood and superfluous shoots, cutting the remaining shoots back to sereral eyes; then pot into good fresh soil, onethird part of which should consist of well-rotted manure, pressing it down very firmly and give them a thorough watering. After this place the potted roses in a cool greenhouse or cold pit, where they are to remain until the middle of January and later for a succession. In bringing them in from the cold pit to the window or conservatory for flowering, do not place in too high a temperature at once. A situation indicating $40^{\circ}$ or $45^{\circ}$ will answer for them at first, and from this they might gradually be changed to a temperature of from $50^{\circ}$ to $60^{\circ}$ at night, and receive treatment as directed for winter blooming plants. Contrary to what might be supposed, thus forcing roses late in the winter does not materially injure the usefulness of the plants, for by planting them out again in May, the monthly varieties will flower considerable, and all will regain their usual vigor in time.

\section{DESCRIPTION OF ORNAMENTAL AND FLOWERING PLANTS} WITH CULTURAL DIRECTIONS.

Plants that are grown for ornament, as well as others, are classified according to their habits, means of reproduction, time of flowerirg and maturity, etc., into a number of divisions, as namers and described herewith.

\section{ANNUALS.}

All those plants that flower the first year from seed, and, after yielding a new crop of seed, die, root and all, are called Annuals. These are sub-divided into several kinds, such as Hardy, HalfHardy and Tender Annuals.

Hardy Annuals are those that readily germinate and make their growth to full maturity in theopen air, without the aid of artificial heat, such as Sweet Pea, Nemophila, Candytuft, etc. 
Half Hardy and Tender Annuals differ from the IIardy Annuals in being more tender, on which account most of them should receive the assistance of artificial heat and protection during germination and in the early stages of their growth, although nearly all flower well later in the season if the seeds are sown in the open ground after all danger of frost to the young seedling is over. The Portulaca, Phlox Drummondi, Marigold, etc., belong to this division.

\section{BIENNIALS}

flower the second and sometimes the third year after sowing, then ripen their seed and die, root and all.

\section{PERENNIALS}

live and blossom from year to year, and, although some seed free$1 y$, many do not, and are best increased by layers, cuttings, separation of the roots, etc. This division is sub-divided into Hardy Herbaceous Perennials, and, in our latitude, Tender or Greenhouse Perennials, each of which include some Bulbous and Tuberous plants.

Hardy Herbaceous Perennials are plants like the Pæonies, Hardy Phlox, Hyacinths, Lilies, Lychnis, etc., whose roots continue to live year after year, although the growth above ground dies annualiy, either soon after flowering or in the fall. Most of these kinds are propagated by division of the roots, which may be taken up for this purpose every few years. Many can also be increased from seed, others by layering.

Tender or Greenhouse Perennials for the most part consist of plants whose entire growth, both plant and root, is continual. and which are, with few exceptions, increased by slips or cuttings taken from growing plants. These plants are usually reared in pots, and belong to a division that, to some extent, is old and well known. The common monthly Rose, Rose, Fish and Horseshoe Geraniums, the Lady's Ear-Drop, Snake and other Cactus, Oleanders, Rosemary, etc., which all of us have been familiar with from infancy, almost, belong to this division, while many varieties and kinds, quite as easy of cultivation, and greatly improver, which have come into general use only within late years are still comparatively unknown, and receive little attention, except from professional florists, and the more enthusiastic amateurs. To this class of plants we are indebted for many of our 
choicest floral gems, either for cultivation in the house, conservatory or garden. Frequently members of the same botanical genus vary so much as to be properly arranged in several of the above divisions. This is the case with the Phlox, some species of which are Hardy Annuals, and other Hardy Herbaceous Perennials: also with the flowering Pea and others.

Conparative Value.-In this connection it may be well to consider the comparatıve value and cost of various kinds of flowers, presuming that the reader who purchases stock, desires to make the best investment with any money to be expended. Although the prices of individual pot and other plants range higher than those of single packets of flower seeds, it should be remembered that the former are always of considerable, often of a flowering, size when purchased, while plants still require to be reared from the latter; then, again, when once a plant is purchased it can be increased by cuttings, divisions, etc., to any desired extent, and the quality of the variety is never materially impaired, because each plant propagated is part of the parent, with a root of its own. With seeds it is different; every experienced amateur knows that it is next to impossible to keep up a superior strain or variety with seed unless this is saved from plants grown isolated, after the manner practiced by regular seed growers. The trouble is they are apt to mix and deteriorate which may necessitate the purchase of the same kind each spring if it is considered desirable to keep up the stock very pure. Should this be necessary however, with rarieties that cannot be saved pure, the outlay to procure superior new seed need not be large each year, and it should be remembered that many of the better annuals and other seed-grown plants can be used with unequaled effect in producing display in the house or about the grounds.

In the descriptions which follow, the division to which (ach sort belongs is named in the parenthesis following the name of the kind. For an explanation of the figures and degrees which follow the name of Greenhouse Perennials, for instance ABUTILON, (Greenhouse Perennial, 33, 45, 85'), see "Temperature," etc., page 44 .

\section{ABELIA (Greenhouse Perennial, 32, 45, 85\%).}

A genus of greenhouse shrubs from Japan; they are of slender branching habit, very attractive and pleasing; of easy culture. 


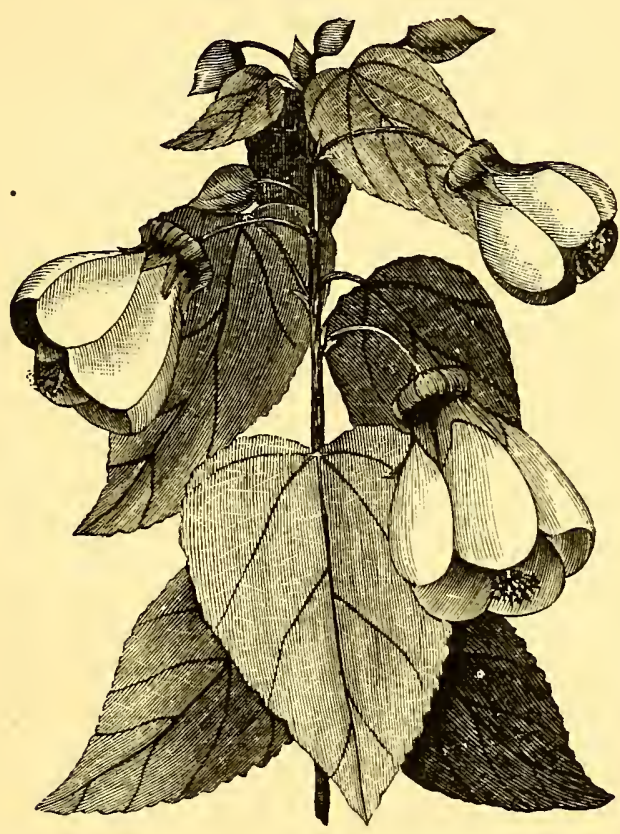

Abutilon.

A. Rupestris-Is of dwarf habit and flowers profusely in autumn or winter; the flowers are produced in compact clusters, white, and of exquisite fragrance; propagated from cuttings.

ABUTILON (Greenhouse Perennial, 33, 45, 85).

A genus of plants noted variously for their peculiar bellshaped flowers of different colors, for the variegated foliage of some varieties, and for the fine drooping habit of others; all are suitable for culture in pots in the house and conservatory, some for bedding and others for planting in vases and hanging baskets, while there is not a delicate or feeble growing variety among them; when bedded out in the summer they can be taken up about September 1st and potted for winter decoration as readily as the average of plants: all should receive an occasional pruning; propagated from cuttings or seed. 
A. Mesopotamicum, has calyx of the flower scarlet; petals yellow; of straggling, slender growth; excellent for training to a stake or trellis.

A. Mesopotamicum pictum-A new variety, and one of the finest drooping plants for planting at the edge of baskets and vases, or for pot culture; the leaves are narrow, of beautiful shape and rather small, and are richly variegated with golden yellow on green, which rendiers the plant exceedingly valuable for contrasting with other drooping plants.

A. Thompsonii-The leaves are distinctly variegated and marbled with bright yellow on dark green ground. This variety is one of the best bedding and also pot plants for inside cultivation; it grows vigorously when planted out and the distinctness of its leaf markings.

A. santana-Purplish crimson flowers; one of the best old sorts.

A. Royal Scarlet-Very dwarf and the darkest colored sort grown.

A. Yellow Prince-One of the newest dwarf; bright y?llow.

A. Prince of Heilbron-Variegated foliage, Jike Thompsonii, but is much better in its markings.

A. Arthur Belsham-Clear crimson without markings; the best of its color.

A. Ed. Layeillon-Dwarf grower; a splendid bedder, with bright golden yellow flowers.

A. Standard-Dwarf habit; flowers light purplish red; large size, being more expanded than in other sorts.

A. Robert George-This is an elegant sort, both as to habit and blooming qualities, being upright; moderately dwarf, producing flowers of orange, veined with crimson in great profusion.

A. Snow Storm--A dwarf-growing variety, producing pure white flower's; a splendid winter blooming variety.

A. Thompsonir plena-This new variety has perfectly double flowers that resemble in form a double hollyhock; color rich deep orange, shaded and streaked with crimson; it is a sport from A. Thompsonii, and still retains the beautifully mottled yellow and green foliage of that variety.

ACALYPHA (Greenhouse Perennial, 35, 60, 95\%).

Handsome greenhouse shrubs with beautiful foliage, being used more each year for bedding purposes; propagated from cuttings. 
A. tricolor-Has variegated foliage of green, copper-colored and red, irregularly mottled and blotched.

A. marginati-Very pretty bronze-colored leaf with distinct edge of pink or red; very pretty.

\section{ACHANIA (Greenhouse Perennial, 33, 45, 85\%).}

A shrub that blooms both summer and winter; not subject to insects of any kind; one of the most satisfactory house plants grown; are propagated from cuttings.

A. malvaviscus-Is remarkable for the beauty of its scarlet flowers and beautiful green leaves.

\section{ACHILLEA (Hardy Perennial).}

A genus of hardy plants, partly natives, sereral of which produce attractive flowers during the summer months; they will thrive in any soil; they are increased by division of the roots. A. ageratum-Has golden yellow flowers.

A. millefolium-Is a pretty rose-colored variety.

A. ptarmica $f l$. $p l$.-Produces donble pure white flowers; is desirable in every collection. It continues to bloom most of the season, throwing up a succession of its pretty little flowers, in corymbs, on stems about one foot high. The foliage is narrow and of a dark shining green color; perfectly hardy.

\section{ACHIMENES (Tender Tuber).}

Tropical piants for summer blcoming; the scaly tubers must be preserved entirely dry during winter. In early spring, pot in peat, sand and a little light soil. They delight in heat, moisture and shade while growing, but in a more cool temperature when in bloom. Excellent for baskets.

\section{ACHYRANTHES (Greenhouse Perennial, 35, 50, 90%).}

The Achyranthes are plants with beautiful foliage, most of which are excellent for planting in masses and in the ribbon style, their distinct colurs forming a strking contrast with Centaureas and other white-leaved plants. All are well-suited for planting in the centre of hanging baskets and rases, and also for house and winter culture, as they develop their colors eren in partial shade and prove to be somewhat hardier than Coleus for 
this purpose. They reach a height of from one to one and a half feet. Any of the varieties may be readily propagated from cuttings in a warm place. For summer culture the cuttings should be struck in February or March, while to have beautiful medium sizerl plants for window culture in the winter or to plant into ferneries-for which purpose they are admirably adapted-propagate in June or July.

A. aureus reticulatus-Has leaves of a light green color, netted with golden yellow, occasionally splashed with crimson; stalk and leaf-stems light crimson; a beautiful and desirable plant.

A. Gilsonii-With leaves striped with various shades of carmine; stems of a deep shade of pink; in some respects an improvement on old Verschaffeltii, being of a more dense and compact growth; excellent in every way.

A. Lindenii-An upright dwarf grower, about one foot high, completely branched from the root; leaves narrow lanceolate, of a deep, blood-red color, reflecting varying tints of red and purple; unsurpassed for hedding.

A. Lindenii aureus variegata-A variety in every respect similar to Aureus reticulatus, except that it resembles Lindenii in growth and form of leaf.

\section{ACROCLINIUM (Half-hardy Annual).}

This is one of the several useful everlasting flowers that are readily grown from seed. The flowers are of medium size, good form, and are not excelled by any other everlasting in points of delicacy and beautiful tints. It is better to start the young plants in heat and transplant to eight inches apart, then to sow directly where they are to bloom, although there is no great danger of failure by doing so about June 1st. The flowers should be cut for use in winter before they are fully expanded.

A. album-Pure white.

A. roseum-Bright rose.

\section{AGAPANTHUS. (Tender Bulb.)}

An old genus of Liliaceous plants, belonging to the greenhouse, and easily grown in light fibrous loam and old manure. During the growing season water must not be neglected. Store away in the cellar during winter. This plant will frequently send up a flower stalk three feet high,crowned with twenty or thirty flowers, 
which will open in succession. It is a noble ornament on a lawn. A. umbellatus-Numercus large umbels of bright blue flowers, on tall stems.

\section{AGave-Century Plant (Greenhouse Perennial, 32, 45, 90).}

This remarkable family of plants belongs to the class known as fleshy plants, and which have thick, massire leaves that present but a small amount of surface in proportion to their bulk. In the present instance the plants have no proper stem previous to the time of sending up their flowering shoot, which, as is well known, takes place at an advanced age, although the popular impression that they do not flower until the age of one hundred years is erroneous. In Central and South America, their native habitats, they flower previous to their twentieth year, but in our greenhouses not usually until they have reached three or four times this age. After flowering the plant dies to the ground, but the root sends up a mass of new plants. The leaves are long, thick, and terminate in a point; they diverge upwards and outwards from the centre and together form one of the most effective pot plants for decorating the grounds in summer and the conservatory or dwelling in winter that can be cultivated. The Agares are easy to grow, being not at all particular as regards light or heat, in this respect resembling the Cactus, and quite as desirable for house culture. Their growth can be retarded or encouraged by more or less frequently shifting them into larger pots, which, at the most, should not be done of tener than once a year.

Their are two varieties in common cultivation-A. Americana, with bluish-green leaves, and $A$. Americana variegata, similar in appearance to the preceding, except that the foliage is striped throughout its length.

AGERATUM (Greenhouse Perennial, 33, 45, $75^{\circ}$ ).

The Ageratums are rapid growing, profuse blooming, easily propagated plants, that will thrive with the most ordinary treatment; either if bedded out or in pots, and are deserving of a place in every collection. The flowers are produced in compact tuft-like heads. and although no striking colors exist in them, they appear in large numbers continually throughout the summer; are of excellent form and have long convenient stems, which render them useful for working into bouquets. Being almost continually in flower, most of the varieties are valuavle for planting in ribbon 
lines or for massing, and they are rery easily reared from cuttings in large numbers, a fact that should not be overlooked. The variety with variegated foliage creates a very pretty effect when similarly employed. Ageratums can be forced to flower in the winter quite well, either in the dwelling or conservatory, but are not prominently valuable for this purpose, as the red-spider is rather liable to trouble the plants. Young summer propagated plants can easily be kept in a growing condition over winter from which to take cuttings for spring stock.

A. Imperial dwarf-Is of compact low growth, attaining the height of eight inches, and spreading to the size of one foot across; it is almost entirely covered with lavender-blue flowers during the greater part of the summer.

A. Mexicanum is one of the best for cut flowers; the flowers are of a delicate lavender color, and very freely produced; the plants grow to a height of from eighteen to twenty-four inches.

A. Mexicanum variegatum-A beautiful variety of the last-named one, which it resembles in habit, but the leaves are variegated with yellow, green and sometimes a faint shade of crimson; suitable for bedding or pot culture.

A. Tom Thumb-The smallest variety of all, rarely attaining more than six inches in height; flowers of a light porcelain blue color.

A. Blanche-Pure white; a most valuable sort.

A. John Douglas-Dwarf and bushy flowers, azure blue, making it oue of the most valuable additions to bedding plants of late introduction.

\section{AGROSTEMMA (Hardy Annual).}

A species of plants that flower freely in the summer. Although perhaps not as valuable as some others, they may be grown easily from seed, and having long stems and rather attractive colors, are so useful and pretty in bouquets and other floral arrangements that they should not be passed by.

The varieties commonly grown are New Scarlet, of bright color, Coeli Rosa, of a deep rose color, but there are still other good ones.

\section{AKEBIA QUINATA. (Hardy Climber).}

This plant is suitable for large arbors or trellises. It will twine around old trees, completely covering the branches from which it 
wiil hang in graceful festoons. The color of the flower is dark brown; very sweet scented; it is easily propagated from cuttings or by layering.

\section{ALLAMANDA (Greenhouse Perennial, 35, 55, 90\%).}

A splendid genus of greenhouse plants, invaluable for exhibition purposes. They should be grown in equal parts of fibrous loam, peat and sharp sand, with a little rotted manure. Give strong heat and moisture; propagated from cuttings.

A. nerifolia-A compact-growing greenhouse shrub, having large, trumpet-shaped, bright yellow flowers, which are borne in great profusion nearly the entire season.

A. Hendersonii-A valuable greenhouse plant, having large, deep yellow flowers four inches in diameter. It can be trained to climb, or can be grown in bush form, as desired. It blooms nearly the entire season; a splendid plant.

A. Schottii-Produces immense numbers of large, funnel-shaped flowers; golden yellow.

\section{ALOYSIA CITRIODORA-Lemon Verbena (Greenhouse Peren- nial, $33,45,80^{\circ}$ ).}

A neat growing shrub, with elegant light green lanceolate leaves that are deliciously fragrant; in this respect hardly equalled by any other plant in cultivation. It is difficult to describe a fragrance with words. That of this plant somewhat resembles the oder of lemons, yet besides possesses a sweetness and agreeableness that is indescribable. Sometimes persons of cultivated tastes may be met to whom the fragrance of such flowers as the Heliotrope, Mignonette, Tuberose, Jasminum, etc., which are prized by nearly every one, are found to be distasteful, but I have yet to find the person who does not like the Lemon Verbena fragrance. Although the Aloysia is a tender perennial; its sheds its leaves in the fall, and enters into a natural state of rest during the winter, in which condition it may be kept over until spring in some moderately dry place, like under the staging of a conservatory or on a shelf in the cellar away from frost. The soil about the root should not be allowed to become dust dry, but occasionally may be treated to a little water. In March or April the plants should be brought to light and should be watered frequently to induce a new growth for the season. They may also be pruned at 
this time. The Aloysia is suitable either as a pot plant or for bedding out, and will prove to be one of the easiest of plants to manage; propagated from cuttings.

\section{ALTERNANTHERA (Greenhouse Perennial, 35, 60, 90%.}

A genus of ornamental plants, with richly-colored leaves in the summer and which are well adapted for pot culture, baskets, vases, and for bedding out in ribbon lines or edging to flower beds. They are of a similar size to, and contrast beautifully with, variegated Alyssum and variegated Thyme for bedding purposes. The plants grow rapidly, and assume compact, globular forms of from five to twelve inches high, which are extremely beautiful. In August young plants can readily be obtained from cuttings for winter decoration and from which to propagate spring stock. The plants are easily injured by frost and should be planted out late enough in the spring to avoid danger from this cause.

A. amabilis-The foliage of this variety is finely variegated with orange, rose and green; vigorous.

A. latifolia-Broad, smooth leaves, with many bright colors and tints on green ground; resembling autumn leaves.

A. spathulata-Leaves carmine and green, the carmine predominating; five inches.

A. spectabile-Leaves orange, bronze and scarlet.

A. versicolor-A beautiful and distinct variety of rose and deep crimson color; nine inches.

A. parychioides-Leaves prettily marked with yellow and red.

A. parychioides major-Foliage with a bright orange-colored tint. A. aurea-Beautiful bright yellow leaves.

$A$. aurea nana-This new variety seems to supersede everything else for a yellow line in massing or ribbon bedding; the leaves are bright golden yellow; habit upright and compact; height four inches.

\section{ALTHAEA-Rose OF SHARON (Hardy Shrub).}

This is really one of the most showy and beautiful flowering shrubs; the flowers are of large size, in some very double, and of various brilliant and striking colors, such as white, purple, striped, rose and violet. It blooms freely during August and September, when scarcely any other tree or shrub is in bloom. There is also a beautiful variety with variegated foliage of green and white; propagated from cuttings. 


\section{ALYSSUM, SWEET (Hardy Annual).}

A pretty little plant, easy to rear from seed and to cultivate in summer and winter for bouquets; its white, fragrant flowers, which are produced abundantly, rendering it valuable for this purpose. For summer culture sow in the open ground where it is to bloom, or transplant from the seed bed, in either case leaving four inches of space between the plants. It is also a useful plant for hanging basket and vase culture. To have an abundance of flowers in the winter, sow about JuJy 1st and cultivate in pots during the summer, not allowing them to bloom for the first four or five months. This plant, although usually treated as an annual, is really a perennial, as is shown when the flowers are picked to prevent seeding, and it is kept in a growing temperature.

Alyssum, Variegated Sweet (Greenhouse Perennial, 35, 50, $\left.80^{\circ}\right)$. - This is a pretty, variegated variety of the common and is grown from cuttings. It is also quite similar in appearance to the parent, but white predominates over green in the color of the leaves, making it exceedingly ornamental, even aside of its many white sweet-scented flowers; although one of the finest droopers for planting at the edge of hanging baskets and vases, and also as a pot plant, it is one of the best low bedding plants for ribbon lines or edgings, as it assumes a dense, rompact form when bedded.

\section{AMARANTHUS (Half-Hardy Annual).}

Some varieties of the Amaranthus family are very highly esteemed as garden and pot plants for their beautiful showy foliage and for the fantastic forms and arrangement of the flowers. Then there are others usually advertised in seedsmen's catalogues which are scarcely deserving of culture, unless planted in the back ground, or grouped with plants to be seen from a distance, because of the coarseness of the foliage. Such kind are, however, so easily grown from seed, which may be put in directly where they are wanted, that after all, they may be entitled to our consideration. As a rule, both the flowers and foliage of the various Amaranthus are more brilliant in a poor than in a rich soil, and in a dry than in wet seasons.

A. bicolor ruber -A fine bedding plant, the seed of which should be sown in heat in March or April; the lower half of the leaf a red scarlet, the upper half maroon, sometimes tipped with yellow. The plants, especially when grown on rich soil, sometimes fail to show their rich colors. 
A. caudatus (Love Lies Bleeding)-Red, graceful; 3 feet.

A. cruentus (Prince's Feather)-crimson; 3 feet.

A. melancholicus ruber-A very showy plant of fine growth;

foliage blood red; well adapted for ribbon belts or groups; one and one-half feet high.

A. salicifolius-The Fountain Plant, so called from the graceful manner in which the foliage is arranged; the leaves are elongated and willow-shaped, and of a bronzy carmine hue; sow the seed in heat.

A. tricolor (Joseph's Coat)-Leaves red, yellow and green; very handsome in a favorable season.

\section{AMARYLLIS (Tender Bulb).}

The Amaryllis are an interesting class of bulbs, desirable for growing in pots, producing showy flowers that are very attractive and handsome.

The bulb may be planted out the latter part of May in rich sandy soil, to a depth at which the neck of the bulb shall be even with the soil; it will flower in June or July. After the tops have been cut down by frost in September or October, the bulbs should be lifted and put away in dry sawdust, safe from frost. The Amaryllis is well adapted to pot culture in the conservatory or on the window shelf; give an abundance of water up to the time of flowering,after which it should be gradually and finally altogether withheld. After several months of rest it may be repotted for another season of flowering; increased by division of the bulbs. A. Johnsonii-Dark red with white stripe; splendid large bulbs. A. grandiflora-Large, fine; scarlet.

A. Mrs. Joslyn-1 new seedling, with beautiful pink flowers.

A. Treatea or Easter Lily-Has stems about a foot high, flowers very large, pure white and sweet scented; bulbs do not grow very large.

A. rosea-Beautiful rose-colored flowers.

A. formosissima-The flowers are large, of a drooping lily-like shape, and of the most brilliant dark crimson color; they are produced on a stalk a foot high; in the sunshine they have the appearance of being sprinkled with gold.

\section{AMOBIUM ALATUM (Hardy Annual).}

An everlasting flower of fine appearance, which ranks high for winter bouquets, on account of its being of a pure white 
color, if gathered and cured by hanging in the shade before being fully expanded; also very useful for cutting fresh. Grows finely in any garden soil.

\section{AMOMUM (Greenhouse Perennial, 33, 50, 90\%).}

This genus of aromatic herbs furnishes the Cardamon seeds of commerce; the plants grow readily in the greenhouse; propagated by division of the roots.

A. Meleguata-Has long, bright green leaves, which emit a very pleasant fragrance; a desirable plant.

\section{AMORPHOPHALLUS (Tender Bulb).}

A genus of plants, with large bulbs; not hardy here, but excellent for summer bedding. The following species is not unlike an umbrella in form, with spotted stem; propagated by offset.

A. Rivieri-The entire plant is marbled with white.

\section{AMPELOPSIS (Hardy Climber).}

Climbers of rapid growth in any kind of soil, and will attach themselves firmly to wood or stone buildings or to the trunks of old trees and soon cover these objects with a fine mantle of rich foliage; propagated by layering or cuitings.

A. Veitchii-A slender growing variety of the Virginia Creeper; the young growth during summer is a dark purplish green, changing in fall to the brightest tints of scarlet, crimson and orange. It clings to stonework, trees, etc., and is a splendid plant for covering unsightly objects; it attains a height of fifty feet. Every year adds to the popularity of this plant; hardy, but should be covered the first winter.

A. tricolor-The leaves of this variety are elegantly variegated with white, pink and green, and the bluish purple berries with which it is covered in fall, adds greatly to its beauty; a splendid basket plant or for covering rockwork.

A. quinquefolia-This is the well-known Virginia Creeper found wild in many parts of the country. It is a fast grower, of strong habit: leaves splendidly colored in the fall.

A. bipinnata-A finely-marked, cut-leaved variety of the Virginia Creeper; equally hardy and entirely distinct, making a novel and valuable plant for covering walls or trees; color of autumn foliage, crimson, scarlet, yellow, etc. 


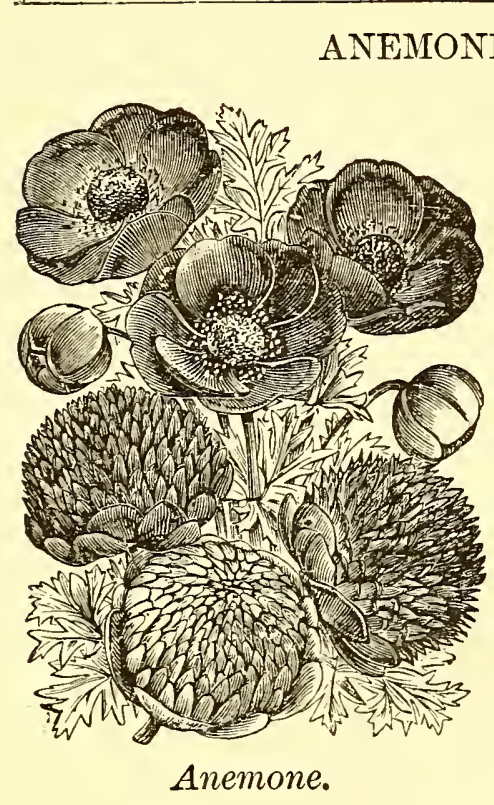

(Hardy Tuber).

Although generally known as a hardy tuberous plant, the Anemone Hortensis is not sufficiently so to render it safe to plant the tubers out in the open ground in the fall along with Hyacinths and the other hardy bulbs. By keeping them out of the ground until early spring, and then at the earliest opportunity planting them in a bed prepared the fall previous, and which has been kept covered, they will succeed very well, and will flower from April until July. The flowers are produced on erect stems, six to nine irches high, in both the double and single varieties; they are of the most brilliant colors with beautiful marks and stripes. The tubers, which have a curious appearance, resembling ginger roots, should be planted about six inches apart and three inches deep. After

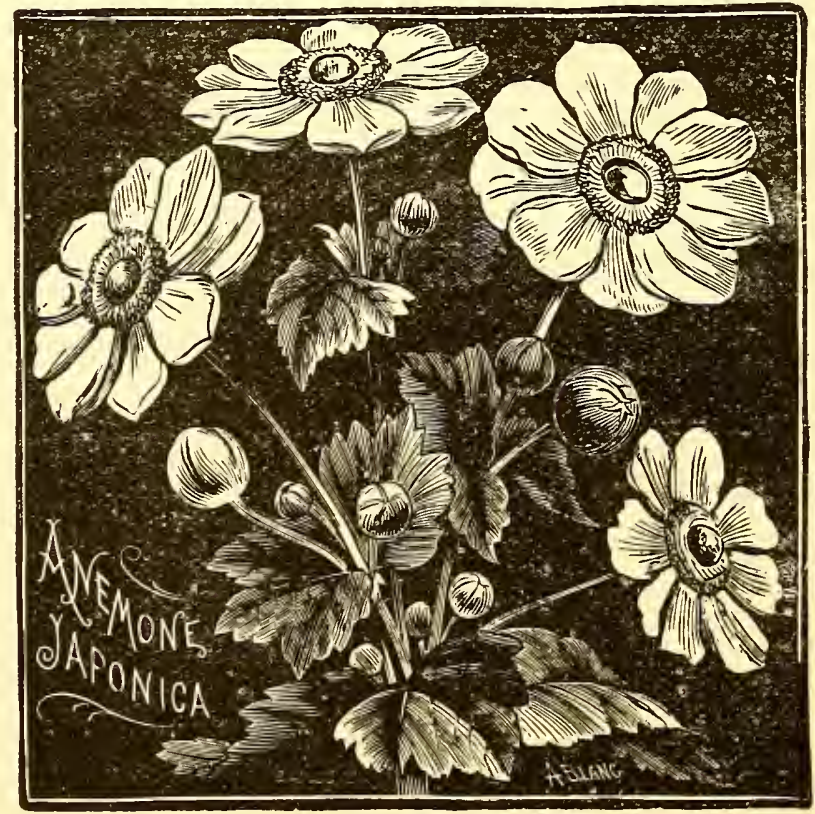


they have produced their flowers for the season, and the leaves turn yellow, the roots may be taken up, dried in the shade and put away for planting again.

Anemone Japonica (Hardy Perennial). - This is a desirable hardy plant, introduced from Japan. There are several varieties: $A$. rubra-with red, and A. alba with white flowers being the most commonly cultivated, The flowers of these are nearly two inches in diameter, and are produced in great profusion for a long time during the latter part of the summer and in the autumn; the plants attain a height of two feet. There are different varieties of wild or wood Anemones found growing in most parts of the United States and Europe, which are attractive among spring and summer wild flowers; increased from root cuttings.

\section{ANIMATED OATS (Hardy Annual).}

Among curious things in the vegetable kingdom, the seeds of this plant are prominent and decidedly interesting. What is striking about them is that they have a strong resemblance to insects with long cricket-like legs that are bearded and covered with spurs, all pointing in one direction. They will throw themselves ahead with a darting, springing motion sufficiently life-like in appearance to be deceptive if laid upon a paper which is being agitated; or if the seeds are moistened, so sensitive are their strong beards to alterations of dryness and moisture that they will twist and keep in motion, resembling an insect crawling on the ground. Sow in the open ground earily in the spring.

\section{ANTHERICUM (Greenhonse Perennial, 33, 45, 85\%).}

An elegant house plant of easy cultivation. It has a hardy constitution, not as against cold, but as against gases, sudden changes and dryness of the atmosphere in the drawing-room, which makes it a valuable plant for the conservatory or for filling in baskets, jardinieres or rustic designs; propagated by seed or division of the roots.

A. vitatum variegatum-Has beautiful dark green leaves, marked with broud stripes of pure white; it throws up long spikes of small, star-shaped flower's.

\section{ANTIRRHINUM-SNaP Dragon (Hardy Herbaceous Perennial).}

The Antirrhinum is a hardy perennial that usually survire our winters if protected, although it is not to be entirely relied upon in this respect, as sometimes it will die out. It is, howerer, so 


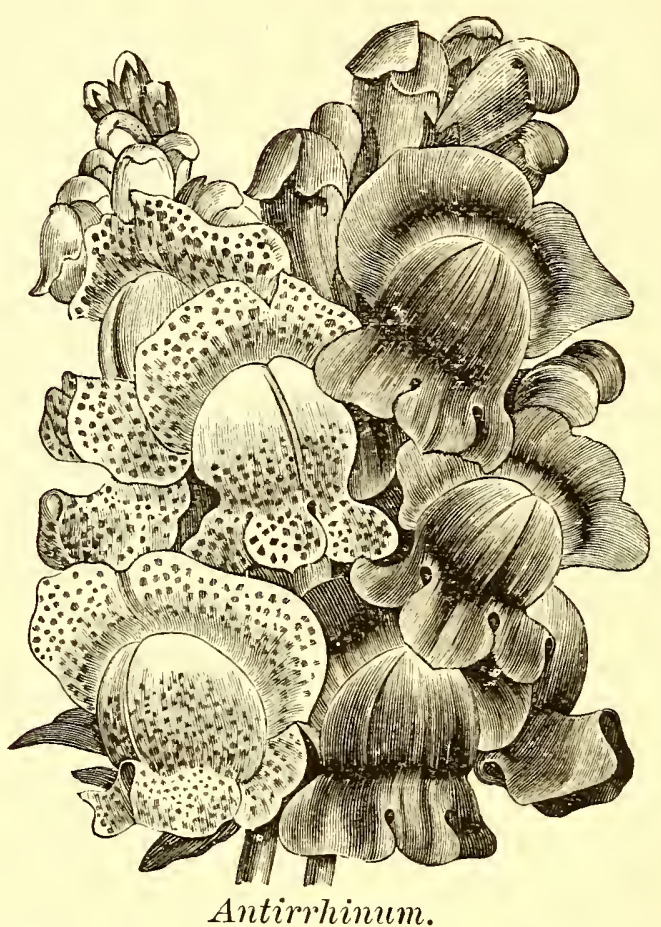

easily grown from seed every year, sown either in the latter part of summer or early in the spring under glass or in the open ground, that there is no necessity of keeping up old plants from year to year. Flowers freely the first season from the seed, and better the second, if the flowers are removed as fast as they appear the first season. The flowers are bright and attractive, appearing for a long time and even up to cold weather: also easily propagated from cuttings, and stock plants can be kept over in a cold pit until February or March, and then started into growth to form shoots for propagation. Among the Antirrhinums are the tall (two feet high), dwarf (one foot high) and Tom Thumb (six inches high) sections, the following being some of the most distinct varieties:

A. album-Pure white, both tall and dwarf.

$A$. brilliant-Crimson and white, both tall and dwarf.

A. delila-Carmine, white throat.

A. firefly-Orange scarlet, white throat, both tall and dwarf. A. papillon-scarlet, white and yellow, both tall and dwarf.

A. purpureum-Deep bright purple; dwarf.

A. striatum-Beautifully striped; tall, dwarf and Tom Thumb. 


\section{AQUILEGIA-Columbine (Hardy Herbaceous Perennial).}

A genus of plants that flower the fore part of the season, some varieties of which are well known, the old garden Honeysuckle being one of these. They may be propagated by dividing the roots and from seed.

A. coerulea-A most beautiful variety from the Rocky Mountains, which is entitled to be universally cultivated. In England I see it is declared to be "not only the Queen of Columbines, but even the most beautiful of all hardy herbaceous plants." The color is a delicate blue, with distinct white centre, and the remarkably long spurs give the flowers a most singular and beautiful appearance.

ARDISIA (Greenhouse Perennial. 33, 50, 80).

Greenhouse evergreen shrubs, with panicles of small white flowers. They enjoy light, fibrous loam, peat and sand, with good drainage; propagated from seeds.

A. crenata-Clusters of brilliant scarlet berries during winter. This is a charming house plant and should be more generally cultivated; the berries remain for a long time, giving the plant an elegant appearance; the plants usually fruit when one year old.

\section{ARISTOLOCHIA SIPHO-Dutchman's PIPE (Hardy Climber).}

This vine is suitable for covering walls or trellises. Under favorable circumstances it will grow twenty feet in a season; the foliage is large, of a deep rich green; the flowers are of a brownish color and resemble in shape a pipe; propagated by seed.

\section{ARMERIA (Hardy Perennial).}

This is the well-known "Sea Pink;" it is perfectly hardy; does well in all situations; flowers bright pink; very useful for bouquets; blooms through the spring, summer and fall; propagated by division.

\section{ASCLEPIAS (Hardy and Tender Perennial, 33, 45, 75 .)}

A genus of very attractice flowering plants. The following specie is used for bedding out during summer, and for pot culture in winter. Good loam and sand is sufficient; propagated by cuttings.

A. Curassavica-A species with scarlet flowers. 
ASPIDISTRA (Greenhouse Perennial, 33, 50, 80).

Liliaceous plants from China and Japan, with oblong lanceoate leaves, easily grown in an ordinary greenhouse, in good turfy loam: propagated by dividing the suckers. They are useful house plants; for the production of well-marked plants of the variegated species the pots in which they are grown should be small.

A. lurida variegata-Leaves with broad white stripes.

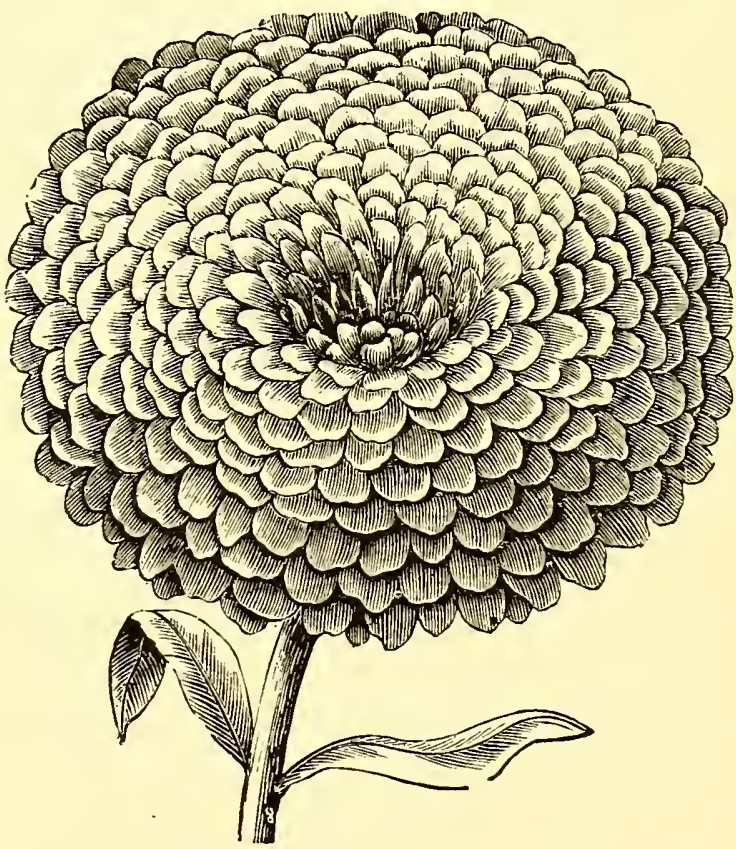

Aster.

ASTER (Hardy Annnal).

The Aster is one of the grandest of seed-grown plants. There are tall growing varieties two to three feet in height, and from these different sections are graded in height all the way down to the very dwarf ones, not more than eight inches high, and which spread out so as to present the appearance of bouquets of flowers set in the ground. The flowers are of the most attractive, as well as delicate colors, including the purest white, and also pre- 
sent quite a variety of forms, many of which are very large and double to the centre. The seed may be started early in the hotbed, cold-frame or seed-bed, as no plants transplant more readily, or it may be sown in the open ground directly where they are to flower. Set the large varieties about ten inches apart, and the dwarfer ones from that down to six. The tall varieties should be supported by stakes in the summer to prevent the rain from bending or breaking them down.

A. bouquet, newest dwarf-A very fine acquisition; each plant looks iike a bouquet of flowers; eight inches.

A. bouquet, duarf pyramidal-Ten inches high; an early and abundant bloomer.

A. chrysanthemum-flowered, dwarf, double-A splendid variety of dwarf compact habit, nine inches in height, producing flowers three to four inches across.

A. cocardeau, or new crown-A fine flower; very double, the central petals being pure white, sometimes small and quilled; sports occasionally; eighteen inches.

A. German, pyradmidal-flowered-Late, branching; good habit; needs no tying.

A. German, quilled-Desirable on account of the quilled appearance of the flowers; about three feet high.

A. hedge hog, or needle-Petals long, quilled and sharply pointed; very curious and fine; two feet.

A. la supsrbo-Large flowering class, often more than four inches in diameter, twenty inches in height.

A. pcony-flowered perfection, Truffaut's Newest-One of the best; very large, beautiful flowers; petals long and a little reflexed: two feet.

A. pearl-This is entitled to be called a gem among Asters; is of dwarf, compact, bushy habit, not above fifteen inches in height, closely set with beautiful imbricated, double, globular flowers of good colors.

A. rose, improved-A valuable class of Aster, producing very double and large flowers. The blood-red color of this variety is the darkest and most brilliant of all Asters; two feet.

A. Victuria-Flowers very double, imbricated, globular and large; the plant is very robust, about two feet high and branching. 
A. Victoria, dwarf-Only one foot high, but very rich flowering, with Howers three to four inches across.

A. Emperor, giant-Very brilliant and beautiful colors; flowers double and of immense size, often four inches in diameter; two feet.

\section{ASTILBE JAPONICA-SPIREA JAPONICA (Hardy Herbaceous Perennial).}

One of the most beautiful of hardy plants. It blooms in early summer, producing upright spikes of white, delicately-formed, fragrant flowers; the foliage is of compound digitate form, and exceedingly attractive, being of a deep, uniform green color; height of plant two to four fcet. By potting the Astilbe at the approach of winter it may be taken into the dwelling or ccnservatory and forced into bloom from January and later, by which course it succeeds easiiy and becomes very attractive. Propagated by division of the roots.

AZALEA (Greenhouse Shrubby Perennial, 35, 50, r0).

Plants of high value for window and conservatory decoration, being covered with one blaze of beauty in the spring months, and continuing to increase in splendor and the profusion of flowers with each year's growth. In the summer they should be moved to the open air, plunging the pots to their rims in soil in some shady place, as against a fence or building, until September, when they should be taken for the winter, either into the conservatory direct, or cellar, or cold-pit, to bring in for flowering at any time between February and May. The most suitable time for re-potting the plants is after their flowering season; they delight in a light soil, containing a good deal of vegetable matter, such as peat or loam from the woods; propagated by cuttings.

\section{BALSAM-LADY'S SLIPPER (Tender Annual).}

Balsams are plants that are readily grown from seed, and which will repay for any time and trouble needed to raise them Their double blossoms of most brilliant colors, fine shape and beautiful texture, rank them among the finest of flowers. but unfortunately being short stemmed, their use in ordinary bouquets is precluded; they can, however, be employed in arranging plate bouquets or upon baskets of moss very well. The pure white 


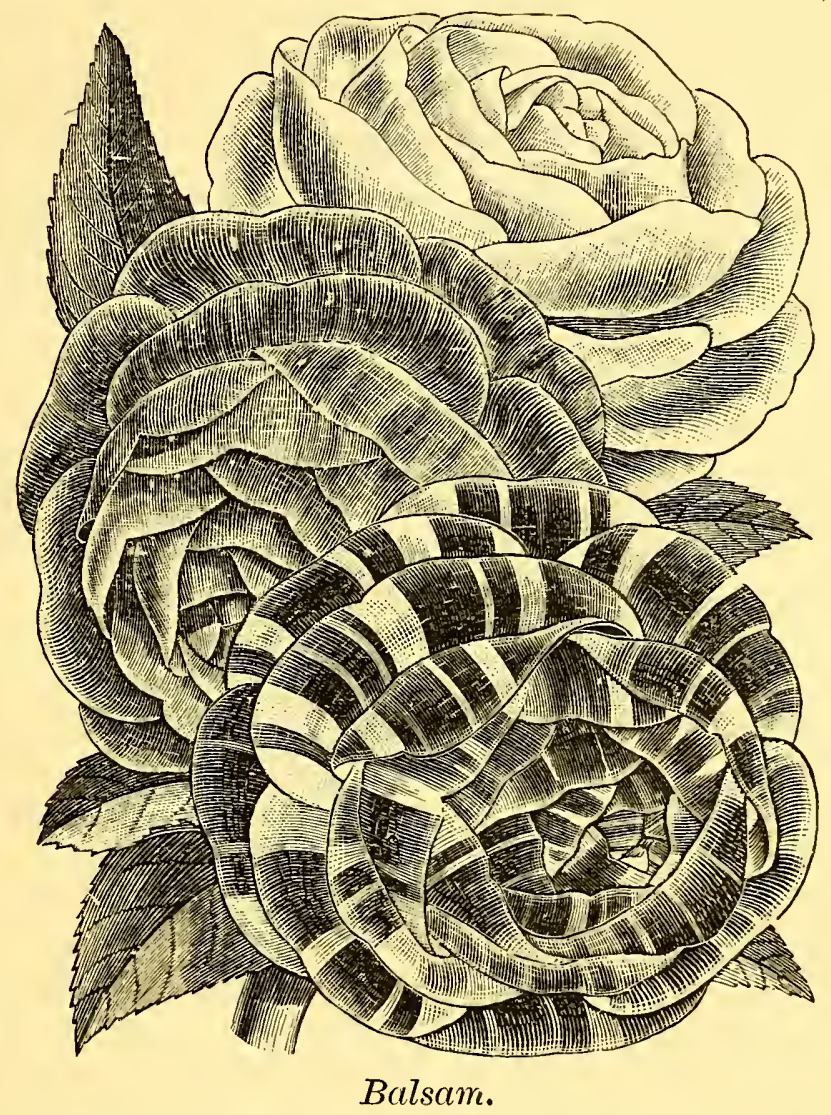

variety is largely grown by florists for making into wreaths and other designs suitable for funerals by first stemming them with wire on short bits of match stick and inserting these into forms of moss, so that the flowers touch. Frequently no other flowers are used for such work but the double white Balsam, and the effect produced is complete. For ordinary culture the seed may be sown in the hot-bed, cold-frame, or seed-bed, transplanting the plants finally to a distance of ten or twelve inches apart, after the second set of leaves have started. Few plants are susceptible of such great improvement by pinching as is the Balsam. The plants may be trained to one, three or five branches for flowering, and in either case will be more pleasing than if allowed to take their. natural course of growth; or some plants may be trained to each style, thus creating variety in this way. To train to one stalk, simply remore all side shoots as they appear; this will cause 
the central one to grow two or three feet in height, and be perfectly covered with bloom. For three or five shoots, pinch back the terminal and all side shoots but the desired number for flowering. The American climate is well adapted to the Balsam, and if it be grown in good rich soil, flowers of great excellence can be produced, although it seems established that some flowers will come only partially donble from the best strains of seed. The plant is well suited to pot culture in summer, by having the soil of good loamy quality, well enriched, and giving it a sunny position and plenty of water. Nothing smaller than a six-inch pot will answer well for this purpose.

B. camellia-flowered, spotted German-Very double and choice, spotted witli white.

B. camellia-flowered-Pure white.

B. camellia-flowered, double dwarf-Very fine; eight or ten inches in height.

B. carnation-Fine double flowers, resembling a Carnation.

B. Victoria-Satiny white, spotted with scarlet; exceedingly pretty.

B. rose-flowered-Perfectly double.

B. extra double dwarf-Very double; eight inches.

\section{BALM-Melissa (Hardy Herbaceous Perennial).}

Pretty hardy plants with highly fragrant leaves, doing well in the sun or shade. Propagated by cuttings, or by dividing the roots.

P. golden-Green leaves with bright yellow blotches.

$B$. silver-Green leaves, blotched with pure white.

BEGONIA (Greenhouse Perennial, 36. 55, 80).

An interesting family of plants in their two divisions of flowering and showy-leafed sorts. The more free-flowering varieties of the former are indispensable in every florist establishment, their handsome blossoms being valuable for bouquets. The plants of this section are also very suitable for pot culture in the window, or the out-of-door plant stand, and also for planting in hanging baskets and ferneries, but possess little value for bedding in the garden unless planted in a warm place well protected from winds. During the greater portion of the year the plants are in the different varieties covered with a profusion of graceful, drooping racemes of rose, pink, white and crimson buds and blos- 


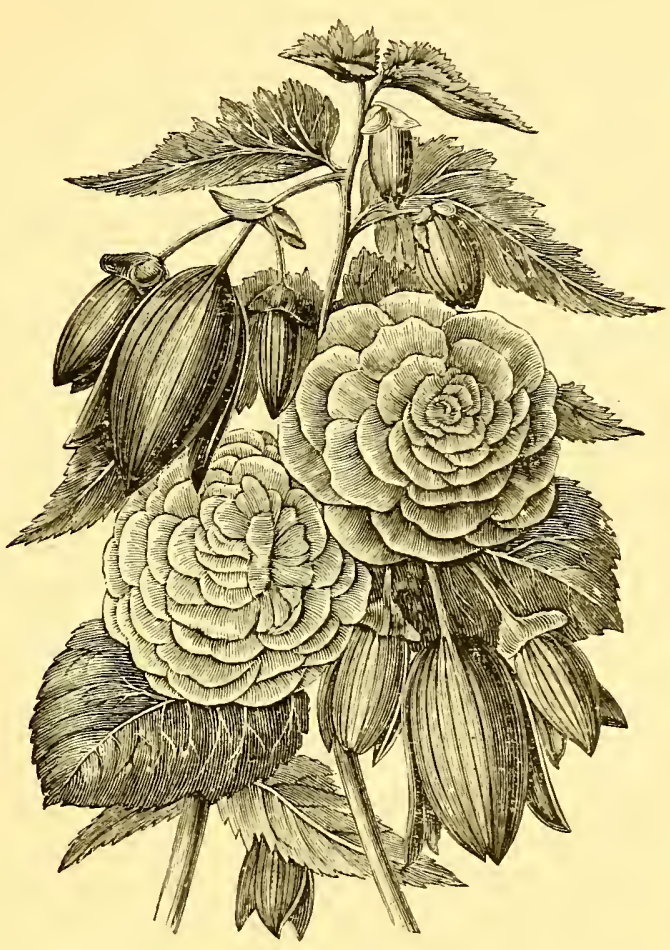

Tuberous-rooted Begonia Flowers.

soms that are exceedingly attractive, and having a waxy, corallike appearance, The plants themselves are of neat, compact habit. with glossy green leares in some varieties and exquisitely cut ones in others. Both sections of the Begonia family delight in warm, sandy, well-enriched soil; they are readily propagated by cuttings or seed.

B. glaucaphyllia scandens-An early flowering variety, producing clusters of rich, salmon-colored flowers from the axil of each leaf, the plant being of a lovely drooping labit; it is exceedingly fine for hanging baskets in a warm place.

B. hybridu multiflora-A remarkably neat and free-flowering variety, with small, ovate, glossy leaves, and many rose pink blossoms; excellent.

B. nitida alba-A free-growing, profuse-blooming variety, having pure white flowers during the winter months.

B. palmata-Attractive, palm-shaped leares. 
B. parviflora-Dwarf; a neat growing plant with white flowers; blooms most profusely in summer,at which time its flowers are very useful for bouquets.

B. Saundersonii (Coral Begonia)-One of the best flowering Begonias; the flowers are of a scarlet shade of crimson, borne in profusion for months at a time; leaves slightly edged with scarlet.

B. Weltoniensis-This valuable plant I consider deserving of more than ordinary notice; it is a rapid, healthy grower, very profuse bloomer, with beautiful foliage, and always presents an attractive appearance, summer and winter. The surface of the leares show various shades of dark and light green of remarkable richness, and presents a transparent depth of texture, without any gloss whatever, of the most exquisite beauty, being somewhat similar-except in colorto the bloom on the grape. The flowers and buds of a beautiful pink color, are produced in clusters by the hundred on an ordinary sized plant, with common culture. The leaf stalks and branches of the plant are dark crimson, and sufficiently striking to create a marked contrast with the brilliant green leares and the pink flowers. Unlike many plants that possess unusual merit in some respects and then have counter-balancing faults, this Begonia is unexcelled by any of the older varieties for freeness of growth and flowering qualities, and the plant naturally assumes a well-proportioned form.

B. metallica-A shrubby variety, good grower and free bloomer; leaves triangular, longer than wide; under side of leaves and stems hairy; the surface of a lustrous metallic or bronze color; veined darker; flowers pale peach, covered with glandular red hairs. It is perfectly distinct from any other. The best house Begonia we know, and a perfect companion to the following, with the additional advantage of having lovely foliage.

B. rubra-This is one of the finest acquisitions to our winterflowering plants; the leaves are of the darkest green, the color of the flowers scarlet rose, glossy and wax-like. This peculiarity is so marked, that when plants are placed singly in a room the glossy appearance of the leaves and flowers give the impression that they are artificial rather than natural. See cut, next page. 


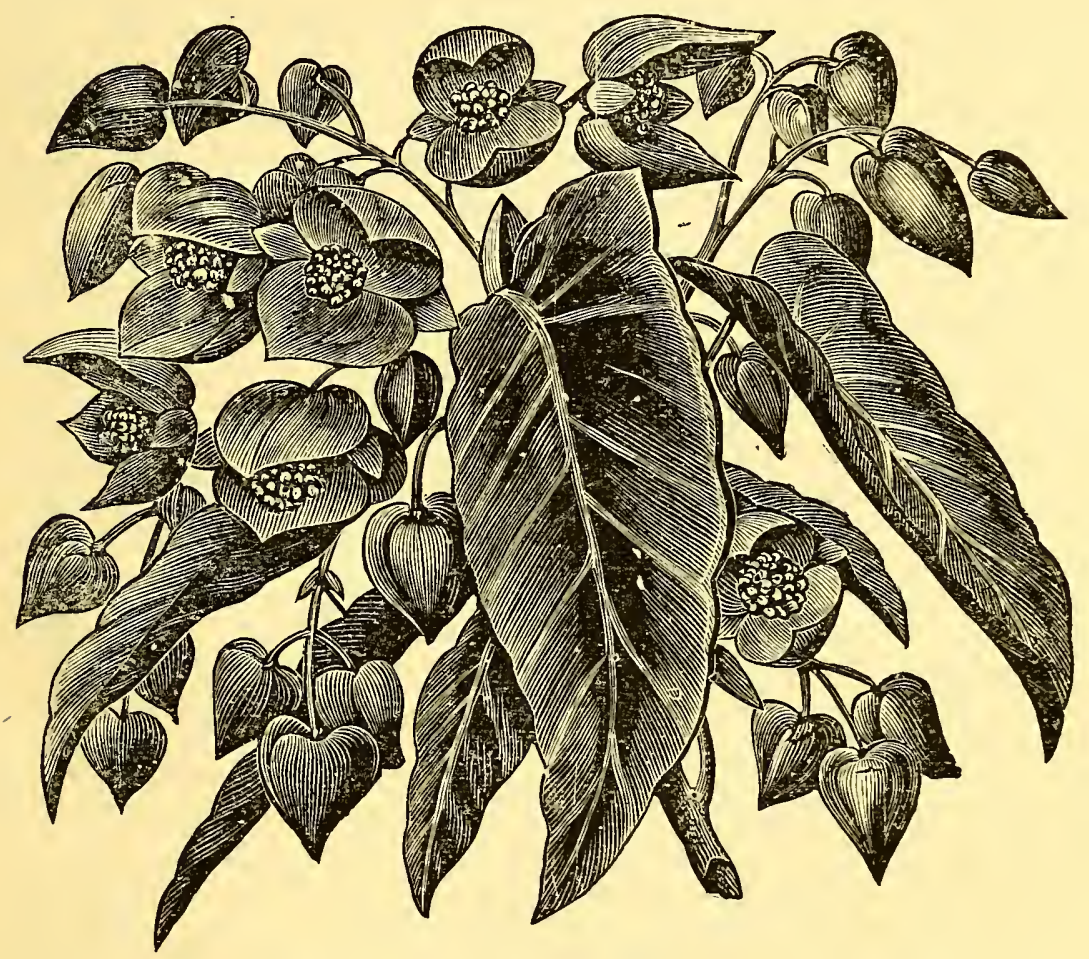

Begonie. Rubra.

B. Washingtonii-A vigorous grower, large leaves; elegant truss of pure white flowers.

$B$. Schmidtii-A new variety with dark metallic green foliage; a profuse bloomer, being covered with white flowers, tinged with pink.

B. ricinifolia-Large palmate leaves, showy flowers; a fine bedding variety.

B. Ricinifolia macalata-Like the above, but with the leaves beautifully mottled bronze.

B. sanguinea-Upper surface of leaves olive color, underside dark crimson, very fine; flowers nearly white.

B. subpeltata Nigricans-Long, pointed leaf, rich crimson bronze, very beautiful; flowers bright rose.

B. incarnata-Vigorous grower; flowers white, edged bright pink.

B. Degswellain $x$-Flowers dark crimson, center pink; rery free bloomer; a beautiful variety; will please everybody. 
B. semperflorens rosea-A most beautiful Begonia, in habit and form exactly like the old Semperflorens. The flowers appear in large clusters, and are white, heavily shaded, and bordered with dark carmine-rose. The contrast of these colors with the bright yellow of the stamens, produces a most charming effect; very free; this variety will become one of the most popular shrubby Begonias.

B. alba perfecta grandiflora-Has beautiful bright green foliage, with large clusters of pure white flowers; this is a choice variety.

B. McBethii-Foliage fern-like; panicles of pure white flowers, produced in the greatest profusion; it is the most persistent bloomer of the Begonias, and supersedes Richardsonii, which variety it resembles in foliage.

B. foliosa-A handsome basket plant; the foliage is small and delicate and contrasts well with its white bloom.

B. robusta-Bright carmine and salmon flowers.

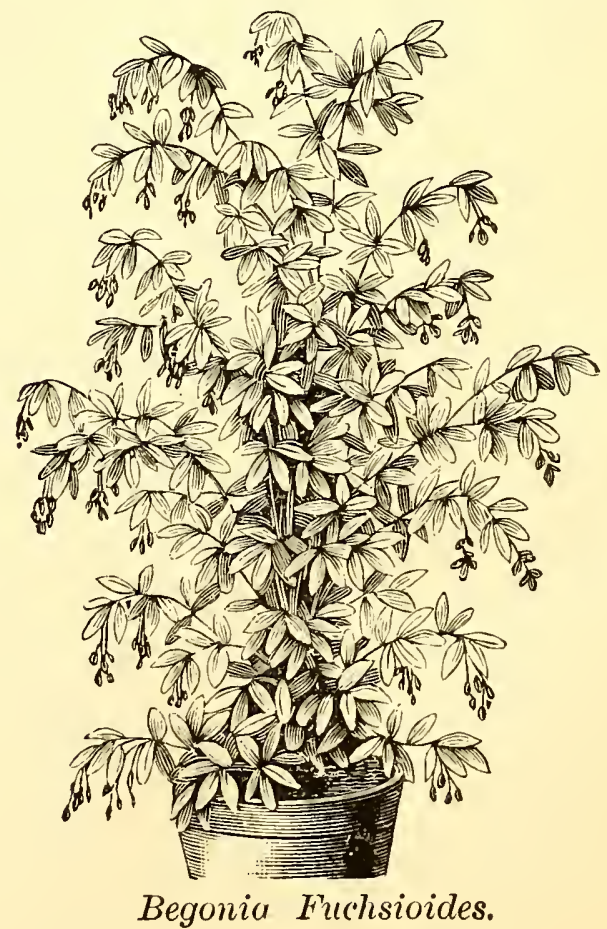


B. fuchsioides-Free-blooming variety; small scarlet fiowers. See cut.

B. Goury-New shrubby variety; flowers pure white.

$B$. Bruanti-Foliage bright green; flowers quite large, white, tinged with pink, completely covering the whole plant; shrubby, like the preceding variety.

Showy-Leaf BEGONaA-Of the show-leaf varieties, I will state that lovers of the beautiful in Nature's grotesque growths will find in this entire division much to admire. Their large and interesting leaves add an effect to collections of plants which can be equaled by nothing else grown. Imagine the larger part of the leaf to be a bright greenish silver hue, with the centre and outer edge a lively deep green in some places, or rather several shades of green, spotted lightly with silver. Then imagine the upper surface of the leaf-ribs to be studded with small crimson hairs, while the extreme edge is fringe-like, and of a crimson scarlet color, as is also the underside, with the veins distinctly prominent and showy, and some idea of the beauty of this entire section can be formed. All the varieties are suitable for pot culture and for hanging baskets in protected places. They delight in a warm, shady place, and should not be exposed to sweeping drafts of air. In habit and general appearance the first and lastnamed varieties in the following descriptions are quite similar to the flowering section of Begonias, being upright growers, with branches, while the others are prostrate in habit, although the leaves stand well up on long stems.

B. argyrostygma Veitchii-Is a handsome variety, the leaves of which are smooth, of medium size, light green and thickly covered with small, clear silver markings; underside of a crimson color, smooth; white flowers; easy to cultivate.

$B$. $E l$ Dorado-Has medium sized leaves, distinctly marked and of a peculiar velvety texture.

$B$. insignis-A free grower, leaves of medium size, with a metallic lustre.

B. luxuriance-Leaves nearly star-shaped, borne on stems a foot Iong; grotesque.

B. Mary Stuart-Large, showy leaves; an old favorite, perhaps the best in cultivation.

B. Mrs. Victor Lemoine-Light-colored leaf, with the edges and centre beautifully marked like lace, 
B. Queen of Begonias-A good grower.

B. Rex-A fine variety; excellent; described above.

$B$. Silver Queen-A variety in which the silvery color predominates.

B. zebrina-A beautiful upright grower of bold appearance,with thick leathery leaves from four to six inches long and. two wide in their widest parts; of a very dark green color, striped with silvery marks; underside and stems of dark crimson and red colors; a very handsome variety.

B. Louis Creticn-The handsomest of all foliage Begonias; ground color dark green, with silver band, tinted violet crimson, with metallic lustre.

\section{BEGONIA-TUBEROUS ROOTED (Tender Tubers).}

A comparatively new section of this beautiful tribe; flowers ranging through all the shades of crimson, scarlet, rose, orange, etc. They require the same treatment as the fancy-leaved Caladiums, Gloxinias, etc ; that is, the tubers are dried off in winter and started again in spring. Excellent for bedding purposes, as they bloom the entire summer season until frost; propagated by division of tubers. See cut, page 145.

\section{BIGNONIA RADICANS-TRUMPET CREEPER (Hardy Climber).}

A climber sufficiently hardy to withstand our severest weather; trains well over a wall; it is admirable to climb trees, reaching to the topmost branches, and is literally covered with its scarlet, trumpet-shaped flowers.

BONAPARTIA JUNCEA (Greenhouse Perennial, 40, 60, 90).

A very scarce genus of plants, with long, graceful, rush-like. leaves; very attractive when grown in a vase out-of-doors in the summer. Flowers borne on long spikcs. It requires a warm temperature in winter; propagated by seeds.

BOUGAINVILLEA SPECTABILIS (Greenhouse Perennial, 35, $\left.50,90^{\circ}\right)$.

This handsome plant is quite easily grown, thriving in almost any temperature that is higher than 40 degrees. It produces very freely large cone-shaped racemes of beautiful rose-colored flowers. Being of climbing habit, it probably has no equal for training to the rafters of conservatories or greenhouses. The Bougainvillea 
has proved to be a very valuable plant to force for the bloom during the winter; propagated by cuttings.

\section{BOUSSINGAULTIA (Tender Tuber).}

A native of the Andes. An elegant climbing vine, with roundish fleshy leaves, long chusters of fragrant whitish flowers and tuberous roots. Will grow in any good garden soil; propagated by division of tubers.

B. Basselloides, (Madeira Vine)-Excellent for trellises, etc.

BOUVARDIA (Greenhouse Perennial, 40, 60, 90).

A highly useful class of shrubby plants for the greenhouse and the window, if these are warm and sunny, and also succeed with bedding out, strong plants blooming all summer in the beds; plants that are properly prepared in pots will also bloom continually during the winter in the conservatory or other suitable place. Thousands of feet of glass are each year devoted to its culture for bouquet flowers in the vicinity of our large cities. The flowers have an exceedingly beautiful, waxy appearance, and are of bright and desirable colors, from the purest white to scarlet. A mellow, open soil is best suited to the Bouvardia. As it requires a high temperature for its growth, the plants should not be bedded out in the latitude of Buffalo before the latter part of May. For winter flowering they should be started the spring previous and grown in about five-inch pots until September, when they may be shifted into a larger size for flowering (observe directions for summer and fall treatment on page 31). Towards spring the flowering and other shoots should be severely pruned back to induce a stocky new growth for summer flowering.

With the exception of one variety, Bouvardias are readily propagated by cuttings; the old way of increasing them by root cuttings is being superseded by this method; the one requisite to success in their propagation is to take the cuttings from plants grown in the open air; cuttings taken in this manner and placed in a frame with very little buttom heat (care being taken as to air and water) will root as easily as Verbenas; the one exception to this method is $B$. Leiantha, which refuses to propagate excent from the root.

B. Davidsonii-Pure white flowers, slightly tinted with a delicate blush; large clusters. 


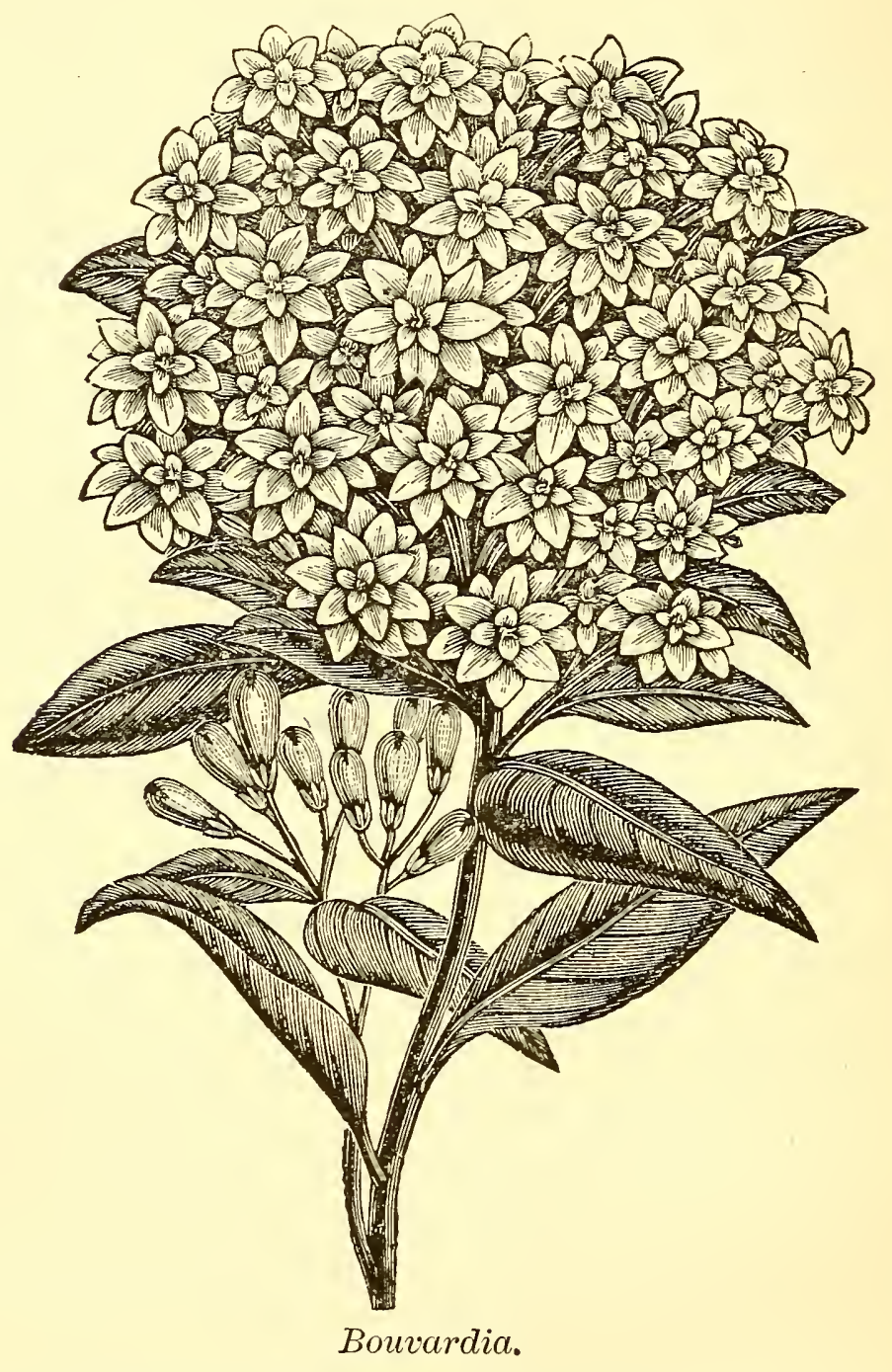

B. elegans-Light scarlet-carmine; immense truss and flower; very brilliant in color and an exceedingly free bloomer; one of the best.

B. Leiantha-Dark, dazzling scarlet; flowers completely covering the plant.

B. President Garfield-Double pink. The flowers of this new variety are the same in size and formation as the double white, while the color is of a bright pink, 
B. Alfred Neuner-Large, double white flowers, composed of three perfect rows of petals of the purest waxy white color, each flower resembling a miniature tuberose. The trusses are large and perfect, freely and without interruption produced even on the small side shoots, which generally produce no flowers in the single varieties; strong, healthy, vigorous grower.

B. Thonıas Mechan - The new double scarlet; this novelty unites the brilliant red color and profuse blooming quality of $B$. Leiantha, with the perfect double flower of $B$. Alfred Neuner, a variety of decided merit.

B. Humboldtii-Flowers of purest white, nearly one-inch in diameter, borne on long foot stalks in loose panicles, blooming from Octoher to June; rich Jass r mine fragrance.

B. flavescens-The uncommon and beautiful shade of color of this variety will commend it to all; color light canary yellow; trusses of good size and moderately compact.

$B$.' rosea multiflora-This splendid novelty is one of the finest single varieties. The trusses are very large and compact, and are produced in the greatest profusion; color bright deep rose. This is a true winter flowering variety of the same class as elegans and Davidsonii.

\section{BROWALIA (Half-Hardy Annual).}

A class of flowers nsually grown in the garden, but also quite suitable for pot culture. There are a number of rarieties, the colors of which are blue and white. The flowers are not large, but are pretty and distinct, and are freely produced for a long time on a stalk about a foot high. The seed may be sown in the open ground where they are to flower, or in a protected bed, from which they should be transplanted to a distance of twelre inches apart. $\Lambda$ lso increased from cuttings.

BRUGMANSIA (Greenhouse Perennial, 33, 45, 85).

Peruvian shrubs will thrive well either planted in open ground or in the conservatory; they will aiso grow well in large pots; when planted out they should be taken up before frost.

B. suaveolens-A magnificent plant, growing four to six feet high; leaves large and relvety; the flowers are huce. trumpetshaped, double and highly fragrant, and are often twelve 
inches long and four to six inches across the mouth; in color, white, with a pale tinge of lemon; blooms profusely all summer; propagated by cuttings, either of the shoots or roots.

BRYOPHYLLUM (Greenhouse Perennial, 33, 45, 80).

This curious plant will grow under the most unfavorable circumstances. By placing a leaf in a damp place it will take root and numerous young plants start up.

B. calycinum - Very easily grown, producing loose panicles of greenish purple flowers.

BUTTRRCUP. (See Ranunculus).

\section{CACALIA-Flora's Paint Brush (Half Hardy Amual).}

Plants grown with the greatest ease from seed, which may be sown in the open ground in May, or earlier in the hot-bed, or other protected situation, and afterwards transplanting them to the garden. The flowers range from scarlet to yellow in color, are bright and pretty, and somewhat resemble a miniature brush; in size they are small and produced in clusters on long stems, on which account they are useful for bouquets, although not strikingly brilliant. The plants attain a height of from eighteen inches to two feet, and are in bloom throughout the summer months. Also do well if sown in the fall.

\section{CACTUS (Greenhouse Perennial, 35, 50, 95 $)$.}

A well-known family of succulent, or fleshy plants, all of which are natives of the warmer regions of America. They are desirable as pot plants, on account of the remarkably interesting forms of growth which the various species assume, their almost unexceptionally beautiful flowers which are freely produced in ordinary culture, and then the ease with which they are cultivated, either in the window or conservatory. To grow the Cactus well, all that is necessary is to imitate the simple natural conditions that exist where they grow wild. They are found in their greatest perfection in sections which are subject to severe drouths of long duration, alternate with long wet spells, and accordingly under culture, a course of treatment that provides for a free application of water for three or four months and then the same largely withheld during the rest of the year suits them 
exactly. They may be kept dryest during the winter, but they should not be stood in a place where it is cold. Repotting them frequently is not wanted, and it should be done not oftener than once a year. April is the best time for performing this operation, after which their wet season may begin. They delight in a sandy soil not too rich. The bottom of every pot should be covered with an inch of broken pots or rough gravel for drainage; propagated by cuttings.

C. Ephiphyllum truncatum, or Lobster Cactus-This species when grafted on the pereskia will form a beautiful head, and makes a very desirable plant for the sitting.room and may be in bloom from November to March. Being in flower in the winter it requires a little more water at this season than other kinds do.

\section{CALADIUM ESCULENTUM (Greenhouse bulb, 35, 55, 85).}

A beautiful decorative plant of imposing appearance that will accommodate itself to various courses of treatment. As a pot plant, grown in a place sheltered from winds in the summer, it grows to the height of four feet, and with its immense leaves, lends a tropical appearance to collections, which is exceedingly effective. For garden culture the treatment suited to the Dahlia with free manuring and watering never neglected, meets the wants of this plant precisely. It delights in a warm, sandy soil, and may be left out until frosts cut down the foliage before taking up for the winter. As a single specimen pot plant or for the centre of vases, it is almost without a superior, provided it receives a rich soil and much water. If it is kept too dry the growth will be comparatively feeble and it will be subject to attacks of red spider; increased by division of bulbs.

Caladium, Fancy Leaved-(Tender Bulbs)-Plants with splendid foliage and of easy culture. Keep the bulbous roots quite dry during winter, and when growth starts, give heat and moisture. Use turfy loam, peat, manure and sand, with plenty of drainage; increased by division of bulbs.

\section{CALANDRINIA (Half-Hardy Anmual).}

Free-growing plants, producing rose, white and other colored flowers freely during the summer, that are desirable in the garden considering the slight expense and trouble necessary to rear 
them, although they cannot be classed among very fine flowers. They remain in flower until after frosts, and are frequently quite pretty thus late in the season. Sow in May, where they are to flower, or earlier in heat or in a protected bed and transplant.

CALCEOLARIA-CARPET Bag oR Moccasin Flower (Greenhouse Perennials, $32,45,75^{\circ}$ ).

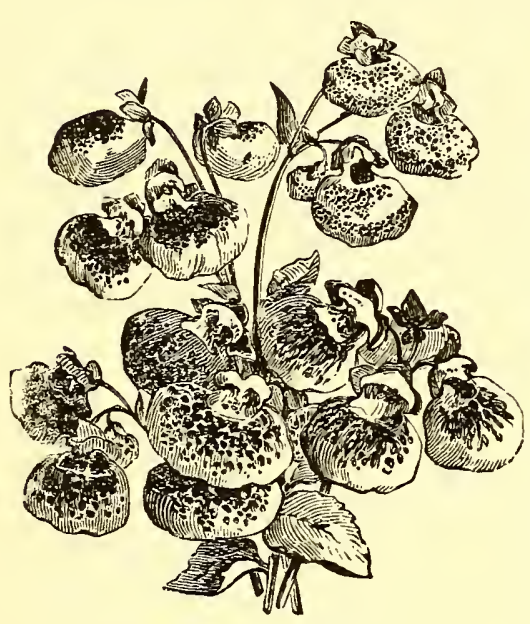

Calceolaria.

Shrubby Calceolarias.

These are free-blooming plants of good habits, which produce exceedingly attractive, irregular flowers, the lower lip of each being a large inflated sac which, by its appearance, not inappropriately entitles $i$ to the common name of Carpet Bag or Moccasin Flower. The plants are of erect, shrubby habit; growing to a height of from six inches to two feet. They are valuable as pot plants in the window or conservatory, or for bedding out in positions that are shaded the hottest part of each day, as the intense heat of the sun is not farorable to growth and bloom. In the autumn they are the last to sustain injury from freezing, and can then be taken up and wintered in a well-protected cold pit or cellar with ease. Also suitable for the conservatory or window in winter. Propagate from cuttings of the young growth. There are numerous varieties, but the following combine the greatest number of good points, all of which have pure, rich colors. and are of good form and size :

C. aurea floribunda-Has rich, sulphur yellow flowers.

C. fulgens-Crimson maroon.

C. Golden Prince-An excellent bright yellow.

C. Mrs. Woodruff-Deep crimson; large and brilliant; a tall grower.

C. Queen of Oude-Large, crimson maroon, mottled in the most pleasing manner.

C. Shower of Gold-This variety blooms in profusion, is a dwarf grower, and stands the hot sun well; color bright clear yellow. 
Herbaceous Calceolarias-These are a distinct section, being always reared from seed sown in the greenhouse in the summer months, the plants flowering the following spring. Although the hybrid varieties are among the most showy plants in cultivation for decorating the conservatory, their culture would hardly be likely to result successfully in the window, except by the most pains-taking care. The seeds are very fine and require careful treatment in sowing to begin with. As soon as the young seedlings can be handled they should be potted into small pots and given a place near the glass. Always shift them into larger pots before the roots mat around the ball of earth, as their growth is liable to be checked if they become pot bound, and by these means the green fly, its greatest pest, be invited. The plants require a rich sandy soil.

\section{CALENDULA-CaPe MaRigold (Hardy Annual).}

Desirable free-growing annuals which flower almost continually throughout the summer and until after frosts. As they havelong, stiff stems, and the colors are attractive, they are much in demand in the cities, for ladies' wear in corsage bouquets, and other floral arrangements; easily grown from seed.

C. la Prousti is a doukle variety, of nankeen color, edged with brown.

C. pluvialis-Single, white, of a remarkably pure color.

\section{CALLA-Ethiopian Lily (Greenhouse Perennial, 33, 45, 80).}

Few plants that are suitable for cultivating in pots in the window are equal to the much-esteemed and easily-managed Calla. The same is quite true of its value as a conservatory plant, excepting that it meets some rivals here which do not prove so formidable in the window garden, because few can be grown in the window to the same degree of perfection. The flowers, or rather floral bracts, are large, pure white, and with the spadix in the centre, possess a delicate fragrance and beauty, which render them typical of all that is pure and elegant. They are produced singly on long stems, and remain beautiful for several weeks. The plants bloom most freely in the early spring, and are grown largely by florists for adorning churches at Easter, being, when in flower, exceedingly appropriate for this purpose. The best course of treatment for the Calla is, after flowering, to give them a state of rest until August, by keeping the entire ball of soil 


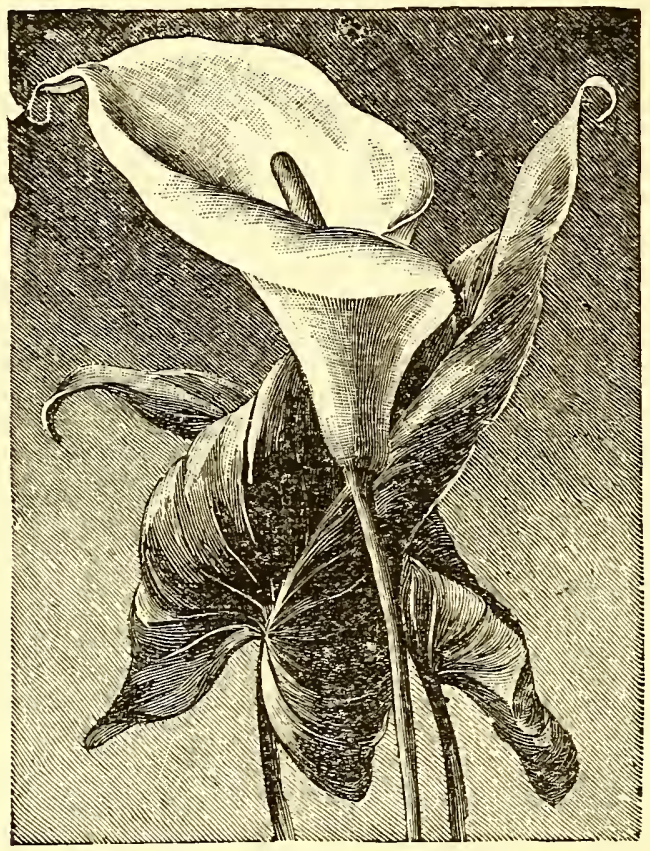

Calla.

nearly dust-dry. After this the earth should be soaked and washed from the roots, repotting into fresh, rich soil. The small offsets that will be found about the base should also be removed. Potted anew, give an abundance of water daily, until and through their flowering season, up to their next annual rest. It is almost impossible to overdo the watering, to the injury of the plant, for its nature admits of its growing in water, and it will grow well in aquariums. The small offsets from the root may be potted for new stock. There are two common varieties, the tall and the dwarf (Calla Ethiopica Nana), both of which have white flowers. The tall kind grows to the height of from two to four feet, and the dwarf from twelve to twenty inches, with a proportionate difference in the size of the flowers; increased by dividing the bulbs.

\section{CALLIOPSIS, OP COREOPSIS (Hardy Annual).}

Annuals that produce an abundance of convenient longstemmed flowers throughout the season, of remarkably rich, bright colors, such as yellow and crimson, yellow at d brown, velvety crimson, blood-red, yellow with crimson spots, etc. There 
are dwarf and tall varieties. the former growing from one to two feet, the latter, two feet and upwards in height. Of easy culture in any garden soil.

\section{CALYCANTHUS FLORIDUS-Sweet-SCented Shrub (Hardy Shrub).}

A native of the Southern States; remarkable for the scent of the flowers (resembling that of ripe fruit), as well as for their peculiar brown color; propagated from seed or offsets.

CA.MELLIA (Greenhouse Perennial, 32, 50, $75^{\circ}$ ).

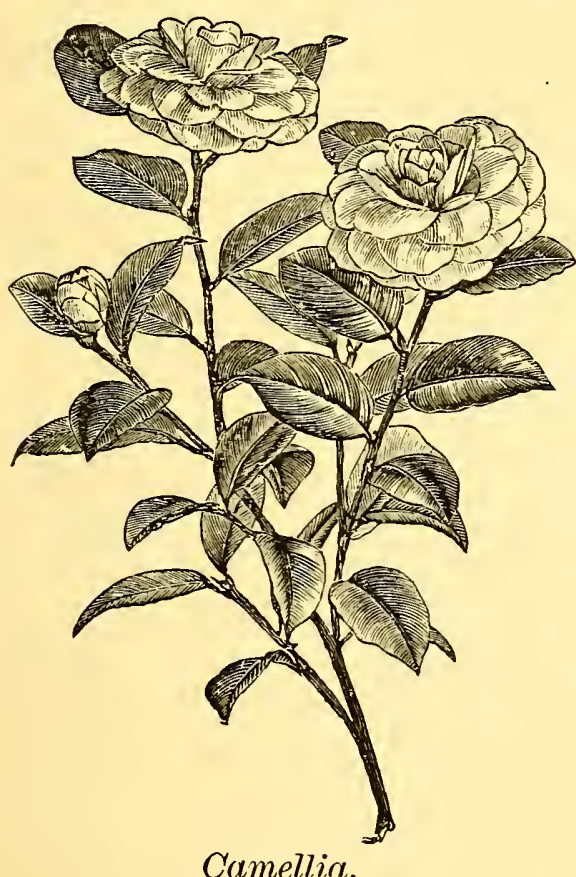

Camellia.

In the conservatory the Camellia has long been one of the most famous of winter flowers, and to the commercial florist of great value for making bouquets, baskets of flowers, etc. It is well enough adapted to cultivation in the window, as regards the suitability of the situation, for the plant naturally grows in shady places in the woods, but to be successful in having it flower well, the plant requires strict attention to its peculiar wants in other respects. The plant produces its large flowers only during the winter, commencing with the early fall months and lingering somewhat into the spring. They are from three to six inches in diameter, very perfect in form, with petals that are thick and of the most extraordinary satiny texture. The principal colors are pure white-the favorite color-bright rose, cherry, scarlet rose, bright red, variegated, salmon rose and others. After flowering, the Camellia makes its growth, preceding which it should be repotted, if at all. The plants require shifting but once in two years, except with very thrifty young ones, which may receive it each spring. Any soil is suited to its growth, provided it is well 
enriched with one-third part of leaf mould and thoroughly rotten manxre. With its growth in the spring, we meet with the peculiarity of this plant, in forming its flower buds, more than half a year previous to their opening, and it is during the long time between the formation of the buds and their opening, that the treatment the plant receives, decides whether the buds-usually formed in abundance, will develop into flowers or drop before opening, an occurrence often met by inexperienced cultivators. Were the treatment it requires during this time difficult, there might be an excuse for this unfortunate termination of the flower buds, but this is by no means the case. The plant simply requires a light, shady place in the summer, such as may be found in a shaded greenhouse that is well ventilated (see "Summer Management of the Amateur's Conservatory"), or in the shade of a building or verandah, and be given an abundance of water, also paying attention to cleanliness of the thick leathery foliage. Its habit is deceitful in the respect, that the leaves will look green and bright, although the soil is quite too dry for its general good, and especially for the flower buds. The soil must, however, not be kept in a soaked condition, as this would prove as great an injury as the other. Water should be applied only when the surface becomes dry, and then a sufficient quantity should be poured on to entirely soak the ball of earth, letting this suffice until the plant requires and is given another thorough watering, which may be the next day or later still. During its flowering season water must not be spared, and in the dwelling the atmosphere should be kept as moist where the plants are as well can be done. Frequent syringing or sponging the foliage is also needed the year through. In the conservatory, that portion where the Camellias are kept, must have the glass shaded from the sun as soon in the spring as the plants start into growth, or the leaves will receive sun scald. Keep a lookout for Red Spider on the leaves; these insects, although not particularly troublesome to this plant, sometimes make inroads upon them before one is aware of their presence; propagated by cuttings or by grafting, or inarching.

\section{CAMPANULA (ilardy Annuals, Biennials and Perennials).}

The annual Campanulas are neat, free-flowering plants of smail size and useful for massing. The colors are not very striking aud yet not bad, ranging from white to rosy purple and blue; should 
be sown where they are to bloom. The hardy section includes the well-known biennial Canterbury Bells (Campanula Medium), which is readily grown from seed, and many fine perennial sorts.

CAMPSIDIUM (Greenhouse Perennial, 35, 55, 90).

A small genus of vines; they have deeply divided compound leaves and are exceedingly ornamental. Grow in light turfy soil, peat and a little sand, propagated by cuttings.

C. filicifolium-Delicate small leaves, resembling fern fronds; the flowers are small, of a rich orange color. An elegant vine for conservatories.

CAMPYLOBOTRYS (Greenhouse Perennial, 40, 60, 95%).

These are beautiful greenhouse shrubs, remarkable for their glossy foliage, propagated by cuttings.

C. regalis-The foliage is a rich bronzy green color, with satiny lustre. A plant of rare beauty.

CANDYTUFT (Hardy Annuals, Principally).

The annual Candytuft is one of the most useful plants for summer flowers that can be grown. It is raised from seed with the greatest ease, and in a remarkably short time after sowing, the plant will become covered with flowers, if the weather is suitable. The same plants will not flower freely during the entire summer, and therefore it is better to sow several times for succession, if flowers are constantly wanted. They will bloom until after frosts. The flowers are pure white, several shades of crimson, and lilac, and very suitable for bouquet-making. The seed for the earliest flowers may be sown very early in the springbetter yet in the fall. Thin out the plants to be four inches apart. The Hardy Candytuft (Iberis Sempervirens) in several sorts, is a hardy plant of spreading habit, producing an abundance of pure white flowers early in the spring. As it does not die to the ground in winter, the plants should be somewhat protected to keep the foliage green; may be propagated by layers.

CANARY BIRD FLOWER. (See Tropæolum).

CANNA (Tender Bulbous Perennial).

This is a genus of ornamental plants that are well adapted to the American climate. They grow with the greatest vigor, either 
as pot plants or bedded in the garden, and produce a stately tropical effect, with their broad massive foliage and beautiful flowers, with little care. There is only one thing to be particular about in managing them, and that is to provide a rich soil and plenty of water and then they will produce astonishing results. The Canna is freely propagated by division of the roots at planting time. During winter, the roots should be kept in dry sand in a dry cellar, or under the bench in the conservatory. Some of the best sorts come well from seed, but the rcally valuable varieties are shy seeders.

C. bicolor-Is a beautiful free-growing variety, with a blending of various shades of green in the foliage.

C. giganteus aurantica-Foliage yellowish-green, of fine appearance and free-growing habit.

C. Indica-Flowers scarlet, foliage green, free grower.

C. tricolor-Is a compact grower three feet high, with beautifully marked leaves. The stem, with the young terminal growth, and also leaf margins, are tinted with red, making an elegant contrast to the general effect of the foliage, which is streaked and mottled with creamy white.

C. warzewiczi-Foliage striped with dark maroon, crimson and green. I have measured clumps of this variety, grown from a single plant set out in spring, that were by September over four feet high, with leaves extending two feet from the eenter each way.

\section{CARNATION-MONTHLY OR TREE (Greenhouse Perennial, $\left.27,50,85^{\circ}\right)$.}

The Monthly Carnation I take pleasure in recommending to all cultivators of flowers, because but few plants possessing its hardiness and ease of culture have so many good qualities. It is a rival of the Rose, the Japan Lily and other plants of equally high order. The flowers are deliciously fragrant, and possess, in the different varieties, colors unsurpassed in richness and beauty. Good plants, if set out in spring, bloom abundantly all summer in the flower garden, and any that are properly prepared. flower just as freely all during winter in the window or conservatory. For this latter named purpose they should be grown in the garden until the middle of September, remoring all flower buds as they appear up until August. (See Preparatory Treatment of Plants designed for Winter Flowering, page 44.) Some varieties are 


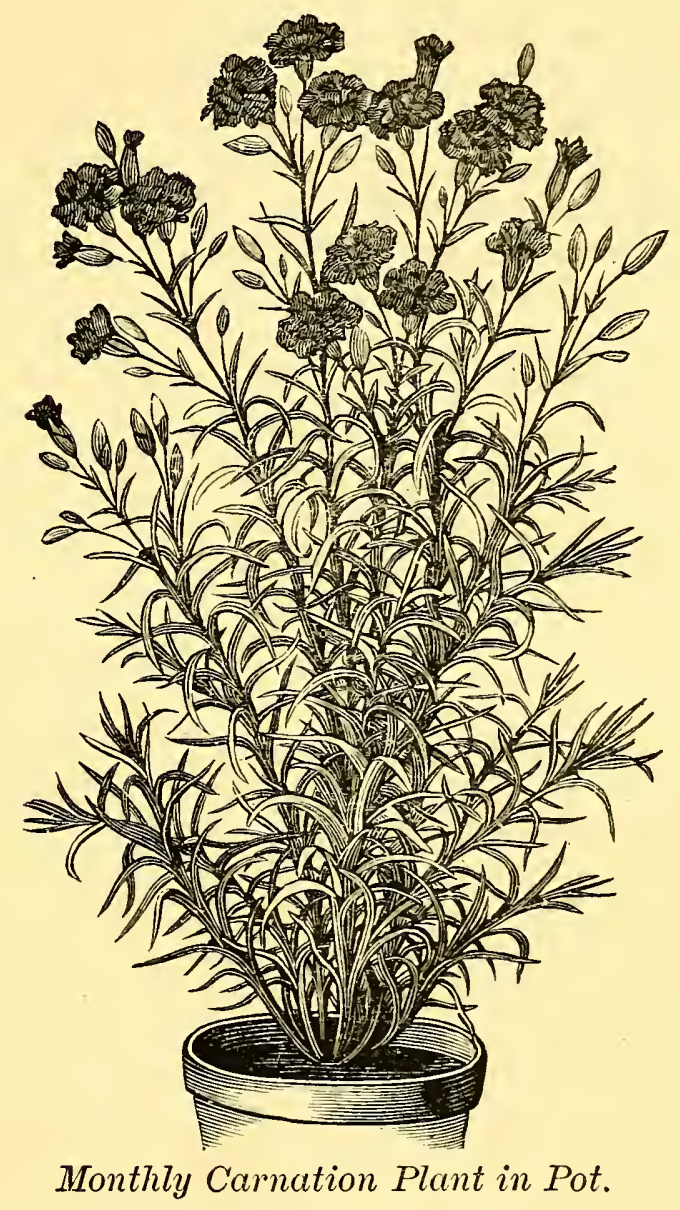

better adapted for winter flowering than others. President Degraw, Hinzies White, La Purite, President Garfield and Snowdon generally are preferred for this purpose. In the open ground plant not nearer than one foot apart; they may be propagated from layers of the branches or from cuttings.

C. Astoria-Yellow, striped with carmine and white.

C. Brussels-One of the very best. Deep cherry-red occasionally striped.

C. Chas. Sumner-Beautiful rosy-pink.

C. Chester Pride-White, penciled with rosy-carmine.

C. Crimson King-Very double, crimson-scarlet.

C. Eduardsii-White, tinted with pale rose.

C. Faragut-Yellow, heavily laced with deep maroon. 


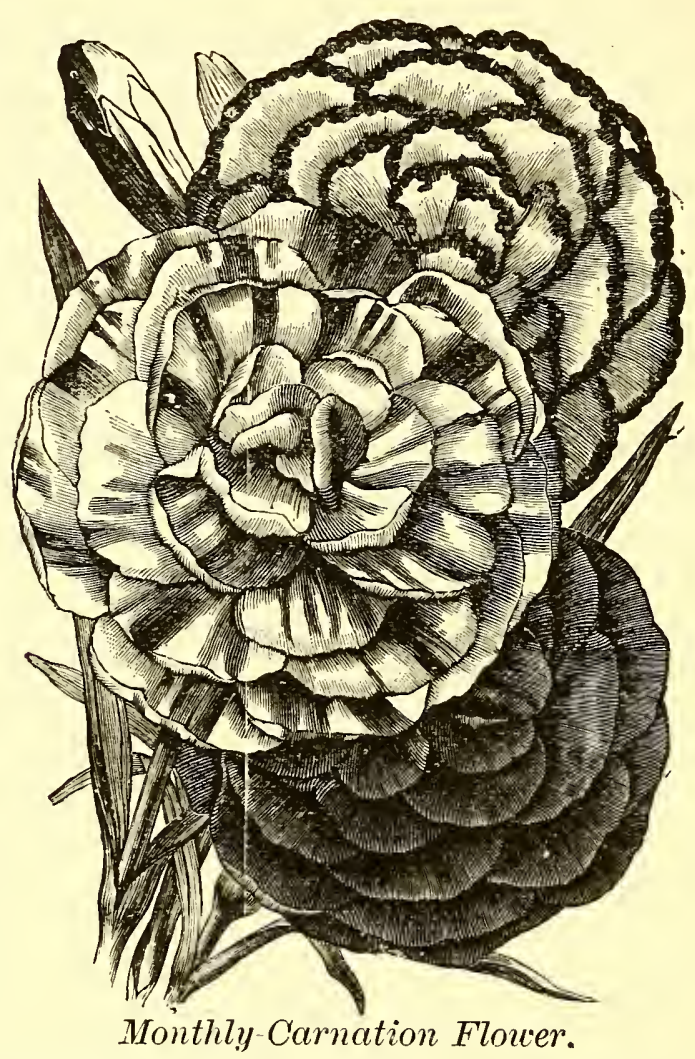

C. George Washington - White, striped and dotted with cherry.

C. Grace Wilder-Color, a beautiful, delicate pink, same shade as

H. P. Rose Baroness Rothschild; flowers large, finely fringed, clove-scented; dwarf habit and very prolific.

C. Hinzies White-Pure white, large, fine flower, supported on

stems of good length, making it desirable for cut flowers.

C. la Purete-Low growing, deep carmine, free bloomer.

C. la Purete variegata-Beautiful variegated, white and scarlet.

C. Lord Clyde-White, thickly striped with carmine.

C. Louis Lenoir-Very dark maroon.

C. Lydia-Yellow, margined with bright deep cherry.

C. Miss Joliffe-Delicate, rosy-blush, blooms freely. Fine.

C. Mrs. McKenzie-Light rose, fringed edges. A splendid large flower, very double, and of excellent form.

C. Peter Henderson-Pure white, very large and double. This is one of the most popular fiowers for florists' work. Blooms very freely. 
C. President DeGraw-One of the finest, pure white, fringed and double.

C. President Garfield-A strong, healthy grower; habit of growth quite dwarf and compact; the flowers are of large size, perfect form, highly fragrant; of rich vermilion color.

C. Snowdon-Pure white, great bloomer.

C. Vesuvius-Rich fiery scarlet, exceedingly double. Large size, a free bloomer, and one of the most valuable varieties.

CARPET BAG OR MOCCASIN FLOWER. (See Calceolaria.) CELOSIA-CocKSCOMB (Half-Hardy Annual).

A class of plants desirable in every collection on account of the singular and attractive appearance of the flowers. They possess numerous good colors, scarlet or crimson being the most striking, the flowers with these colors being exceedingly rich and showy. The plants are grown from seed which should be started in heat, and transplanted to the garden after frosts are over, as they are easily killed by freezing. In the hot-bed or window give plenty of air to the young seedlings lest they dampen off or rot to the groun 4 . The plants, especially of the dwarf varieties, are well suited to pot culture in the summer, thriving here almost equal to those planted out, if the soil is rich and sandy. Some of the new varieties of late years are attracting considerable attention.

CENTAUREA (Greenhouse Perennial, 30, 45, 80).

An interesting and beautiful genus of white-foliaged plants that rank higher perhaps among the various kinds possessing similar attractions than any others, and this too whether grown in pots, baskets or vases, or if bedded out. For the last named purpose they are especially desirable when used for planting at the edge of beds containing Cannas, Caladiums, Ricinus and other tall growers, or for contrasting with Coleus, Achyranthes, etc., in ribbon lines and masses. They are easily grown from seed, comparatively hardy, and few plants in our collection are more satisfactory to the cultivator.

C. candida-Is a lovely plant of neat, compact, bushy growth, with exceedingly pretty silver-colored foliage.

C. gymnocarpa-Is a variety with attractive cut foliage, of graceful, drooping habit. It is one of the finest plants in cultivation for the center of hanging baskets, vases, etc., or for bedding out, being also more readily propagated than Candida. 
CENTRADENIA (Greenhouse Perennial, 35, 55, 95%).

Beautiful, neat plants adapted only to window and conservatory culture in pots, or for planting in ferneries, baskets, etc. They delight in light soil, considerably enriched with leaf mould and manure. Are propagated from cuttings.

C. grandiflora-Elegant, narrow, green and crimson colored foliage, of changable hue.

C. rosea-Small fine leaves, of pretty form and color. The plant is profusely covered with small rose-colored flowers during a portion of the year.

CENTURY PLANT. (See Agave).

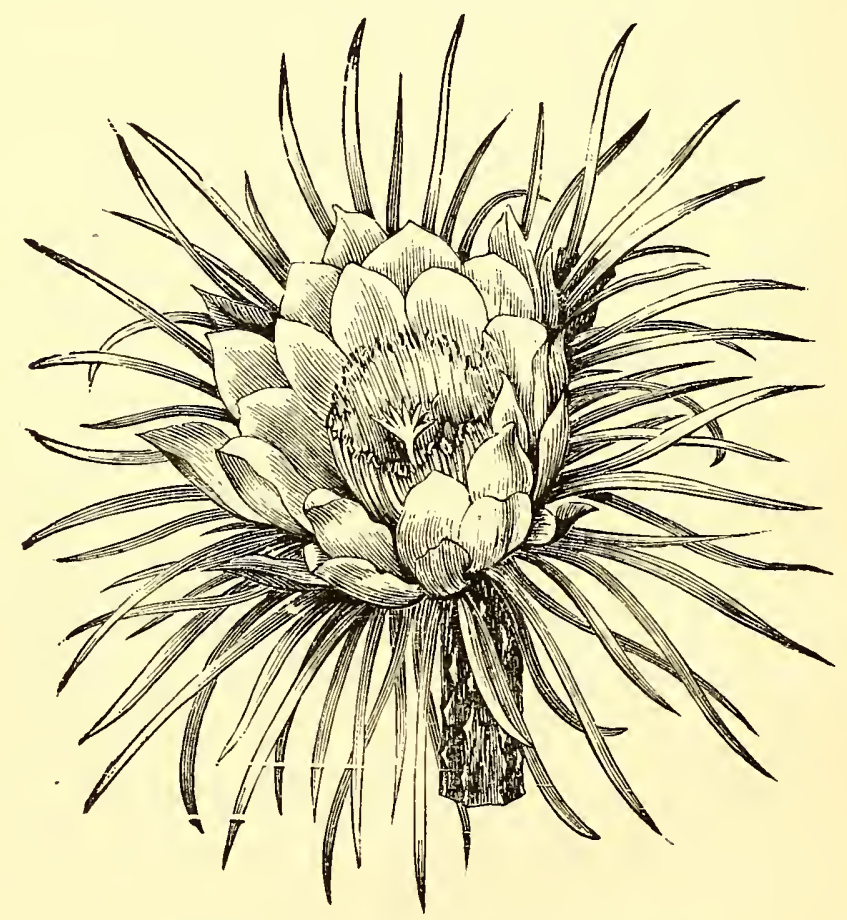

Flouer of Cereus Grandiflorus.

CEREUS GRANDIFLORUS-Night-Blooming CEREUS (Greenhouse Perennial, 35, 50, 95).

The flowers of this noted Cactus, which opens only at night, are of large size, beautiful and sweet-scented. They begin to open about sundown, and are fully expanded by eleven o'clock. 
The flower is from seven to ten inches in diameter; the petals are white; the outside of sepals a delicate brown and the inside a fine yellow color. Its fragrance perfumes the air to considerable distance. The plant is of thrifty habit, and as easily grown to flower in the house or: conservatory as any Cactus, requiring the treatment described for that family. Are-propagated from cuttings.

\section{NEW SEEDING CEREUS OR CACTUS.}

C. Alice Wilson-This is an entirely new and beautiful striped flowered Cereus. The flowers are large, about eight inches in diameter, of a brilliant scarlet, with a stripe of bright orange through the center of each petal. It flowers when only six inches high.

C. Dr. Regel-This is without a doubt one of the finest of the family. Flowers very large (sometimes measuring twenty inches in diameter), of the purest white.

C. Exquisite-Orange-salmon, violet tint.

C. Hoveyi-One of the most superb sorts, the entire flower being of a clear pinkish-blue violet tint, and eight inches in diameter. It frequently comes into flower when not more than twelve inches in height.

C. Orainge Gem-Orange, tinted violet.

C. Pink Queen-Beautiful mauve pink.

C. refulgens-Scarlet, with deep violet.

C. superbum-Salmon, tinted magenta.

CESTRUM (Greenhouse Perennial, 33, 50, 90).

Shrubs from Brazil; cultivated for the delicate fragrance of their beautiful flowers, which are borne in clusters; of easy cultivation in good loam and sand; excellent for conservatories; propagated from cuttings; they are frequently called "Night Blooming Jasmine."

C. anriantiacum-Deep orange yellow.

C. parqui-Pure white.

\section{CHOROZEMA VARIA (Greenhouse Perennial, 32, 45, 80॰).}

A small shrubby plant for pot culture, with dark green Hollyshaped foliage, thriving and flowering freely in any cool place in the winter. The flowers are yellow and crimson, of pea shape and attractive; one of the easiest plants to cultivate; are increased by cuttings. 


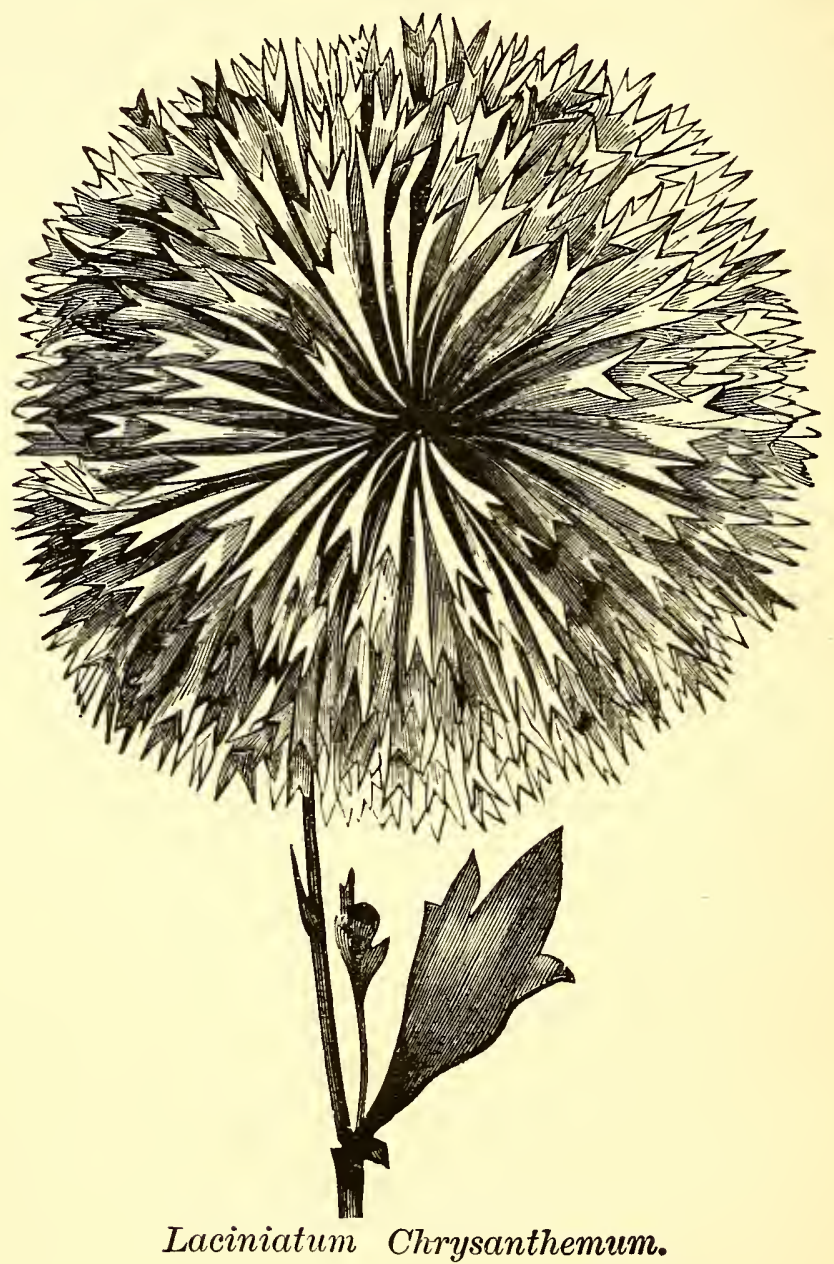

CHRYSANTHEMUM (Hardy Perennial).

The Chinese Chrysanthemums are exceedingly handsome late flowering plants, and although about hardy in our latitude, the blossom buds are liable to be injured by hard fall frosts, unless protected. The best way to manage them is to start from cuttings; grow them in pots during the summer, or bed and take them up and pot them in September, in either case removing them to the house or conservatory, where their many gorgeous flowers of various colors and tints will expand in succession for a long time. If grown in pots these should be plunged during 
the summer to the rim in the border; it is necessary to turn them occasionally to prevent the roots that strike through the bottom from growing into the garden soil. As they start in to bud treat them to occasional waterings of liquid manure. After flowering the plants shoula be cut down and put in a cool part of the conservatory, in a cold-pit or in a light cellar until spring. They may be increased in number either from cuttings of young shoots or by division of the roots in the spring. The Chrysanthemums are especially recommended to inexperienced cultivators, for no class of plants are easier to manage, and besides they produce their flowers late in the autumn when all kinds of flowers are scarce.

\section{JAPANESE CHRYSANTHEMUMS.}

These are noted for their varied forms and markings, together with the enormous size to which some of the varieties attain.

C. Abd-el-Kader-Rich crimson maroon.

C. Beau Siljaur-Violet carmine, tipped white.

C. Bras Rouge-A charming combination of gold and maroon.

C. Early Red Dragon-Dark red, tipped yellow.

C. Elaine-Pure white, back of petals tinted.

C. Emperor Nicholas-Red, tipped gold.

C. Fair Maid of Guernsey-Large white.

C. Golden Dragon-Golden yellow.

C. Gloire de Toulouse-Crimson and white.

C. grandiflora Japonica-Large yellow.

C. Hero of Magdala-Purplish red.

C. Incomparable-Yellow, brown and crimson.

C. Javena-Very dark maroon, thread-like petals, very striking.

C. laciniata-The white Japanese fringed flower; a very interesting and beautiful variety.

C. La Frezure-Amaranth, reverse of petal, white.

C. Magnum Bonum-Rosy lilac, with a lighter back; large flower.

C. M. Plancheneau-Rosy mauve, shaded silver.

C. $M$. Roux-Beautiful dark crimson, white center.

C. Mr. W. Bull-Crimson maroon, shaded yellow.

C. Mons. Chas. Huber-Crimson, tipped gold.

C. Ne Plus Ultra Nova-Lilac, golden tips.

C. Parasol-Golden buff, shaded salmon.

C. Snow White-Very large, pure white.

C. Temple of Solomon-Rich golden yellow. 


\section{LARGE FLOWERING CHRYSANTHEMUMS.}

C. C. H. Glover-Rich, deep yellow. Exquisite form, free bloomer.

C. Glori Mundi-Bright yellow, dwarf habit.

C. Golden Aurora-Light orange flame.

C. Golden Star-Fine golden yellow.

C. John Lester-Yellow, shaded amber.

C. John Poore-White, shaded lilac.

C. Kate Reynolds-White, tipped yellow.

C. La Nymph-White, tipped pink.

C. Margaret de York-Sulphur yellow, fine.

C. Mrs. Geo. Glenny-Bright amber.

C. Mrs. Stevens-Pure white, finely formed.

C. Mrs. Georye Rundle-Fine white.

C. Princess Teck-Pure white, large and full.

C. Polycarp - Light rosy pink.

C. Prince of Anemones-Lilac blush.

C. Peter the Great-Light, bright yellow.

$C$. Refulgence-Rich purple maroon.

C. Red Gauntlet-Fine dark red.

C. Seastris - Brownish red, with yellow shading.

C. Webb's Queen-Perfect shape, broad petals, pure ivory white.

POMPONE OR SMALL FLOWERING CHRYSANTHEMUMS.

C. alba perfecta-Pure white, bushy habit.

C. Brilliant-Bright red.

C. Boule de Neige-White, imbricated.

C. Bob-Dark brown crimson; fine color; a great favorite.

C. Bouquet Blanche-Pure white, intermediate late.

C. Cite of Flowers-Velvety crimson, shaded amaranth.

C. Commodore Nutt-Size of silver half dime; rich, old gold color.

C. Crimson Perfection-Bright crimson.

C. Daisy-Very small, pure white.

C. Figaro-Rich buff, crimson edge.

C. La Fabree-Straw yellow, fine.

C. Mrs. Campbell-Carmine, tipped with white.

C. Mdme Aristee-Golden yellow.

C. Montgolfier-Rich gold. maroon tipped.

C. Model of Perfection-Rich lilac and yellow.

C. Mayer Lusk-Purplish red, fine. 
C. Perle des Beautes-Crimson amaranth, pointed with seal brown.

C. Petite Marie--Creamy white, dwarf.

C. Robert Kift-Pure white, fine.

C. sanguineun-Blood red.

C. Serenity-White, tinged with rosy lavender.

C. Snowdrop-Sparking white, extra fine.

C. Sunray-Deep golden yellow.

C. White Eve-Pure white.

CIGAR PLANT. See Cuphea Platycentra.

CINERARIA (Greenhouse Perennial, 33, 45, $75^{\circ}$ ).

In late winter and early spring, few pot plants present a more attractive appearance than do the Cinerarias when at the height of their beauty, bearing immense crops of bright, handsome flowers, in clusters, boldly above the large leaves. They are capital plants for winter culture in a cool greenhouse, or with great care in a window, and are raised from seeds sown annually at any time from July to September. The culture suited to the Herbaceous Calceolaria (which see) will answer fully for the Cineraria, and any person may expect to be successful with their culture in the conservatory, also in the window, if a cool and regular atmosphere can be sustained with the admission of plenty of air. They should be kept near the light and must never be crowded as regards root space in the pots.

CISSUS DISCOLOR (Greenhouse Perennial, 45, 65, 90 ${ }^{\circ}$ ).

A climber, the leaves of which are beautifully shaded with dark green, purple and white, the upper surface having a rich, velvet-like appearance. The plant requires a continually high temperature to develop the beautiful coloring of leaves, and there will be little use of attempting its culture unless this can be provided; but with this and other favorable conditions supplied and no plant in cultivation can exceed its rare beauty in the matter of foliage; propagated from cuttings.

CLARKIA (Hardy Annual).

Plants of considerable beauty for the garden and easily raised from seed. The seed should be sown directly where the plants are to flower, either early in the spring or in August and September. The latter time of sowing is perhaps the best, by protecting the young seedlings, with a slight covering of straw or litter 
during the winter and which must be removed early the following spring. The flowers in double and single varieties are attractive in form and color. They attain to the greatest perfection in the spring and autumn, as the hot sun of summer interferes somewhat with their development.

\section{CLEMATIS (Hardy Climber).}

Recently, the improvements made both in the size and coloring of the Clematis have been very decided and marked, and we have now a wide range of color, varying from white to dark blue and velvety purple. They are perfectly hardy, of rapid growth, attaining a height of twenty feet, and blooming during the greater part of the summer and fall. The effect produced by a well-grown plant when in full bloom, is grand; propagated from cuttings, layering and root grafting.

C. Blue Gem-A most profuse bloomer, continuing in full beauty late into the autumn; flowers large, a most intense rich blue.

(?. Jean d'Arc-Flowers white, large and perfect, with three pale blue stripes on each sepal. The plant is of vigorous habit, elegant in appearance.

C. Jackmanii-Flowers, when fully expanded, are from four to six inches in diameter, intense violet purple, with a rich velvety appearance, distinctly veined; perfectly hardy. Flowers continually from July until cut off by frosts.

C. Lady Caroline Neville-Fine flowers, from six to seven inches in diameter; color delicate blush white, with a broad purplish lilac band in the center of each sepal.

C. Lucie Lemoine-Fine, double white; the flowers are composed of seventy-fire to ninety sepals. In the first period of its flowering the blooms are semi-circular in shape, resembling a gigantic doubie white Zinnia.

C. Miss Bateman-A magnificeut plant, both in growth and flower. The blooms are large, of good shape, pure white; banded with creamy white down the center of each sepal. C. rubella-Fiowers of a rich velvety claret, the deepest color of any Clematis; generally has six sepals to each flower.

C. Standishii-Flowers large, violet blue; May and June.

C. Mme. Grange-Flowers large, purple violet, with maroon midrib; redder than any other Clematis. 
C. viticella rubra grandiflora-A vigorous free growing variety.

Flowers profusely; color, violet red.

C. grandiflora-Single white.

C. lanuginosa pallida-Pale violet, with bright red veinings.

Very beautiful.

C. lanuginosa candida-Grayish white; very fine.

C. The Queen-Of free habit and very beautiful foliage. Flowers of pale lavender.

C. Mrs. Baker-French white, with claret bar.

C. Modesta-Delicate lavender; very pretty.

C. blanc lilas-White and lilac in color; very large.

C. Francofurtensis-Wine red, with violet shading.

C. lanuginosa azurea-Bright azure blue.

C. flammula, European Sweet-Flowers white, small and very sweet scented.

C. virginiana-Common Virgin's Bower, a native plant of rapid growth, with clusters of small, white flowers, succeeded in autumn by fruit with conspicuous feathery tails.

C. coccinea-Fine rosy scarlet; one of the most beautiful of all trailing plants. Its foliage is exceedingly pretty and its flowers graceful and charming. It will delight all.

CLERODENDRON (Greenhouse Perennial, 35, 55, 90).

Tropical shrubs, with loose terminal panicles of showy bloom. They should be potted in a mixture of peat, loam and manure, with a little sand. When growing, give strong heat and plenty of water; propagated from cuttings.

C. Balfouri-The flowers are of a bright scarlet, encased in a bag-like calyx of pure white.

C. speciosum-This variety is dwarfer than the preceding and very free flowering; the flowers are pure white, encased in a bag-like calyx of bright scariet.

C. fragans-Dwarf plant producing very compact heads of pinkish-white double flowers of a highly agreeable scent such as is preferred by many to that of either Daphne, Tuberose or the Clove Carnation. This variety can also be increased from root cuttings.

COBCEA SCANDENS (Greenhouse Perennial, 35, 55, 85.)

An excellent climbing plant grown from seed or increased by cuttings, and which is, perhaps, more generally useful than any 
other one grown, being alike suitable for the conservatory, the window or the open air in summer. The plants produce many large, bell-shaped flowers and magnificent foliage when grown in the open ground, but are rather shy in the former respect in the winter when cultivated in pots, although their growth is satisfactory, and the foliage endures the confined heat of the dwelling admirably. When planted in a border, either in the conservatory or in a sheltered place out doors, the growth of well established plants attain to great proportions, having been known to reach an aggregate length of two hundred feet in one season. The seeds require starting in heat and should be set edgewise in the soil of the seed bed. Until the young plants appear, water rather lightly, but never allow the soil to get entirely dry. The Coboea delights in a warm, sandy soil.

COCCOLOBA PLATYCLADA (Greenhouse Perennial, 33, 50, 85).

A singular looking pot or bedding plant of fern-like, angular growth. It is readily grown, under almost any circumstances, and is suitable for cultivating in ferneries, while it is not out of place in a hanging basket. On account of its grotesune appearance, it will be admired where many flowering plants would scarcely attract attention. Propagates from cuttings.

\section{COCKSCOMB. (See Celosia.)}

\section{COLEUS (Greenhouse Perennial, 40, 60, 90).}

This popular genus of comparatively recent introduction, possesses the most varied and striking colors imaginable in the foliage, while unlike miny other plants with remarkable foliage these may be propagated and grown with the greatest ease. There is one, and about only one special condition, that is absolutely essential to its well doing, and that is a high temperature. Where this is present, the plants will grow with the greatest freedom, either in the open air, the window or conservatory, and form strong plants of remarkable beauty in a very short space of time. It is on account of their rapid growth, and great beauty, that such vigorous varieties as Verschaffeltii. Setting Sun and others, rank among the best plants for masses in ribbon lines, even though naturally tender. In our dwellings that are heated by anthracite coal stoves or ranges, and in which the fire is kept up day and night, the Coleus if grown in pots or baskets will 


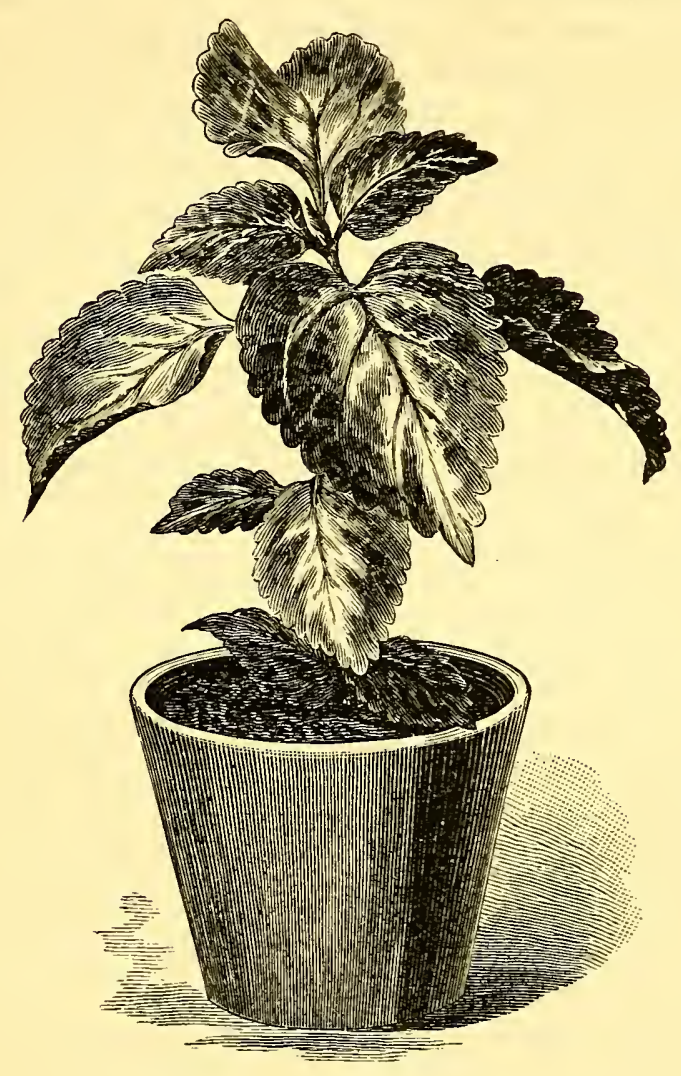

Coleus.

usually do very well. Some plants may be raised for winter decoration by striking cuttings in July or August for the purpose. Plant into light, rich soil and water moderately during winter, also paying attention to heading back strong growing shoots, to prevent an unshapely appearance. Propagated from cuttings or seed.

C. Acme-Foliage large, under good cultivation 10 to 12 inches long and 8 to 10 wide; ground color deep chocolate and creamy white, beautifully veined and striped.

C. Fairy Knoll - Carmine rose, rimmed with velrety maroon.

C. Garland-New, elegantly colored with purple, cream, green and carmine, deeply serrated edges, forming miniature leaflets of great beauty. 
C. Glory of Autumn-Deep crimson bronze, margined gold.

C. Golden Bedder-A grand acquisition for bedding; bright yellow ; recommended.

C. Hero-Chocolate maroon ; fine bedder.

C. Innisfallen-A grand bedding variety; rich prune color, blotched with garnet; extra fine.

C. J. Burnsham (New)-Yellow and crimson ; spotted.

C. Joseph's Coat-The leaves present a gorgeous blending of maroon, yellow, rose, olive and carmine.

C. Kentish Fire-Pink, carmine and bronze.

C. Kirk Alloway-Blazing shades of color; violet, suffused carmine and rose.

C. Kirkpatrick-Large leaf, blotched in the centre like Geranium Happy Thought.

C. Mr. Micawber-Olive green, distinctly marked in the centre with violet rose ; beautiful.

C. Mrs. Humphreys-Light claret, rimmed yellow.

C. multicolor-Maroon and crimson.

C. Pictı-Marbled yellow, maroon and crimson.

C. President Garfield-A grand variety ; leaves eight to ten inches long, six to eight wide, color chocolate, marbled with bright rosy carmine.

C. Queen of the Lawn-Dazzling carmine, rimmed with velvety maroon.

C. Rocket-Violet, rose centre. black next and olive green serrated edge.

C. Ruby-Rich crimson maroon ; centre dark rose color, beautifully fringed edges; a suberb variety.

C. Sensation-A new and beautiful sort; edge of leaf chocolate, then a circle of maroon, with large centre of bright red.

C. Setting Sun-Bronze, crimson centre, bright golden margin ; splendid bedding rariety.

C. Spotted Gem-Yellow grcund, regularly blotched crimson, green and orange.

C. Suez-Blood red, shaded and veined violet, rose and bronze.

C. Verschaffeltii-Rich velvet crimson; best bedder. 


\section{CONVOLVULUS (Hardy Annual).}

Convolvulus MaJor (Morning Glory).-One of the best-known climbing plants in cultivation and most excellent for covering trellises, rustic work, cords for shading the veranda, etc., during the summer. There are many varieties of different colors, all of which are more or less attractive. It comes very easily from the seed, which should be sown in the open ground early in the spring. As soon as the young plants stretch forth for support on which to spin, it should be seen that something suitable is provided, as they do not take hold so readily after getting older, besides they become entangled with each other.

Convolvulus Minor (Dwarf Convolvulus). - Free flowering annuals of distinct and rich colors, that are desirable for massing or for individual effect. The seeds germinate readily, and may be sown where they are to flower. Thin out the plants to stand not nearer than fifteen inches apart in rich soil.

CORONILLA (Greenhouse Perennial, 34, 50, 90%)

Pretty flowering shrubs of easy culture, especially adapted for winter blooming; the species have been long under cultivation and is much esteemed; propagated from cuttings or seed.

C. glauca-splendid fine foliage, and produces bright yellow, peashaped flowers in great profusion, which are very fragrant.

CRAPE MYRTLE. (See Lagerstroemia.)

CRASSULA (Greenhouse Perennial, 34, 45, $80^{\circ}$ ).

Succulent greenhouse plants with fleshy stems and leares, and producing either pink or white flowers. Many of them form curious specimens on account of their forms. For potting use light sandy loam with plenty of drainage; propagated from cuttings and seeds.

C. cordata-Of strong growth, with a profusion of pinkish white flowers.

C. portulacea Of strong growth, with thick leaves: flowers white. 


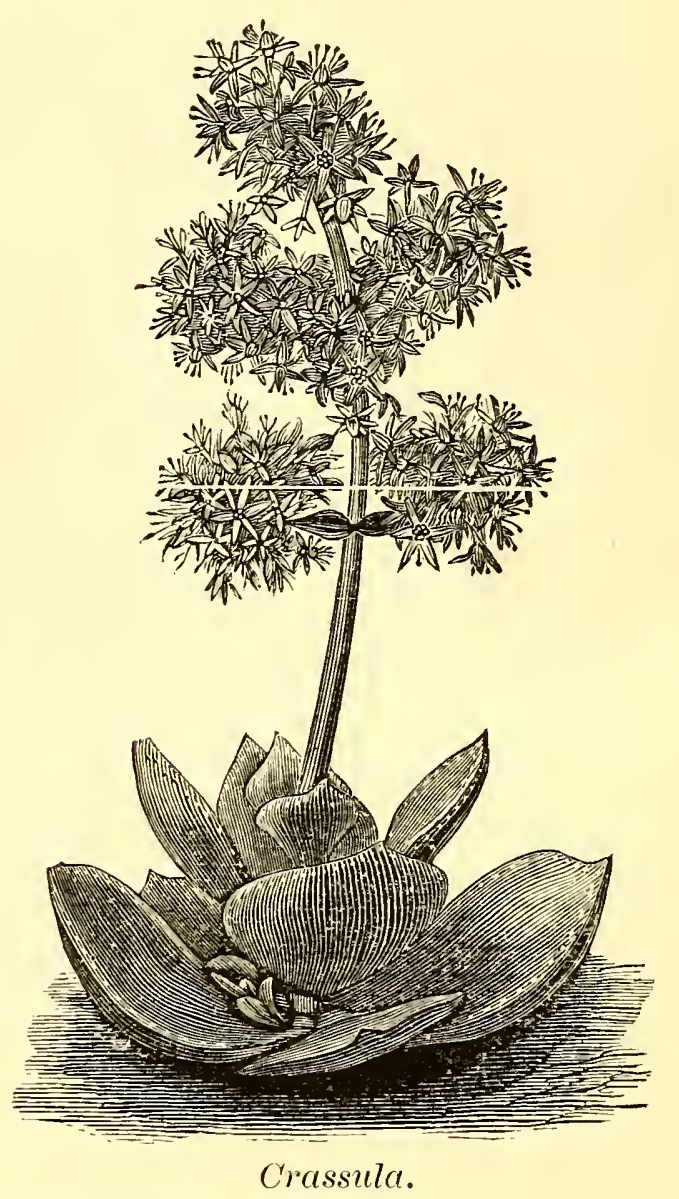

C. perfoliata-A dwarf plant, forming a perfect rosette; blooms about Christmas, at which time it throws up long stems, surmounted by large clusters of small, white, star-shaped flowers.

\section{CROCUS (Hardy Bulb).}

The Crocus is an interesting class of bulbous plants, and which produces its flowers in the open air from the month of March and up to the flowering of Hyacinths. Being thus very early, and also very showy when in bloom, they should have a place in every garden. The flowers are white, blue, yellow and striped, and present a gay appearance, as they appear with few companions 

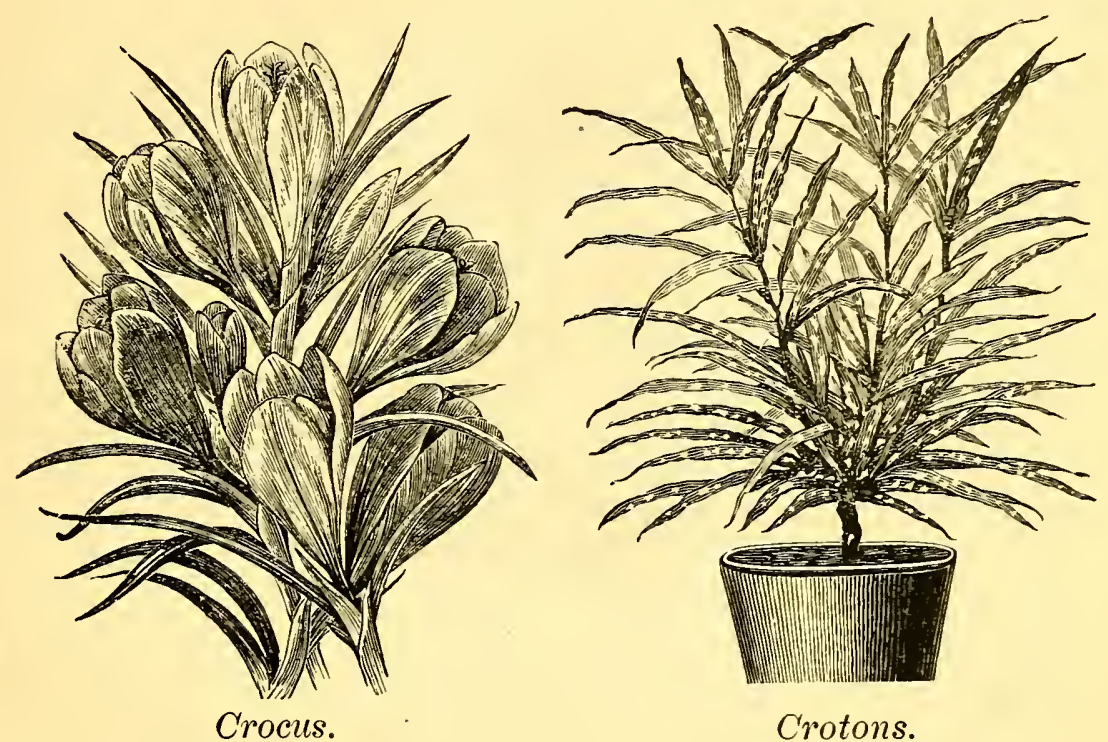

Crotons.

at their early season of flowering. The bulbs require to be planted in the fall, and should be set about three inches apart and not more than two inches deep. Their culture, in common with other hardy bulbs, is treated on on page 32. The Crocus will also flower well in the house. Directions for cultivation in pots, glasses, etc., is given on page 52 .

\section{CROTONS (Greenhouse Perennial, 40, 60, 90%).}

The Crotons are among the finest decorative foliage plants known. The leaves of all are more or less veined and margined, sometimes entirely variegated with shades of yellow, orange and crimson. Some have long narrow leaves, arching gracefully, fountain-fashion. Others broad and short, cak-leaved; some re curved very much; others twisted, cork-screw like. Crotons lore heat, sunshine and moisture; propagated from cuttings.

C. andrianum-Neat habit; free growth; foliage colored in a most delightful manner; one of the best.

C. angustifolium-Leaves long and narrow, golden yellow.

C. acubifolium-Foliage dark glossy green, studded with yellow blotches, midrib and veins slightly tinged with pink.

C. aurea maculatus-..Small leaved; neat habit; leaves orate, oblong, deep bright green, profusely spotted with yellow. 
C. Bismark-Leaves almost fiddle-shaped; base broadest and ovate, the apex swelling out into an ovate form; color deep green, with broad band of golden yellow along the costa, and yellow markings indicating the course of the lateral vems, with yellow blotches scattered over the surface.

C. Camptophyllus-Foliage very narrow and richly mottled with golden yellow; a fine dwarf growing variety, distinct from all others.

C. cascarilla-Narrow leaved, light green, yellow blotched.

C. cornutum-Green, with a profusion of spots of rich yellow.

C. Disraeli-A lobed variety, with golden yellow ribs and spots.

C. Earl of Derby-A remarkable trilobe variety, the stems and mid-rib being a very bright yellow, which diffuses itself over a greater part of the leaf; this, as the plant matures, becomes a bright red.

C. elegans-Bright green, striped with golden yellow.

C. Evancianus-Well distinguished by the peculiar form of its triobated leaves and the depth of coloring pervading the whole plant; newest-formed leaves are light olive green and golden yellow, deepening and changing to bronzy crimson and orange scarlet in the older ones.

C. hillianum-Ribs and veins crimson, dark purple beneath.

C. Imperator, or Challenger-Leaves from 12 to 18 inches long, 2 to 3 inches wide, and gracefully arching; ground color pale green, much suifused with creamy white, changing to magenta.

C. interruptum-Long narrow leaves, spotted with yellow.

C. irregulare-Leaves long, marbled with different shades of yellow, orange aud crimson; leaves are irregular in shape, often changing in form.

C. Johannes-Leaves a foot or more long, narrow and pendulous; ground color, bright shining green; margin and mid-rib bright orange yellow.

C. longifolium-Leaves green, blotched and striped with golden yellow; very long and graceful; a magnificent plant.

C. Lord Cairns-Leaves trilobate, the middle lobe considerably elongated, with a broader expansion toward the point; ground color bright green; mid-ribs bright yellow, and blotches of same color.

C. maximum-Leaves shining green; mid-rib and cross-base, from mid-rib to margin, yellow; leaves ovate-acuminate. 
C. maculatus Katonii-Leaves fiddle-shaped, but very irregular, of an olive-green color, spotted with rather large golden spots ; compact in habit.

C. majestictm-Mottled and margined with crimson and yellow.

C. Moreanus-Mid-rib and margins of leaf clear orange, blade crossed with paralleled bands of the same color upon a deep green ground; robust grower.

C. multicolor-Leaves light green, blotched with yellow, but changing to glossy green, blotched with yellow, reddish yellow and red, the mid-rib crimson.

C. Nobilis-Long, pendulous leaves, richly colored with crimson, yellow and green, the former being most prominent in the stem leaves, stalks and mid-rib, where it is banded with yellow.

C. ovalifolium-Oval outline, central golden bar and reticulations.

C. Princess of Wales-The handsomest of all the narrow-leaved types; fine branching habit; leaves pendulous, arching and slightly twisted; margins undulating; colors are pale yellow, bright carmine, bright magenta and irregular blotches of light green.

C. pictum-Dark green foliage, spotted with rich reddish crimson.

C. Queen Victoria-Growth medium; habit branching; leares oblong; lanceolate; colors golden yellow, rich magenta, crimson-carmine and green.

C. spirale-Curious spiral twisting leaves, with markings of yellow.

C. undulatum-Edges of leaves undulating, marked and blotched, crimson and yellow, on dark green ground.

C. variegatum-Veins broadly margined with golden yellow.

C. Veitchii-Leaves attain a length of twelve to fourteen inches, and two and a half inches broad; they are traversed with broad bands of creamy yellow, changing to rose and carmine purple.

C. volutum-Leaves rolled up from the end like a ram's horn: ground color deep green; mid-rib golden and rays of same color towards the margin.

C. Weismanii-Leaves of ten twelve inches long and three-quarters of an inch wide; ground color shining white green, striped and mottled with golden yellow. 
C. Youngii-Leaves from one and a half to two feet in length: deep red underneath, upper surface dark green, densely blotched with creamy yellow and bright rosy red.

\section{CROWN IMPERIAL (Hardy Bulb).}

An old-fashioned, early spring-flowering bulb, bearing on a stem, severaî feet high, drooping bell-shaped flowers, which, in their arrangement around the stalk, may be fancied to resemble a crown. There are both double and single varieties, the colors of which are principally yellow and red. They delight in a deep rich bed, and should not have their bulbs lifted for re-setting oftener than every third year.

\section{CUPHEA (Greenhouse Perennial, 33, 45, 80).}

Pretty shrub-like plants adapted to a variety of purposes; they are almost constantly in bloom under fair circumstances. The plants thrive beautifully in hanging baskets or vases, or if planted out in the border where they will, during the season, assume a dense globular form and constantly produce an abundance of flowers. They are also valuable as pot plants for the window, where their free-flowering, and other qualities make them great favorites; propagated from cuttings.

C. platycentra (Cigar Plant)-Tube of flowers scarlet; lip white and crimson.

C. hyssopifolia-Leaves dark glossy green, flowers bright lilac.

C. hillfildiana-Tube of flowers purple; lip and throat darker.

\section{CYCLAMEN PERSICUM (Greenhouse Bulb, 35, 55, 75\%).}

Beautiful plants for the window or conservatory, with finely marked foliage, and which produce from autumn until spring a pro:usion of drooping flowers of the most pleasing appearance, on long stems. The soil in which they are grown needs to be rich and of a light nature. After the plants have done flowering they may be plunged in the open ground for the summer and receive a shift into larger pots for another season's growth, in August or September. The plants are raised from seed, which may be sown at any time from early spring until mid-summer, for flowering the next year. 


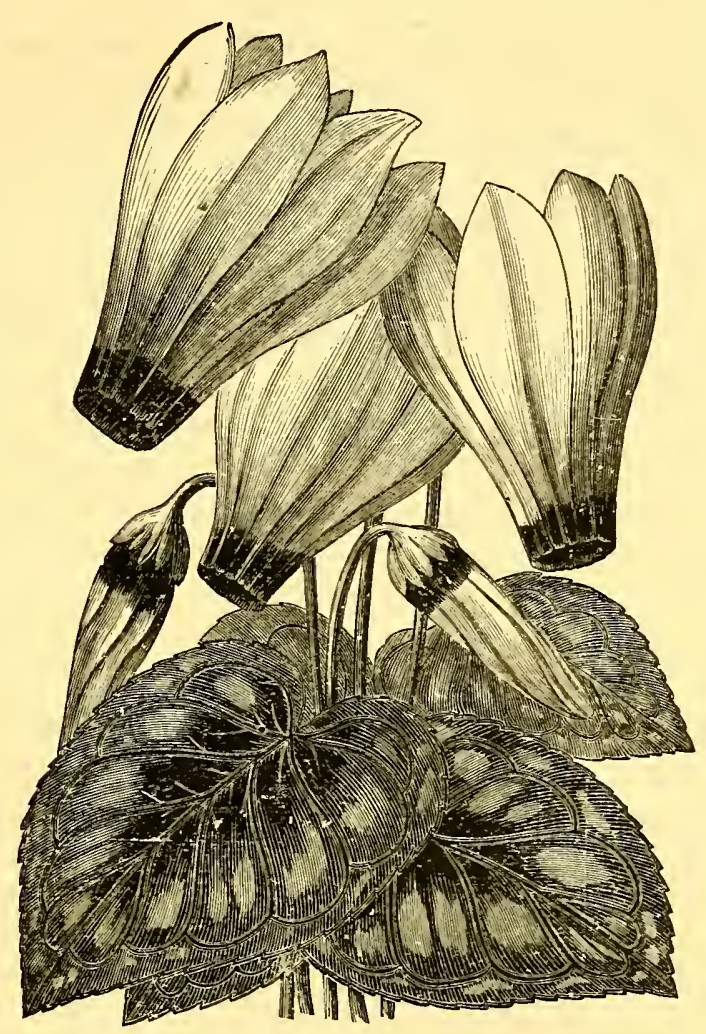

Cyclamen Persicum.

C. persicum giganteum-This is a decided improvement over the preceding variety, being of a more robust habit and stronger grower; produces its flowers on stout stems somewhat shorter than in old variety, and of immense size, often measuring on well grown bulbs, two inches in diameter.

CYPERUS (Greenhouse Perennial, 33, 45, 85%).

A grass-like plant, throwing up stems to the height of about two feet, surmounted at the top by a cluster or whorl of leaves, diverging horizontally, giving the plant a very curious appearance. A splendid plant for the center of baskets, vases, or wardian cases, or as a water-plant.

C. alternifolius-An attractive rush-like plant, of a pleasing bright green color.

C. alternifolius variegatus - A beautiful form, striped with white.

CYPRESS VINE. See Ipomœa. 
CYTISUS RACEMOSUS (Greenhouse Perennial, 35, 50, 80).

Cytisus Racemosus is a winter flowering pot plant, suitable for the window or conservatory, and which assumes an irregular bushy form of growth, which is very attractive. The flowers are small, fragrant and of a pleasing, deep golden yellow, borne on racemes, and for a long time, give the plant a beautiful appearance. It is rather difficult to propagate, this being done from cuttings.

DAFFODIL. See Narcissus.

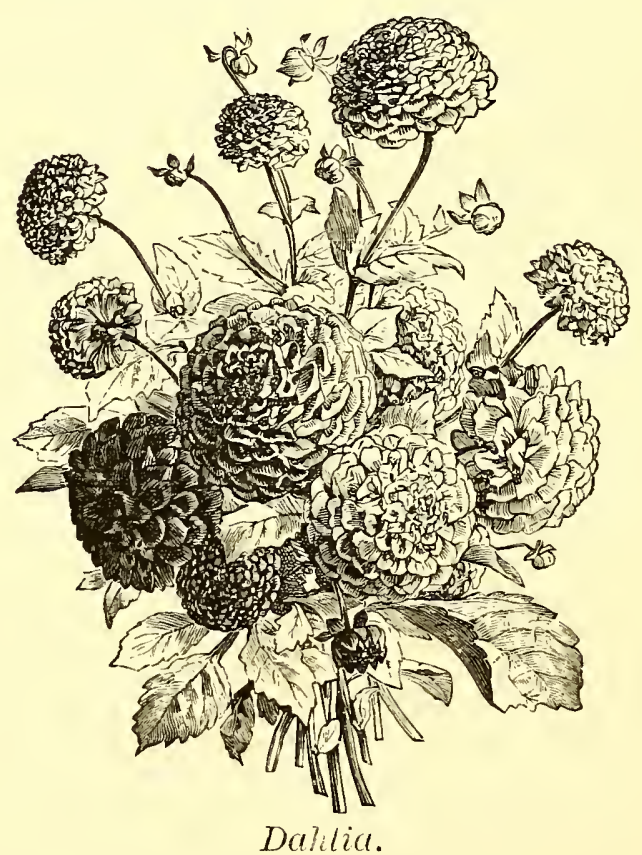

DAHLIA (Tender Tuber).

Well known tuberous plants, only suitable for open-air culture, which produce flowers of the most symmetrical form, and of brilliant and good colors, during the summer and autumn months. The plants luxuiriate in a moist, rich soil. In dry weather the flowers will be finer, and the plants grow better, by receiving a thorough watering occasionally of an evening. Nothing gives thrifty Dahlias a better appearance than to keep them neatly tied to strong stakes about four feet long, driven by each plant. All flowers should be removed as soon as they begin to decay, and 
imperfect buds be cut off. The tubers should be lifted after frosts have killed the stalk, usually in October in our latitude. They should then be properly labeled, and after drying, either in the sun or in an open shed, be packed in sand and kept in a dry, warm cellar during winter or under the benches in the conservatory. In the following spring they may be divided into pieces, each with a crown, and planted in the flower beds again. Their flowering season is considerably advanced by starting them in heat in April and keeping them there up to near the first of June, before planting them out; are also readily propagated by cuttings.

\section{DAHLIAS-LARGE FLOWERING.}

D. Amazon-Yellow, margin fringed red.

D. Aglea-White, tipped rose.

D. Chief-White, edged dark crimson.

D. Dom Pedro-Scarlet, tipped white.

D. Duchesse de Cambridge-Blush, tipped and edged with dark purple; fine form.

D. Dr. J. P. Kirtland-Dark red, very large, good form.

D. Frank Smith-Bright red.

D. Forget-Me-Not-Crimson, largely tipped white.

D. Golden Bedder-Fine yellow.

D. Hoofmeister-Yellow, tipped red.

D. Helen Potter-Blush white.

D. Hercules--Yellow ground, striped and speckled with rich crimson.

D. incarnata rosea -White, shaded with bright rose.

D. John Bennett-Yellow, deeply edged scarlet.

D. John Sladden-Nearly black; fine form.

D. Kleiner Knab-White, tinged and tipped with rosy purple.

D. La Phare-Deep scarlet; free sloomer.

D. L'Emancipe-Orange and violet.

D. Madam Perignon-Rose and salmon, tipped white.

D. Mrs. Wheeler-Rich, deep scarlet; solid, fine flower.

D. Mary Eustace-White, with flesh-colored center.

D. Mrs. Dodd-Lemon yellow; fine form.

D. Niger-Dark maroon; fine form.

D. Oblata-Pure white.

D. Princesse-White, large, full.

D. Queen Victoria-Yellow, red margin.

D. Reine de Prusse-Dark cherry, largely tipped with white. 
D. Royal Purple-Very free.

D. Sambo-Rich maroon, tinted black.

D. Summit of Crupton-Dark maroon.

D. Tam O'Shanter-Blush lilac.

D. Yellow Boy-Bright golden yellow.

\section{DAHLIAS-POMPONE OR BOUQUET.}

This class includes all the colors of the larger flowering sorts. Being more dwarf and compact in liabit of growth, they are very valuable for bedding purposes and cut flowers.

D. Dr. Webb-Ricl, scariet, small.

D. Exquisite-Orange, scarlet edge.

D. Gluwurmchen-Brilliant scarlet.

D. Goldfinch-Yellow, scarlet and white.

D. Guiding Star-Pure white; fimbriated.

D. Harry-Dark red, spotted and tipped white.

D. Kleiner Schutze-Deep scarlet, distinctly tipped white.

D. Ladies' Jewel-White, with crimson tip.

D. Seraph-Bufi yellow, tipped orange red.

D. Scarlet Gem-Bright scarlet.

\section{DAHLIAS-SINGLE.}

This new section of the Dahlia family has now become exceedingly fashionable, owing to the value attached to the cut blooms, their airy, butterfly-like forms giving the flower a grace never attained by the finest double sorts. The flowers range from three to five inches in diameter, all having a bright yellow center surrounded with petals running through all the shades of scarlet, crimson, rose, yellow, orange, white, lilac, carmine, etc.

D. Butterfly-A beautiful shade of pink.

D. Ballot-Deep carmine; large and showy.

D. Moonstone-Large, light canary yellow.

D. Sandusky-Orange; immense size; very distinct disc.

D. Chancellor-Delicate lilac; large size, free blooming.

D. Crichton-Maroon, of a rich velvety shade.

D. White Queen-Pure white, lily-like flower, with yellow disc.

D. Corsage-Intense bright scarlet; very fine.

D. Vicarage-Bright vermilion; large.

DAHLIAS-CACTUS.

This new class of Dahlias has opened up an entirely different section. They are intermediate between the double and single 
varieties, of peculiar and very pleasing form, resembling somewhat some of the Japanese Chrysanthemums, and we have no doubt there will soon be as many colors as there are now in the other classes.

D. Imperial Prince-A variety with plaited flat petals about half an inch wide, somewhat twisted; color rich deep Tyrian purple; dwarf and early flowering.

D. Juarezii-A most valuable and very decorative plant for all purposes through the late summer and autumn months; its blossoms are of a rich crimson, and very much resemble in shape and color the well-known Cactus, Cereus Speciosissimus; leight about 3 feet, very bushy; flowers of very striking appearance, and quite unlike those of an ordinary double Dahlia, the florets being flat and not cupped.

D. Lyndhurst-The same style of flower as the preceding variety, excepting that the color is of the brightest scarlet. It commences to flower about two weeks earlier.

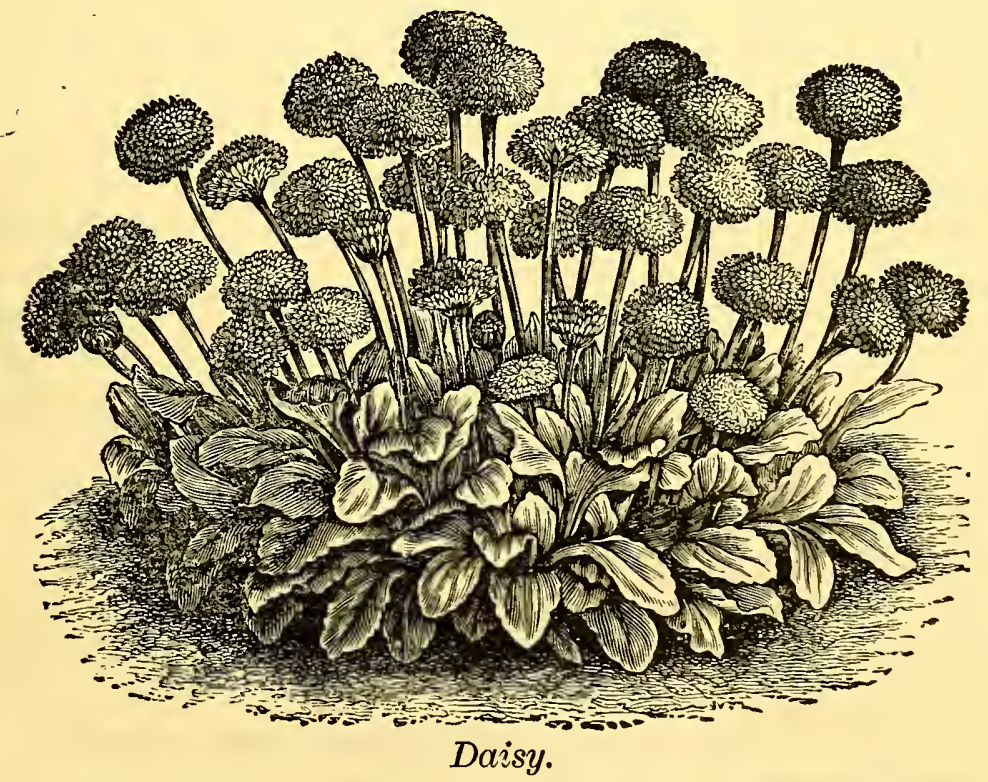

DAISY-Bellis Perennis (Hardy Perennial).

A pretty little plant for the garden, which, in the better sorts, bear a profusion of perfectly double flowers, of red, white and variegated colors, throughout all but the hottest portion of the season. The plants are propagated by division and also from the 
seed, but are not very satisfactory if reared from the latter, as a large proportion always will come single or only semi-double from the best of seed. Set the plants about six inches apart, and protect slightly in winter. A few may be potted in the fall to flower in a cool place in the window or conservatory during the winter.

\section{DAPHNE (Greenhouse and Hardy Perennials).}

An extensive genus of small shrubs (mostly evergreen), with very beautiful, fragrant flowers; grow in good, turfy loam, with a little sand and manure. Drain the pots well. The following variety is much prized :

D. Indica $\left(33,45,85^{\circ}\right)$-An old greenhouse plant, always scarce.

It is evergreen, growing three feet high, bearing clusters of small, pinkish-white flowers, exquisitely fragrant; it propagates from cuttings.

There is also a variety (D. cneorum) which is a hardy trailing evergreen shrub, growing about a foot high, which produces beautiful pink or crimson, deliciously sweet-scented flowers in terminal clusters, in April and May; it is propagated by layers.

\section{DELPHINIUM-LARKSPUR (Hardy Annuals and Perennials).}

Annual Delphiniums-A class of annuals possessing bright colors and free flowering qualities to an extent that render them worthy of culture in every considerable collection. The dwarf varieties are regarded as the most beautiful, attaining as they do a height of one foot, and throwing up a flower shoot that somewhat resembles a Hyacinth. These should stand at a distance of six inches from each other, and the tall varieties a foot and a half apart. Sow where they are to bloom.

Delphinium Formosum is one of the most desirable hardy perennials in cultivation. It blooms more or less freely from July until November, yielding exceedingly attractive flowers. The flowers are large, of a dark blue, with the centre white, shaded with reddish purple and produced in spikes. There are a number of other varieties similar to this one excepting in the colors. When the plants of the hardy kinds become large they should be divided and reset; they can also be grown true from seed, which should be sown in the spring, and will flower the next summer. 


\section{DEUTZIA (Harāy Shrub.)}

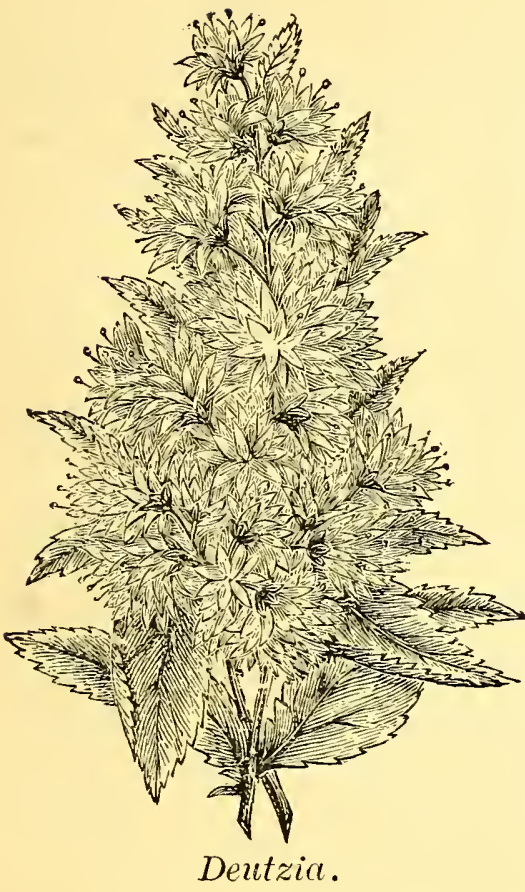

Although a family of hardy shrubs, and one of the best for permanentplanting, the rarieties Deutzia gracilis, pure white, and Deutzia crenata. fl. pl., double, pure white, serve admirably for pot culture and forcing in the window or conservatory. The plants should be grown in the open ground, and after the leaves have fallen in autumn, be brought into the cold-pit or cellar, until New Year's, after which time they may be mored to the window or conservatory for flowering. With bearing a profusion of pretty flowers in due time nothing can be handsomer. Propagated from cuttings.

\section{DIANTHUS (Hardy Perennial).}

This is an extensive genus of desirable flowering plants, which ombrace numerous important kinds, the Carnation, Garden Pink, Sweet William, etc., being of the number. I shall here treat of those that are generally raised from seed, the other will be found under their respective heads. The species known as D. Chinensis, embracing the old Chinese pink, which has been very mich improved of late years, and the new and superb varieties from Japan, known as $D$. Heddevigii and D. lacinatus, with the new varieties that have sprung from them by hybridization, are among the most brilliant and useful of garden flowers. They are easily grown from seed in any good soil, and flower freely throughout the season, even up to winter. This they will do for sereral years, provided they are in suitable condition for surviring the winter. For keeping orer it is better to secure strong. stocky plants by pruning them back somewhat at times, even at the loss of some bloom, for then they will not only winter better, but will produce larger and finer flowers the second season. The seed may 
be sown in heat and the young plants transplanted to the garden, if large plants are desired the first year, or by sowing in the garden at any time from late spring until September, excellent plants may be had for flowering the following year. The plants should be set at a distance of from six to twelve inches apart.

Dianthus Barbatus (Sueet William), useful garden perennials, with double and singie flowers of various colors. They have long been in cultivation, but great improvements have been made in the quality of the flowers, as well as in the list of desirable varieties. Easily raised from seed, or fine varieties may be perpetuated by dividing the roots after they have flowered.

\section{DICENTRA SPECTABILIS-Love LIES BleEdING (Hardy Herbaceous Perennial).}

One of our most ornamental, spring-flowering hardy plants, and also excellent for forcing in the window or conservatory. The flowers, which appear in racemes, on long, drooping stems, are of a bright, rosy pink, with a pearly white corolla. As they are produced by hundreds o: large plants in the open air, they serve to render the plant for the time one of the most attractive objects the garden can possess. For winter flowering the plants should be taken up in October, be potted, and placed in a coldpit or some place where they may be got at in the winter. Any time after cold weather sets in (the plants should go through at least one freeze), they may be brought indoors, and will flower in about two months afterwards. Increased by division of the roots.

DIEFFENBACHIA (Greenhouse Perennials, 45, 60, 95º.

A genus of greenhouse plants grown for their strikingly showy foliage. Use peat and loam in equal parts, with a little sand. Give them a strong heat, and water as well as syringe frequently. Propagated by division and by cuttings.

D. Bausii-New and rare, charmingly tinted.

D. Brasiliensis-Elegantly mottled with white.

D. nobilis-Deep rich green, marked with irregular large white spots.

D. nova sp.-A species, with leaves long, narrow, light green.

D. picta-A handsome plant, striped and spotted with white.

DIGITALIS-Fox Glove (Hardy Biennial).

A well-known hardy border plant, flowering in June and July, possessing great beauty. The flowers in the different varieties are 
purple, crimson, white and spotted, as to color; have a thimblelike shape, and are produced in dense spikes. The plants may be propagated by sowing the seed in the spring or up to the middle of August, and then they flower the second year, or the roots may be divided and reset annually.

\section{DRACANA (Greenhouse Perennial, 35, 65, 95̃).}

Tropical plants of rare beauty, only suited to pot or Fernery culture in the window or conservatory, but may be introduced outdoors in pots, vases and hanging baskets for summer decoration with good effect. The beauty of the plant lies in the leaves, which in color vary from different shades of green to bright crimson and pink, striped, and as regards shape, are long, narrow and straight, somewhat resembling those of Indian Corn excepting that sometimes they are shorter. They succeed best in a soil consisting of one-third part leaf mould, also containing some sand, and then kept pretty moist.

D. draco-Stiff, sword like, green leaves; propagated from seed.

D. indivisa-Is of graceful habit and rapid growth; long, narrow leaves of green and bronze; useful as a decorative plant for vase or on the lawn; propagated by seed.

D. terminalis-Rich crimson foliage marked with pink and white; this varity is extensively grown for baskets, window gardens or the conservatory, the vivid coloring of its leaves rendering it at all times attractive; propagated from the root or from the stem.

\section{ECHEVERIA (Greenhouse Perennial, 35, 50, 90%).}

A remarkable class of plants, with thick succulent leaves of grotesque appearance, and suitable for pot culture in the window or conservatory, and also for bedding, some of the varieties being extensively used for carpet beds, also for ribbon lines and letters in bedding, for which purpose they are admirably adapted. They are prized chiefly for their odd, yet delicate appearance; few would consider them possessed of any greater beauty than is found in plants of the Cactus family. They are of the easiest culture, and while delighting in moisture generally, should be kept quite dry during the winter; propagated from leaves or cuttings. 
E. secunda-This variety forms a neat roseate tuft of green leaves, and produces freely for several months in succession, bright scarlet flowers with yellow centres.

E. secunda glauca-Similar to the above, with beautiful glaucous green leaves.

$E$. metallica glauca-A varjety with larger leaves than the preceding; flowers yellow and red.

ERANTHEMUM (Greenhouse Perennial, 45, 60, 95 $)$.

A large genus of greenhouse plants, valuable for their handsome foliage or for winter flowers. Pot in peat and loam in equal parts and add a little sand. Keep up a good heat and moisture; propagated from cuttings.

E. Andersonii-This charming plant is a native of India, and is not surpassed by any other plant in the beauty of its flowers, resembling some of the handsome Orchids; the spikes of flowers are borne on quite small plants, the two upper and lateral lobes are pure white, while the Orchidlike lip or lower segment is thickly dotted with crimson.

$E$. atropurpureum - Large dark-purplish shining foliage; very fine. E. Eldorado-Another good variety for bedding ; foliage green ; mottled golden yellow.

E. laxiflorum-Foliage green, flowers purplish-violet, very profuse. $E$. marmoratum-Surface of the leaf splashed with grayish-green and creamy white.

E. pictum-Foliage prettily streaked with white.

E. pulchellum-Dark green, wrinkled leaves and bright blue flowers.

$E$. sanguinea-A rather scarce species; foliage thick and leathery, of a deep crimson maroon. Leaves glossy-looking as if varnished-making a very attractive plant for decorative or bedding purposes.

E. tricolor-Like the Croton, Dracena, etc., this plant requires a warm temperature to bring out its beautiful variegations, which run through all the shackes of pink, purple and maroon. It has proved valuable for massing in open ground.

\section{ERIANTHUS RAVENNZE-"AMERICAN PAMPAS."-(Hardy} Perennial).

This ornamental grass, when in full bloom, attains a heiglı of from nine to twelve feet, occasionally having over fifty flower 
sijics on one plant, in two or three seasons, from seed. Perfectly hardy. Also increased by division of the roots.

ERYSIMUM (Hardy Annual).

Free flowering little annuals, producing flowers of beautiful orange shades, which are esteemed for their sweetness and suitability for cutting. Sow the seed where they are to flower.

\section{ERYTHRINA CRISTA GALLI-CORAL TREE-(Greenhouse Perennial).}

A half-hardy shrub, growing about four feet in height, with neat, cut foliage, the stems terminating with spikes of rich scarlet, pea-shaped flowers. Grows freely if planted in a warm situation; should be treated so as to remain dormant the same as Dahlias in winter. Propagated from cuttings or seed.

\section{ESCHOLTZIA-Californian PopPy-(Hardy Annual).}

The Escholtzia is a desirable garden annual easily grown from seed, and which flowers for a long time during the summer. The flowers are of a splendid yellow color in E. Californica, which is generally considered the best, and po sess a dazzling brilliancy in the sunshine. The dense growth which the plant takes on should be supported by sticks, or a portion of it may lie so close to the ground as to be detrimental to perfect flowering. Sow where they are to flower and thin out to one foot apart.

\section{EUCHARIS (Greenhouse Bulb).}

$E$. Amazonica-This is the famed "Lily of the Amazon." The flowers are white, star-shaped, exquisitely fragrant and borne in clusters of from four to six, on long stalks, above the foliage. They increase rapidly, but the bulbs should be disturbed as little as possible, repotting when necessary without division. These plants enjoy a warm and moist temperature. If wanted to flower in the winter water should be withheld during the latter part of the summer sufficiently to allow them to rest from August to October.

\section{EULALIE (Hardy Perennial).}

A hardy perennial from Japan, with long, narrow green leaves striped with yellow and white, throwing up stalks four to six feet 


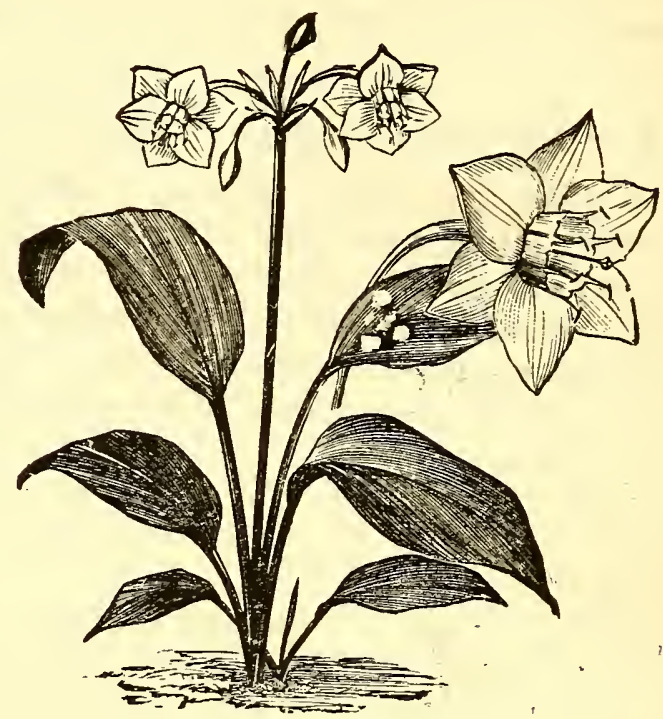

Eucharis.

high, terminating with a cluster of flower spikes on which the individual flowers are arranged; the flowers are surrounded with long silky threads, which, when fully ripe, or when placed in a warm room expand, giving the whole head a most graceful and beautiful appearance, not unlike that of an ostrich feather curled. These driec flowers are valuable as parlor ornaments, as they retain their beauty for a long time. Are propagated by division. E. Japonica variegata-Leaves striped lengthwise with creamywhite.

E. Japonica zebrina, or Zebra Grass-Leaves striped crosswise with yellow.

EUONYMUS (Greenhouse Perennial, 30, 45, $90^{\circ}$ ).

Very beautiful plants of a shrubby nature, valuable when small for pot culture, ferneries, winter hanging baskets, and in fact for any in-door purpose, as they are of neat, vigorous habit, with lovely leaves of glossy texture, in some kinds are variegated, and are scarcely equaled for growing in the shade. They are hardy south of Ohio.

The finest varieties for pot culture are aurea variegata and radicans variegata, which are nearly alike, except in their colors. The leaves of the former are of a rich golden yellow color on a green and in radicans variegata, a bright pea green, 
deeply margined with creamy-white, both having a striking and pretty appearance that is not common. Easily propagated from cuttings.

EUPATORIUM (Greenhouse Perennial, 33, 45, $75^{\circ}$.)

These are plants extensively grown by florists for the large crops of pure white flowers they produce in the winter. The flowers are borne in dense clusters on good stems. The plant is vigorous, of upright habit, and requires considerable pot room; of the easiest culture under any circumstances. As it propagates readily; it is best to start young plants early each spring for flowers the following winter; they should be grown in pots out of doors during the summer in a place protected from wind. Cut down the plants after flowering, which will induce a new growth to propagate from.

There are three varieties generally cultivated, the flowers of which are white and nearly alike in appearance. E. arboreum, the earliest to flower, $E$. salicifolius (very pure white) the next, and $E$. elegans the latest, the three varieties together affording a succession of bloom almost through the winter.

E. triste-Is of more recent introduction and certainly the best, being quite distinct in foliage, which is more vigorous than in the preceding varieties, its white flowers borne in trusses of immense size in mid-winter make it one of the most desirable plants for culture at that season.

EUPHORBIA (Greenhouse Perennial. 34, 45, 90)

An extensive genus of plants, of which the following varieties are suitable for greenhouse culture, producing an abundance of flowers, which are suitable for bouquets, etc,; they are of easy culture and are propagated from cuttings :

E. splendens-A continuous blooming variety, densely covered on the stems with long spines, giving it a curious appearance; bright scarlet flowers, with a yellow center; of great value for bouquets.

E. Jacquiniflora-Long racemes of orange scarlet flowers, which are very graceful.

EVERLASTING FLOWERS. See Acroclinium, Amobium Helichrysum, Helipterum, Gomphrena, Rhodanthe and Xeranthemum. 
FABIANA IMBRICATA (Greenhouse Perennial, 34, 50, 90).

One of the prettiest little shrub-like pot plants in cultivation, being of a dense pyramidal habit, with fine foliage and profusely covered with white flowers in the spring; excellent for baskets in summer or winter. Ordinary treatment and a good soil will suit the plant well; propagated by cuttings.

FARFUGIUM GRANDE (Greenhouse Perennial, 35, 50, 90).

A singular looking plant of easy culture in pots in the window or conservatory, the leaves of which are its attractive feature. These, borne on long stems, are large, round, smooth, of a deep green color, and blotched with distinct golden yellow spots, ranging from the size of a pin's head to nearly an inch across and distributed with a striking irregularity over the surface. The plants are increased by new shoots starting from the root, and then should be taken off and potted. Suitable for planting in baskets, vases, etc., for summer decoration.

FERN (Greenhouse Perennial, 35, 40 or 50, 80).

There are many species of Ferns or Brakes found growing in woods and swamp lands, in all parts of our country. These are kinds, the roots of which are perennial, but the tops of most of them die annually. The tender greenhouse species are perennial or evergreen, and are continually attractive, summer and winter. This class are among the most attractive plants which can be grown under glass or in the window, and especially in the latter place, with the use of a fernery or plant case. On page 43 this means of growing plants is treated upon, but I may repeat that it exactly suits Ferns and many other plants of similar requirements. Ferns are propagated from the spores which appear on the leaves, these being sown in earth after the manner of very fine seeds. The plants should be grown in soil largely composed of leaf mould from the woods.

We name the following ferns as embracing some of the most suitable varieties for general culture:

F. Adiantum Formosum (Maiden Hair Fern)-Jet black stems and light green fronds.

F. Alsophila Australis (Tree Fern)-A magnificent tree fern of rapid growth.

F. Asplenium Belangeri-Elegant feather-like fronds; deep green color. 
F. Lygodium scandens (Climbing Fern)-A climbing fern from Japan, of a graceful, twining habit, often attaining the height of fifty feet in its native wilds. It is easy of cuiture, treated as other ferns, and is a handsome plant,grown either climbing or drooping; the foliage is finely cut and very beautiful; a splendid house plant, unequaled in beauty.

F. Microlepia hirtha cristata-An elegant crested fern of good habit and growth.

F. Nephrodium molle-Long, dark green fronds, upright growth. F. Nephrolepis exaltata (Sword Fern)-Of easy culture, and soon grows to a great size.

F. Nephrolepis Duffii-An exquisite miniature variety of the oldfashioned, but ever popular Sword Fern, that commends itself to every one by its easy growth and graceful appearance.

F. Nephrolepis Davallioides Furcans-A beautiful and ornamental crested fern of easy culture.

F. Platycerium alcicorne (Staghorn Fern)-Resembles a stag horn; of easy culture.

F. Polypodium cureum (Hare's Foot Fern)-An elegant variety.

F. Polystichum Angulare-Long foliage, resembling plumes of feathers; light green color.

F. Pteris argyrea-Called by some Silver Fern. A very showy, strong growing Fern, with variegated foliage; fronds large, light green, with a broad band of silvery white down the centre of each; rery distinct.

F. Pteris serrulata (Crow's Foot Fern)-The fronds are pendulous and grass like; of easy culture.

F. Pteris tremula (Shaking Fern)-Very large, rich green foliage, beautifully cut. The strongest growing and best Fern for house culture; grows very rapidly and soon makes handsome specimens; should be found in every collection of house plants.

F. Scolopendrium vulgare (Hart's Tongue)-Very desirable for pot cu'ture, being among the hardiest kinds.

FEVERFEW-PYRETHRLM (Greenhouse Perennial, 33, 45, 85').

Very useful plants in several varieties, all of which are nearly hardy, of the easiest possible culture and readily propagated from cuttings. The double white Feverfew (Pyrethrum 
Parthenium) produces an immense crop of perfectly double, pure white, daisy-like flowers, an inch and upwards across, in clusters, on stems eighteen inches high, the fore part of summer, and then less freely at intervals, until late in the season, on which account it has become an important plant in every florist's greenhouse, and is deserving of general cultivation at the hands of amateurs, especially as there need be no failure in managing it, to produce an abundance of bloom.

PrinceAlfred is a variety similar to the preceding, but of dwarfer habit. Golden Feather Feverfew possesses no merit as a flowering plant, but is highly esteemed for its attractive, delicate cut foliage of a greenish golden color, and the dense symmetrical growth it assumes. It is a beautiful plant for massing or planting in ribbon lines, and like the two varieties described above, is very suitable as a pot plant or for planting in vases and large hanging baskets. The flower shoots should be pinched back as they appear. All the Feverfews may be taken from the ground in the fall and wintered in a cold-pit. To rear an abundance of stock for bedding, take plants thus secured into heat in February and then make cuttings, or else raise from seeds sown in January, which is a favorite course with florists.

FICUS (Greenhouse Perennial, 34, 45, 90).

A fine plant, very popular, not only in the hothouse, but as a decorative plant for the drawing-room or flower garden. Its thick leathery leaves make it especially valuable in consequence of doing perfectly well in the dry air of inhabited rooms; propagated from cuttings.

F. elastica (India Rubber Plant)-The old and favorite sort; fine large shining foliage.

F. Parcelli-Large leaves, beautifully marbled with bright green and white. The plant is of free growth and extremely effective.

$F$. repens-A fine creeper for green and hothouse decoration; it will cling tenaciously on a rough surface.

FITTONIA. See Gymnostachyum.

FORGET-ME-NOT. See Myosotis.

FORSYTHIA - GOLDEN BELl (Hardy Shrub).

A small genus of ornamental hardy shrubs, coming in flower very early. 
F. viridissima-Produces beautiful yellow flowers early in spring; leaves deep green.

F. Fortuni-An upright-growing shrub with bright green foliage; flowers bright yellow, dropping before the leaves appear. A fine early flowering shrub.

FOUR O'CLOCK. See Mirabilis Jalapa.

FOX GLOVE. See Digitalis.

FUCHSIA-Lady's EAR Drop (Greenhouse Perennial, 35, 50, 85).

The Fuchsia is one of that superb class of plants which, to an extent, are indispensable in every good collection. It is a well-known genus, and has for years attracted much attention by its elegant appearance as a pot plant, and more especially, its lovely flowers. The Lady's Ear Drop, as it is commonly called, is associated with our earliest recollection of window plants, cultivated many years ago, but since that time, like many other things, the florist's arts of improvement have caused wonderful changes in the flowers, and rendering the varieties of to-day immensely superior to those known a score of years ago. The Fuchsia is well adapted for pot culture on the window-shelf or in the conservatory-some varieties flowering beautifully in the winter. They delight in the winter, not so much in a high temperature as in a light place, in which they can frequently be treated to a bit of fresh air. By nature they require a season of rest annually, which should be given the ordinary varieties during the latter part of summer, and the winter-blooming kinds for several months in the spring and summer. During the rest water should be withheld from the plants to an extent that will cause many of the leaves to drop, a little being applied occasionally to prevent the soil from becoming entirely dry. They may be placed in any dry, airy situation, but at no time where it freezes. After resting sufficiently, they should be cut back to encourage the formation of a well-formed plant from the new growth, and should be well supplied with water. As the flower buds appear, plants may receive an occasional watering with liquid manure. Frequently repotting the plants as needed into larger sizes, and in a soil of the most fertile nature-it may be one-third well-rotted manure-are important in growing the plant to perfection. By paying attention to all these points, a growth of an astonishing magnitude 


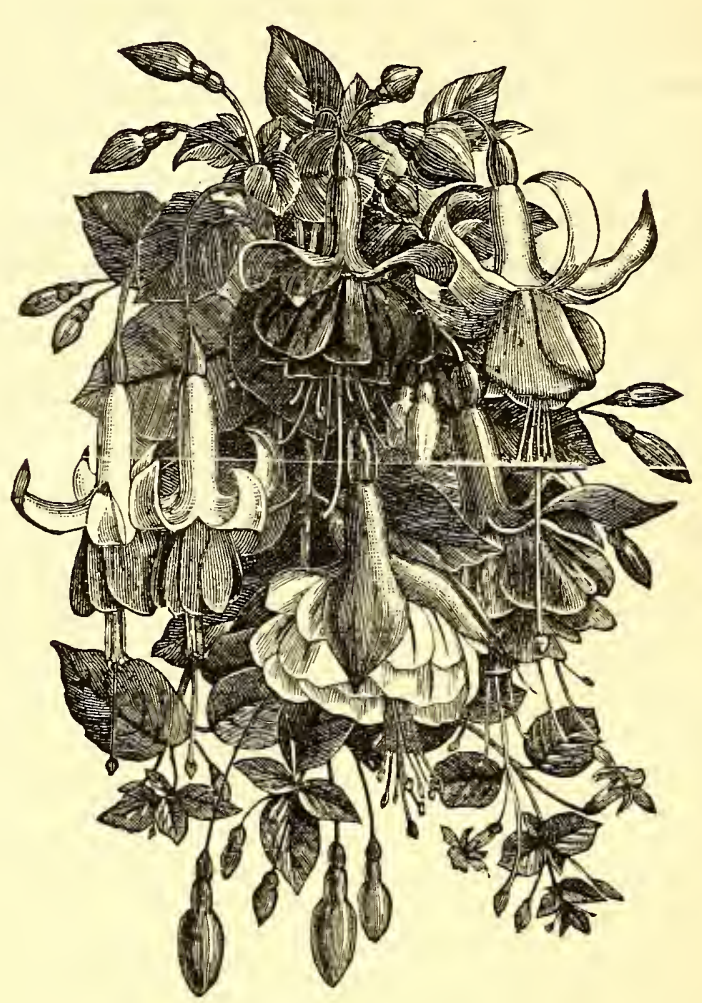

Fuchsia.

may be had in the time of a few months, by starting with healthy young plants. Excellent as a flowering plant in the centre of hanging baskets and rases in shaded sicuations, and the double varieties are quite suitable for bedding in partially shaded places that are also protected from sweeping winds; easily propagated from cuttings.

\section{SINGLE VARIETIES.}

F. Aurora superba-Orange scarlet corolla, sepals rich salmon. $F$. Arabella-White tube and sepals; corolla rose.

F. Black Prince-Tube and sepals bright waxy carmine; sepals large and broad, with pale green tips, and large, open, pale pink corolla, margined with deep rose; of a very distinct and vigorous, free branching habit. One of the best. 
F. Earl of Beaconsfield-Vigorous growing, free flowering, beautiful habit, quite distinct; one of the best hybrid varieties; the blooms are three inches in length and of great substance; the tube and sepals are of a light rosy carmine; corolla deep carmine.

F. Elizabeth Marshall-Tube and sepals scarlet; corolla white.

F. England's Glory-Pink corolla with carmine shade; a beautiful sort.

F. Fairy-A miniature variety of clear red color.

F. Gracieux-Single light red sepals ; corolla lavender blue; very fine.

F. Gov. Baker-Plum corolla; sepals crimson.

F. May Queen-Beautiful violet rose corolla; sepals pure white; extra.

F. Monarch-Immense flowers; tube and sepals of bright red and great length.

$F$. Prince Imperial-Dwarf; early; extra fine.

F. President McMahon-Corolla scarlet; sepals greenish yellow.

$F$. Rose of Denmark-Tube and sepals ivory white; corolla clear pink.

F. Rose of Castile-Corolla rosy purple, with lighter streaks, free bloomer and good grower.

$F$. Syringceflora-Large truss of flowers resembling in shape a bunch of lilac.

$F$. Sunray-This is an exceedingly novel and interesting plant; its leaves are richly marked in about equal proportions, with bright crimson, creamy white and bronzy green.

F. Try me'oh-Tube and sepals bright crimson, with large, open, bell-shaped black corolla, the darkest yet known; fine habit. $F$. Wave of Life-Foliage bronzy yellow; scarlet tube and sepals; violet blue corolla.

\section{DOUBLE VARIETIES.}

F. Avalanche--Beautiful golden foliage, and dark double violet purple corolla.

F. Champion of the World-Large double flowers; tubes short; sepals very broad and of great substance, well reflexed and of a most beautiful coral red; corolla most intense bright dark purple.

F. Dolly Varden-Very double dark corolla. 


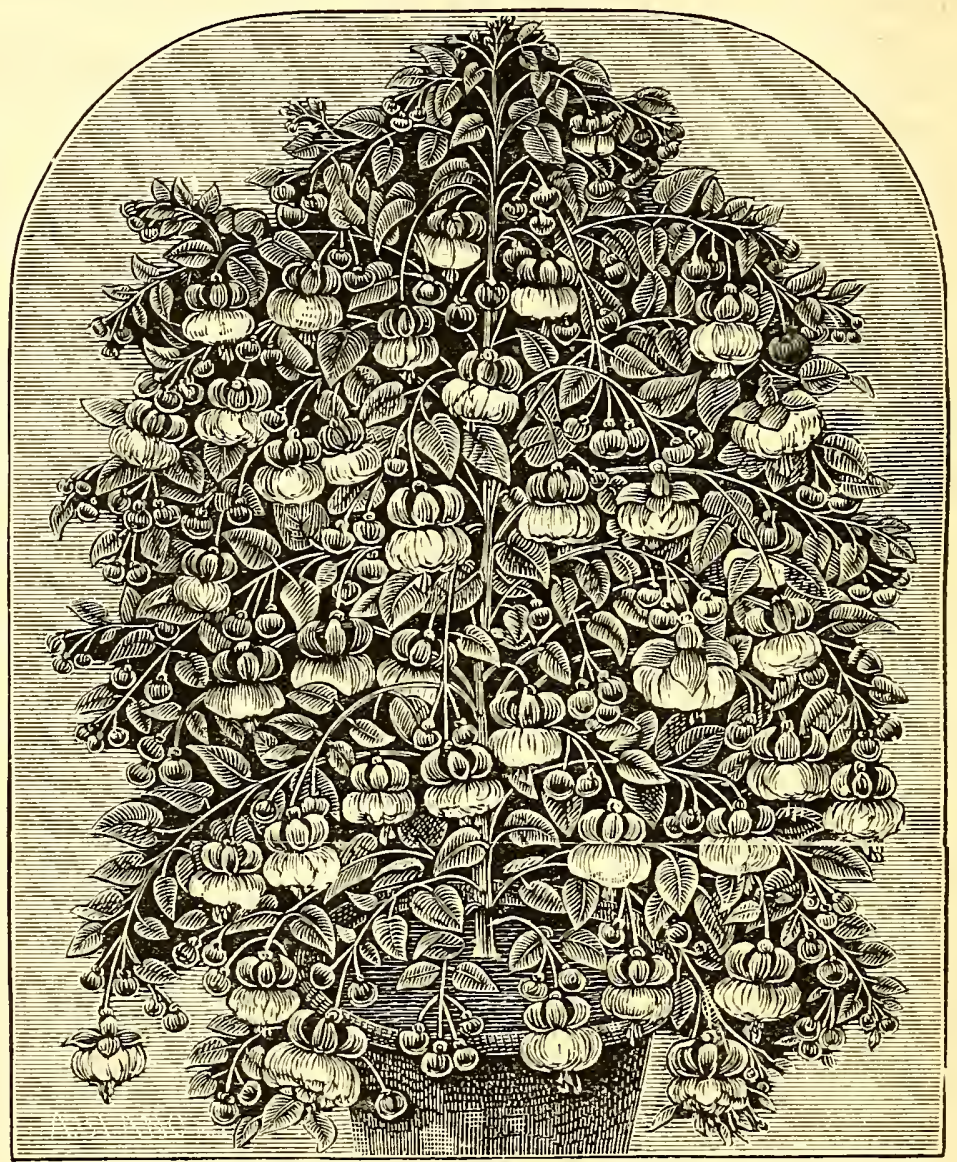

Double White Fichsia.

F. Elm City-Sepals rich crimson, enclosing corolla forming globular balls; dwarf and compact in habit; extra fine.

F. Joseph Rossain-Dark double, violet blue corolla; striped deep scarlet.

F. Kingsburyana-A variety of good habit and a most abundant bloomer, producing fine flowers with bright red tube and sepals, the latter refiexed and large; double, open and spreading white corolla.

F. Nellie Morton-New; one of the very finest Fuchsias yet raised, very large and double; pure white corolla, beautifully reflexed bright scarlet sepals; magnificent. 
F. Nonpareil-Two double dark corollas; very peculiar and striking.

F. Purple Prince-Tube and sepals waxy carmine scarlet; corolla rich violet; double.

F. Punch-Double violet corolla, sepals red.

$F$. Victor Hugo-Double; flowers very large; sepals red; corolla clear lilac. A new color.

WINTER-BLOOMING FUCRSIAS.

The following four sorts are the best for winter flowering:

$F$. Carl Halt-A white and red striped variety.

F. Mrs. Marshall-Corolla very bright purplish scarlet.

$F$. Lustre-Waxy white and sepals elegantly reflexed; corolla vivid crimson, tinted with pale orange.

$F$. Speciosa-A well-known variety, producing large flowers two inches in length, tubes and sepals of which are blush, the corolla crimson. Some plants of this variety grown in eight or nine inch pots will produce from three hundred to five hundred flowers from December to May.

FUnKIA-The Plantain Lily (Hardy Herbacous Perennial).

The White Day Lily ( $F$. alba odora) is an attractive, bulbous garden plant, with luxuriant, broad, veined foliage of a rich, yellowish green culor, and which grows in an elegant clump one foot high. The flowers are pure white and fragrant, of a pleasing appearance, being borne on stems twenty inches high, about mid-summer, opening only in the day. A mass of this beautiful plant growing on the lawn is very handsome. $F$. сcerulea is quite similar to the above, excepting that the flowers are light blue, and the foliage of a deep green. F. marginata has elegant variegated leaves, distinctly edged and striped with sulphur yellow.

\section{GALANTHUS-SNowdRoP (Hardy Bulbous Perennial).}

Delightful little pure white flowers, blooming in the open air very early, and sometimes in warm, sunny exposures even before all the snow is gone. There is a double and a single variety. No garden can be considered well stocked, without having, at least, a few clumps of these earliest of all flowers. The bulbs should be planted in the fall months with Hyacintlis, Tulips, etc., about two or three inches deep, and if set three inches apart in clumps 
a foot or two across, the effect will be the finest. Reset them once in three years. The Galanthus may also be forced into bloom in the winter in the house. (See page 52.)

GARDENIA. See Jasmine.

GAZANIA (Greenhouse Perennial, 32, 45, 85).

Summer and autumn flowering bedding plants of low, prostrate habit; the prevailing colors are orange and yellow, with a broad, intensely black velvety ring around the center. Excellent for planting at the edge in hanging baskets and vases for drooping over. Propagated from cuttings and layers.

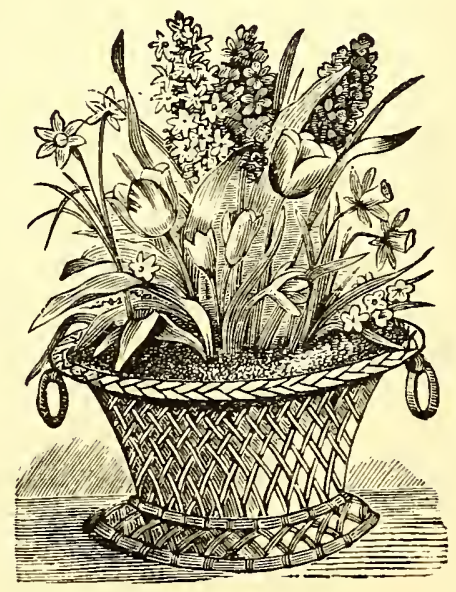




\section{GERANIUMS.}

GERANIUM-PELARGONIUM. (Greenhouse Perennials, 33, 45, $85^{\circ}$, except where noted).

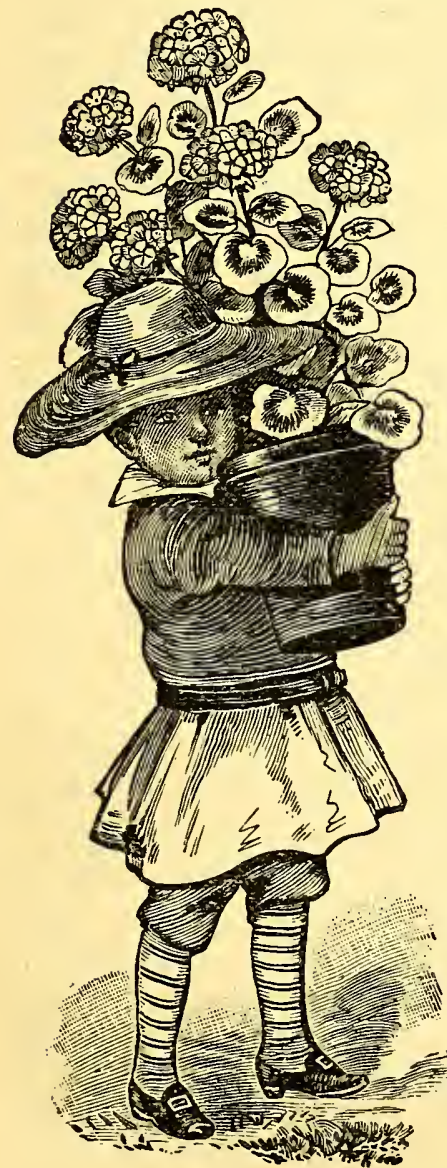

An extensive, varied and interesting family of plants of great value for pot culture and summer beảding in the open air. Indeed, in such a degree is this true, that a showy flower and window garden quite varied in its character, might be sustained by employing no other plants than those included in the genus. Their requirements in culture are throughout of the most simple kind, and there is scarcely such a thing as failure in realizing satisfaction from cultirating them, even by inexperienced amateurs. All the varieties of the several sections strike root readily from cuttings. August and September are suitable months for propagating, as an abundance of growth is then available, and cuttings struck at this season will make strong plants for next year's use. They will also, each year, afford many young cuttings during the winter for propagation. Young plants make such a rapid growth that it is better to provide plenty of new stock each fall and winter for bedding in the spring, and also for pot culture, than to work much with the old plants. A light place, where air can be introduced to them, is the most suitable one for their winter quarters. Old plants can easily be kept over in a warm cold-pit or light cellar, which is not too damp. (See Pelargonium.) 
The Geraniums are, perhaps, the most useful and popular plants in cultivation. Wherever we go where plants are grown, in any part of the civilized world; in the humble little garden; in the latticed window of the thatched cottage; in splendid palace grounds and national gardens; everywhere do we find the Geranium at once useful and beautiful, and entirely eclipsing by its mass of bloom and brilliant coloring, its more aristocratic and costly neighbors. They not only bear beautiful flowers, but the foliage of many varieties is almost as handsomely colored as the flowers; the leaves of some are loaded with the sweetest perfumes, while the others are of the most elegant forms, and inake a better setting for a button-hole bouquet than any other leaf known.

For constancy of bloom the Geranium is unequalled. Small plants, that can be bought very cheap, if put out in May and June, will soon after planting, completely fill a bed and will be a mass of flowers, and continue getting better, until blackened by the frosty nights of autumn. While other plants are wilting under the scorching rays of our sunmer sun, the Geranium seems to glory in the hottest weather.

The Geraniums make excellent winter blooming plants, if not kept too warm; but for this purpose should be grown in pots all summer, and the buds picked off as they appear.

\section{ZONALE, SINGLE OR HORSE-SHOE GERANIUMS.}

This is, perhaps, for all purposes, the most useful class in cultivation, the plants being easily grown, affording a large variety of colors, embracing all shades from purple and scarlet to white. As bedding plants they are unequalled, being rapid growers, vigorous and healthy, bearing the hottest sun admirably and are remarkably free flowering. Scarcely a more pleasing or yet more simple disposal of plants can be effected than to mass the scarlet varieties a foot or more apart, according to size, in a bed upon the lawn, to be viewed from a distance as from a walk or a favorite window in the living room. The plants should not be put into the ground until the weather is quite warm and all danger from frosty nights is over-in the Northern States toward the last of May. Set the plants so that when grown, they will cover the ground. For brilliancy the varieties, Gen. Grant, Gen. 
Sheridan and Queen of the West are the best, being strong gruwers and immense bloomers. All during the season many large, dazzling heads of bloom are conspicuous over the green, compact mass of leaves, affording a continual, never-tiring sight for months, which, for attractiveness, cannot be fully approached by any other plants in cultivation, similarly arranged. The number of plants employed or the size of the bed has less to do with its general effectiveness than the adherence to the principle of using only one variety in the same mass, and also that the plants be nearly uniform in size (see "Planting in masses of color." page 21). Besides the excellent scarlets named, there are others quite as suitable for bedding in masses, but my advice to amateurs is to make their first choice from the above named varieties for this purpose, leaving other colors for subsequent plantings, unless it is desired to plant a compound bed with Geraniums, each part with a distinctly colored variety. As stated before, masses of Geraniums should be all of one color for the best effects, but a departure from this rule may be suggested as being, perhaps, quite as satisfactory, and that is to have the general mass one colorsay, for instance, scarlet, and then bringing an edging of another color, like white or pink, around the outside of the scarlet. The following varieties are the best for massing: Gen. Grant, bright scarlet; Gen. Sheridan, darker scarlet; Queen of the West, orangescarlet; Master Christine, pink; White Perfection, white; Celestial, deep rose, tinged white; Bishop Simpson, salmon: Louis Uhlbach, light yellow; Hoffgartner Eichler, dark crimson; Ralph, amaranth purple.

In massing Geraniums the beds may or may not be edged with plants of other kinds such as have showy foliage, as best suits the planter. The ground to be planted with Geraniums should always be slightly raised in the center to a mound-like form. This class of Geraniums are much used as pot plants, and for planting in the center of hanging-baskets, and vases for which last named purpose there can be nothing better. Indeed some of the best filled vases we have ever seen, were planted with Geraniums alone.

G. Apple Blossom-Beautiful trusses of a pearly white, suffused with rosy-pink.

G. Alcibiade--Red-salmon, shaded clear violet at center; pips large; gcod trusses.

G. Amaranth-Beautiful lilac pink. 
G. Audiffret-Pasquier-Carmine lake, slightly veined rose upon the upper petals.

G. Antonin Proust-Violet-carmine; upper petals marked purplish crinson; very fine flowering.

G. Bishop Simpson-Large trusses of rich salmon.

G. Beauty of Kingsessing-Salmon center, margined with white.

G. Bramford's glory-Bright, clear scarlet.

$G$. Blonde Beauty-Deep flesh color, shading to white.

G. Celestial-Deep rose, tinged white; an extra fine sort for bedding out, or winter flowering.

G. Christine Neilson-Bright rosy pink.

G. Cinderella-Bright rosy salmon, fine truss, new color; a beautiful variety.

G. Challemel Lacour-Rich, vivid crimson; immense trusses; very fine.

G. Cherry Lips-Bright cherry; distinct color.

G. Dazzler-Exceedingly rich scarlet, with large white eye; very brilliant.

G. Evening Star-This beautiful sort is most attractive, having a white ground with large pink eye.

G. Eva-Magenta; fine color.

G. Fairy-Salmon, flaked white.

G. Favorite-Light pink; immense truss.

G. General Sherman-Light crimson; a fine bedder.

G. General Hood-Very large flowers of a deep velvety scarlet color; a beautiful sort.

G. General Sheridan-Showy scarlet; a fine winter flowering geranium, and also a fine bedding geranium: always in flower.

G. General Grant-Fine scarlet; this variety is used largely for bedding out.

G. Gnome-Immensely large pips of the most intense glowing scarlet; small white eye; single florets measure full two inches in diameter.

G.Guinea-Brilliant orange yellow; the nearest approach to a yellow Zonale yet sent out.

G. Harry King-Intense scarlet with large white eye.

G. Hoffgartner Eichler-Dark crimson shaded to bright scarlet.

G. Illustre Citoyen-Dark orange red, centre whitish lilac; flowers and trusses large.

G. Institutor Deleval-Upper petals currant red; lower petals flame color; magnificent. 
G. Ianthe-Purplish crimson; fire.

G. Jersey Lily-New, tender, rosy salmon, the base of the upper petals marked white; flowers of beautiful form; a truly magnificent variety.

G. Jacques Leinhart-Rich scarlet, lined with crimson; of fine form and habit.

G. Jealousy-Bright orange scarlet, so much so as to give a decided yellow hue; a beautiful sort.

G. Jean Sisley-Fine scarlet, white eye; fine winter bloomer and good bedder.

G. Jules Favre-A new and peculiar shade; violet shaded with lilac and light crimson.

G. Jacquard-New, orange red; upper petals touched with violet; white centre; a fine flower; a beautiful sort,

$G$. Leviathan-A fine sort; bright crimson scarlet, shaded vermilion; free bloomer; immense trusses five to six inches in diameter.

G. La Franche Gaite-Centre pure white; edge of petals light red.

G. La France-Violet purple, with fiery markings at base of upper petals.

G. $L^{\prime}$ Elysee-Deep orange-colored flowers, graduating to salmon toward the edges.

G. Louis Uhlbach-Yellowish red in color; a seedling of the Guinea.

G. Mrs. Jas. A. Garfield-A new Geranium with the purest white flowers; dwarf and one of the finest sorts for pot culture.

G. Madame Rampler-Fine, clear white, veined with purple; extremity of the petals snow white.

G. Madame Recamier-Large, round flowers of perfect shape; deep rich crimson.

G. Master Christine-Bright pink; fine bloomer; one of the best for summer bedding.

G. Mrs. Windsor-A beautiful new variety with large trusses of blush white, with a scarlet eye.

G. Mrs. Moore-New, pure white, with a beautiful ring of bright salmon around a small white eye; very tine.

G. Mrs. James Vick-White edges, pinkish centre; without an equal for winter.

G. Mathilda-Rose pink; fine, 
T. Mary Halleck Foote-Bright pale salmon.

G. Mazeppa-Pure scarlet; immense trusses.

G. Md. Danelle-Clear delicate rose; upper petals marked with white.

G. $M d$. Domage-Very fine scarlet.

G. Merimee-Orange, with white toward the edges.

G. Marietta Pacha-Carmine red, deepened with crimson.

G. Maid of Kent-Pure lake-rose or pink.

$G$. Masterpiece-Rosy scarlet; of great size.

G. Newland's Mary-Beautiful dark pink.

G. New Life-Scarlet flowers, flaked and striped with salmon and white.

- G. Othello-Very dark scarlet.

G. P. L. Courier-Immense trusses rich vermilion.

G. Perseus-Light pink shaded with salmon.

G. Par Excellence-Scarlet magenta; large trusses.

G. Pride-Fine large salmon.

G. Princess Maud-New, scarlet, pure white eye; very fine.

G. President Garfield-Color lake carmine; upper petals marked orange; a very fine variety.

$G$. Queen of the West-Bright orange scarlet; large truss and profuse bloomer. We know of no finer Geranium for planting out in beds.

T. Rose Unique-Large trusses of an incarnate rose color, rayed with white in the centre, reverse of petals violet.

G. Rienzi-Rich scarlet.

G. Renomme-Clear apricot, passing to copper rose, veined centre, large trusses.

G. Ralph-One of the best bedding sorts $y=t$ introduced; profuse bloomer; color dark amaranth purple.

G. Streak of Luck-A rival of New Life; saimon color striped with white; very free flowering.

1 $\frac{1}{x}$. Scarlet Vesuvius-Bright scarlet; very free bloomer.

G. Salmon Rienzii-A most beautiful salmon of great size; very fine.

G. Salmon Leviathan-In the style of Crimson Leviathan but larger; salmon flowers.

G. Sara Bernhart-A splendid new white Geranium; flowers purs white, without even colored stamens; a beatiful sort. G. Sunshine-Vermilion scarlet.

G. Thomas Carlyle-Center vermilion, shading to salmon. 
G. Von Moltke-Dark soft red, tinted with scarlet and heavily shaded with maroon. Its glossy, velvety color can not be excelled.

G. W. K. Harris-Blush, pale red center; fine, large round flowers.

G. Wood Nymph-Bright clear pink, with white markings on upper petals.

G. Wilsonii-Light amaranth.

G. White Perfection-Pure white; fine bedder.

G. White Vesuvius-Color, white ; round petals ; very free flowering.

(․ William Cullen Bryant-The finest shaped single flowered Geranium known. Each floret on strong plants will measure two inches across ; color a soft, rich, pure scarlet. The thickness of petal and size of flower makes it appear as if stamped out of thick velvet. The trusses are large.

G. Zuleika-Upper petals shaded crimson, lower petals blush purple.

\section{DOUBLE GERANIUMS.}

The Double Geraniums have now been in cultivation for a number of years, and at the present time include almost every desirable color, even to pure white. Their general habit and appearance is similar to the Single Geraniums. The plants are equally valuable, whether employed for bedding or for growing in pots. The Double Geraniums have been wonderfully improved the past few years and are in every way proving formidable rivals to the Single Geraniums, not only as to variety in color, but also in free flowering qualities, and in the dwarf branching habit. So excellent are many $\mathrm{cf}$ the sorts of the present day, that those who grow flowers for sale depend largely on these for contributing lively colors to their cut flowers and bouquets. When well grown it is not rare to find flowers as large and full as a Carnation. while the colors are brighter than those of that favorite flower. They are very fine for winter blooming, lasting much longer than the single, varieties.

G. Admiral Seymour--Rich, dark amaranth.

G. Ami Hoste-Dark crimson, shaded with purple.

G. Amazone-Creamy white, free bloomer.

G. Asteroid-Deep rich crimson.

G. Alba Perfecta-Large, fine, snowy-white flowers; very free bloomer. 
G. Asa Gray-Salmon-pink flowers, edged with white; one of the best sorts; a constant bloomer.

G. Bousingault-Orange-vermilion, softened with rose.

G. Bishop Wood-The upper petals carmine-scarlet, lower petals a violet-rose; a new color.

G. B. K. Bliss-Of all varieties this has the largest flowers and most vivid coloring; the individual flowers are two inches in diameter, of good shape, trusses large; color, a rich tone of pure scarlet.

G. Charles Darwin-Rich deep violet-purple, the base of the superior petals marked with a flaming color.

G. Commandant Ott-Scarlet-orange, shading into vermilion; habit and form very fine.

G. Cybele-A new and fine sort; has immense trusses of large flowers of a bright salmon-rose color, some of the petals fluted and blotched blush white ; very distinct.

G. C. H. Wagner-Brilliant orange-scarlet, with a purple hue on the lower petals.

$G$. Candidissima-A large, full, finely formed flower of the most snowy whiteness.

G. Casimer Perier-Very double flowers of flaming orange, bordered wtth salmon.

G. Cabanel-Plant dwarf and a vigorous grower; truss extraordinary large; spherical; bright carmine color.

G. Cheerfulness-A new color; flesh pink, shaded and mottled rose: extremely double petals somewhat fluted or fringed: a fine and distinct variety.

G. Depute Ancelon-Deep magenta-rose, with a violet cast ; very double and fine.

G. Depute Berlet-A beautiful shade pink with a tinge of violet.

G. Depute Laflize-Flowers a dark vermilion purple, large trusses with the pips closely packed.

G. Depute Varroy-A bright lake color, deep at edges of petals and shading to white at the center ; a beautiful shade.

7. D. Dr. Jacoby-Enormous trusses of large double flowers of clear nankeen salmon; one of the finest Geraniums in our collection.

G. Ed. Andre-A beautiful flower, of dark rose, shaded with violet.

G. Emil de Girardin-A splendid variety with enormous trusses of rose-colored flowers. 
G. Ernest Lauth-A magnificent variety; flowers large, full and well-formed; deep-glowing crimson, illuminated with scarlet.

G. Flocon de Niege-Plant dwarf; free flowering; trusses very large; flowers pure white.

G. Guillion Mangilli-Splendid large, round truss of rich carmine crimson; prolific bloomer and good bedder.

G. Grand Chancelier Faidherbe-A new sort; very thick and double flowers of a dark soft red, tinted with scarlet and heavily shaded with maroon; very dark and rich, and at the same time very bright; simply a superb variety.

G. Gilded Gold-Bright orange scarlet or flame color; flowers large, of fine form, branching habit, very constant bloomer and one of the best geraniums either for pot culture or for bedding.

G. Gustave Dore-A fine Hower of shaded scarlet, reverse buff; very fine.

(․ General Saussier-Rosy salmon, shaded into violet; a very beautiful color; habit good.

G. General Campenon-Large, fine truss, deep purplish red, shaded with violet.

G. (reneral Billot-Large truss; extra large florets; its color is lake, tinted with flame.

G. George Thorpe-The trusses are of immense size, on very strong foot stalks; the color is of the most intense light crimson; the habit is branching and the foliage never burns; a grand variety.

G. Hoff. Beach-Rich amaranth purple: of fine habit and robust constitution, the foliage wearing well in the hottest weather; the flowers are of good size, the trusses large and freely produced; a good variety for bedding.

G. Henry Cannell-The richest, most vivid and dazzling scarlet; florets of great size and perfect form; always in bloom. Its glowing, velvety color cannot be excelled, and it will bed as well as the singles; the best double Geranium grown.

G. Iroquois-New, intense deep scarlet, very large and double flowers; very free flowering.

G. Illuminator-Black velvety crimson; very double and brilliant; quilted.

G. John Fennely-Very double, light salmon, striped with white. 
G. J. C. Rodbard-Brilliant red, upper petals tinged with purple. G. Jennie Reid-Very dwarf; bright scarlet.

G. J. H. Klippart-Entirely distinct from any Geranium yet offered; flowers double, of the most dazzling vermulion scarlet. shaded with mahogany at base of petals; trusses very large, often measuring five inches in diameter; of globular shape, resembling a scarlet ball; a remarkably free bloomer, and equaling General Grant as a bedder; a magnificent variety; commended.

G. J. P. Kirtland-Large, double flowers; color rich deep crimson dashed with purple; upper petals stained with scarlet.

$G$. Jewel-One of the most beautiful; very dwarf and compact; bright scarlet; very double.

G. James Vick-Fine shade of crimson; lower petals changing to violet rose; a new color.

G. J. P. Stahl-New, deep soft rose, edged with salmon; a beautiful color and one of the finest new geraniums introduced.

G. John Heron-Rich plum purple; flowers and trusses larger; habit compact and spreading; a fine bedder and quite an acquisition.

G. La Negre-Dark maroon, full and perfect; large trusses; one of the best.

G. L'Abbe Gregoire-Free flowering; the upper petals are of a fiery amaranth; the lower of a capucine red.

G. Lemoines Cannell-New. This is by far the most highly-colored Geranium grown: as nearly as it can be described, the color is a rich amaranthine red; the under petals very strongly marked with purple, producing a very rich and heautiful effect.

G. Le Pilote-Glowing crimson scarlet; very brilliant, handsomely-formed flowers, beautiful in its rich coloring.

G. M. Hardy-Large flowers, very double; perfect in form; of a delicate rosy pearl color.

G. M. Puteaux Chaimbault-Plant dwarf and compact in form; spherical trusses; flowers semi-double; fine rose color; excellent for pot culture.

G. Mrs. Cope-Rich carmine red, of large size and immense trusses.

G. Madame Amelia Baltet-Dwarf habit and remarkably clear; double pure white, in good trusses; the freest flowering double white yet raised. 
G. Madame Thibaut-Flowers very large, of a rich rose color, washed with violet carmine; the upper petals strongly marked white at their bases; one of the best for winter flowering.

G. Md. Grangeorge-Bright mauve; upper petals clear white toward the centre; a most beautiful sort.

G. Mrs. Charles Pease-Has flowers of an exquisite deep pink color, with upper petals of each flower distinctly marked with pure white, so much so as to make it appear as if onehalf the flower is white, producing a novel effect; one of the best for pot culture.

G. M. Deriard-Enormous trusses of a magenta red, with a metallic shade; a very free bloomer.

G. Minister Constans-Flowers very large and full; bright orange shaded with salmon.

G. Mary Anderson--Fine vermilion scarlet; a fine new sort.

G. Mrs. Hayes-Very double flowers of a beautiful light shade of pink or flesh color; very fine.

G. Monsieur Buchler-Flowers double, of good size; beautiful bright mahogany color.

G. Monsieur Dibos-Flowers well made, in the form of roseites, porcelain white; centre glossy rose.

G. Maiden's Blush-White, finely flaked with rose; a new color.

G. Paul St. Victor-Enormous truss, large florets, rosy carmine; foliage fine and compact.

G. Phallas-A rich, apricot orange; most vivid in coloring; trusses very large; habit neat and free; fine and distinct bedding variety.

G. President Charton-Salmon, brilliant at the centre, white extremities of the petals

G. Peter Henderson-Bright orange scarlet, very double; base of petals pure white; a remarkably fine Geranium.

G. Queen of Roses. Dwarf; beautiful light rose flowers.

G. Queen of the Fairies-A bi-colur variety of the most perfect shape; rich flesh color, mottled with pearly white.

G. Robert George-Deep crimson scarlet of great size; free bloomer.

G. Sapier Pompier-Flowers large, very double and finely-shaped; color deep scarlet.

G. Sylphide--Flowers delicate, slightly tinted with lilac, with a disinct white spot at the base of the petals. 
G. Simon Delaux-Very double, large pips, rich violet purple.

G. Souvenir de Custıle-A splendid variety; flowers amaranthine red, beautifully toned with violet; a grand sort.

G. Soleilett-In form dwarf, free blooming; of a rich violet lake color; very fine.

G. Siren-Very large individual florets of pure white.

$G$. The Ghost-Flowers white, finely formed; petals waxy and of great substance.

$G$. The Blonde-Salmon, deeply shaded orange; base of petals white, with a white margin,

G. Victor Hugo-Flowers very large and double, and color a flaming orange touched with the tints from the dawn of day; novel and superb effect.

G. William Hamilton-New, a grand variety, rich deep crimson, with very bright maroon shadings; large flowers.

G. Ziccot Mangenot-Very large truss, speckled with cream color on a ground of light rose, with tints of carmine.

\section{IVY-LEAVED GERANIUMS.}

A splendid class of climbing or trailing Geraniums, adapted for baskets, vases, rock-work and training on trellises in pot culture. They have thick glossy foliage of a peculiar waxy texture, possessing mostly the Ivy-leaf shape, which of itself would be of sufficient beauty to warrant their cultivation, but they also have the charming attraction of beautiful flowers as well as foliage. They bloom with the greatest freedom during the spring and summer, flowers varying from pure white to dark rose, and the flowers show to delightful advantage, owing to the habit of the plants. The plants are also interesting for bedding, as they grow freely and creep beautifully, if not supported, forming dense masses of glossy green, covered with beautiful flowers.

\section{SINGLE-FLOWERED IVY-LEAVED.}

G. Butterfly-Bright rose, striped crimson.

G. Bridal Wreath-Fine, large trusses of pure white flowers; a very distinct variety.

G. Innocence-Pure white; excellent.

G. l'elegante-An extremely pretty variety of bright green foliage, with a broad band of creamy white, often margined with pink; its pure white blossoms are produced in dense clusters. 




Ivy-Leaved Geranium.

G. Mrs. H. Cannell-Large trusses of flowers of a deep mauve purple, perfectly round and produced in great abundance; largest flowered and most distinct ivy-leaved Geranium grown.

G. Princess Alexandria-Blush pink, feathered with violet crimson; a strong grower; very free flowering, making one of the handsomest basket or vase plants that can be grown.

\section{DOUBLE FLOWERED IVY-LEAVED.}

G. Charm-A very fine large flower of a beautiful bright pink color, with rich crimson marking in the upper petals.

G. Candeur-Flowers very double; pure white, of excellent form and habit; a very beautiful variety.

G. Countess Horace de Choiseul-Plant vigorous; leaves without zones; flowers very large, double and imbricated in good trusses; color bright golden salmon; the brightest colored of all the ivy-leaved varieties; one of the finesi hangingbasket plants grown. 
G. Glorie d'Orleans-A magnificent variety; flowers very large, of light violet red; always in bloom and-flowers in clusters.

G. Jeanne d'Arc-Flowers very large and double, of the purest white; fine habit; free flowering; the best.

G. la Rosiere-Flowers of perfect shape, double and of good size; color satin rose; an excellent variety.

G. Madame Dubos-In this variety we have a real advance in double flowering Ivy Geraniums; the flowers are very large, full, double; in color a deep, beautiful pink; an extra fine sort.

G. Monsieur Pasteur-Flowers finely formed, very large petals, fine cherry color, suffused with rose; good habit and fine grower.

G. Plutus-A fine variety; produces a fine, large rosette-like flower of a violet rose color.

G. Vice-President Joly-Flowers round and finely-formed; petals imbricated; color clear rosy lilac. This variety rivals the well-known zonale-Mme. Thibaut in form and color.

\section{GOLDEN TRICOLOR AND SILVER-LEAVED AND TRICOLOR GERANIUMS $\left(33,50,85^{\circ}\right)$.}

As their names imply, the chief merit of this section consists in the distinctly margined and variegated foliage, although, without an exception. they produce fine flowers. Well-grown specimens as pot plants are exceedingly handsome for decorating the parlor or conservatory, but they should have a position as near the glass as possible, as the colors will be more clearly defined for being thus treated. The different varieties are useful for planting in ribbon beds to contrast with Coleus, Achyranthes, etc., or for edgings to beds of Scarlet Geraniums, and also for planting in baskets and vases.

\section{GOLDEN TRICOLOR GERANIUMS.}

(7. Countess of Tyrconnell-Yellow margins with a bright carmine zone.

G. Countess of Craven-Margin of clear golden yellow, with a rich crimson zone.

G. Crown Jewel-This has a fine bold leaf and good colors.

G. Earl of Derby-Zone dark chestnut red and black; margin of golden yellow. 


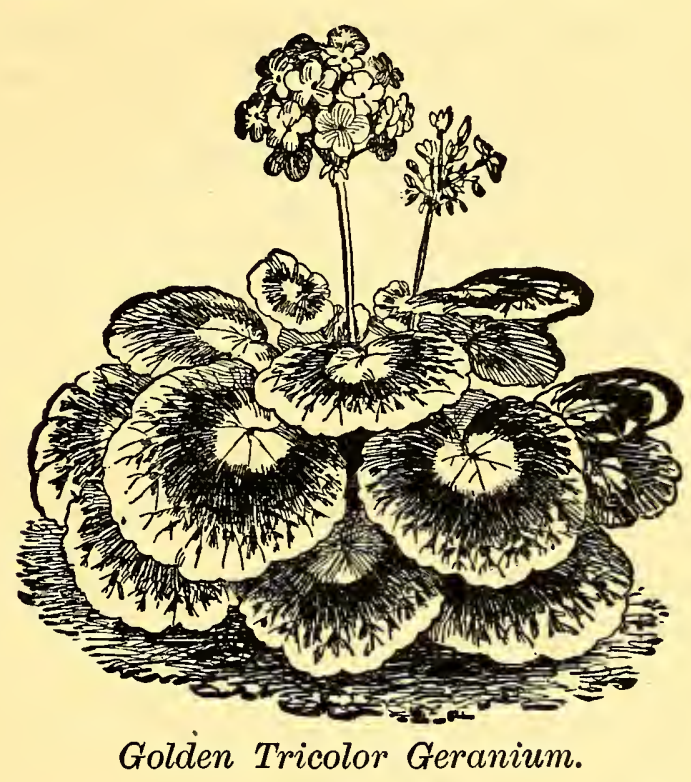

G. Edwina Fitzpatrick-Green, red zone, belted with crimson, edged with golden yellow.

(7. Ebor-Broad gold margin, broad zone, tinted with flame red.

G. Golden Pheasant-Leaves green; centre bounded by a splendid bronze zone; rich yellow belt.

G. Humming Bird-A beautifully-shaped leaf; it is certainly one of the best.

G. Jetty Lacy-Bronze gold margin, deep crimson zone; good grower.

G. Louisa Smith-Deep yellow, margined with distinct zone of bright red and black.

G. Mrs. Pollock-A magnificent variety; the green leaf disc, overlaid by a beautiful bronze red zone, belted with bright crinuson and outwardly margined with golden yellow; very fine for the parlor or conservatory during winter and spring.

G. Needle Gun-Margined with deep yellow; zone bright and lively.

G. Queen of Tricolors-Crimson scarlet zone, with brimstone edge.

G. Rosina Saul-This is a beautiful tricolor, zone exceedingly bright and clear, with a bright yellow margin.

G. Sir Robert Napier-The broadest and darkest zone, indented with brilliant scarlet; flesh-colored flowers; extra. 
G. Sunset-A rich, broad, outer golden belt, the inner margin of which is overlaid with a bright carmine red zone and flame scarlet tints.

G. Sophia Dumaresque-Golden margin marked by a brilliant flame-tinted scarlet zone.

$G$. Socrates-Golden leaf margin; zone flame red upon a bronze belt.

G. Star of India-Margin golden yellow; zone flame scarlet.

\section{SILVER-LEAVED AND TRICOLOR.}

G. Argus-Chocolate zone, white and green markings; a stron $\xi$ grower; one of the best.

G. Bijou-Leaves finely margined with white; scarlet flowers.

G. Bright Star-A white edge; scarlet flowers.

G. Brilliant--Leares margined with white; bright scarlet flowers.

$G$. Cherub-Leaves deep green, white and orange; flowers carmine.

$G$. Castlemilk-The whitest margined variety; olive green center.

G. Countess of Warwick-Vigorous grower; deep green, with pinkish carmine zone, creamy edge.

G. Empress Eugenie-A rose zone on a chocolate ground, white margin.

T. Flower of Spring-Leaves margined white; scarlet flowers.

G. Fontainbleu-Margined with white; bright carmine zone.

G. Freak of Nature-New; a very unique and attractive variety; outside leaves light green, with a large, pure white center; flowers light scarlet, dwarf and spreading.

(․ Glen Eyre Beauty-A beautiful variety with well-defined zone of dark chocolate and rosy carmine and very pure; white margin.

G. Happy Thought-A tricolor Geranium, with very dark green foliage, having a light creamy, almost white center, with a dark band about the light zone. It is a beautiful plant, and flowers bright scarlet.

G. Litlle Beauty-Silver margin, with pretty rose-tinted zone.

$G$. Jane-Leaves margined with white; very fine bedder.

G. Mountain of Snow-The finest of this class; a vigorous grower, an abundant bloomer, and for riblon lines of massing is one of the best; the center of the leaf is bright green; the outer margin broadly marked with silvery white; one of the whitest leaved sorts; flowers bright scarlet. 


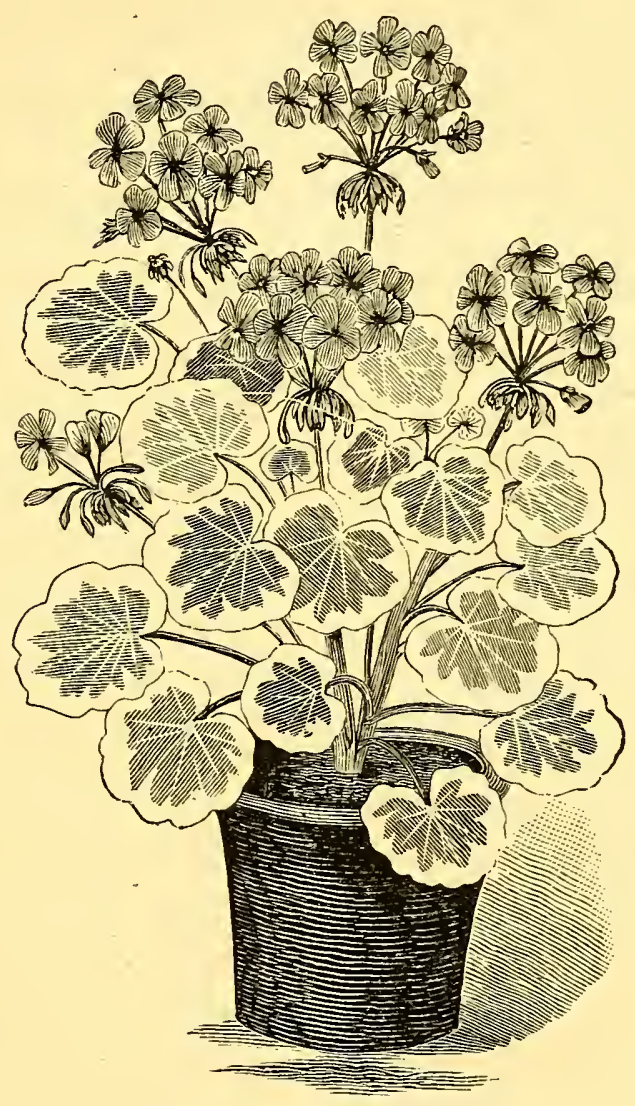

Silver-Leaved Geranium.

G. Mrs. John Clutton-A very attractive sort; leaves pale green, with a creamy white edging and a bright crimson zone, which is very brilliant on the young foliage, giving it almost the appearance of flowers.

G. Mad. Sallervi-A very compact variety of Silver Geranium; very fine for massing or bordering; a thrifty, healthful grower, rarely reaching a height of more than six inches; leaves very small, of a peculiar clear green, edged with pure white.

G. Prince Silverwings-A beautiful variety, silver tricolor; foliage green, yellow and white edge, crimson zone.

G. Queen of May-Foliage white, green, brouze and pink. 
G. Snowstorm-One of the finest in the class of Silver-Leaved Geraniums; the margin of the leaf is very broadly margined with white; dark green centre and scarlet flowers. G. Silver Cord-Pure white margin, green leaf. G. Silver Pheasant-A vigorous grower and good bedder; leaves margined creamy white; flowers scarlet.

\section{SCENTED AND CUT-LEAVED GERANIUMS.}

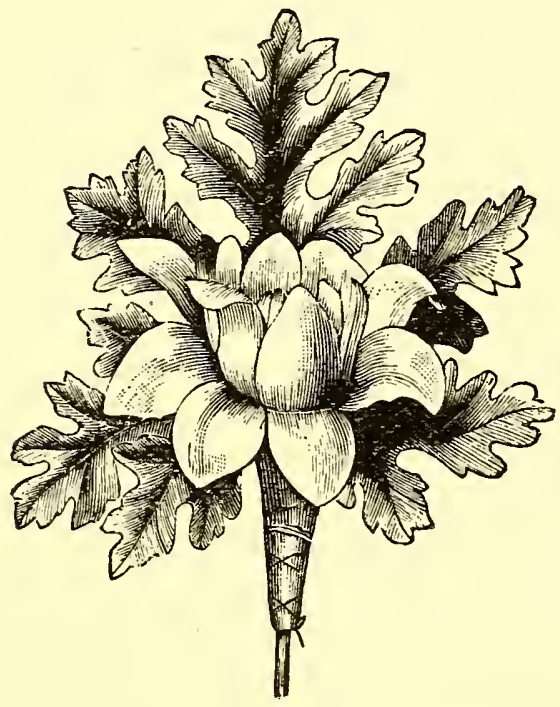

Cut-Leaved Geranium.

The Geranium family affords in this delightful section, a remarkable diversity of sweetsmelling odors in their foliage, resembling fruits, etc., which is not common with any other class of plants to anything like a similar extent. The Rose, Apple, Lemon, Orange and Peppermint are sufficiently distinct in fragrance that no imagination or fancy is required to detect the resemblance to tie natural fruits, etc., from which they derive their names. The Nutmeg fragrance in the variety so called is not quite so apparent; neither is that of the Citron and Pennyroyal, yet these each possess quite a distinct fragrance which is agreeable and desirable for variety. The Oak-Leaved variety closely resembles the oak leaf in shape; has clearly defined variegations and bears attractive pink flowers with brilliant dark spots on the petals. Fernifolia is a beautiful variety with very thin, finely cut leaves of fern-like texture and of a transparent green color, which renders it of real interest. The Skeleton-Leaved is a very attractive variety with foliage of a skeleton-like appearance, that is to say: the leaves are singularly cut, the fleshy material lying along both sides of the frame-work of ribs, but generally less than oneeighth of an inch in width in any part. Dr. Livingstone somewhat resembles the skeleton-leaved and makes a remarkably pretty plant. Lady Plymouth, besides possessing fragrance, is similar in the form of its foliage to the Rose, with distinctly 
marked edges and variegations of white throughout. This is a beautiful variety for pot culture or for bedding out. Shrubiand Pet is a free-growing variety with leaves of sweet fragrance somewhat resembling Rose; it grows rapidly when bedder, assuming a height of eighteen inches, and bears constantly in summer, hundreds of rich crimson flowers. Little Gem is a dwarf grower and profuse bloomer, with deep green foliage resembling the Rose in form; very desirable as a pot or summerbedding plant.

G. Balm Scented-Has very large foliage; deliciously fragrant.

G. Betulini (Birch-Leaved)-Leaf small, flowers nearly white; delicious birch fragrance.

G. Mrs. Taylor-Foliage not very fragrant, but beautiful; flowers scarlet, in good clusters, shaped like a small Pelargonium; blooms very freely and constantly.

G. Rose Scented - There are two kinds-one the broad leaf variety and the other more finely cut.

All the scented and cut-leaved Geraniums are valuable as pot plants, as they are not alone dependent upon bloom to make them attractive, although nearly all bear flowers freely, and some are really very desirable on this account. For making bouquets, and as a back ground for button-hole flowers they are indispensable. Their value as bedding plants seems not to be justly appreciated by cultivators. They are without exception, rapid, handsome growers, and become, in a short time after bedding, exceedingly beautiful. All the varieties propagate readily from cuttings, except the Apple, which is reared from seed.

\section{GOLDEN BRONZE GERANIUMS.}

This class of Geraniums has been greatly improved in the last few years, combining the brightest colored flowers, with beautiful foliage. They are admirable bedding plants, attracting all by their bright foliage; even during the heat of summer they possess qualities that are not attained by any other class of Geraniums.

\section{SINGLE-FLOWERED VARIETIES.}

G. Beauty of Caulderdale-Light golden yellow foliage, dark chestnut zone, scarlet flowers.

G. Black Hawk-Dark brown zone on yellow ground; scarlet flowers. 


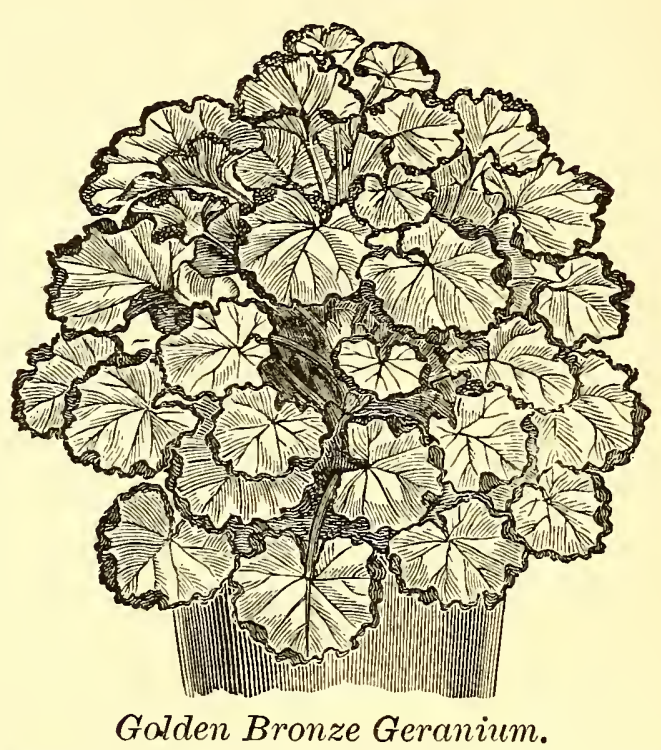

G. Bronze Model-Golden foliage, brown zone, scarlet flowers; extra fine.

$G$ Crystal Palace Gem-Fine yellow, with green disc; extra fine bedder.

G. Distinction-Very peculiar leaf markings, not a bronze; the leaves are enriched near the edge with a very narrow zone of deep black. Placed here for want of class suitable for it.

G. Earl Roslyn-The foliage is large, of a brilliant yellow color, with a broad, chocolate zone.

G. Exquisite-New; large chocolate zone; large golden yellow center; edges variegated; flowers salmon, tipped white. A perfect beauty; no one should fail to have this fine Geranium in their collection.

G. Fanny-Light golden foliage; chocolate zone; the flowers are large and of a delightful peach color; very free blooming; one of the best winter blooming Geraniums grown. Excellent.

G. Gen. R. E. Lee-Leaves deep green, distinctly marked with a large, light golden blotch in the center, forming a well marked variegation; flowers dazzling scarlet, with attractive white eye.

G. King of the Bronzes-New; large, finely formed leaves, with broad chocolate zone, in a pure yellow ground; a striking and distinct variety. 
G. Marshal McMahon-The best of all the Bronze Geraniums; ground color of leares, golden yellow, marked with a deep chocolate zone; a splendid bedding variety. The variegation withstanding our hot, dry atmosphere admirably.

G. Prince Henry-Center of the leaf, rich yellow; zone very broad and of a rich, dark color. One of the best. Very distinct and beautiful.

G. Pride of Mt. Hope-Large foliage, of a brilliant yellow color, with broad, chocolate zone.

G. Warrior-Light yellowish green leaf, with a broad, light chocolate bronze zone; flowers reddish scarlet; a splendid rariety.

$G$. $Z u l u$-Bright yellow leaf, with very deep chocolate zone. Decidedly the darkest and best of this class.

\section{DOUBLE-FLOWERED VARIETIES.}

G. Corinne-Clear golden yellow foliage, with elegant zone; flowers double; trusses good size; color fiery orange.

(x. Magician-Foliage dark green, with greenish-yellowish disc. Flowers orange scarlet, and foliage as fine as some of the golden tri-colors.

GESNERA ZEBRINA (Greenhouse Bulbous Perennial, 35, 60, 90).

A pot plant with beautiful velvety foliage that is richly variegated in green and maroon. It dies down to the root at the approach of winter, after which water should be withheld almcst entirely, keeping the pot in a warm place. In spring the bulb may be repotted, dividing it if desirable, and it should then be given plenty of water to induce a new growth. The plant likes a sandy loam soil, which will be the better for an admixture of some thoroughly decayed leaf mould.

\section{GLADIOLUS (Tender Bulb).}

Of the summer flowering bulbs the Gladiolus heads the list as the most imposing, varied and beautiful class. The flowers on a bed of good varieties are gorgeous and attractive beyond description. They are produced in spikes, two feet and upward in height, and have especially in the newer varieties, a rich, substantial texture, which make them the subject of irresistible admiration from all beholders. By planting at intervals, from the middle of April till June, the flower garden may be brilliant with 
their colors for several months in summer and early autumn. Plant two or three inches deep and six or nine inches apart; keep tied to stakes, or, if in beds, to twine stretched across the bed. By the middle of October take up the bulbs, leave them to dry for a few days, but not exposed to frosts, remove the tops, and store in a moderately warm dry place through the winter for next year's planting. The rapil natural increase of the Gladiolus under common cultivation, together with the slight first cost of superior bulbs, always tends to make their culture satisfactory.

G. Adonis-Light cherry, marked with white.

G. Annatal Levanneur-Brilliant crimson, with maroon and azure.

G. Antonius-Cherry color, tinged with orange.

G. Aristole-Rosy lilac, mottled with crimson, yellow and carmine.

G. Berenice-Rose, streaked with carmine and purple.

G. Brenchleyensis-Deep rermilion scarlet; fine.

G. Chas. Dickens-Delicate rose, blazed with crimson rose.

G. Couranti Fulgens-Brilliant crimson, with yellow.

G. Daphne-Light cherry, with darker stripes, stained with carmine.

G. De Audry-Brilliant.

G. Don Juan-Rich, fiery orange, with darker marks and bilotches.

17. Emma-Clear, deep carmine; dwarf.

G. Eugene Verdier-Rich carmine, with deep crimson spots.

G. Fanny Rouguet-Rosy flesh color, with carmine stripes excellent.

G. Galathea-Fine pinkish white, with carmine spots and stains.

G. Gandavensis-Red, marked with yellow, amaranth stripe.

$G$. Gem-Rosy lilac, slightly penciled with carmine and yellow.

G. Hercules-Fawn and scarlet, with yellow.

G. John Bull-White, slightly tinged with lilac, and sometimes of pinkish color; large and excellent.

G. Lelia-Peach blossom, stained lilac.

G. Lord Byron-Brilliant scarlet, stained with pure white.

G. Madame de Vatry-White, with violet crimson tint.

G. Madame Hercinque-White, yellow and rosy violet; marbled.

G. Madame Hocquin-Blotched and marbled scarlet.

G. Madame La Febre-Light pink and rose.

G. Madame Victor Verdier-Scarlet and rose, with violet spots. 
G. Mars-Fine form and color.

$G$. Mazeppa-Iiosy orange and red, large yellow stems; late.

G. Meteor-Dark brilliant red with white stains.

$G$. Meyerbeer-Very brilliant light red, blazed with vermilion, amaranth stain; superb.

G. Mons. Vinchon-Light salmon red.

G. Nemesis-Rosy scarlet, with yellow and purple.

$G$. Ninon de Endor-Fine rose, flushed with carmine.

G. Osiris-Purplish rose, with dark blotches.

G. Pallas-Bright rose, shaded with orange.

G. Princess de Montrague-Brilliant red; dwarf.

G. Princess of Wales-White, blazed with carminate rose.

G. Princess Fred. William-Flesh color, lightly streaked.

G. Proserpine-Rosy white, marked with deep rose and crimson.

G. Rembrandt-Bright scarlet.

G. Stuart Bow-Violet rose, stained deep rose.

G. Urania-White, blazed with carminate rose.

$G$. Vesta-White, shaded and marked with carmine pink.

$G$. Victoria-Rosy red, with a slight white centre.

\section{GLOXINIAS (Tender Bulb).}

These are among the handsomest of our summer-blooming greenhouse plants, the rich and varied coloring of the flowers being beautiful in the extreme: flowers 2 inches long by $1 \frac{1}{2}$ inches in diameter; upright and pendulous; colors crimson, violet, rose, scarlet, white etc. The bulbs should be started in April, and after blooming all summer, require a season of rest. This can be given by gradually withholding water from them. After they are dried off, they may be kept in a warm, dry cellar or under the stage of a greenhouse.

GNAPHALIUM LANATUM (Greenhouse Perennial, 33. 45, 90\%).

A white-leaved plant, of spreading habit, about one foot high; well adapted for the front lines of ribbon beds, also suitable for use in baskets and vases; propagated from cuttings.

\section{GODETIA (Hardy Annual).}

Annuals of good quality, readily grown from seed which may be sown where they are to flowcr. They thrive in any garden soil, and bloom nearly the entire season. 
GOLDFUSSIA (Greenhouse Perennial, 34, 45, 90 ${ }^{\circ}$ ).

Natives of India, shrubs with dark green leares, and spikes of very pretty funnel-shaped flowers, blooming most of the winter in moderate heat and moisture. In good friable soil they will grow luxuriantly; propagated from cuttings.

G. anisophylla-Flowers pale lilac, and very abundant.

\section{GOMPHRENA-ENGLish Clover (Half Hardy Annual).}

An indispensable class of everlasting flowers, with colors as brilliant and showy as any belonging to this interesting group. Aside from the desirable quality in the flowers of drying and retaining their forms and colors for years, they are lighly useful as summer decorative plants. For this purpose they may be planted singly in the border, or used for massing and ribboning, on account of their free-flowering habit. The flowers are also useful in their fresh state for summer cutting. The colors are white, flesh-color, dark purplish crimson, and orange. Sow the seed in a hot-bed or window-box, quite early, and transplant the young seedlings, the latter part of May, to a foot apart in the garden. By removing the cottony husk which envelopes the seed, it will germinate more freely. For drying, do not pick before they are of full size, which will be in August or September. Gomphrenas are also well adapted for pot culture in summer, flowering nearly as freely in this way as in the open ground; for this purpose the soil should be rich, and no lack of water allowed at any time.

GOLD DUST SHRUB-AucUBA JAPONICA (Greenhouse Perennial, $\left.30,45,85^{\circ}\right)$.

A beautiful pot plant, prized for its attractive foliage; the leaves, of which are large, smooth, and of a deep green color, exquisitely blotched or speckled with golden yellow. The plant is almost hardy, and will thrive under the most ordinary treatment; very desirable in the window, conservatory or for summer decoration in pots.

\section{GRASSES FOR DRYING (Annuals and Biennials).}

These seed-grown grasses, though, of course, not brilliant as regards colors, are always interesting in the garden and not undesirable for cutting with flowers in summer. But, it is for their use with the everlasting flowers for the formation of winter 
bouquets, wreaths and other ornaments that they are particularly valuable. For this purpose they should be cut in a green state and dried in the shade.

G. Agrostis nebulosa-Is a most elegant, ornamental grass; fine feathery and very delicate.

$G$ Briza maxima-Is one of the best of the ornamental grasses; perfectly hardy; sow in the open ground any time in the spring.

G. Briza minor-Is very small and pretty; sow early.

G. Bromus brizaformis-Is much like Briza Maxima, but is only useful the second summer after sowing.

F. Coix Lachryma (Job's Tears)-This plant is of no value for drying to be used in the formation of winter bouquets, but is grown for its wonderful bead-like seeds. These appear to be as hard as glass, possessing a glazed surface, and each seed is naturally punctured with a hole, which admits of their being strung like beads; not brilliant, but interesting and easily grown.

G. Lagurus ovatus (Hare's Tail Grass)-Has a showy head; excellent.

G. Stipa pennata (Feather Grass)-A most useful and exceedingly graceful and handsome grass for winter bouquets, flowering the second season. Wherever the seed is sown the rows should be distinctly labeled, for the growth so nearly resembles ordinary grass that it would be in danger of being weeded out, unless guarded by such means.

GYMNOSTACHYUM (Greenhouse Perennial, 38, 55, 90).

Beautiful pot plants for the conservatory or for fernery culture in the window, with smooth leaves; richly painted with reticulations, which vary from red to rich pink and white, on a deep green ground. A warm, damp, shady place suits them best. Propagated from cuttings.

G. argyronera-Distinctly veined with white; creeping habit. $G$. gigantea-Strong grower, veined with pink; creeping habit. $G$. Verschaffelti-Beautiful, reined with red; creeping habit.

GYNERIUM ARGENTEUM-PAMPAS GRasS. (Half-Hardy Perennial).

A highly ornamental reed-like grass from South America, attaining a height of six or seven feet, with magnificent plumes 
of white flowers, measuring from one to two feet in length; excellent for massing in lawns, where it presents a noble appearance. Its roots can be preserved through the winter by keeping in a cellar or cold frame. Propagated by division.

GYPSOPHILA (Hardy Annual and Perennials).

Free-flowering, graceful, little plants for the garden. Readily grown from the seed, and bears very small, rose-colored flowers on delicate stems, which present an exceedingly light and airy appearance, somewhat resembling the seeds of grasses.

HABROTHAMNUS (Greenhouse Perennial, 34, 45, 85).

The following graceful species are greenhouse plants of easy cultivation. They may be trained as vines or as small trees. Grow in fibrous loam and a little sand; they are among the gayest of shrubs, with their panicles of red and purple flowers, which are borne in profusion. Propagated from cuttings: H. elegans, flowers bright carmine or purple; $H$. coccineus, bright scarlet, tassel-like flowers. Both varieties are good winter bloomers.

HANGING BASKET, VASE AND TRELLIS PLANTS. Select list, page 40.

HEDERA. See Iry.

HELIANTHUS-Sun Flower (Hardy Annual).

A well-known genus of rather coarse, large flowering plants for the garden, which can be rendered useful in mixed collections of tall growing Ricinus, Cannas, etc., in beds in the back-ground. There are double and single varieties, all of which may be grown with the greatest ease by sowing the seed where they are to bloom. There are also some hardy perennial species.

HELICHRYSUM-EverLasting Flower (Hardy Amnual).

Everlasting flowers of great merit for winter bouquets and other indoor decorations, as well as for their beauty in the flower garden in the summer. There are several beautiful and even brilliant colors and shades, including dark purple, yellow, orange, white, bright rose, etc. Some of the colors are not common to the other families of everlastings. The flowers also being very double, should not be overlooked by the cultivator who is seeking good kinds for drying. Cut the flowers before they are fully 
expanded, and also cure some of the buds, which make up beautifully, and are desirable for variety. The young plants transplant readily; the seed may be sown in the hot-bed or in the house in April, afterwards setting the seedlings out at a distance of a foot apart.

\section{HELIOTROPE (Greenhouse Perennial, 35, 50, 85).}

This is an important plant either for pot culture or bedding out. The flowers, which are freely produced, are prized for their delicate colors, they being colors that are rare among choice flowers-but, above all, for their delicious, vanilla-like odor, which has given to the plant a great reputation among fragrant flowers. The plants make a rapid growth in the open air and bear an immense number of flowers until frost. For winter blooming in the window or conservatory it is best to start with young plants of the spring previous, or some propagated from young shoots in May or June. Such will make strong plants by the first of October, provided they have been brought along in rich soil, and have never become badly pot-bound before receiving a shift into larger pots; and always amply supplied with water. For winter flowers the Heliotrope should be given the most sunny exposure that can be afforded, providing it is sufficiently warm, as they will not thrive in much shade. Wash the foliage occasionally and see that no red spider attacks the plants. The soil should contain a small portion of sand. The Heliotrope can be grown to a great age by training the shoots to a trellis, but its culture is more satisfactory, with plants that are renewed each year, and then keeping them bushy, by pinching back.

H. B. Pfitzer-Lavender rose, shaded.

H. Cardinal Richelieu-Bright bluish lavender.

H. Caroline des Antoines-Lilac-blue.

H. Chieftain-Light blue; exceedingly fine.

H. Duc de Lavendary-Rich blue, dark eye.

$H$. Florence Nightingale-Light lavender.

H. Incomparable-Light; very fragrant.

$H$. Juliette-Dark violet; the darkest sort.

H. Mrs. Burgess-Deep lilac.

H. Snow Wreath-Pure white; fragrant; the best of its color.

H. Swanley Giant-The color might be termed a carmine rose. The size of the truss is immense, often measuring ten inches in diameter, and of the most exquisite fragrance. 
HELIPTERUM SANFORDII (Tender Annual).

A choice and distinct everlasting flower, growing less than one foot in height, with large, globular clusters of bright golden yellow, star-like flowers, which, individually, are of small size. Very desirable for winter bouquets, and cutting fresh in summer. Sow in heat and transplant to the garden after all danger of frost.

\section{HESPERIS MATRONALIS ALBA PLENO (Hardy Herbaceous Perennial).}

A fine, hardy, herbaceous plant, with spikes of clear, double white flowers a foot long, produced in early summer, and which are highly esteemed for their fragrance and beauty.

\section{HETEROCENTRON (Greenhouse Perennial, 35, 45, 90%).}

A genus of vigorous growing, free blooming plants of easy cultivation; they also bed out in the open air with equal facility. Pot in good, light, fibrous soil, with plenty of drainage; they are a fine class of winter blooming plants; propagated by cuttings. H. album-Long racemes of white flowers, produced freely. H. roseum-Color of the flowers pale rose; a valuable plant.

HIBISCUS (Greenhouse Perennial, 35, 50, 90%).

The Chinese Hibiscus are among our most gaudy sub-tropical shrubs, with very glossy foliage. They can be grown in tubs and kept for years by wintering over in a warm dry cellar or pit, or by placing them in a greenhouse at that season will well repay the little care bestowed on them in return for the profusion of brilliant bloom they will bear. They are also admirably adapted for bedding in the open border during summer, and under the hottest sun will produce gorgeously colored flowers of enormous size, averaging five or six inches in diameter. They make noble specimen plants and are easily propagated from cuttings.

H. auranticum plena-Double orange, salmon flowers.

H. Cooperi tricolor-Foliage beautifully varlegated with dark green, pink and white; flowers crimson.

II. Collerii-A remarkably new distinct variety, introduced from the South Sea Islands. Flowers buff yellow, with a crimson scarlet base, and particularly handsome.

H. Denisoni-rosea-Large single flowers; clear, transparent rose, changing to pure white. 


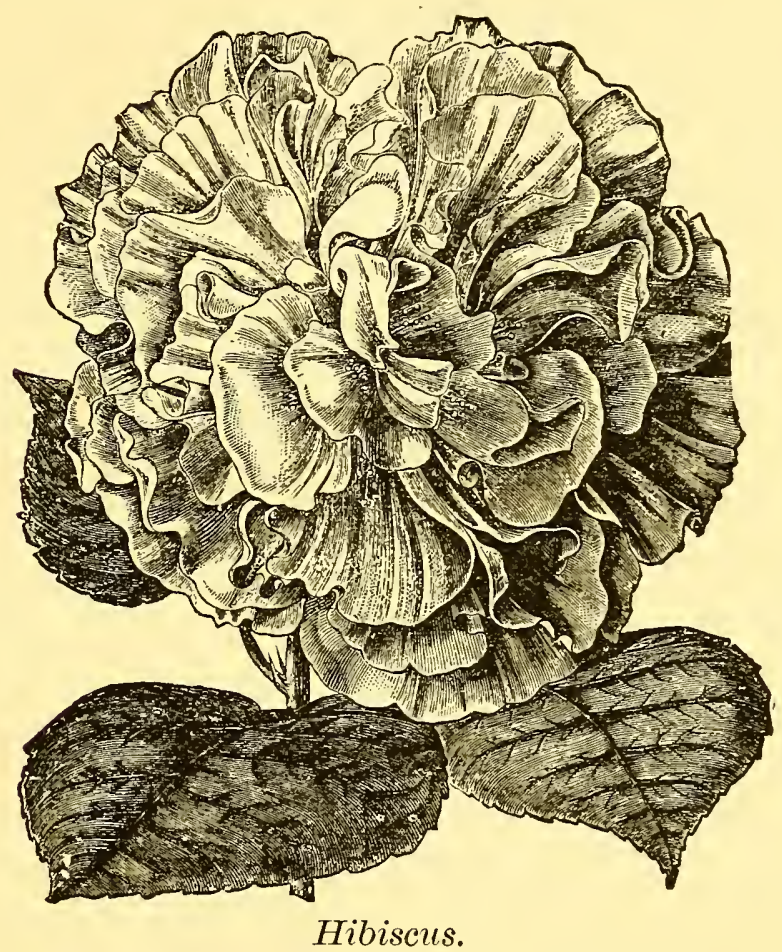

H. grandiflom -Rich glossy foliage, blooming profusely through the summer, literally covering the plant with scarlet-crimson single flowers.

H. miniatus semi-plena-The finest and most brilliant, semi-double vermilion scarlet flowers; petals waved and recurred and very handsome.

H. magnificus-Very large flower anil of perfect form; color deep magenta, ends of the petals touched with brown; foliage fineiy toothed.

H. rosa sinensis-Flowers red and very large, areraging nearly five inches in diameter.

H. rubra plena-A magnificent double variety, with large red flowers.

H. Schizopetalus-Flowers drooping, with reflected orange-red laciniated petals; a curious and valuable variety.

H. sub-violaceous-Flowers enormous; semi-double. clear carmine, tinted with violet; probably the largest flower in the Hibiscus (Chinensis) family, and an unusually free bloomer. It is a pleasure to recommend this fine plant. 
H. versicolor-A variety combining in its flowers all colors of the whole fanily, being handsomely striped, crimson, buff rose and white.

H. zebrinus-Double, outer petals scarlet, edged with yellow; inner petals very irregular, curiously variegated, with creamy-yellow and scarlet.

\section{HOLLYHOCK (Hardy Herbaeous Perennial).}

A well-known and splendid hardy plant for the garden, ranking with the Dahlia for summer decoration, and, from its stately growth and the varied colors of its magnificent spikes of flowers, may justly demand a place in every collection where suitable situations for its tall growth are found. It may be perpetuated from the seed, or by dividing the roots. The plants flower the second year, from seed sown in the spring or before the flrst of September. To increase it by division, the stalks should be cut down in August, afterwards dividing the roots with a sharp knife. They are impatient of a wet soil and will winter badly unless grown where it is dry, a well drained light rich soil being best suited to them.

\section{HONEYSUCKLE-WOODBINE LONICERA (Hardy Climber).}

The Honeysuckles are among the most desirable of all our hard climbers. Certain it is that the associations connected with the fragrant Honeysuckle will make them always popular. Among flowers none are more classic in flower-lore. For real home vines, to be near you, clambering over your windows and doorways, there is nothing prettier or more desirable than fine, sweet-scented Honeysuckles; the foliage is pretty, neat and clean, the flowers almost continuous and their fragrance delicious. Propagated from cuttings.

H. Chinese Evergreen-This varisty blooms nearly all the season and is deliciously fragrant ; flowers buff-yellow and white; retains its foliage during winter, making it very desirable. H. Aurea reticulata or Golden-Leared Honeysuckle-A variety with beautiful variegated foliage; the leaves are netted and veined with clear yellow, flowers yellow and fragrant. This variety is somewhat tender and requires slight protection. 
H. Halliana-(Hall's Japan)-This species is the most constant bloomer of the class, being literally covered all summer with its beautiful yellow and white flowers, which are very fragrant.

H. Red Coral or Scarlet Trumpet-This is the old well-known variety ; it is a rapid grower, the flowers are bright red and trumpet-shaped.

H. European Sweet-scented (Belgian)-A fine hardy grower; flowers large and exceedingly sweet; color bluff, yellow and red; a constant bloomer; the finest Honeysuckle; suitable for trellis or pillar.

$H$. Yellow Trumpet (flava)-A fine grower, yellow flowers.

\section{HOYA CARNOSA-Wax Plant (Greenhouse Perennial, 35, $\left.50,90^{\circ}\right)$.}

A pot plant of climbing habit, with finely formed, thick, waxy foliage, and well adapted to window and conservatory culture. The flowers, which are produced in clusters, have a pearly, wax-like appearance, anci are star-shaped, with a pink or crimson center. The plants are of easy culture and continue to increase in beauty for years if provided with suitable trellis for support. The Hoya does not require much water, when growing in the window, it should have its foliage cleaned of accumulatirig dust occasionally. There is also a variegated variety; foliage deep green, broadly bordered and margined with pink and pure white. Both varieties easily propagated from cuttings.

\section{HYACINTH (Hardy Bulb).}

The Hyacinth is a well-known genus of those hardy bulbs that are planted in the fall and which flower early in the spring. In common with the Tulip, Crocus, etc., it is adapted for winter flowering in the window or conservatory, and is preferred abore all other bulbs for such purposes. The flowers are very fragrant, of beautiful forms, both donble and single, possess attractive colors, and remain beautifui for a great length of time, either when forced or in the open air. In the garden they should be planted six or eight inches apart and four inches deep. On pages 32 and 52 will be found directions for cultivating the Hyacinth. and other bulbs of similar requirments, in the garden and in pots for winter blooming. 


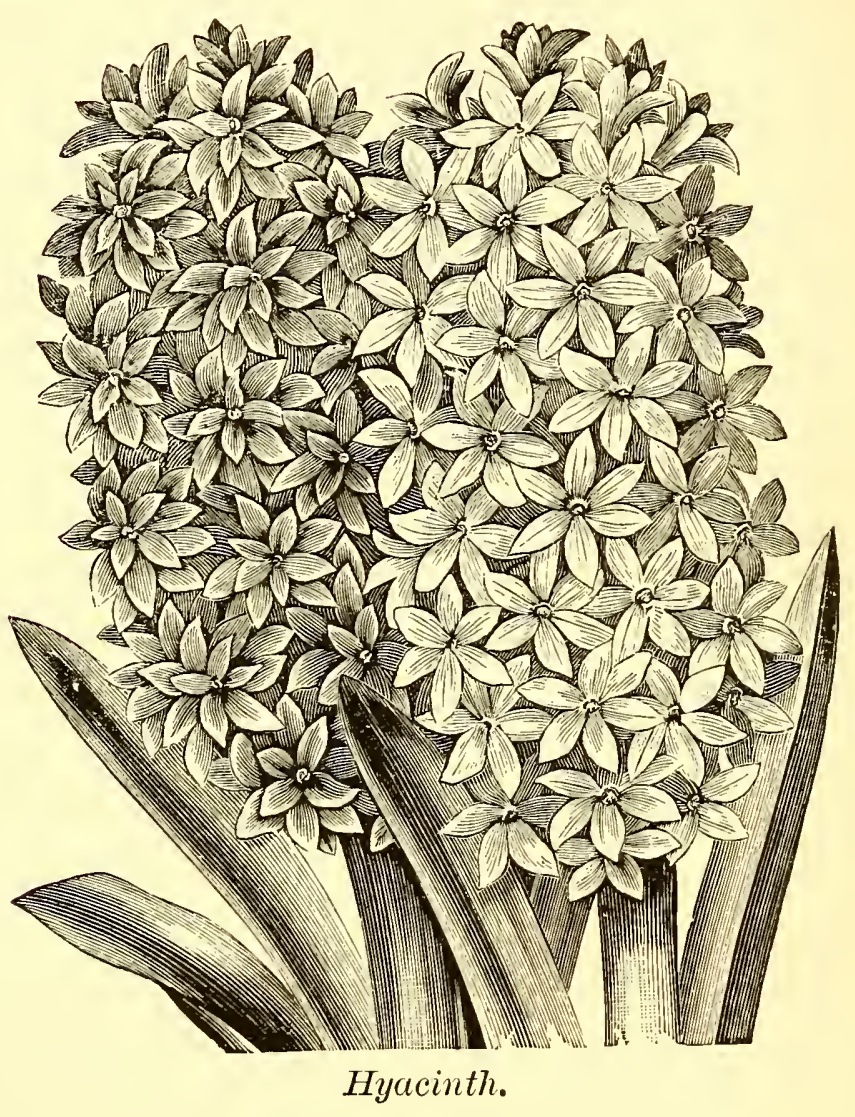

HYDRANGEA (Greenhouse Perennial and Hardy Shrub, 32, $\left.45, \varepsilon 0^{\circ}\right)$.

A species of woody shrubs, generally hardy throughout the Middle States when protected, with the exception of Paniculata grandiflora, which is perfectly hardy. They do the best in a cool, moist and shady situation; propagated by cuttings.

H. Hortensis variegata-Is a somewhat rare and beautiful variety of the preceding, with the foliage distinctly blotched with clear white upon green. It is readily grown and forms one of the most delightful variegated house plants which can be cultivated. 
H. Hortensis - Is a well-known pot plant, and much esteemed for its great profusion of elegant but monstrous flower-heads, which pass in rotation through sereral shades of pink colors, and remain upon the plant for months. The plants succeed rather better in a shady place than where it is sunny, on which account they are valuable for house culture. The pot plants require a plentiful supply of water during their season of growth and flowering. Being tolerably hardy, in the Southern States it may be planted in the open air and remain out during winter with protection, and here it will flower profusely from June to October.

H. Thomas Hogg-The immense trusses of flowers are first slightly tinged with green, becoming of the purest white and remaining so a long time; the florets are of good substance and of fine texture, making them very desirable for decorative purposes; the clustcrs, when well grown, are very large, being from twelve to eighteen inches across.

H. Schizophragma hydrangeoides (New Climbing)-A new variety from Japan. Mr. Thomas Hogg describes it as growing in its native wilds to the height of fifty feet, producing corymbs of white flowers similar to the ordinary Hydrangea. It climbs exactly like Ivy, and one can imagine the effect of a wall or a tree so covered while in full bloom. Reported to be perfectly hardy.

H. paniculata grandiflora-This is one of the most valuable hardy shrubs in cultivation. It attains a height of three or four feet, and is perfectly hardy in all parts of the country. The flowers are white, borne in immense pyramidal panicles nearly a foot in length. The plants should be cut back every Spring at least one-half of the last season's growth, as the flowers are borne on new wood and are much finer when the plants are treated in this way. Fine for cemetery decoration.

H. Otaksa-A splendid variety from Japan. Flowers large, bright pink, tinted with blue; produced very freely.

ICE PLANT. (See Mesembryanthemum.)

IBERIS. (See Candytuft.)

IMPATIENS SULTANI (Greenhouse Perennial, 40, 55, 90).

This is one of the most distinct and beautiful of all flowering plants of recent introduction, either as a winter-blooming 
pot-plant, or for bedding in the border in the summer. It is of a compact neat habit of growth, with good constitution, and a perpetual bloomer; the flowers are of a brilliant rosy-scarlet color, of a peculiarly distinct but most effective hue, about one and a half inches in diameter, and are produced singly or in twos and threes from the axils of the leaves, especially toward the summit of the stems, but so freely that a well-grown specimen appears to be quite a ball of flowers. It propagates by cuttings.

\section{IPOMGEA (Tender Annual).}

A splendid family of climbers, with which the Morning Glory is classed by some, although all the varieties, besides, are more tencler than this well-known climker. Our seasons are rather short in the North to derive great satisfaction from the texder kinds, unless they are brought forward in heat. By sowing the seed in March or April and cultivating in pots, or transplanting, with great care, to a sheltered situation in the ground after June first, they will amply repay all the care bestowed upon them, and will, by this means, flower profusely until frosts. There will be little use of sowing the seeds in the open ground before the last of May, as the soil must be warm to enable them to germinate. The seeds are hard, and previous to sowing should be soaked in boiling water, and allowed to remain until the water is cold. The Ipom eas are very desirable plants for cultivation in pots for conservatory decoration. Under any circumstances, they require a soil well enriched with rotten manure.

I. coccinea (Star Ipomœa)-Is a handsome variety of free growth and profuse blooming liabits, especially after mild summer. The product consists of small, bright scariet flowers that are very attractive. This species does quite well ordinarily, by sowing in the open ground, towards the end of May.

I. hederacea grandiflora-Includes several beautiful varieties, with flowers somewhat similar to the Morning Glory, but much larger and of the most delicate colors, such as light blue, blue with a white edge, blue with a purple center, white with pink center, and white shaded with purplish red. They are exceedingly handsome and well repay the care necessary to rear them. 
I. Quamoclit (Cypress Vine)-Is an exceedingly beautiful variety, that, for elegance of foliage, gracefulness of habit, and loveliness of flowers, is without a rival among annual climbing plants, but it is quite tender. There are varieties with scarlet, white and rose-colored flowers, all of which open in the morning, and contrast delightfully with the rich green, delicately cut foliage.

IPOMAEA (Greenhouse Perennial, 33, 45, 80).

I. Mortonii-A valuable vine or creeper, well suited either for climbing on trellis work or drooping over the sides of baskets or vases; flowers pinkish lilac.

I. noctiphiton (Evening Glory, or Moon Flower)-As a climber of rapid growth to cover arbors, verandas, old decayed trees or walls, it has no superior. Its flowers are pure white, five inches in diameter, moon-like and as they expand at night have a striking effect : both of the greenhouse varieties are propagated by cuttings.

\section{IRIS-FLOWER DE LUCE (Bulbous Hardy Perennials).}

Garden plants of elegant habit and beautiful flowers, comprising several divisions-those most commonly met with being the English and Spanish Iris, which are bulbous, and the German Iris, which are the well-known hardy, tuberous perennials, generally going by the name of Flag Lily, and which thrive in any garden soil.

English and Spanish IRIS.-This division includes numerous varieties, flowering in June, which embrace the most delicate shades of light and dark blue, brown, purple, yellow, white and variously striped and spotted flowers of exceedingly handsome appearance. The bulbs should be planted in the Autumn, with Hyacinths, Tulips and other hardy bulbs (see directions, page 32). and need not be taken up oftener than once in three rears. These are also desirable for pot culture in winter (see "Culture of Hyacinths and other Hardy Bulbs for Winter Decoration," page 5?). The English varieties are of more robust habits than the Spanish, but in other respects quite similar.

GERMan IRIS. - These are valuable plants for the garden, being of the easiest culture in any soil, and producing many beautiful flowers in the Spring. There are numerous rarieties, of almost as many colors and shades, including yellow, blue, purple, white 
and salmon-some distinctly of one color, and others striped, spotted and tipped with various colors. The tubers grow rapidly and should be taken up once every three or four years, and be re-set.

\section{ISOLEPSIS GRACחLIS (Freenhouse Perennial, 33, 55, 85).}

A small genus of very pretty, low-growing, fine, rush-like grasses; they are peculiarly adapted for hanging baskets, vases, window boxes, etc. One variety is plain green, and another sort is green with a bluish or white caste, which makes it very effective; increased by division.

IVY-HEDERA (Hardy and Tender Perennials).

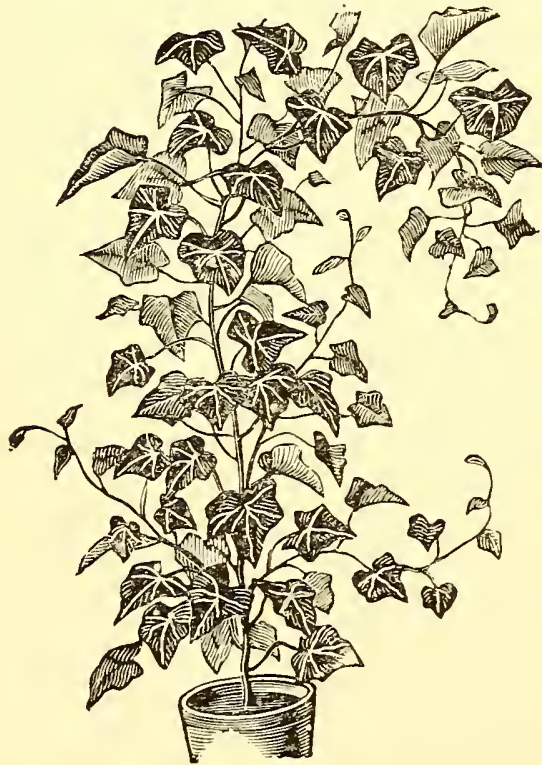

Ivy.

Sometimes I think the reason why Ivies are not grown in every house is, because amateurs have not all become acquainted with their perfect adaptability to house culture. In the first place the Ivy naturally delights in a situation, partially or wholly shaded from the sun, which allows of its being grown or trained in any part of the room, and at a distance from the window. Then again, wholly unlike most plants, the Ivies are not at all particular as regards temperature, or whether the atmosphere is dry or damp. Frosts do not affect the plants as they are evergreen, and all the varieties are nearly, some quite hardy in the latitude of Buffalo, while on the other hand, they will all bear $75^{\circ}$ or upwards of heat with impunity. The plant requires but little attention, is exceptionally free of insects and would continue to thrive for a long time under neglect that would kill most other plants outright. It is true the Ivy ordinarily bears no flowers, but the foliage presents a remarkably bright and glossy appearance, and is of an attractive green color, except where variegated or blotched; besides in 
the different varieties numerous distinct and interesting forms and variegations exist permanently, on which account we do not mind the lack in this respect. The Ivy is a very tractable climber and if planted in a large-sized pot and is kept in the parlor or sitting-room, it may be trained to cover the side of the room or ceiling, festoon a pillar, climb and train about a window sill, or $u_{s}$ a wire screen or trellis, and endless other uses. It is also unequaled as a climber or drooper for hanging baskets. As a rule, the variegated varieties are of slower growth than the others, and not so good for planting where a large space is to be covered with foliage, but for pot culture they are excellent. Propagate easily from cuttings or by layers.

$H$, bicolor-A variety of free growth, the leaves edged with silvery white.

H. canariensis (English Ivy)-An excellent variety for cultivation in the house, being a free grower and very beautiful.

$H$. canariensis marmarata-Very similar to the above, except that the foliage is distinctly marbled with silvery white and yellow; vigorous.

$H$. chrysocarpa-Exceedingly pretty, with narrow, elongated

leaves; a handsome and free grower.

$H$. folia picta-Leaves clearly blotched with golden yellow.

$H$. gracilis-A slender, rapid-growing variety, with attractive narrow-lobed leaves; by pinching back the ends of shoots, to induce a dense growth, it forms a beautiful pot plant without a trellis; also superior as a drooper in baskets, etc.

H. Helix (Irish Ivy)-The hardiest of all Ivies; leaf similar to

Canariensis; will thrive unprotected in the North, if planied where the sun in winter cannot strike it.

H. japonica argentea-Silver margined Japanese; distinct.

H. latifolia maculata-A free-growing variety, marbled and

blotched in a very attractive manner.

H. marginata Cullissi-Cullis' silver margined; very fine.

H. marginata elegantissima-Margined with light yellow.

H. palmata (Palm-leaf Ivy)-An attractive and interesting Iry, with beautifully defined foliage.

H. poetica (Poet's Iry)-A handsome variety, of beautiful form of leaf and growth.

H. regneriana-Very large leaves of roundish outline and massive growth.

H. rhomba variegata-Silver margined, distinct and beautiful. 
$H$. conglomerata-A very curious dwarf form of fan-like growth; small crested; erect foliage.

IVY PARLOR, oR GERMAN. See Senecio.

IXORA (Greenhouse Perennial, 35, 59, 90).

Among our most splendid flowering plants, requiring a high temperature and moist atmosphere. Care must be taken to keep them free from injurious insects, as they are very liable to the attacks of mealy bug and scale. Pot in good strong peat, fibrous loam and a little sand. Shade and water must never be neglected. They produce their handsome flowers in corymbs of a variety of colors; should be more generally grown; propagated from cuttings.

I. blanda-Very conspicuous scarlet flowers.

I. coccinea superba-Large heads of orange scarlet flowers.

I. Frazeri-Light orange scarlet; elegant.

I. princeps-Bright scarlet; brilliant.

I. regina-Rich violet-salmon color; large trusses.

\section{JAPANESE STRIPED MAIZE (Tender Annual).}

A plant closely allied and quite similar to the common Indian Corn, the foliage of which is beautifully striped throughout its entire length with white of various widths, rendering the plant very effective when grouped with Cannas, Helianthus, Hollyhocks, Ricinus, etc., or if planted in ribbon lines. May be started in pots about May 1st, or planted where wanted several weeks later. The plant retains its attractiveness for a long time, as it does not tassel and seed as freely as the common Maize or Indian Corn.

JASMINE oR Jessamine (Greenhouse Perennial and Hardy Shrub, 35, 50, 85 ).

The Jasmine is a favorite greenhouse or house plant everywhere north, while in the south it is perfeetly hardy. It is the idol of the poets and one of the sweetest flowers. Among the species are found equally desirable subjects for decorating the greenhouse and the out-door border, combining in every instance freedom and elegance with the most delicious fragrance; propagates from cuttings. 


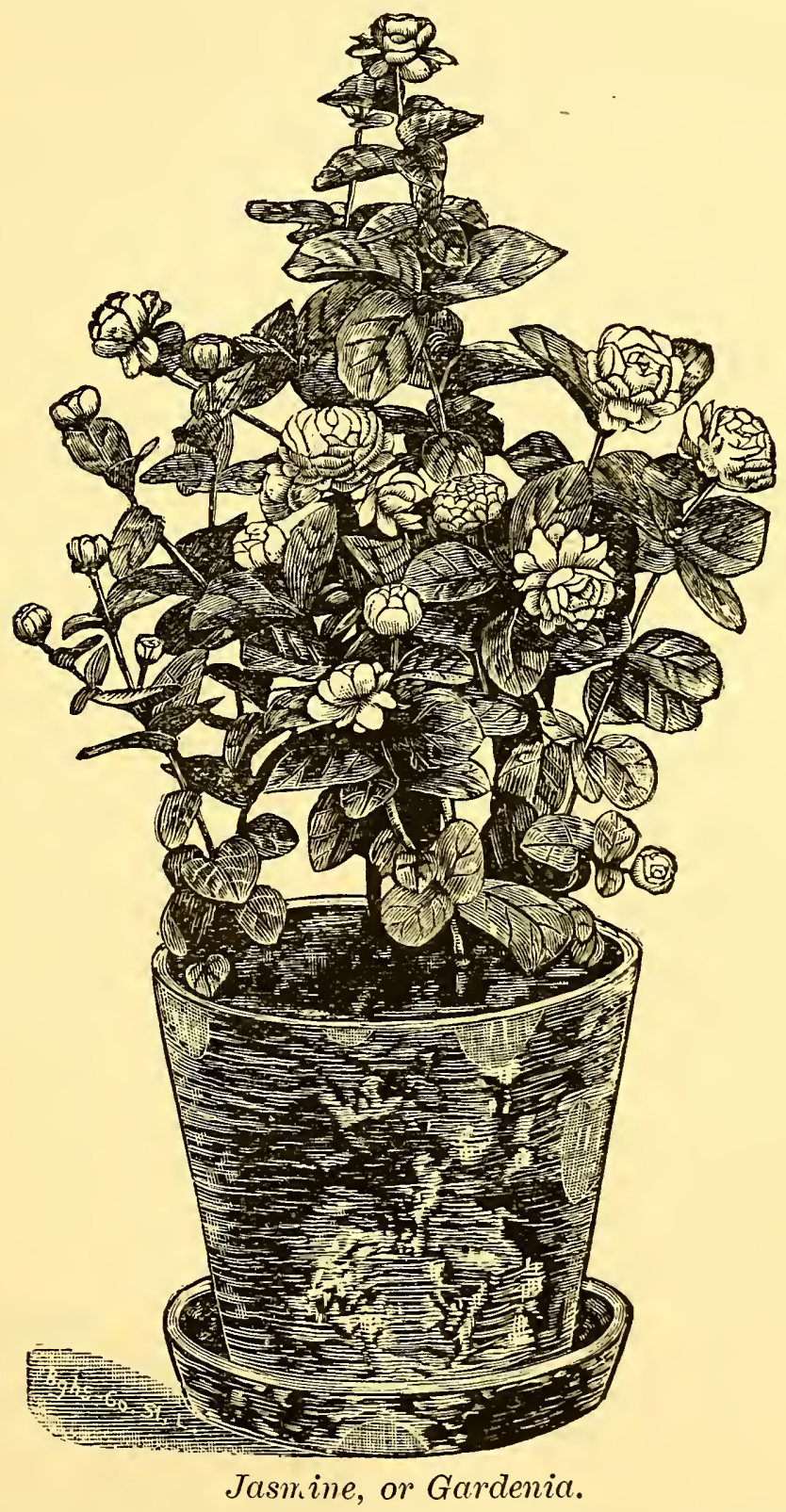

J. Radicans-A narrow-leaved variety of the Cape Jasmine; very fragrant double white flowers.

$J$. hirsutum-Produces its pure white flowers in great abundance; very fragrant. 
J. grandiflorum (Catalonian Jasmine)-A plant for pot culture; of climbing habit, with delicately cut foliage, and which is much esteemed for the fragrance of its pure white single flowers. Fine for winter flowering in a warm light window or in the conservatory; it can be trained to a stake or trellis, o: be planted for twining up pillars. The soil in which it is grown should be loose and of a fertile character.

J. Maid of Orleans-Very large, creamy white, fragrant flowers.

J. Grand Duke of Tuscany-The finest of all double Jasmines for scent, which is quite distinct from any other flower; blossonis very white and double, resembling white roses, and in flower a long time.

$J$. poetica-Similar to the Catalonian Jessamine; flowers smaller, but borne on larger spikes. The leaves are larger, and it is a stronger grower; makes a most valuable climbing plant, though, if desired, it can be grown in bush form; fragrant.

.J. revolutum-A yellow-flowered Jessamine, growing rapidly to the height of from ten to twenty feet. A splendid plant for the Southern States, as it is hardy south of Maryland; very fragrant.

J. multiflorum-The flowers, which are pure white, are borne in clusters. It flowers freely, and as a house plant it is unequaled, blooming constantly from early fall until summer. It requires plenty of light and will thrive in considerable heat, making fine specimens and producing thousands of flowers.

J. nudiflorum-Hardy, blooming very early; yellow flowers.

J. officinale-Flowers pure white and quite fragrant; it grows from four to six feet in height. The common white Jasmine of our gardens.

$J$. Sambac-Very double, white; very fragrant; hot-house plants.

$J$. frutescens-A hardy shrub, yellow flowers, slender shoots; very free blooming.

J. Gracillimum (New)-Exceedingly floriferous; a flowering shoot is produced from every joint, which terminates in a dense cluster of pure white fragrant flowers, blooming from October to February.

J. trifoliata-An improved variety of the Grand Duke Jasmine style; very free bloomer, very fragrant and double white. 
CAPE JASMINE-Gardenia Florida.

Well known for its delicious fragrance and the beauty of its flowers, which are white and double; shaped like miniature Camellias.

\section{JONQUIL. (See Narcissus.)}

JUSTICIA (Greenhouse Perennial, 35, 50, 90).

An upright growing pot-plant of free growth, crowned with terminal spikes of flowers nearly the whole year. The plants are easily grown in any soil, but should be well drained with potsherds or gravel, and there should be abundant pot room; propagated from cuttings.

$J$. carnea-Produces beautiful spikes of a rosy-pink color.

$J$. hydrangoides-Large flowers; lilac and white.

$J$. sanguinea-Large spikes of a beautiful dark red.

KENILWORTH IVY. (See Linaria.)

KLEINIA (Greenhouse Perennial, 35, 45, 80\%).

A genus of African succulents, with fleshy stems and thick candelabra-like branches; fine for ornamental gardening. They love heat and dislike dampness. Pot in peaty rough loam and sand; propagate from cuttings.

$K$. articulata or Candle Plant-A dwarf, glaucous, bluish-green plant; a great curiosity.

\section{LADY'S EAR DROP. (See Fuchsia.)}

LAGERSTREMIA oR CRAPE MYRTLE (Greenhouse Perennial, $33,45,85^{\circ}$ ).

Neat woody shrubs bearing elegant flowers during Summer. They need the protection of a cool greenhouse or even cellar during winter. Use sandy loam and some peat. Propagated from cuttings.

L. Indica-A neat little tree bearing exquisitely fringed pink flowers. Petals curiously curved.

L. Indica Alba-Same as above, but white flowers.

LANTANA (Greenhouse Perennial, 35, 50, 90).

These desirable plants are annually growing in favor, both for bedding purposes and pot culture. They are of robust growth, 
and profuse blooming habits, with flowers of good colors, which qualities, together, render them worthy of a place in every collection. The flowers, while somewhat resembling those of the Verbena, are produced on shrub-like plants, and present the most delicate shades of orange, sulphur, creany white, and other colors which are not found in that plant. The flowers of the Lantana are also interesting from the fact of their changing from one distinct color to another on the same plant, as they develop. In the house they should be placed in a light, warm place; are particularly useful for wirdow culture, as they will thrive in a dryer atmosphere than most plants will stand. By proper pruning, the plants may be grown to handsome shapes. Propagate easily from cuttings.

L. alba perfecta -Pure white; very fine.

L. Comtesse de Biencourt-Flowers bright rose and yellow; center sulphur, dwarf and bushy.

L. La Pluer d' Or-Small, pure yellow flowers; very dwarf and bushy; very abundant bloomer.

L. Michael Schmidt-Flowers fresh and sparkling, of a brilliant yellow, passing into purple vermilion.

L. Toison d'Or-Very free flowering; deep chrome yellow. changing to purplish-red.

L. Mine d'Or-A new variety; orange and crimson flowers, and golden variegated foliage.

L. Innocence-Dwarf; light sulphur, changing to pure white.

L. Le Patriote-Brilliant yellow, with fiery center, changing to a dark scarlet; very beautiful.

L. Jacques Minot-Orange, changing to bright orange-yellow; always in bloom.

L. Triomphe de Commerce-Bronzy-yellow; red center, tinted with lilac; very dwarf, and an excellent variety.

L. Giselle-Very large flowers; rich purple rose, and light yellow center.

L. Reveil Pure white, golden-yellow center; very large trusses and flowers.

L. Marechal MacMahon-The very finest Lantana ever raised; trusses as large as tinose of Verbenas; flowers bright crimson and gold.

L. Golconda-Saffron, changing to soft orange; very distinct.

L. Diademe-Rose color, sometimes shaded with yellow in the center; delicate and distinct. 
L. Don Calmet-Lilac, orange center.

L. La'lis-Small white flowers; wonderfully free; of strong growth.

L. Californie-Very dwarf, seldom growing more than six or eight inches high; flowers dark rich yellow.

L. Janus-Deep yellow, passing into rose.

L. delicatissima-A fine old variety; lilac white eye; one of the best.

LAVENDULA CRISTATA (Greenhouse Perennial, 33, 45, 90 ).

A neat, compact, pot and bedding plant, also useful in baskets, vases, etc., of the easiest culture. The leaves are of an ashy green, an inch long, nearly round, of a singularly notched appearance, seeming to have been shaped in a mould. Propagates from cuttings.

\section{LARKSPUR. (See Delphinium.)}

\section{LAURESTINUS (Greenhouse Perennial, 33, 50, 90%).}

A shrubby perennial for pot culture, that blooms freely only in the winter and spring. The flowers are pure white, produced in large flattened panicles, and are universally esteemed. The foliage is deep green, smooth and of pretty form. It is quite hardy, and in the South will stand the winters with slight protection. The plant always assumes a handsome form, and is seldom troubled with insects. In summer the pots should be moved to the open air. Propagated by cuttings.

\section{LEMON. (See Orange and Lemon.)}

\section{LEMON VERBENA. (See Aloysia Citriodora.)}

\section{LEPTOSIPHON (Hardy Annual).}

A charming class of free-blooming annuals of the easiest culture from seed. They are of bushy growth and produce an abundance of small flowers of remarkably distinct colors. Sow the seed where they are to bloom early in the spring, or it may be done the fall previous.

L. Aureus - Is less than six inches high and spreads to the width of one foot. Very handsome as an edging plant, being covered with a profusion of exceedingly pretty, little yellow flowers with dark centers, which give them a singularly rich appearance. 
L. densifloms albus-One foot high, pure white; very useful for loose bouquets. There is also a rosy lilac variety similar to this, but being of less desirable color is not so greatly esteemed.

L. hybridus-French hybrids of pretty appearance, which embrace yellow, orange, rose, purple and other colors.

\section{LIBONIA (Greenhouse Perennial, 33, 45 or 50, 85).}

Neat growing, winter blooming plants, well adapted for the window shelf or conservatory. The flowers, which are about an inch in length, are scarlet orange at the base, running into deep yellow at the top, somewhat similar to the Cigar flower, but larger. They are produced freely under ordinary circumstances, and are quite certain of affording pleasure to the cultivator. The plants are of the easiest culture, any well enriched soil suiting them. A frost among plants of sufficient severity to injure many, would leave this unharmed. Propagated by cuttings.

L. floribunda-Beautiful yellow and orange-colored bloom.

L. Penrhosiensis-- A dwarfer form, and lighter colored flowers.

LILAC. (See Syringa.)

\section{LILIUM-Lily (Hardy Perennial Bulb).}

The Lilium genus, including the numerous superb species from Japan, are eminently valuable garden plants, and no collection can be so limited but that some of the choicer varieties at least should be included. They possess many desirable qualities, being, with a few exceptions, perfectly hardy; easy of culture in any dry soil, continuing to increase in strength and beauty for many years, and, above all, are of matchless colors. The variety $L$. longiflorum affords one of the principal exceptions to their being entirely hardy, and this one will stand the winter well, with a protection of strawy manure on the roots, applied late in the fall, after the ground is frozen. Such a covering is desirable for all the varieties, and especially newly planted ones. Lilies may be planted either in the fall months or early in the spring. Avoid applying rank manure to the soil, which is apt to cause a diseased condition in the bulbs. They should be set deep, the top of the bulbs not less than six inches below the surface. This is essential, in order that the roots which support the flowering shoot, and which being above the bulb, may be fully protectea 


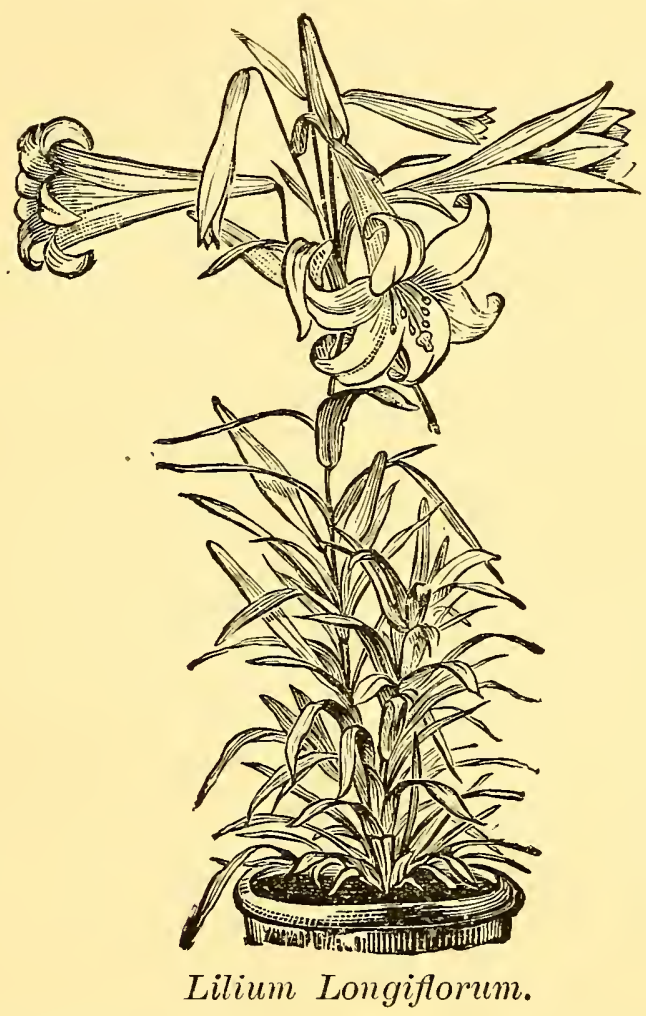

from the sun in summer. They should be allowed to remain sereral years without resetting, if possible. The various Lilies can also be cultivated to a great degree of perfection in pots, with ordinary care.

L. atrosanguineum-Orange red, blotched and marbled.

L. auratum (Golden Banded Japan Lily)-This Lily is of remarkable size and magnificence, usually measuring nearly a foot across. It is delicately fragrant, and is composed of six petals (so called) of ivory whiteness, each thickly studded with crimson spots, and having a golden band lengthwise through its centre. The plant will succeed in any dry deep soil, but cannot be considered quite as robust as most of the other sorts, yet is not very delicate.

L. tigrinum (Tiger Lily)-A well-known strong growing variety, the flowers of which are orange spotted with black. A new variety of this desirable old sort has been introduced, having double flowers. 
L. candidum-Is the ordinary fragrant White Lily, frequently found in cultivation. It flowers about the first of July on stems three or four feet high, and a mass of the plants are always beheld with admiration. There is a double flowering variety of this sort which, however, will not compare with the single in point of desirability.

L. lancifolium album, roseum and rubrum-Are introductions from Japan, of the very highest merit for garden culture. The three varieties are quite similar in form, kut vary in color-the former being pure white of great purity and beauty, but the plant is a little delicate in character. The two latter varieties are almost alike in appearance, the flowers being of an ivory white ground, spotted in rose and red, and quite fragrant. They are hardy and flower in August; strong plants producing numerous flowers on stalks three feet high.

L. longiflorum-Is a snowy white, trumpet-shaped flower, five inches in length. Although a vigorous variety, it should be treated as being not quite hardy. This variety is perhaps the best one for forcing to flower in the winter in the window or conservatory. (See engraving.)

L. Washingtonianum-An interesting species from California and Oregon. It produces delicately fragrant, pendulous flowers which are pure white shaded with lilac.

L. tenuifolium-Although not a new variety, this dazzling little gem is worthy of all praise. It blooms out of doors about the third week of May, and its graceful wax-like flowers of a lovely vermilion scarlet, cannot fail to impart unalloyed pleasure to all lovers of the beautiful in nature. It is easily grown and perfectly hardy.

L. Harrisii-The great value of this Lily consists in its earliness and free-blooming qualities, and the superiority of the individual flower. The flowers are larger than those of $\mathrm{L}$. longiflorum, and the curled points of the petals give it additional beauty; color pure white and very fragrant. This new Lily has the valuable peculiarity of flowering from two to four times in succession without rest; a single plant frequently has as many as 30 flowers on it at one time; plants have been exhibited with over one hundred blooms; its height is only 12 to 20 inches. 
LILY OF THE VALLEY-Convallaria Majallis (Hardy Perennial).

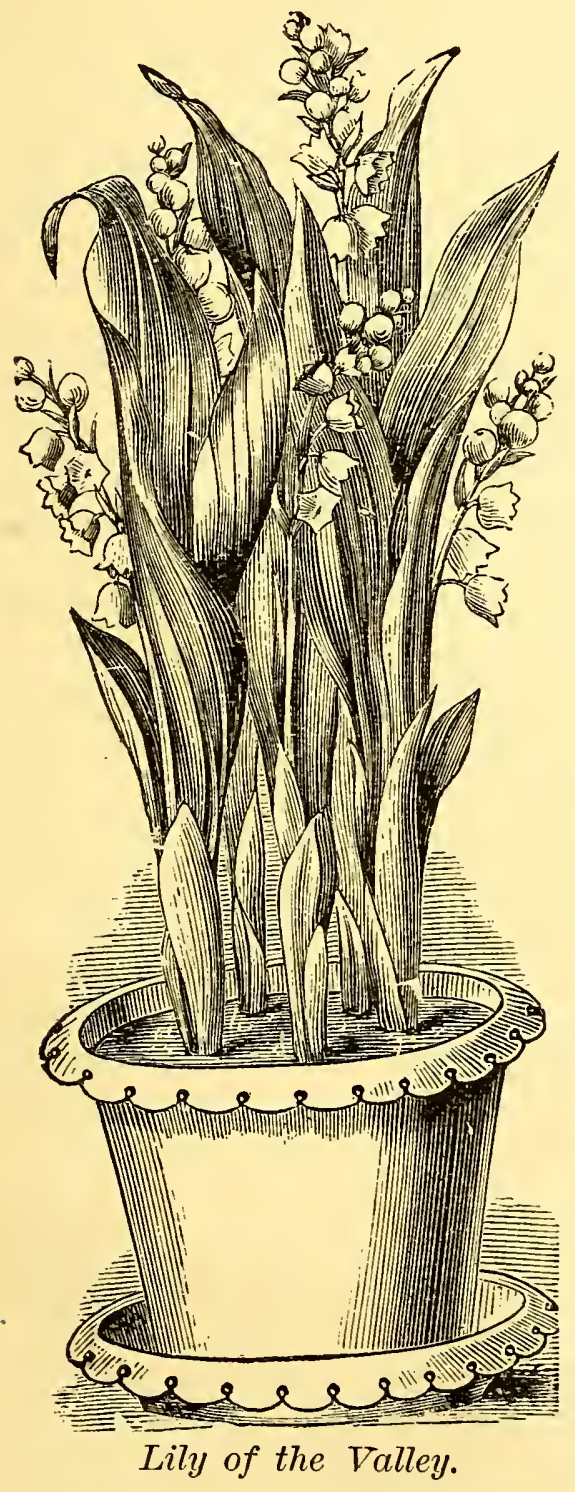

For a combination of such charming qualities as elegance, purity, grace and fragrance in a small compass, this little flower is without a true rival in the garden, and it has been esteemed as a favorite for ages. The flowers are pure white, bell shaped, and less than onethird of an inch across. They droop gracefully, each on its own curved stalklet, from the side of an upright stem six, and upwards, inches long, supporting a dozen or more of the flowers. The leaves, which spring from the root, are, in themselves most elegant, being large and smooth, of a luxuriant green, and furnish an admirable accompaniment to the flowers in choice floral arrangements. Flowers may be had easily in the winter in the window and conservatory, by taking up and potting clumps of the roots in the fall, and after subjecting them to sereral severe freezes, bringing them into a heat of forty-five or fifty degrees, in the night-time, and giving them an abundance of water. In our large cities much attention is paid to forcing this plant in this way, as the flowers are eagerly sought, at remunerative prices by lovers of choice flowers during all the winter months. The plants are perfectly hardy and succeed well in a shady place, in any garden soil, flowering in May and June. 
They increase rapidly by their slender roots, which spread to a considerable distance. Altogether may be considered one of the most desirable plants in rultivation.

\section{LINARIA (Hardy Perennial).}

Herbaceous plants, of which the well-known yellow Toad-flax is a type. The following species is a neat little vine with numerous small white and lilac flowers. Easily grown in light soil from seed.

L. cymbalaria (Kenilworth Ivy)-Suitable for baskets, etc.

L. cymbalaria variegata-Same as preceding, but has beautifully variegated foliage of white green and pink.

LINUM (Greenhouse Perennial, 33, 45, 85 ).

Where yellow flowers are desired in the winter there is no plant that will give more satisfaction than this one; it is of easy culture and a constant bloomer, being at times literally covered with bright yellow.

L. flavum-Bears large yellow flowers which are two inches in diameter on a bush about one foot in height, of very neat habit. Propagates from cuttings.

LIVE FOR EVER. (See Sedum.)

LOBELIA (Greenhouse and Hardy Perennials, 32, $4580^{\circ}$ ).

The Lobelias are universally admired, and the drooping varieties are used to an ex:ent, probably, second to no other plant in cultivation, for planting in hanging baskets and similar decorative arrangements. Their graceful, drooping and free blooming habit renders them especially valuable for such purposes, as under favorable circumstances, the flowers are produced by hundreds for a long time. They are equally desirable as pot plants, forming a dense mass of drooping foliage and flowers over the edge of the pot, in a most pleasing manner. The Lobelias are among our most suitable plants for winclow culture, as they flower quite constantly and do about as well in shady places, as in the full sun, while their delight in an abundance of moisture in the soil, is here easily afforded them. When bedded out in a partially shaded place they flower during the entire season, so profusely, as to render them very useful, for ribboning or massing in certain places and where low growing plants are desired. 
This is especially true in a wet season, or if the soil is frequently watered. The plants propagate from cuttings and seeds.

L. cardinalis (Cardinal Flower)-A splendid, hardy native plant, of excellent upright habit; producing spikes of brilliant scarlet flowers, of a dazzling hue ; excellent either for pot culture or for bedding.

$L$. erinus grandis-Large blue; in every way excellent as a drooper for hanging baskets, vases, etc., or for pot culture.

L. erinus Paxtonia-Similar to the preceding, but is blue, with a white eye.

L. Miss Murphy-a neat dwarf grower; very beautiful, either as a pot plant or for planting in beds and borders. It grows to a dense globular tuft, six inches in diameter, and can be trimmed to any desired shape.

L. alba maxima-Snowy white flowers of drooping spreading habit.

LONICERA. (See Honeysuckle.)

LOPEZIA (Greenhouse Perennial, 35, 50, 80).

This is a genus of very handsome plants from Mexico, valuable from the fact that they bloom in winter, at which time they are completely covered with sinall, bright flowers. Propagated by cuttings or from seed.

L. rosea-A most profuse and persistent winter-blooming plant; flowers fine rose color.

L. alba--Same as preceding but bearing white flowers.

LOPHOSPERMUM SCANDENS (Greenhouse Perennial, $\left.35,50,85^{\circ}\right)$.

A vine of rapid growth and beautiful dark grecn foliage, excellent for covering fences or outhouses in summer ; attains a height of twenty feet. It is also valuable for pot culture, and bears a profusion of large rosy purple flowers, somewhat in the shape of Gloxinias. Propagates from cuttings.

LOTUS JACOBEUS (Greenhouse Perennial, 34, 45, 85).

This is a great curiosity on account of the dark color of the flowers, which are, perhaps, nearer black than any other flower, and are produced on a graceful plant, having small foliage. They are increased from seed. 


\section{LUPINUS-LUPINE (Hardy Annual).}

A genus of annuals for the garden that are rather showy, and which flower until after hard frosts; in fact the beds will frequently appear at their best late in October and November, after most of the summer flowers are past their usefulness. Blue, white and purple are the principal colors, being distinct in some varieties and intermixed with yellow in others. The seed should be sown early where they are to bloom.

\section{LYCHNIS (Hardy Perennial).}

A useful class of hardy garden and pot plants, of easy culture and free bloomers, which are throughout, exceedingly showy of flowers. Some of the varieties are easily grown from seed, flowering the first season if sown early ; others propagate by division of the roots, and still others with difficulty from cuttings. They delight in a rich soil.

L. Chalcedonica-Is a tall kind, growing two feet in height, which produces in the variety that is mostly cultivated, heads of intense light scarlet flowers, and in others white and flesh-colored flowers respectively. The plants of this genus may be propagated from seed or by dividing the roots early in the spring of alternate years; succeeds best if protected during the winter.

L. fimbriata-Has double pink flowers on stalks a foot high ; very showy and desirable and perfectly hardy.

L. flos cuculi flore alba pleno (Double White Lychnis)-Is a valuable summer bloomer in flower from the middle of June until October; flowers pure white, somewhat resembling a Carnation; very highly esteemed by cultivators. Should be protected by a covering of straw or leaves at the opening of winter.

L. flos cuculi pleno (Ragged Robbin)-Is a well-known hardy plant, flowering in May, with flowers that are crimson and double.

L. fulgens-Is a hardy species with scarlet flowers and which grows one and one-half feet high.

L. Haageana-Is of dwarfish growth about one foot high, and is readily raised from seed. The flowers are large, single and embrace white, rose, red and vermilion-colored varieties.

LYCOPODIUM. (See Selaginella). 
LYSIMACHIA (Hardy Perennial).

Herbaceous perennial plants, which, although hardy, are well fitted for pot culture. They are very readily grown in good turfy loam with a little manure and sand; propagated from seed or from cuttings.

L. clethroides-From Japan, with pure white flowers in curving spikes.

L. nummularia (Moneywort) - For baskets or vases; flowers of golden yellow.

LYTHRUM SALICARIA (Hardy Herbaceous Perennial).

A hardy garden plant, growing to the height of three feet, and producing long attractive spikes of rosy-red flowers in the summer; propagates by dividing the roots.

\section{MADEIRA VINE. (See Boussingaultia.)}

\section{MAHERNIA ODORATA (Greenhouse Perennial, 35, 50, 85).}

A profuse winter-blooming plant, with golden yellow flowers that emit a strong honeyed fragrance. The plant itself is quite an ornament with its fine cut foliage; propagated by cuttings.

\section{MANETTIA CORDATA (Greenhouse Perennial, 35, 45, $85^{\circ}$ ).}

Is one of the most beautiful summer-climbing plants, especially for pot culture and in training on trellis, bearing crimson scarlet flowers in great profusion the entire season; can be dried off in the winter; propagates from the root.

MARANTA (Greenhouse Perennial, 36,55 to $60,90^{\circ}$ ).

Among the most elegant greenhouse plants known to florists, being a valuable class of plants for Wardian cases and ferneries, requiring a warm, moist atmosphere; propagates by division.

M. Baraquinii-Silvery gray; centre and margin light green.

$M$. bicolor-Pale green leaves. dark spots, purple underneath.

M. eximia-Dwarf; upper surface striped with grayish white; under, purplish violet.

M. faciata-Bright green; broad bands from mid-rib to margin; purplish beneath.

M. leopardina-Pale green, with oblong blotches of deep green. M. Majestica-Dark, glossy green, pinkish lines above, purple beneath. 
II. Makoyana-An elegant dwarf, markings deep bottle green; underneath, bright wine red.

M. Massangeana-Outer portions olive green; middle, delicate silvery gray.

M. mikans-Shining green, with a white feathery stripe.

M. pardina-Pale green; brown blotches each side of the midrib.

M. Porteana-Long bright leaves, white stripes, underside purple. M. pulchella-Very much like the old Zebrina, although more dwarf.

M. Van den Heckii-Dark glossy leaves; mid-rib silvery-white.

M. zebrina-Leaves striped above and purple beneath.

MARIGOLD-TAGETES (Half Hardy Annual).

Well-known free-flowering annuals, with single and double, also quilled flowers, of sulphur, orange, brown and striped colors. They are raised with the greatest ease from seed sown either in heat or where they are to flower. Although there are some very rich and showy varieties, which are attractive wherever enployed, yet the plants will never be ranked among the highest in value by cultivators, on account of their rather distasteful fragrance, but still they are too beautiful to be entirely ignored for such a reason.

Tagetes Signata Pumilia-A splendid half-hardy annual, forming a dense globular mass from one foot to a foot and a half in diameter, and producing hundreds of bright yellow and orange flowers on the surface of the plant. It is a handsome plant for the garden, and as easily grown from seed as are the common Marigolds.

\section{MAURANDYA BARCLAYANA (Greenhouse Perennial,}

$$
\left.33,45,85^{\circ}\right) \text {. }
$$

Flowers similar to the Snap-dragon, but borme on vigorcus, slender vines. A popular summer climber of the easiest cultivation, needing only good loam and a proper support. They also make splendid climbers for in-door decoration; the colors are violet, pink, purple and white; they are easily grown from seed or from cuttings.

Mesembryanthemum Including ICE and Dew Plants (Greenhouse Perennial, 33, 45 to $60,90^{\circ}$ ).

A genus for the most part natives of the Cape of Good Hope. There are many varieties, but the several here noticed are 
the inost valuable for ordinary cultivation, and these are highly prized wherever introduced. The sorts named are of trailing habit, and being free growers they prove to be very desirable for planting in baskets, vases, etc. They are also excellent for pot culture in the window or conservatory, and very handsome if bedded, continuing in flower during most of the season, and growing with great freedom in rich ground.

M. chrystallinium (Ice Plant)-This species is noted for the peculiar cold, icy appearance the foliage presents, the stems and leaves throughout having a frost-like coating, which renders the plant very attractive; grown from seed, and should be treated as a tender annual.

$M$. cordifolium (Dew Plant)-Another species possessing the remarkable features of the Ice Plant to a slight extent, but, aside of this, is a stronger and handsomer grower, with rich-looking foliage, and is covered with a profusion of attractive small, rosy-pink blossoms almost constantly. This is one of the handsomest drooping plants in cultivation for hanging baskets, vases, etc., and also as a trailing bedding plant; propagates from cuttings or seed.

M. cordifolium variegatum-Similar to the preceding, but in addition, the foliage is variegated in creamy white and green, which renders it exceedingly pretty for any use to which it is suited.

$M$. grandiflorum-A variety with round-pointed foliage, producing large pink flowers several inches in diameter, more or less continually from early spring throughout the season.

MEYENIA (Greenhouse Shrub, 40, 60, 95).

This is one of the most beautiful greenhouse shrubs. The leares are dark green, habit of plant robust and graceful. It is in bloom all through the early spring and summer, at which time it is completely covered with its beautiful gloxinia-shaped flowers; propagates from cuttings.

$M$. erecta-Flowers dark blue, getting lighter towards the centre,

with a yellow throat.

$M$. erecta alba-Same as preceding, but white flowers.

MIGNONETTE-RESEDA (Hardy Annual).

A deliciously fragrant flower, too well-known to require any special description. It is easily grown from seed, which may be 
sown very early in the spring where the plants are to flower, and then several times later for a succession. The seeds may also be sown late in the fall. Every garden should have a bed for cutting from. Some pots may be started in the summer for winter flowering in the window or conservatory. The plants do not transplant well.

\section{Mimosa SEnsitiva-Sensitive Plant (Tender Annual).}

A remarkable annual cultivated for the curious peculiarity of its delicate pinnate leaves, which suddenly close and droop if touched or shaken. They open and regain their upright position in the course of an hour or two, without the leastinjury to themselves or the plant for the surprising transition through which they have passed. The plant is only suitable for pot culture, and may easily be reared from seed by sowing in a warm window or hot bed.

\section{MIMULUS-MONkey Flower (Half Hardy Perennials).}

Herbaceous plants with showy flowers. The following varieties make interesting greenhouse plants and require plenty of fresh air and not too much heat or moisture. Grow in light soil with a little manure and sand. They are easily raised from seed, cuttings, or by division.

M. moschatus (Musk Plant)-A dwarf plant, with musk odor.

M. moschatus tigrinus-Flower golden-yellow, with brown spots.

Musk odor.

MIRABILIS JALAPA.-FOUR O'ClOCK FlOWER. (Half hardy Annual.)

A very ornamental plant of good habit with glossy bright foliage and fragrant flowers, which mostly open in the afternoon, hence its appropriate common name. The plant grows to several feet in height, and blooms profusely after mid-summer. The flowers include various colors, such as different shades of red, red striped with white, red and yellow, yellow, lilac striped with white, violet and white, and sport into many attractive variegations. May be raised from seed planted in the Spring where the plants are desired. or the roots may be taken up in the fall and preserved like Dahlias during winter. The plants should stand from one to two feet apart. 
M. Jalapa folis variegata-A variety of the above, the leaves of which are faintly variegated or marbled; several different colors of flowers.

M. longiflora alba and violacea-With long, sweet scented flowers, in the former, pure white with purple below, and in the latter violet.

\section{MONKEY FLOWER. (See Mimulus.)}

\section{MONTBRETIA CROCOSMIAEFLORA (Tender Bulb).}

The flowers of this plant, relatively speaking, are of large size of an intense orange sinade, beautifully formed, and something in their arrangement on the stem is suggestive of the Orchid family. A single plant bears several spikes of flowers, cach spike having from ten to twelve florets; it retains its bloom for a long time. The florets are very brilliant in fine cut flower work. The foliage is somewhat similar to the Gladiolus, but radiates like the spars of a fan, the flower spikes also radiating with the foliage. A plant of the first order, it flourishes in the open ground, and is also extremely ornamental as a pot plant. It grows to a height of between two and three feet, and is fully three feet across the foliage. It is propagated by offsets.

\section{MORNING GLORY. (See Convolvulus.)}

MUSA OR BANANA 'Greenhouse Perennial, 35, 55, to 60,90 .)

These make very ornamental and showy plants, always attracting notice either from their enormous size or beautifully variegated foliage. Some of the sorts bear the Banana of commerce. During the hot summer when planted out they grow rapidly and luxuriantly, producing a tropical effect on the lawn, terrace or flower garden. They can be stored in a light cellar or cool greenhouse during the winter with a covering of soil, or planted in a tub, watered sparingly. They are increased from suckers.

M. Cavendishii-Is a dwarf species, very ornamental; bearing edible fruit. This is the variety commonly grown in greenhouses; if kept at a high enough temperature fruit much superior to that found in our markets will be produced.

M. Ensete-The noblest of all plants is this great Abyssinian banana. The fruit of this variety is not edible, but the leaves are magnificent; long, broad and massive, of a beautiful green, with a broad crimson mid-rib. 
M. zebrina-The stem of this Banana is slender and the leaves a fine dark green, striped and blotched with bronze, red, purple and chocolate ; very effective.

MUSK PLANT. (See Mimulus Moschatus.)

\section{MYOSOTIS-FoRGET-ME-Not (Half Hardy Perennial).}

An old and well-known genus of garden plants, growing about six inches high, which survive our winters with protection. They bear in different varieties blue, yellow and white star-like flowers with bright centers. The flowers are small, but highly esteemed for their distinctness and perfection of form. They appear in little clusters during the greater portion of the season, if the plants are grown in moist soil in a somewhat shaded situation-a condition also most favorable to their growth. Easily raised from seed sown in the early spring or in August.

\section{MYRSYPHYLLUM ASPARAGOIDES-SMILAX (Greenhouse Perennial, 33,45 to $55,90^{\circ}$.)}

One of the finest tender climbing plants in existence, and with care suitable for pot culture in the window. The plant is esteemed for the exceeding grace and delicacy of the vine and its beautiful glossy green foliage. Smilax has become conspicuous among plants cultivated by florists for foliage alone, and large beds are now devoted, summer and winter, to cultivating a supply. Each plant is provided with a twine for support, which extends from the earth to the roof of the greenhouse, and upon this the shoots twine. After the top has been reached, the entire length is cut away for use, and another twine is fixed, which in turn answers for a support for the new shoots that quickly start again from the root. The stems of foliage are usually sold by the yard, and are greatly in demand for festooning, and also for cutting into short lengths to intermix with cut flowers. For window cultivation the plants should be trained to strings or trellis, and be kept near the glass. Smilax is closely allied to the common garden Asparagus, and like that plant will bear frequent cutting back to the roots. After a large growth has been obtained, the plant should be nearly all cut away as soon as the leaves are inclined to turn yellow; the root should then be given a rest for a month or two by withholding water almost wholly, after which it may be started into a new growth. Bears very fragrant little white flowers. Will thrive in any soil ; is propagated from seed. 


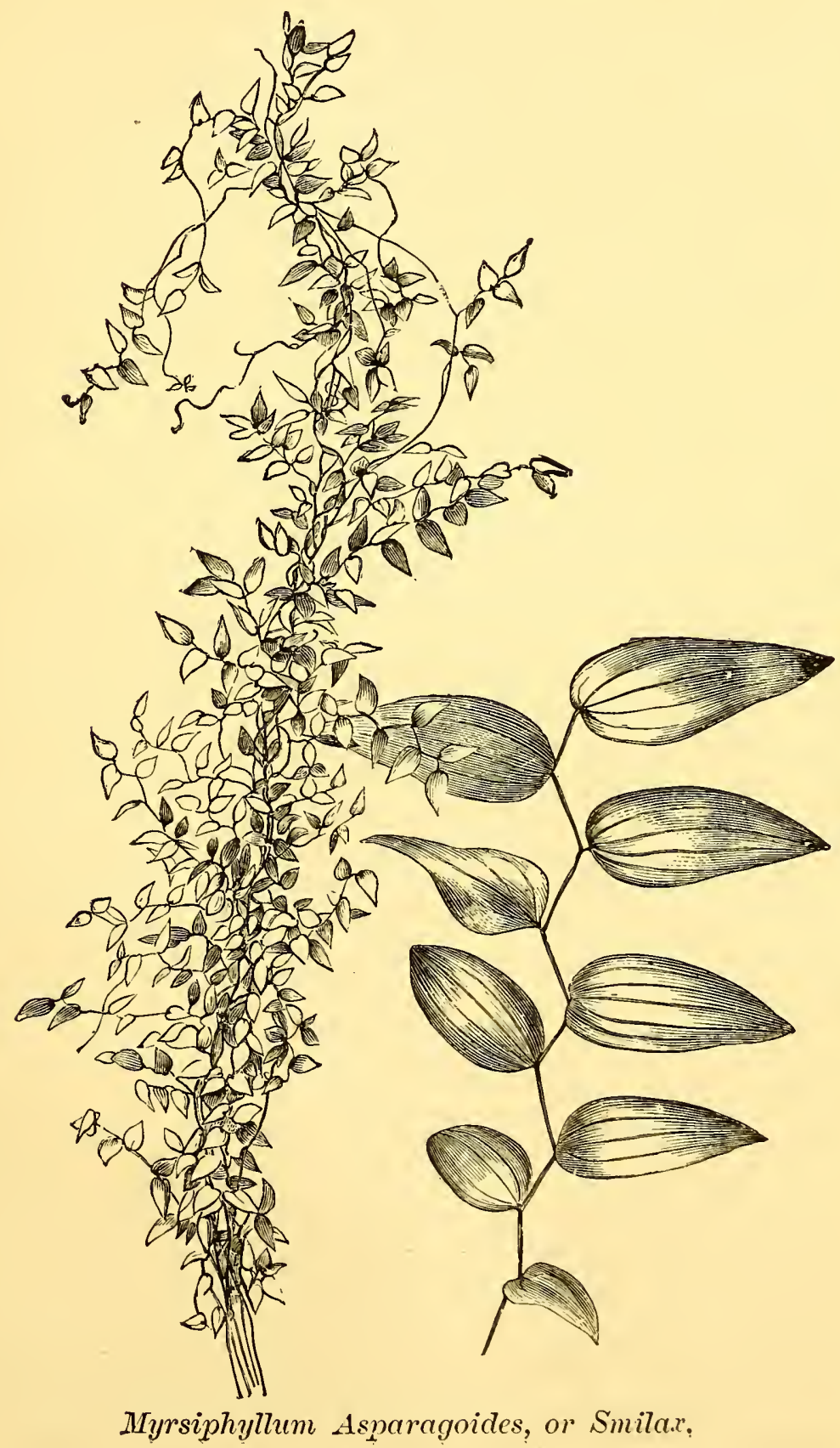


MYRTUS COMMUNIS-MyrtLe (Greenhouse Perennial, 32, 45 to $\left.\tilde{5} 0,90^{\circ}\right)$.

This, the true Myrtle, is a pretty pot plant of erect shrubby habit, which has been grown and highly esteemed for ages very remote. At the present day it is valued by florists for its twigs of small dark, smooth foliage, which are a useful green in making wedding and funeral bouquets and designs of white flowers. Besides being slightly fragrant the plant bears small white flowers quite freely. Of the easist culture in the window or conservatory.

\section{NARCISSUS (Hardy Bulb).}

An early spring flowering bulbous family, which embraces numerous forms and colors of flowers, including the well known Daffodil and Jonquil. The flowers appear very early, are highly ornamental and fragrant. Nearly all are hardy, and should be planted in the autumn like the Hyacinth, etc., but should remain in the ground for several years until they have formed large clumps, when they may be divided and reset. All the kinds are desirable, and some are unequaled for pot culture in the winter in the window and conservatory (see "Culture of Hardy Bulbs for Winter Decoration," page 52).

Double Narcissus (Daffodil, etc.), include besides the double yellow Daffodil, varieties of white (Alba pleno odorata) very handsome), light yellow, orange and other colors, all of which are double, and some deliciously fragrant. Hardy and desirable in every garden, also useful for forcing.

Single NARcissus are hardy and of great beauty, including N. Poeticus (Poet's Narcissus), a snowy white variety, in which the projecting cup from the centre is of cream color, delicately fringed with reddish purple.

N. bulbocodium (Hoop-Petticoat Narcissus), having the cup two inches long and broad at the brim.

$N$. Odorus (known as Great Jonquil), a large yellow variety with powerful fragrance; and other desirable varieties.

Polyanthls NaRcisst's, an exceedingly handsome division, but not sufficiently hardy in the North to be reliable in the open ground. They will sometimes succeed if planted deep in light, dry soil, and heavily protected at the approach of winter. It is in pot culture in winter, however, either in the window or 
conservatory, that this species can be employed with the greatest advantage by cultivators, and for this purpose nothing can be more satisfactory. There are numerous varieties, which show many colors and shades, from purest white to orange red. The flowers appear in clusters, numbering from six to upwards of a dozen in each The white flowers of this division have yellow cups, and the yellow, orange cups. There is also a double variety which is very fragrant.

Narcissus JoNquilla (Jonquil). - The Jonquils are well known hardy bulbs, producing both double and sweet scented flowers which are very attractive. Plant in autumn six inches apart and cover three inches deep. They do not flower so well the firstyear as the second and third, therefore the bulbs should not be lifted oftener than every third year.

\section{NASTURTIUM. (See Tropæolum.) NEMOPHILA (Hardy Annual).}

A genus of low growing annuals which afford in the different varieties many singularly colored flowers, such as white with black spots, white and purple, white blotched with violet, white with chocolate centre, black edged with white, rich maroon margined white, bright blue with white centre, blue blotched with black, and so forth. While interesting, these plants can scarcely be styled showy, although when at their best, they are very attractive. A cool partially shaded situation suits them the best. The seeds should be sown in frames early in the spring or late in the fall previous, in order to secure strong plants by hot weather, as young plants that come on late, never do so well. Transplant to five or six inches apart.

NIEREMBERGIA GRANDIFLORA (Greenhouse Perennial, 33, $\left.45,90^{\circ}\right)$.

A valuable plant, either for the flower garden, or for planting in baskets, pots, vases, window boxes, etc. The leaves are small and pointed, flowers pale bluish white, one inch and a half in diameter: and salver shaped. They are borne in great abundance all during the summer, and by fall fifty flowers can, almost at any time, be counted on each plant that is growing in the garden. They may be lifted in October without wilting, and will be showy for a long time in the window or conservatory. Any soil will suit them. Propagate from cuttings with some difficulty. 
NIGELlA-Love in a Mist. (Hardy Annual).

This singular plant is known as Lady-in-the-Green and Devil-ina-bush, because the blossoms are partly concealed by the abundance of finely cut foliage. The plant and flower are both handsome, require but little care, and are worthy a place in the flower garden. Sow the seed in Spring, and thin to one foot apart.

NIGHT BLOOMING CEREUS. (See Cereus.)

NIGHT BLOOMING JASMINE. (See Cestrum.)

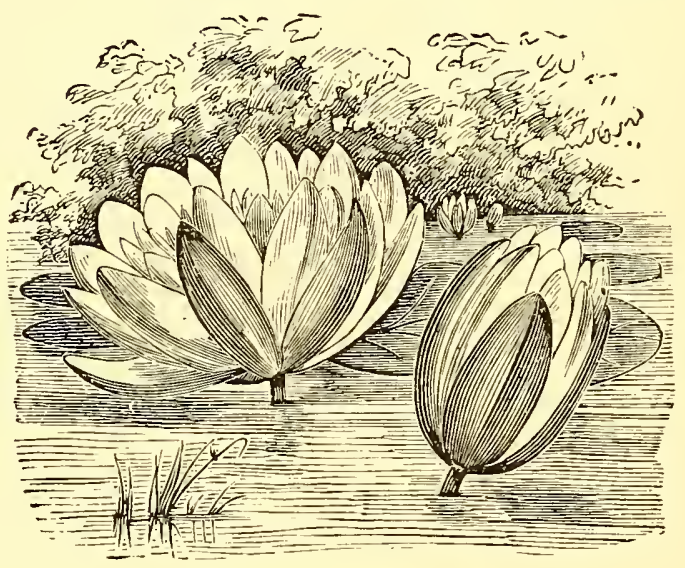

Water Lily.

\section{NYMPHAA ODORATA-WATER LILY (Half Hardy Roots).}

This plant is the well-known double white Water Lily or Pond Lily. The cultivation of this species affords much pleasure and gratification to the amateur, as it is attended with so little difficulty. The roots should be obtained in the early spring and placed in a tub or cask from eighteen inches to two feet in depth; put in six inches of rich loam, barely covering the tubers, and fill the cask with water, replenishing it, as it loses by evaporation. They can be cared for in winter by emptying nearly all the water out and keeping in a cool cellar, or if protected from hard freezing, can remain on the lawn. This is all the care required to produce their large white deliciously-fragrant flowers; increases rapidly from the roots. There is also a yellow Water Lily common in ponds and stagnant water in most of the Northern States which can be cultivated in the same way. 
OLEA FRAGANS-Sweet Olive. (Greenhouse Perennial, 34, $\left.50,90^{\circ}\right)$

This is a favorite greenhouse plant with deep green foliage similar to a camellia, and bears small clusters of delicate white flowers in great profusion during the fall and winter. Highly odoriferous both in the foliage and flowers; the perfume of a single plant is sufficient to fill a conservatory; propagated by cuttings.

\section{OLEANDER-NERIUM. (Greenhouse Perennial, 30, 45, 85.)}

A well known genus of erect-growing, evergreen shrubs, with narrow elongated leathery leaves. The plants are well adapted for culture in pots and boxes, to be used in adorning the lawn, or plant collection in summer, as they are easily managed to produce an abundance of bloom. Naturally deighting in a moist soil, they should at all times during their flowering season be well supplied with water. After they are done blooming, keep rather dry at the roots until spring, storing them during winter in any cool dry place, a light cellar answering very well. Early winter is the most suitable time for pruning the plants, which operation may be done quite severely to their benefit. The young shoots can be cut back to within two buds of the old wood. In March they should be shifted into larger pots or boxes and a new growth encouraged by an increase of water. Decayed turfy loam, with one-fourth part old rotten manure, forms an excellent compost for them. As the plants advance in growth, a weekly watering of liquid manure, not very strong, will heighten the size and beauty of the flowers ; during their approaching season of bloom keep a sharp look-out for scale insects on the leares and bark and remove any such by washing. Scrubbing affected parts with tobacco water heated to $120^{\circ}$ and afterwards with soap and water, will completely destroy them if it is thoroughly done. The Oleander is easily propagated from cuttings of the young growth in the spring and summer. A favorite and timehonored method of proceeding with this operation is by placing the cutting in a bottle of water suspended in the window or under the piazza; this means is quite similar to the saucer system of propagation described on page $3 \tilde{5}$, and in the case of this plant is perhaps quite as good a one. Immediately as the roots appear, the cutting should be potted and should receive an 
abundance of water until it becomes rooted in the soil. The double varieties do not show their character until the plants become strong.

O. album plenum-An introduction from the West Indies. Long, slender foliage ; fine double white flowers.

o. atropurpureum plenum -The richest blood-red crimson color, quite double and finely imbricated.

O.flavum Duplex-Large, semi-double, yellow flowers; early and free flowering.

O. madoni grandiflora-Fully as large as the double pink, and nearly as double; pure white ; strong habit.

O. Prof. Durand-White, duplex flowers, yellow throat.

O. splendens-Double pink.

O. gloriosum-Brilliant carmine-pink flowers; very double; showy and desirable

O. Henry Sahut-A beautiful variety with delicate flesh-colored flowers, occasionally flaked with white; the edge of petals changing to white as the flowers become fully expanded. O. lutea-Single yellow; free flowering.

\section{ORCHIDS (Greenhouse Perennials).}

A natural order of endogenous plants remarkable for the structure of their flowers, which are also of great beauty and exquisitely fragrant. The species are very numerous, several thousands being described. They are found in all parts of the world except the coldest and most arid regions, but are most numerous in the humid forests of the torrid zone, and particularly in America. They have of late been much cultivated, houses being sometimes specially devoted to them. It is a mistaken notion, however, which is prevalent among amateurs, that the cultiration of them is attended with much difficulty. It is true that there are certain requisites to their successful culture which main1y depends on the conditions of their natural state being complied with. Careful attention to temperature is necessary and also to rentilation, and although much heat and moisture are required for the tropical sorts, the atmosphere must not be constantly hot and humid, but seasons of rest must ke given to the plants which in their native climates have generally a wet and dry season, the latter being to them in many respects what the winter is to plants of the temperate regions. It is getting better understood of late years that the cultivation of many of the most beautiful Orchids, 
is no more difficult than the growing of ordinary greenhouse and hothouse plants, nor are houses of special construction at all needed for producing the best results from these fascinating plants. Those from the tropics can be asscciated with Ixoras, Marantas, Eucharis, etc., while others from cooler climates flourish in the company of Camellias, Azaleas and other plants requiring the temperature of an ordinary greenhouse. The genus of the tropics are at home in the densest jungles and are found clinging to the trunks of trees, rocks, etc. Among this group are found the ones most prized by the enthusiast for their wonderful beauty and rarity, but there are found some of the most interesting specimens in the more temperate climates. The varieties of epiphytes show a wonderful tenacity of life and possess the remarkable property of imbibing the whole of their nutriment from the atmosphere without the intervention of any kind of earth. These may be placed in baskets or fastened to blocks of wood, with a little moss or some such thing around the roots to keep them from becoming too dry, and are thus placed on the shelves or suspended from the roof of the house. The plants of themselves are odd; of some of the sorts the foliage is very handsome, while many of the most expensive and rare specimens would hardly be afforded a casual glance when out of flower. But it can be said of the whole species that the elegance and rich perfume of their flowers combine to make them objects of universal adniration. The following list embraces the most popular and easier grown kinds of this beautiful class of plants:

(T.) Distinguishes the Tropical species, such as require the temperature of a hot-house.

(I.) Intermediate or warm greenhouse.

(C.) Cool, or such as may be grown in an ordinary greenhouse. (T.) Aerides virens-Light peach color, spotted with purple, the lip being spotted with crimson; fragrant.

(C.) Bletia hyacinthina.

(C.) Bletia Tankervillae-Large showy flowers, produced on stems about 18 inches high; flowers white, marked with brown.

(I.) Cattleya Labiata Pescatorei-Light green foliage, free blooming; the sepals and petals light rose; the lip rich crimson.

(I.) Cattleya Labiata Percivaliana.

(I.) Cattleya Mossicle-Flowers very large, from five to six inches across, of a rosy crimson color. 
(C.) Cattleya Citrina-Large flowers, of a bright yellow, produced from the top of the bulb; very fragrant.

(C.) Chysis Bractesceus-Sepals and petals white, with a yellow blotch in the centre of lip.

(I.) Cypripedium Barbatum-A pretty species, with beautifully spotted foliage, and flowers of a brownish purple, spotted with white.

(C.) Cypripedium Insigne-Solitary flowers are produced in winter, lasting six weeks in bloom; sepals and petals yellowish green, the dorsal tipped with white and spotted brown.

(C.) Cypripedium Venustum-Light green leaves, curiously blotched and mottled dark green and black. The flower is of a greenish white, the lip of yellowish green color.

(T.) Dendrobium Formosum-Sepals and petals white, with bright yellow spot in the centre of lip.

(T.) Dendrobium Formosum Giganteum-Flowers from four to five inches across; color snow white, with bright yellow on centre of lip.

(C.) Dendrobium Nobile-Flowers pink and white, with a spot of crimson in the center of the lip.

(I.) Dendrobium Pierardii-A beautiful winter-blooming species, with beautiful white and yellow flowers, lasting for three weeks.

(T.) Dendrobium Superbum Giganteum-A showy variety, with flowers from five to seven inches across; sepals and petals beautiful rose-purple, the lip the same color, fringed and marked at the base with a pair of rich purplish-red spots.

(I.) Dendrobium Primulinum-White and pink flowers, produced in two rows along the stem.

(T.) Dendrobium Wardianum-Sepals and petals white, tipped with magenta, the lower part of the lip rich orange, spotted on each side with crimson.

(T.) Dendrobium Suavissimum.

(C.) Epidendrum Machrochilum-Sepals and petals brown, the lip large, pure white, with a purple blotch at the base.

(C.) Epidendrum Vitellinum-Sepals and petals rich orangescarlet, the lip bright yellow; lasts in bloom for six weeks.

(C.) Laelia Acurninata-The sepals and petals are white, the lip white with a dark blotch on the upper part.

(C.) Laelia Anceps-Sepals and petals rose-lilac, the lip a beautiful dark purple. 
(I.) Laelia Purpurata-Flowers very large and showy, sepals and petals pure white, the lip dark crimson-purple.

(I.) Limatodes Rosea-A charming winter-flowering species of a beautiful rose color.

(C.) Lycaste Aromatica.

(C.) Lycaste Cruenta-Sepals and petals yellow, with a dark spot in the centre of the lip.

(C.) Lycaste Skinneri-The sepals and petals are pure white, tinged at the base with rose; the lip of the same color, spotted with crimson.

(C.) Masdevallia Tovarensis-Flowers in pairs, pure white, lasting a long time in perfection.

(C.) Odontoglossum Grande-Very large flowers, mottled and striped with brown yellow.

(C.) Odontoglossum Rossii-White and purple flowers, lasting in beauty a long time.

(I.) Oncidium Ampliatum-Fine large yellow flowers.

(I.) Oncidium Caminiophorum.

(I.) Oncidium Cebolleta Macranthum.

(C.) Oncidium Ornithoroynchum-Delicate rose-colored flowers, on gracefully drooping spikes.

(I.) Oncidium Roseum-A pretty small-flowering species, with colcred flowers spotted with red.

(I). Oncidium Volvox.

(T). Saccolabium Blumei Majus-Beautiful large flowers, violet and white in color.

(T.) Saccolabium Guttatum-An elegant species, sepals and petals white spotted with deep rosy purple : lip small purple.

(T.) Stanhopea Insignis-Sepals and petals pale yellow, white spotted with red, the lip nearly white spotted with purple.

(C.) Stanhopea Oculatx-Pale yellow spotted with purple.

(C.) Stanhopea Trigrina-Very large flowers of a pale yellow. barred and blotched with deep chocolate.

(I.) Tricopitia Coccinea-Sepals and petals yellow and reddish brown in color, the lip deep crimson with narrow edge of white.

(C.) Tricopitia Suavis-White flowers, spotted with pink. 
ORANGE AND LEMON-Citrus (Greenhouse Perennials, 32, 45 to $\left.55,90^{\circ}\right)$.

These well known fruits of commerce both belong to the genus Citrus, and are quite identical in many respects. The genus comprises a great number of kinds and varieties, some of which are known as wild and others as cultivated, the former possessing little value, except as stocks upon which to graft the better sorts. Both the Orange and Lemon can easily be cultivated in pots in the North, and form attractive plants when in health with their rich glossy leaves which are also pleasantly fragrant if chafed. Under favorable circumstances, they may be had to flower and fruit in the window or conservatory, and if the stocks be grafted with the improved varieties the fruit produced will be edible, although such varieties are always more difficult to cultivate than the stronger growing plants produced from seed. The flowers of the Orange are noted for their sweetness and pure white color in some of the kinds. There is an excellent dwarf growing species of the Orange, which is known as the Chinese Dwarf, and embracing several varieties. These dwarf sorts are very suitable for cultivation, being of good habit and producing fruit freely, which. although not edible, renders the plant highly ornamental. They can be perpetuated by cuttings, thus allowing of their purity being maintained to any extent. The genus love a rich soil, and one containing a fair proportion of well decayed turf, taken up from a loamy soil, will suit it as well as any. For young plants, it may contain a portion of sand until they arrive at a fruiting age. The months of March, and also August, are suitable times for repotting the plants, which may also then be pruned. All stunted or straggling shoots should be well cut back and a general system of pruning be adopted to effect a well shaped head. The Lemon especially, is greatly inclined to irregularity of growth. All the varieties of the Citrus tribe will bear a good deal of shade, but throughout winter they should have all the light that can be secured for them. The foliage and branches should also receive an occasional cleansing with water and sponge, and insects of no kind must ever be tolerated.

\section{OTHONNA SEDIFOLIA Greenhouse Perennial, 35, 45, 85º.}

It has a dwarf, creeping or pendulous habit, with slender, round, fleshy, light green leaves, and small axilliary flowers. As a plant for hanging baskets, flourishing in a cool temperature, 
it is very fine. Its numerous graceful stems droop over the sides of the pot or basket, and its sedum-like foliage glistens under the bright sun. Also suitable for carpet bedding among succulent plants. Propagated by cuttings. Frequently called Othonna Crassifolia.

OXALIS (Greenhouse Bulb, 34, 45, $80^{\circ}$ ).

These are bulbs of the easiest culture, requiring very little heat, and esteemed for decorating windows, etc. They are handsome as basket and vase plants and will well repay the small amount of care bestowed on their culture. The colors embrace white, pink, yellow, etc.

\section{PAEONIA (Hardy Herbaceous Perennial).}

A well known genus of plants noted for their hardiness, ease of culture, vigorous growth in any garden soil, and for the wonderful size and attractiveness of their flowers. The flowers in many of the varieties are nearly half a foot in diameter, well rounded and perfectly double. There are also semi-double and single sorts. The Herbaceous Pæonias are increased by dividing the roots. This may be done once every few years, the best season for the work being September or October, but the spring will also answer if it be done very early. The roots should be taken up whole, cut in pieces, each with at least one bud, and be reset. Plant in rich deep soil, with the crown or bud three inches below the surface.

PALMS (Greenhouse Perennial, 35, 50, 90).

The natural order Palmacea embraces the finest decorative plants in cultivation. They all like shade, and an abundance of moisture at the roots, as well as frequent sprinkling and syringing overhead. The proper soil to grow them in is two parts loam, one part peat and one part sand. The following handsomespecies can be recommended of ea $y$ culture for apartments, conservatory decoration or vase plants•during summer.

$P$. Chamcerops excelsa-Leaves fan-shaped, dark green color.

P. Corypha Australis (Livistonia Australis)-Leaves divided into small segments, dark green.

P. Cycas revoluta (Sago Palm)-Showy crown of dark green leaves.

P. Jaubcea Spectabilis-Pinnate leaves, six to twelve feet long, deep green. 
P. Latonia Borbonica-A beautiful Palm, with large deeply divided, fan-shaped leaves ; it is of easy cultivation and makes a splendid piant for vases, baskets, etc. This is the most desirable and most ornamental of all the Palms.

P. Pandanus utilis (Screw Pine)-So called from the arrangement of the leaves on the stem; very graceful, glaucous green.

$P$. Veitchii-Bordered with conspicuous bands of pure white.

$P$. Phonix reclinata-A cool greenhouse Palm, dark green leaves.

P. Ptychosperma Alexandra-An elegant slender-stemmed species, not unlike a Seaforthia.

P. Sabal Andansoni (Dwarf Palmetto)-Native of our Southern States.

P. Seaforthia Elegans-A very graceful Palm, dark green.

PANICUM (Hardy Herbaceous and Greenhouse Perennials).

Panicun Plicatum. - This is a desirable grass for the garden, with deep green foliage, striped white, and occasionally rose; grows in clumps, and attains a height of about two feet ; propagates by division. Protect in winter.

Panicuil Variegatudi $\left(25,50\right.$ to $\left.60,90^{\circ}\right)$. - A very attractive grass, of trailing or creeping habit, excellent for hanging baskets or pot culture in the greenhouse or window. The leaves are willow shaped, and distinctly variegated with white, rose and green The plant requires a warm place, and rather delights in shade; propagates from cuttings.

\section{PANSY-Heart's-ease, Viola Tricolor (Hardy Anmual).}

The Pansy is a flower of such excellent qualities, that it ranks in general esteem perhaps higher than any other one in cultivation, not even excepting the Rose. Treated as a hardy annual, and it is very easy to raise from the seed; is remarkably productive of flowers for a long time, and the flowers are the subject of admiration from all beholders. Their colors range from white to jet black through the various shades of violet, dark and light blue, red, bronze, yellow, purple, etc, and there are some varieties which are most beautifully and distinctly striped and blotched. To grow the Pansy to perfection simply requires that they be planted in soil of high fertility, and with this requisite secured there is no need of hot-bed, conservatory, or any other appliance to have an abundance of flowers, if the directions here given are 
PASSION FLOWER-PASsIFLORA (Greenhouse Perennial, 35, $\left.50,90^{\circ}\right)$.

Climbing plants for the greenhouse and window that possess a pleasing appearance, in the foliage, the form of growth and in the flowers. They withstand the dry heat of dwellings better than the average of plants. The plants are frequently set out permanently in the conservatory to climb along the rafters, for which purpose they are well suited and very ornamental.

\section{PELARGONIUM-LAdy Washington GERANIUM (Greenhouse Perennial, 33,45 to $55,90^{\circ}$ ).}

A division of the Geranium family (popularly speaking, for, in a botanical sense, the so called tender Geraniums are Pelargoniums), the plants of which are only suitable for pot culture, producing flowers of an extremely high rank of beauty. The plant is in appearance somewhat similar to the common Horseshoe or Scarlet Geranium but more upright in its habit, and with stiffer leaves. The flowers are also quite similar in form, but are much larger, averaging about two inches across, and possess the richest colors, and shades of colors imaginable, ranging from purest white, through carmine, crimson, rosy pink, vermilion, to the darkest maroon, and through the intervening shades for the ground colors, and then upon these the most exquisite veinings and shadings, and upon petals of the finest satin-like texture, yet, of such a thickness that but the deepest markings run through them. Usually the under side of the petals are of a tinted white. or a lighter and uniform shade of the predominating color of the flower. The Pelargonium is not so valuable a window plant as some of the Geraniums, for, although of a free, healthy growth, it is here inclined to be a shy bloomer. As spring and early summer flowering plants in the conservatory, however, all the varieties possess the greatest value for decorative purposes, blooming with great freedom. No conservatory can be considered well stocked without some of these plants in the collection. After the piants have flowered in the summer they should be given a rest of two months by almost entirely withholding water from them. At the end of this time they should be cut back and be repotted into fresh soil of a fertile nature, first soaking the ball of old earth in which they have been growing, and removing all of this that can be taken off, without mutilating the roots. Water may be 
freely applied from this time on. During the winter the plants should be placed in a light situation, and given sufficient space to enable the air and light to reach all the foliage. Due attention should be paid to pinching back any strong growing shoots, and neat stakes should provided if necessary, to keep the plants to a pleasing shape. The plants propagate quite readily from cuttings. The end shoots obtained in pruning back the plants in September after their annual rest, are the most suitable for striking, and strong plants can be grown from these by spring, if they are repotted as required during winter.

P. Arcadian Prince-Deep glowing rosy crimson, slightly penciled with maroon; an excellent grower and free bloomer. P. Augusta Odier-An exceedingì rich, carmine-veined variety. P. Beadsman-Pink, maroon spots.

$P$. Belle Blonde-White, edged and penciled with carmine, and spotted with maroon.

$P$. Bianca-Shell tinted pink, with dark spots running through crimson to pink, on two petals.

P. Captivation-Pure white, with striking spots of dark maroon.

P. Diadematum-Bright crimson pink, penciled with maroon.

P. Dr. Andre-Blush pink ground, the margins of the petals elegantly fringed.

$P$. Gen. Taylor-A free flowering carmine pink variety, slightly marked with maroon on two petals ; a superb variety.

P. Alorie de Bellevieu-Light, veined crimson, with blackish maroon spots; fine.

$P$. James Odier-Upper petals white, under shell-tinted with maroon markings.

P. Lavina-Pure white, with the lower petals distinctly marked with maroon and edged with crimson.

P. Marksman-White ground, profusely marked and stained with purplish crimson.

P. Madella d'Or-Darkest crimson, with darker spots and light center; exceedingly rich.

P. Manzinella-Pink, crimson and maroon.

P. Norma-Light lilac on white, with dark spots.

P. Sir Casper-Light pink, blotched with maroon and crimson.

$P$. White Lady-A pure white variety, the flowers of which, although freely produced, are rather below the average in size. 
PENSTEMON (Greenhouse Perennial, 30, 45, 75\%).

A class of nearly hardy plants (there are also some species that are entirely hardy) suitable for the flower garden and pot culture. They bloom for a long time during the summer months. The flowers are produced in spikes of Foxglove-like form, are of good colors and very nicely shaded and mottled. The plants can be taken up from the flower garden in the fall and preserved in a cold-pit or the cool end of a conservatory or in the cellar during the winter. Propagate readily from cuttings.

PEPEROMIA (Greenhouse Perennial, 35, 55, 85).

A pretty and valuable genus of dwarf plants with fine silvery markings and reticulations in the foliage. They require partial shade and moisture and are particularly adapted for Wardian cases and cabinets. Propagates from cuttings.

$P$. Verschafelti-Large foliage, brilliant silvery markings.

$P$. maculosa-Silvery cornate foliage; very pretty.

$P$. resedceflora - Leaves small ; flowers white, constant bloomer; very handsome.

P. magnolicefolia-Of taller growth, with long fleshy leaves.

$P$. prostrata-This very pretty and slender growing basket-plant proves to be a welcome addition to this popular class of plants. The leaves, which are round, are produced close together on long thread-like creeping rhizomes, and are beautifully variegated with brown and light green. The mature leaves assume a somewhat globular shape, giving to the plant a distinct and unique character.

\section{PERISTROPHE Angustifolia Aurea (Greenhouse Perennial,} $\left.40,60,90^{\circ}\right)$.

A heautiful plant native of India, has showy purple flowers well adapted for baskets or wardian cases and also beds out well ; the foliage is handsomely marked with golden yellow; propagates by cuttings.

PETUNIA (Half-Hardy Annual or Greenhouse Perennial, 33, 50, $\left.85^{\circ}\right)$.

For out-door decoration in summer there are few plants that excel this class. They commence to flower early and continue a mass of bloom the whole summer and until after frosts. There are both double and single varieties, the former usually being 


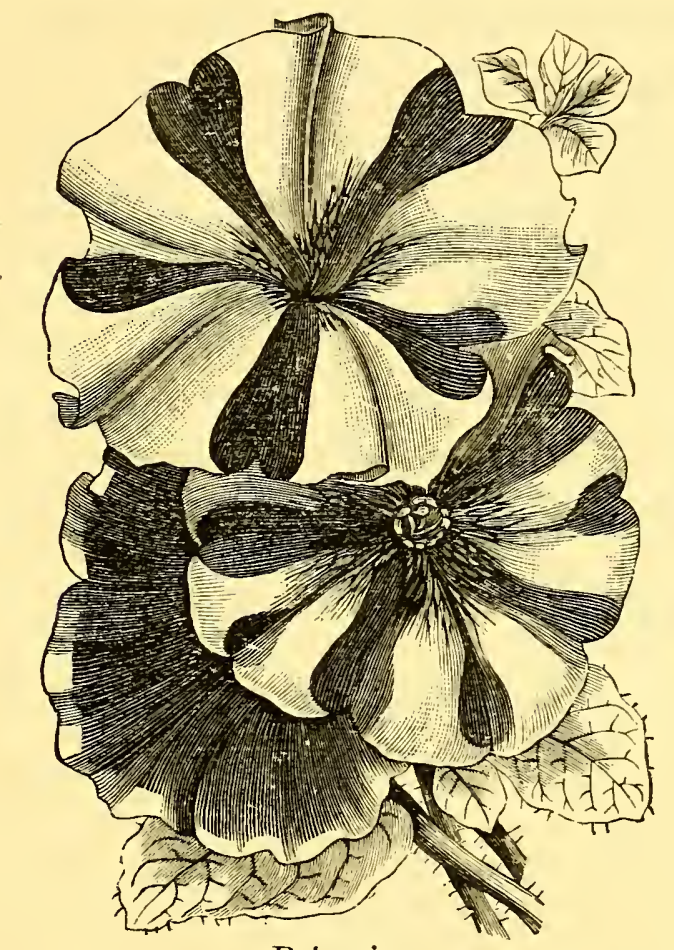

Petunia.

increased from cuttings and treated as greenhouse perennials in winter, and the latter as annuals, raising them from seed every spring, although the best of these can also be perpetuated very profitably from cuttings, thus insuring the purity of any desirable strain. Double varieties can also be raised from seed, but only a limited percentage can usually be depended upon to come double. Aside from the great value of the entire family as bedding plants, the double varieties especially are very satisfactory if grown in rich soil in pots, and the stronger growing single varieties are excellent for planting in hanging baskets or vases for trailing over the edges. For this latter named purpose the seed should be sown as early as March. For ordinary summer decoration the seed may be sown in a hot-bed, cold-frame or prepared seed bed, transplanting the seedling plants eighteen inches apart in the garden, in May, or sowings may be made where the plants are desired, which will do quite as well, excepting that these will not flower within several weeks of as early as the others.

The most desirable varieties among the double Petunias are : 
P. Beauty-Rich crimson and white striped; sometimes sports.

P. Cleopatra-White, blotched with violet crimson.

$P$. Delicata-Lavender and blush,

P. Maiden's Blush-Light rosy pink; very beautiful and a free bloomer.

P. Queen of Whites-Pure white; very double; somewhat resembling a white Carnation, but larger.

P. Wm. White-Crimson and white.

$P$. Wm. Heines-Dark violet crimson.

Among the single varieties which may be raised from seed, the following are prominent for their superiority :

$P$. Countess of Ellesmore-Rosy carmine, with white throat; an exceedingly desirable variety, coming true from seed.

In the large flowering (Grandiflora) section :

$P$. Green Margined-Crimson color, white throat, green edge.

$P$. Inimitable-Purplish red, spotted and margined with white.

$P$. Kermesina-Large crimson.

P. Maculata-Purple and crimson, spotted white.

$P$. Venosa-Beautiful veined variety.

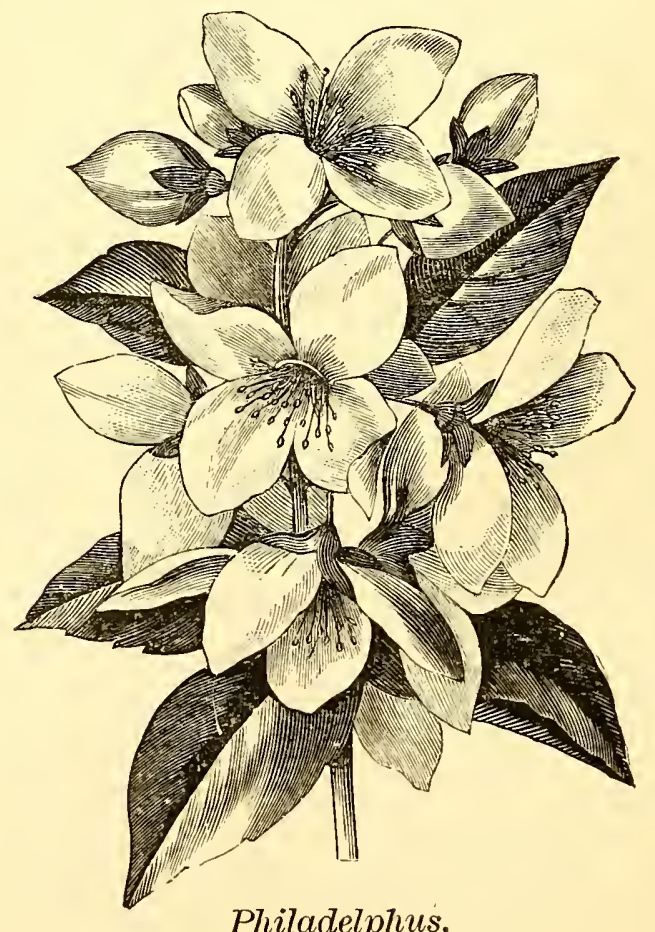

Philadelphus. 
PHILADELPHUS-Mock ORANGE (Hardy Shrub.)

These lovely, hardy, exquisitely fragrant, flowering shrubs, should be in every garden. Indeed, the old-fashioned, sweetscented, single Mock Orange (so-called because of the exquisite fragrance of the flowers, like orange blossoms, ) is known to nearly all lovers of hardy plants.

$P$. dianthiflorus plenus-Flowers very large and numerous, starshaped, nearly double, prolucing bunches of five to seven in each.

P. primulceflorus-Double white, resembling the blossoms of the double white Chinese Primula.

P. Keteleeri flore pleno-Producing an abundance of pure white, semi-double, very fragrant flowers.

P. Grandiflora Single, or Mock Orange-A rapid growing, medium-sized shrub, with very fragrant white flowers.

PHLOX (Half-Hardy Annuals and Hardy Perennials).

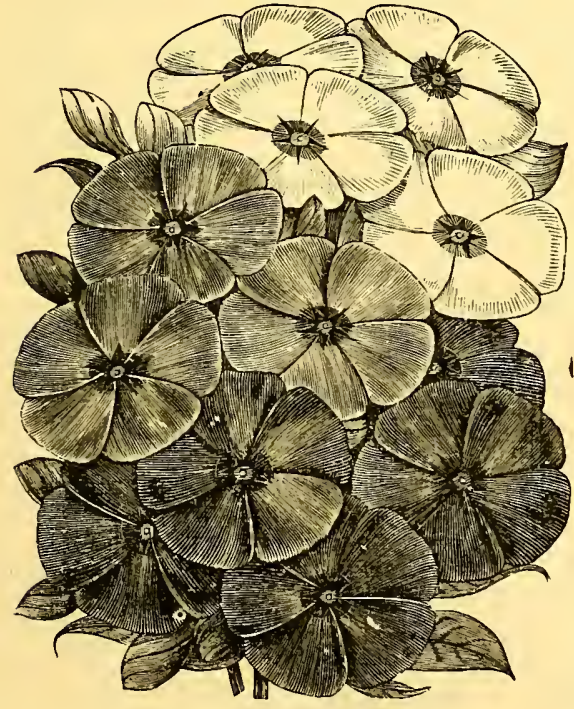

Phlox Drummondii.

This genus, in its several sections embraces many plants of value to the amateur florist. Indeed, no garden can be well stocked without some of the Phloxes. Throughout they are of fine habit and vigorous growth, producing flowers of very attractive colors in great profusion, the plants thriving in any garden soil, and with the most ordinary attention. On account of these desirable qualities they can be recommended to cultivators of little experience, as there is little danger of failure to realize successful results in their cultivation.

Phlox DrummondI.-Among seed-grown annuals for the garden the Phlox Drummondii stands without a rival for brilliancy of colors and continual display. It is to this class, what the Verbena and Geranium are to tender greenhouse bedding plants. It is even a most formidable rival of these brilliant flowering 
plants named, when effect is considered. Taking into account the small cost of the seed of this Phlox, the readiness with which plants can be grown, and their general attractiveness when in flower, either in ordinary beds or in ribbons and masses, and it is seen at once how greatly deserving of attention it is from cultivators generally for bedding and also for cut flowers. The different varieties afford many distinct and striking colors, such as pure white, white with purple eye, deep blood purple, brilliant scarlet, beautiful rose color, rose with white eye, dark violet with white eye, red with white eye, crimson striped with white, slate color, and many others, all of which come true from the seed. The seed may be sown either in the hot-bed, cold-frame or in the open ground. The plants should stand about nine inches apart for the best results in flowering. They commence flowering early and continue to produce an abundance of bloom until towards winter, especially if the flowers are removed as they mature.

HARDY UPRIGHT PhLOXES. - These are hardy herbaceous perennials, and among the most useful and showy ones in cultivation. The flowers are produced in great profusion, on upright stems from one to three feet high, in the summer and fall months. The plants are perfectly hardy, and will thrive in any garden soil. After they have attained some size, the roots may be taken up in the fall or spring, and be divided and reset. The following is a list of desirable varieties:

P. Alexandriena Varennes-Deep rose.

$P$. Delecata-Rich dark purplish crimson.

P. Glorie de Nieully-Brilliant salmon red.

P. Harlequin-Brilliant crimson, somewhat nottled.

$P$. Hector Rouillard-Distinctly striped crimson and rose.

P. L. Avenir-Salmon and red; very fine.

P. Mad. Amezi Pothier-Pink with deep red eye.

P. Mad. Bellvenue-Deep rose, crimson center.

P. Mad. Bernian-Rosy purple, crimson eye.

P. Mad. de Chambrey-Large rosy purple, distinct dark eye.

P. Mad. de Wendall-Almost pure white, crimson eye.

P. Mad. Masson-Crimson, petals edged and striped with purplish rose.

P. Mad. Pepin-Rose, with salmon centre and crimson eye ; distinct.

P. Mad. Van Houtte-Light pink with bright crimson eye.

$P$. Mons. Duffe-Brilliant crimson. 
P. Napoleon-Pure white distinctly striped with purple.

P. Roi des Roses-Rosy purple with bright crimson eye.

P. Startler-Striped rose.

$P$. Venus-Blush with carmine eye.

$P$. Victor Hugo-Striking purplish crimson.

Hardy Procumbent Phloxes (Moss Pink). - These differ from the other sections of the family, in being of creeping habit, with small pointed leaves. They produce their pretty flowers in May, at which time the prostrate plants are literaly covered with bloom. Of the easiest culture. Propagate by division.

$P$. subulata-Pink flowers in immense numbers.

$P$. subulata alba-Pure white, similar in form and growth to the preceding variety, and very attractive.

PILEA-Artillery Plant (Greenhouse Perennial, 35, 50, 80).

Unique plants in their way, with graceful frond-like leaves, which, when in flower, produce a snapping sound if water is thrown upon them. They are useful either as pot plants or for planting in baskets, vases, Ferneries, etc., being in either case easy to manage. Propagate from cuttings.

PILOGYNE SUAVIS (Greenhouse Perennial, 34, 45, $90^{\circ}$ ).

A charming climber, very dense grower; very useful for forming growing festoons between small trees or stakes, etc.; also, fine fur the house in winter.

\section{PINK, GARDEN OR FLORIST'S (Hardy Perennial).}

A class of hardy plants for the garden that belong to the genus Dianthus. They much resemble Carnations, but are more dwarf. The flowers are perfectly double, clove scented, and embrace numerous colors in the different varieties, including pure white, carmine, pink, etc., in some of which striking deep rose, maroon, deep carmine and other colors appear in the center of the flower or distinctly on each petal. Some are also beautifully fringed. The plants may be propagated by cuttings or by layers, and will thrive in any garden soil.

\section{Pure White Hardy Pinks.}

P. Sarah Howard-A fragrant, double, pure white, free flowering summer and fall Pink, not entirely hardy, but with slight protection, very desirable; exceedingly valuable for bouquet making. 
P. Alba fimbriata-A double white early spring flowering sort, of good form and substance, being fringed and very fragrant. This one is grown extensively by florists for bouquet flowers; perfectly hardy and unequaled for forcing in pots in the winter, for which purpose any of the ordinary plants from the garden may be taken up and potted in the fall without previous treatment. (For forcing, 32, 50, 80 $0^{\circ}$ )

PITTOSPORUM TOBIRA (Greenhouse Perennial, 32, 40, 85).

An evergreen winter blooming shrub of very easy culture, producing small white flowers of exquisite fragrance not unlike the orange bloom; there is a variety of same with variegated leaves; propagates by cuttings.

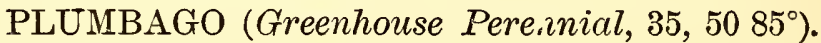

Shrubby greenhouse pot plants, also suitable for bedding out, producing large trusses of flowers during the season. They flower freely in plants six inches high, and are desirable plants in any collection.

$P$. capensis-Azure blue.

$P$. rosea-Beautiful bright rose.

P. alba-Pure white.

$P$. larpentea - Deep dark blue. This is entirely hardy and during the summer is covered with its bright flowers. It does not grow over eight to twelve inches in height.

POINSETTIA PULCHERRIMA (Greenhouse Perennial, 35, 55 to $\left.65,100^{\circ}\right)$.

A tropical plant of remarkable habit, and possessed of gorgeous beauty when in bloom. The flower, or rather the floral bracts that surround the flower proper, in well grown specimens attain a diameter of one foot, and are of the most dazzling scarlet. The plants require a warm place to develop the flower heads, which appear in December and January, but with this requi rement supplied, they are of the easiest culture. Sandy soil suits them the best. After their flowering season is over and until spring they should receive only enough water to prevent the soil from becoming powder dry. The plants may be set under the staging of the greenhouse during this time. In the spring they may be repotted, afterwards when the weather is hot, plunging the pots in soil in the open ground and leaving them 
here until the time of returning them under glass, which should be in September. There is a double variety of recent introduction which in some respects is superior to the single kind.

\section{POLEMONIUM REPTANS (Hardy Perennial).}

A fine hardy plant of dwarf spreading habit, blooming in early spring; the flowers are borne in clusters ; are bell shaped and of a most beautiful bright blue.

POLYGONUM (Greenhouse aud Hardy Perennial, 34, 45, 80).

$P$. scandens-A neat creeping or trailing plant of easy growth; has slender stems and small round leaves and bears a profusion of very sinall waxy white flowers; splendid for baskets.

P. filiforma folia variegatí (Hardy Perennial) - Entirely hardy variety, the leaves of which are variegated white and green, bearing rosy pink flowers in long racemes, which drop over the foliage, giving a very pleasing effect. It grows to the height of two feet.

POLYanthUS-Primula Elatior, Cups and Saucers (Hardy Perennial).

Pretty, early flowering, hardy garden plants that are found in many collections. They flower mostly in May. The flowers appear in trusses on erect stems, and embrace various colors. including brown with yellow eye and delicate yellow edge, rich brown, almost black, either shaded or plain, various combinations of crimson, yellow, sulphur, etc. The plants may be increased by division, and also from seed. They delight in a light loamy soil and are benefited by a covering of leaves or other material through the winter.

POMEGRANATE, DWARF (Almost a hardy Shrub).

The fruit-bearing Pomegranate is a native of Asia, and is much cultivated in warm countries. The dwarf, flowering kind is valuable for pot culture, bearing flowers of leathery substance. It is a deciduous plant, and with pot culture may be stored in a cellar, cold-pit, or under the staging in the conservatory during winter, and until April, when it should be brought to light and started into growth. In the Southern States the dwarf Pomegranate is hardy with slight protection, 
P. Double White-Large double white.

P. Jas. Vick-A variety which blooms when quite young, the flowers are large and of the most brilliant orange scarlet, grows from four to six feet in height.

$P$. Variegata-The flowers are very double, yellow, flaked with scarlet, and almost the size of a Hibiscus flower.

\section{POPPY-PAPAVER (Hardy Annuals aud Hardy Perennials).}

Showy and well known border flowers, apt to be despised through ignorance of the really good qualities of the improved varieties. The annual varieties are easily grown from seed, which should be sown where the plants are wanted. Among the perennial sorts $P$. bracteatum is a scarlet variety. $P$. croceum orange ; an early and free bloomer. $P$. orientale (Oriental Poppy), large, orange red ; flowering the fore part of summer. These are best rased from seed or may be increased by division of the roots.

\section{PORTULACA (Half-Hardy Annual).}

Excee lingly brilliant and popular low growing annuals of the easiest culture. There are both double and single kinds, including white, rose, golden, orange, crimson, scarlet, rosy purple and other colors, besides beautifully striped varieties. The Double Portulacas are of remarkable beauty, being as double and perfect as a Rose. All luxuriate in an exposed sunny situation, and produce throughout the summer their distinct and showy flowers in the greatest profusion, on which account they possess value for planting in masses or in ribbon lines, as well as for other purposes in adorning the grounds and garden. A bed of either the double or single varieties, but especially of the former, forms as attractive an object as can be introduced, particularly in all sunny weather. The plants are grown with readiness from seed, which may be sown early in the open ground, or in the hot-bed, or pots in the window, and afterwards setting the young seedlings about eight inches apart in the garden. The seeds saved from double flowers will not all produce perfectly double flowers, although a lirge enough percentage may be depended upon from these to be satisfactory. 


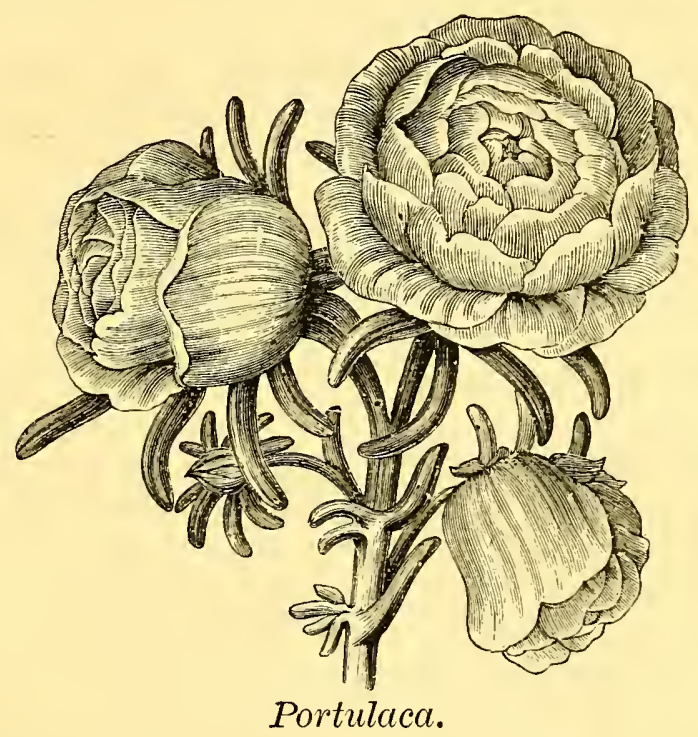

POTENTILLA-Cinquefoll (Hardy Perennial)

An extensive genus, mostly natives of the temperate zones, some of which are worthy of cultivation, while many are ranked among weeds. The foliage of nearly all the varieties resembles that of the strawberry somewhat. There are in cultivation both single and double flowering varieties, with such colors as dark crimson, orange scarlet, blood red, blush and salmon, red shaded with maroon; many are showy, and are produced with little intermission through the entire season. Succeed in any garden soil, and are increased either from seed or by dividing the roots.

PRIMROSE-PRIMUla (Greenhouse Perennial, 35, 50, 85).

This is a most valuable class of plants for pot culture, either in the conservatory or window. They grow less than one foot in height and produce an immense number of the purest white and other colored flowers during fall, winter and spring. There is a Double White variety, which is extensively grown for winter flowers by florists. The flowers are an inch across, perfectly double and of the purest white. This variety is increased with some difficulty by division and from cuttings in the spring ; is rather impatient of ill-treatment, and will not do as well in the window as the single varieties. It requires a fine, rich soil, containing 


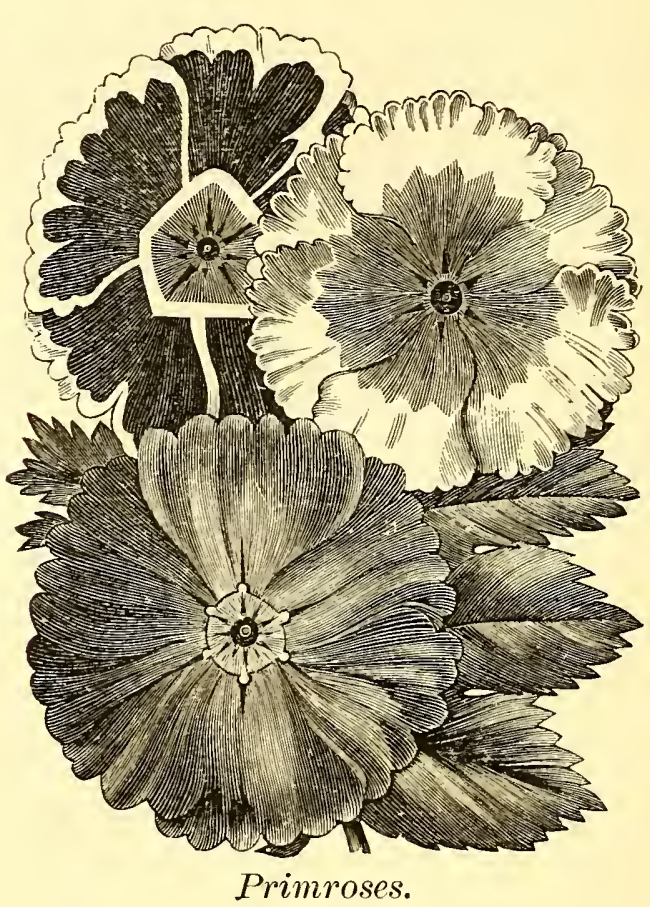

considerable sand, and does not bear to be crowded closely among other plants. In the summer it should be grown under glass, heavily coated with a wash of lime and water. During winter the glass should also be kept slightly whitened over the plants, and as uniform a temperature as possible be maintained. Water may be freely applied, but sprinkling the leaves or flowerstems should be aroided. The Single varieties are reared from seed, which is sown in the summer. These include flowers of white, rose and crimson colors, and also some with finely imbricated edges. The directions given for managing the Double Primrose are also applicable to the single varieties.

PYRETHRUM. (See Feverfew).

\section{RANUNCULUS (Hardy Perennials).}

Ranunculus Acris Flore Pleno (Butter Cup, Crowfoot)-A hardy herbaceous perennial that is quite common. The flowers are double, glossy, of a pretty yellow color, produced on upright stems, two feet high, in June and July. Will thrive in any soil, and when once introduced in a garden, there is no difficulty in keeping it, as it grows freeily and propagates by division very easily. 
RANUNCULUS AsIaticus-Is a section which affords some of the most splendid flowers in cultivation, but, unfortunately, our winters are too severe to grow them without difficulty in the open ground, on which account their culture is generally precluded, except in the window and conservatory, where they may be grown by observing the directions given for cultivating the Hyacinth and other Hardy Bulbs, etc., on page 52.

\section{REINECKIA CARNEA (Hardy Perennial).}

This plant has grassy leaves six inches to a foot long; the flowers are rose colored and fragrant. They are very useful plants in aquariums or for margins of fountains; propagates by offsets.

RHODANTHE (Half-Hardy Annuai).

A beautiful, though somewhat delicate, genus of Everlasting flowers, grown from seed, which must be started in heat, and succeed better growing in pots than if planted out.

R. atrosanguinea-Is a distinct variety, of dwarfish, branching habit, the flowers of which are deep purple and violet, with magenta ray scales.

R. maculata-Rosy purple, with yellow disc: of quite strong growth and large flowers.

R. maculata alba-Similar to the preceding, except that the flowers are pure white, with yellow disc. This is the finest, pure white, everlasting in cultivation.

R. Manglesii-Bright rosy color, and silvery calyx; rather delicate for the open ground, but succeeds finely as a pot plant.

\section{RHODODENDRON (Hardy Perennial).}

The Rhododendron is one of the most valuable of our hardy decorative plants. The leaves are broad, glossy. and evergreen and the plants when growing in groups, or belţs, or alone, gire a pleasing effect in the midst of winter. Did it produce no flowers, it rould still be a most desirable hardy plant for every style of lawn planting. In June, when the masses of rich and glossy green are surmounted by scarlet, purple and white clusters, each cluster large enough for a bouquet, the display is worthy of any expression of admiration. They bear pruning well, and can be kept down to two feet. or allowed to grow six or eight feet; as standards, they are particularly fine. 
They require only a good garden soil, which should be dug at least two feet deep and mixed with some leaf mould or peat; the ground should be mulched during the summer and a protection of leaves and brush be applied during the winter.

RHYNCOSPERMUM JASMINOIDES (Greenhouse Perennial, 36, $\left.55,95^{\circ}\right)$.

A beautiful greenhouse plant, with glossy evergreen foliage, producing masses of pure white Jasmine-like flowers, delightfully fragrant; in bloom about May and June. It is of a climbing habit, and presents a beautiful appearance when properly trained. The flowers are very desirable for bouquets, etc.

R. jasminoides aurea variegata-Foliage variegated green, white and carmine.

R. jasminoides argentea variegata-Foliage edged with silvery white.

\section{RICHARDIA ALBA MACULATA (Tender Bulb)}

A plant belonging to the same genus as the Calla, with beautifuily spotted leaves. It flowers during the summer months, either in pots or if planted out in the open border. The flowers are shaped like those of the Calla, and are white, shaded with violet inside. It is a deciduous plant, the root of which should be kept dry in the winter in the cellar or under the bench of the conservatory, and started in the spring like a Dahlia.

\section{RICINUS-Castor Oil Bean (Half Hardy Annual).}

A genus of ornamental seed-grown plants of stately growth, and with picturesque foliage, that are highly useful for planting, either singly or in groups, about the lawn or garden, or with other strong-growing plants, possessing striking foliage or flowers such as Cannas, Caladiums, Japanese Striped Maize, Hollyhocks, Helianthus, etc. The seeds may be planted in the open ground in May, or may be started a month earlier in pots, in the hot-bed or window, thus securing showy plants some weeks earlier. The young plants will not bear much moisture or cold, and when brought on inside should be kept near to the glass.

ROSE. (See pages 65 to 122.) 
RIVINA HUMILIS (Greenhouse Perennial, 36, 55, 95).

Greenhouse evergreen, grown for its beautiful racemes of bright scarlet berries. A plant of some size, is always full of the fruit, which makes it quite attractive; of easy culture; the flowers are white; increased by seed or cuttings.

RONDELETIA ANOMALE (Greonhouse Perennial, 35, 55, 95).

A genus of greenhouse plants of dwarf habit, requiring a rather warn temperature and frequent syringing. It is a very neat plant, bearing vermilion blooms when quite small and continues in flower during the summer; propagated by cuttings.

ROSEMARY-Rosemarianus OfFicinalis (Greenhouse Perennial, 33,45 to $\left.55,85^{\circ}\right)$.

A common sweet-scented plant, of erect habit, much cultivated as a house plant. It thrives with the most ordinary care, and is generally prized by all who cultivate it. The plants may easily be propagated from cuttings.

RUELLIA (Greenhouse Perennials, 35, 50, 90).

A genus of free flowering plants, blooming continuously during the season, and of easy culture.

$R$. Formosa-Bears scarlet salvia-like flowers in great profusion, making it desirable for bedding.

R. macrantha-Has beautiful purplish pink flowers of large size, being several times the size of the preceding variety.

RUSSELIA JUNCEA (Greenhouse Perennial, 34, 45, 85).

A splendid basket plant of neat, slender habit, with bright scarlet flowers, which are very conspicuous, a color that is scarce in basket planis.

\section{SALPILGLOSSIS (Half-Hardy Annual).}

Beautiful annuals for the garden, with funnel-shaped flowers, richly colored, reined and marbled. On close examination the blossoms will be found to have a rich, velvety softness seldom seen in other flowers. But for the fact that the plants are of somewhat slender and straggling growth, they would be exceedingly desirable. Seed may be sown in the open border. The plants should stand about eight inches apart. 
SALVIA-SAGE (Greenhouse Perennial, 33, 45 to 50, $80^{\circ}$ ).

A family of late summer flowering plants, suitable for the garden. They are of robust growth, easily cultivated in any soil, and form very attractive plants when in bloom. Easily increased from cuttings, and most of the varieties from seed. The plants may be lifted in the fall and be cut back severely and potted, and thus kept in a growing condition, either in a light cellar, the window or conservatory, until February, when new stock may be propagated for spring planting.

S. officinalis tricolor $-\mathrm{A}$ beautiful variegated variety of the common Sage; foliage blotched with white, green and sometimes pink; dwarf. bushy habit; fine for bedding.

S. patens-Flowers of the richest and most distinct blue; excellent for pot culture.

S. splendens-A superb fall flowering bedding plant, growing to a height of two to three feet, and completely covered with spikes of dazzling scarlet flowers, causing it, while in bloom, to be, perhaps, the most attractive plant in the garden. A sharp lookout should be kept for the green-fly on this plant in the winter, as no other one is more liable to attacks from this insect.

S. splendens alba-A white variety, similar in form of growth and flowers to the preceding. An excellent plant for decorating the conservatory and window in the autumn, if grown in a good-sized pot.

S. splendens variegata-Has beautiful white and scarlet flowers. S. amabilis-Unquestionably the freest flowering of all the Salvias. Small plants, set out the first of June last year; were a sheet of bloom all Summer. Color deep violet, shaded porcelain blue and white. A splendid flower to cut for bouquets; it will stand a severe frost.

S. rutilans (Apple-Scented)-Produces very freely neat spikes of magenta-colored flowers, graceful foliage, with a very agreeable apple fragrance.

S. bruantii-A dwarf growing variety, producing fine, large flowers of a dazzling, velvety red color; extremely attractive.

S. rosea-A distinct winter-flowering Salvia, with rich, rose-colored flowers, borne in spikes six inches in length, to contrast with the white, blue and scarlet varieties of Salvia. It is very valuable. 


\section{SANCHEZIA NOBILIS VARIEGATA (Greenhonse Perennial,} 35,50 to $90^{\circ}$ ).

A highly ornamental plant of good habit and vigorous growth, producing large leaves of an intense green, the reins of which are broadly margined with golden yellow. As a handsome, variegated plant of easy culture in pots, it is very desirable, particularly in a warm conservatory. A light, rich soil suits it the best.

SAXIFRAGA SARMENTOSA (Greenhouse Perennial, 32, 40, $80^{\circ}$ ).

A handsome plant of low habit, leaves nearly round and striped freely with silver bands; blooms white, of great beauty and borne in spikes of nearly 12 inches in height. It is especially adapted for hanging baskets, vases, etc.

\section{SCABIOSA-Mourning BRIDE (Half-Hardy Annual).}

$\Lambda$ garden plant of considerable value, grown from seed. There are tall and dwarf kinds, the former attaining a height of two feet; the dwarf, one-half as high, but both are of free growth and produce distinct flowers of many colors and shades, from white, through lilac, brick color, dark purple, etc., down to almost jet black. The flowers are produced on long, straight stems, and, with being neat and pretty, are very useful for cutting for summer bouquets. In flower from July to October. The seed may be sown early in the open ground, or started in heat, afterwards setting the seedlings a foot or fifteen inches apart in the garden.

S. nana $f l p l$. A d dwarf variety, somewhat distinct, the flowers are quite double and globular, extending through all the colors of the tribe.

S. stellata (Starry Scabiosa)-The petals, or rather seed ressels, of this variety are of peculiar scaly texture, and when dried are useful for arranging with the Everlastings and dried grasses into winter bouquets.

SCUTTELARIA PULCHELLA (Greenhouse Perennial, 36, $50,90^{\circ}$ ).

A neat greenhouse plant requiring but little care, being of rery easy culture. It makes a very desirable winter blooming plant, at which time it produces its dazzling red flowers profusely. The bloom is produced in terminal spikes. Propagated by cuttings. 
SEDUM-STONe CRop (Hardy Perennials, principally).

Mostly garden plants, with thick succulent leaves, and very tenacious of existence; the common Live-for-Erer belonging to the genus. Some of the varieties are of erect habit, and are attractive, while others are of creeping and trailing habit, being useful for cultivating in pots in the window or conservatory, or for planting in baskets, vases, etc., to droop over the edge. Among the latter S. Seboldii, with grayish green foliage and wiry-like stems, and $S$. Seboldii variegata, similar to the preceding, except that the leares are variegated with yellow, are considered the best. Will thrive in any soil and propagate readily by division or from cuttings, which, of some varjeties, will root if simply laid where it is damp.

SELAGINELLA-Lycopodium (Greenhouse Perennial, 35, 55, 90\%).

Delicate plants of creeping and erect habits, with fine foliage, and which delight in warm, moist, partially shaded situations, being, with the Ferns, an unequalled class of plants for fernery culture. Properly treated they are a delight to every cultivator, no matter what may be the extent of his collection. Propagated from cuttings.

S. apus-A delicate little moss-like plant with small creeping stems.

S. Cunninghamii-Tall, erect, Fern-like; deep green.

S. densa-A dense species, resembling a light green cushion of moss.

S. denticulata-A pretty creeping kind; leaves dark green and rounded.

S. denticulata aurea-A variety of the preceding marked with bright yellow.

S. flabellata-Upright in growth and of a very deep green color.

S. involvens-Small, closely-set foliage of a bright green color.

S. lepidophyllum-Dwarf, cushion-like, pale green.

S. paradoxa-Very dark green; semi-erect; distinct.

S. plumosa--Large, spreading, erect, fern-like.

S. serpens-Of creeping habit; bright green, fading towards evening.

S. uncinata-Brilliant, metallic, bluish foliage.

S. Warscewiczii-Large, erect, pale green.

S. Wildenovi-Delicate bright green; fern-like. 
SEMPERVIVUM REPENS (Greenhouse Perennial, 35, 40, 80 ).

May be justly called the miniature banyan tree. Its roots are sent downwards, and becomes stems of the plant for its support, and, when grown in a pan or shallow pot, it is a very interesting plant, and cannot fail to excite the curiosity of all who behold it.

SENECIO (Greenhouse Perennial, 34, 45, 80).

S. scandens (German or Parlor Ivy)-A well known, rapid-growing climbing plant; well adapted for covering trellis work quickly or training in the parlor; leaves glossy green, flowers yellow, in clusters.

S. macroglosis-A variety of this popular plant, which is, perhaps, more valuable than the old sort. It resembles the English Ivy to such a degree that it is often mistaken for it ; the leaves have a metallic lustre, the veins and ribs being of a lighter color. It has the same strong; vigorous growth as the common German Ivy, and for baskets, etc., it is unsurpassed.

SENSITIVE PLANT. (See Mimosa Sensitiva.)

SMILAX. (See Myrsiphyllum Asparagoides).

SNAP-DRAGON. (See Antirrhinum.)

SNOWDROP. (See Galanthus.)

SOLANUM-Jerusalem CherRy, Etc., (Greenhouse Perennial, 33,45 to $\left.55,90^{\circ}\right)$.

A genus of plants including several useful species for pot culture in the window and conservatory and also for bedding. They are of the easiest possible culture, thriving in any soil and under apparently adverse circumstances. All may be easily raised from cuttings, and the free fruiting varieties from seed.

S. jasminoides-Possesses a neat climbing habit, and has small, dark green foliage and pure white flowers; suitable for training to a trellis or pillars in the conservatory.

S. pseudo-capsicum fol. var.-Is a dwarf variety of the abore. Aside of its other good qualities, the foliage is margined with sulphur yellow to half the depth of the leares. Whether used as a house plant, for bedding, or for rases or baskets, it is a useful plant. 
S. pseudo-capsicum-Is the well known Jerusalem Cherry, producing a large crop of scarlet, clierry-like fruit, from early in the fall until after Christmas. Plants grown from seed are more productive of fruit the first season, than those struck from cuttings, or those several years old. Sow in the spring for fall bloom, and bring forward during summer either in ample sized pots, plunged in the open air, or else by planting them in the border and taking up and potting the plants in September.

SPIREA (Hardy Herbaceous Perennials and Shrubs).

A genus containing species natives of Europe, Asia, and America, and embracing both herbaceous plants and shrubs. They are all hardy, and produce showy flowers, usually in panicles, their prevailing colors being white, pink, crimson, etc. Of the easiest culture in any garden soil, the herbaceous varieties propagating by division of the roots. The Astilbe Japonica, which is treated upon elsewhere, belongs to this family. S. filipendula pleno-Is a highly esteemed species, with deep green foliage of beautiful form, and clusters of pure white bloom, produced in June on stems from one to two feet high. There is also a variety of the last named one with variegated foliage and whitish flowers.

S. Reevesii $f l$. $p l$. Beautiful pure white flowers. Very double, like small Roses, hardy.

S. Thumbergia-A pretty white-flowering variety, with narrow linear leaves. Valuable for forcing.

STEPHANOTIS FLORIBUNDA (Greenhouse Perennial, 40, 55, $\left.95^{\circ}\right)$.

A noble greenhouse climber, can be planted out in the border of the house and trained over the pillars and roof, or can be grown in a pot with a trellis. It produces its waxy white flowers in clusters like Bouvardias, and has a delicious fragrance unsurpassed. Much esteemed by bouquet makers.

STEVIA (Greenhouse Perennial, 33, 45, 85).

The Stevias, although distinct from the Eupatoriums, are, in points of free-growing and winter flowering qualities and their general requirements quite similar to that genus, being with them also of the easiest culture and a valuable class of plants for the 
conservatory, and also useful for window culture. As to their management, follow the directions given for the Eupatoriums.

S. compacta-An early flowering species, with large compact heads of pure white flowers; continues in flower nearly all winter, and longer than any other variety of either Stevia or Eupatorium.

S. serrata-A free-flowering species, blooming most freely about the holidays. The flowers are white, fragrant, and arranged loosely and gracefully along the stems.

S. serrata nana-A very distinct variety of the well-known winter-flowering Stevia Serrata. It never grows over eighteen inches high, and it produces a far denser mass of flowers than the old variety; the flowers are whiter, and it is a great improvement in every respect.

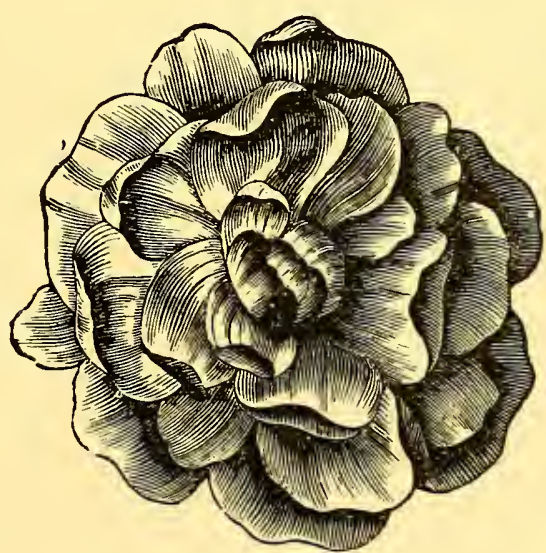

A double flower of the Stock.

STOCK-GJLLYFLOWER (Half-Hardy Annuals, Biennials and Perennials).

A genus of half-shrubby plants grown from seed, which produce spikes of elegant, fragrant, single and double flowers of many desirable and showy colors, including pure white. The plants are in no respect delicate, being easily grown by almost any one, and in the different sections afford varieties of the greatest value, either for bedding or for pot culture in the window, the conservatory (temperature 33,45 to $55,80^{\circ}$ ) or the open-air plant stand. Stock plants of every kind should be transplanted from the seed pots or beds in which they are started while they are 
quite small, as their slender roots soon extend to such a distance that the plants cannot be taken up without loss of fine rootlets, and consequent injury.

Tex WeEK Stocks. - These are important annuals, ranking in general desirability with the Aster, Balsam, Phlox Drummondii, Portulaca, Zinnia, etc., but are superior to any of these in their admirable adaptability to potculture for blooming in the winter. The section includes varieties, ranging in growth from one-half to one and one-half feet in height, which embrace a large variety of colors, such as white, bright crimson, carmine, blue, lilac, chamois, rose, blood-red, yellow, violet, purple and various shades of these, most of which are beautiful, striking and fragrant, and a large percentage of the plants will produce flowers that are perfectly double. They delight in a well-enriched soil. For summer flowering the seeds may be sown in the hot-bed or coldframe in April, or the open ground in May, and the plants should stand twelve inches apart. For winter flowering, sow in July, August or September, and cultivate in pots in the open ground until cool autumn weather, when they should be moved under protection, but still treated to an abundance of fresh air as late in the season as possible, and also frequently in winter. During their flowering season in pots, they will be benefited by occasional waterings with weak liquid manure.

AUtumnal or Intermediate Stocks. - This section are prized on account of their flowering late in the autumn and winter, which necessitates that they be grown in pots, and brought into the window or conservatory for blooming. For this purpose the seeds should be sown in the spring. Seeds may also be sown in July or August, for plants to flower in the spring, A large num. ber of bright and desirable colors are embraced.

EMPERor or IMPERIAL Stocks,-This desirable class of Stocks are better suited for pot culture than for bedding, and are perennial in habit, frequently lasting for several ycars. If the seeds are sown in the spring they will bloom the following autumn, while for spring flowering they should be sown in July and August. The colors are white, rose and crimson, and the plants attain a height of about eighteen inches.

Brompton Stocks. - The Brompton Stocks are biennial in habit, flowering in the winter or spring from seed sown the previous spring, in the window or conservatory. By wintering the 
plants in a place sufficiently cool not to excite them into a free growth and flowering condition, they may be planted into the border early in the spring and will flower handsomely during the summer. If a good quality of seed is sown, more than one-half may be expected to produce double flowers. The flowers vary from straw color to pure white, and rose to deep purple and violet.

\section{STREPTOSOLEN JAMESONI (Greenhouse Perennial, 34, 45, 90)}

Resembling in growth the Browallias, the leaves being rich, deep green, alternate; of a compact, bushy growth, flowering very profusely in numerous trusses; the flowers are lobed, nearly one inch in diameter, opening bright orange and passing to rich, deep cinnabar-red. It commences to flower early in March, continuing quite full through June and Julp.

\section{SUNFLOWER. (See Helianthus.)}

\section{SWEET PEA-LATHyrus (Hardy Annuals and Perennials).}

The flowering annual Peas are desirable and popular plants for the garden; excellent in every way for bouquets and cut flowers, and on the whole may be commended as one of the most essential plants to every collection. The flowers are delightfully fragrant, and yield a great variety of shades and colors, such as white,rose and white, purple and white, scarlet, scarlet striped with white, black, black with lizht blue, brownish purple, etc. Being a perfectly hardy annual, the seed may be sown as early in the spring as the soil can be prepared. Sow in clumps, groups or drills, placing sticks or other fixtures for the Peas to run upon, and otherwise treat them the same as the common Garden Pea. By cutting the flowers as fast as they bloom and keeping the plants mulched, they will continue prolific all season.

Perennial Pea (Everlasting Pea). - A beautiful climbing perennial, easily grown from seed. The flowers are red, white,rose-colored etc., and are produced in clusters in long succession. An excellent plant for trailing to trellis, or an arbor, and is perfectly hardy. 
TABERN $\notin M O N T A N A$ CORONARIA $f l . p l$. (Greenhouse Perennial, $\left.35,55,95^{\circ}\right)$.

A stove shrub, bearing in profusion snow white flowers of delightful fragrance. This is a highly valuable plant where cut flowers are a requisite, and should be cultivated in every collection.

TAGETES SIGNATA PUMILIA. (See Marigold.)

TECOMA JASMINOIDES (Greenhouse Perennial, 33, 45, $80^{\circ}$ ).

In style of growth this somewhat resembles some of the Jasmine, though belonging to an entirely different family. Its flowers are tubular shaped, white, with a beautiful pink throat. It is naturally a climber, but can be grown in bush form by keeping it well cut back; does well in the sitting room or greenhouse, or bedded out in summer.

\section{THUNBERGIA (Tender Annual).}

Trailing and climbing plants for the conservatory and for window culture, being among our most valuable basket plants in protected situations, and are also suitable for bedding. The flowers are large, round, single and embrace peculiar colors, that are certain to be admired. These are such as yellow, orange and buff, with an intensely dark eye of large size in the center, and there is also a pure white variety. The seeds should be started early, in a warm place. The plants are of slow growth while young, but as warm weather comes on they advance rapidly and flower constantly for a long time.

\section{THUNBERGIA (Greenhouse Perennial, 36, 50, 95).}

These are among our most useful greenhouse climbers requiring but little attention; can be run up the rafters or on trellis.

T. Harrisii-An excellent vine for covering trellises, etc. The flowers are tubular in form, two inches in length, bright porcelain blue, with a yellow throat. A free blooming plant of great merit

T. fragrans-Same as preceding, but with pure white flowers of delicious fragrance. Much esteemed. 
THYME-Lemon Scented (Hardy Perennial).

This plant is valuable for border decoration and for using in baskets and rustic designs. The leaves are variegated, there being two kinds, gold and silver.

\section{TIGRIDIA-Tiger FLower (Tender Bulbous Perennial).}

A bulbous plant for the garden, producing beautiful and curious large flowers for a long time in the summer. Their colors in the different varieties embrace orange, scarlet and white, with golden variegations, and are distinctly spotted with black. The bulbs may be planted in the open ground in May in warm situations, and should be lifted again early in October. After allowing them to dry, pack in dry sand or sawdust and store away from frosts and mice also, I may add, for these will eagerly devour them if an opportunity occurs.

TORENIA ASIATICA (Greenhouse Perennial, 50, 65, 100 ${ }^{\circ}$.

One of the prettiest summer plants for vases or hanging baskets. Flowers blue, of a Gloxinia-like shape. Flowers during the summer months.

TRADESCANTIA-W ANDERING JEW (Greenhouse Perennial, 34, $\left.40,85^{\circ}\right)$.

Well known vines which are fine for hanging baskets and vases, or for brackets. Will also grow well in water making a drooping fringe of from two to four feet long.

TROP EOLUM-NASTURTIUM (Half Hardy Annuals and Greenhouse Perennials, 35, 50, 90 $)$.

A well-known genus, affording plants of strong-growing and free-flowering habits, some of which are of dwarf nature and others climbers. The flowers are attractive and showy in all the varieties, the prevailing colors being dark crimson, brilliant scarlet, dark orange, sulphur spotted with maroon, etc. There is a double flowering variety, of orange scarlet color, which, with Star of Fire and varieties belonging to the Lobbianum section, are mostly cultivated as perennials, being increased by cuttings. 
The varieties which come under the headNasturtium, are grown from seed planted either in the open ground, or in heat, and afterwards set in the garden. Those classed with T. Majus, being climbers of rapid growth, make an excellent covering for old walls, trellises, etc.; while the varieties of T. Minus (Dwarf Nasturtiums), from their close, compact growth and richly colored flowers, are suitable for bedding purposes.

T. Star of Fire-Is an exceedingly useful and easily cultivated variety for pot culture in the conservatury, producing dazzling flowers in the greatest profusion, and climbing freely on a trellis, pillar or rafters, if planted in a large pot. By starting with young plants of this variety in the spring, keeping them in pots, and placing them in a light situation in the conservatory, each plant will produce hundreds of flowers from November until spring, of the following winter.

Tropelolum Peregrinum (Canary Bird flower). -This is a beautiful climber, with finely cut foliage, the flowers of which are a bright Canary-yellow, and when half open have a pretty and fanciful likeness to little birds. The plants are well adapted for covering trellises, etc.; and are easily grown from the seed, which may be sown directly where they are required, or in heat, afterwards transplanting the seedlings. In flower from July until frosts.

\section{TULIP (Hardy Bulb).}

The common Tulip is so well known as not to require any description, suffice it to say that it is esteemed for its hardiness, ease of culture in any soil, and the amazing brilliancy of its flowers, which are produced early in the spring. The genus comprises numerous classes, including the early and late flowering, both double and single, the Parrot, Duc Van Thol, Bizarres and Byblooms, in different varieties and colors, all of which are highly desirable. The gorgeous coloring in many of the improved varieties is remarkable, and a superiority can be claimed for the family in this respect over any other garden plants. Among the large and most double varieties, as well as the single, are to be found pure white, white striped with rose, intense scarlet, velvety crimson, rich bright yellow, glittering red, and many other distinct colors. Tulips should be planted in the autumn, as directed on page 32 , at a distance of five or six inches apart, 


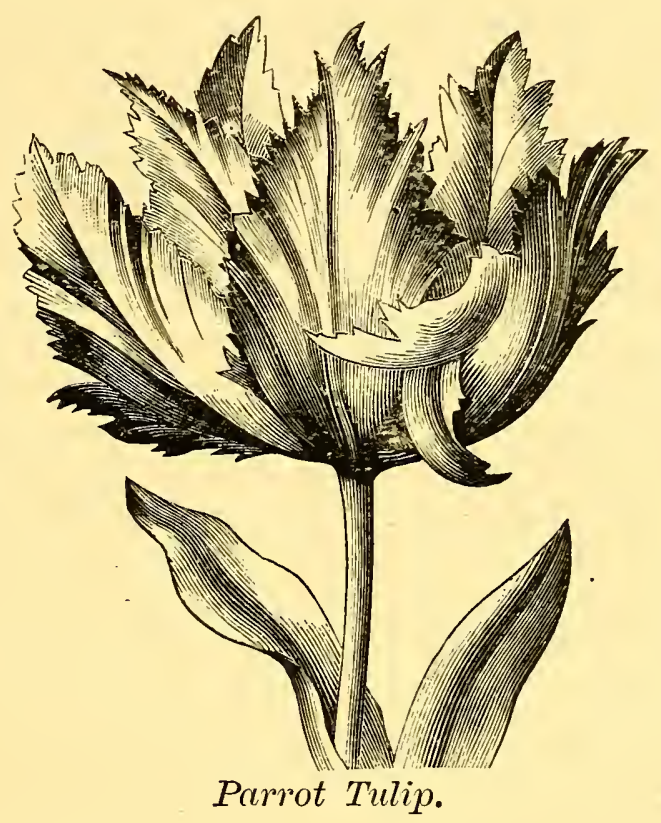

giving the tall, late varieties even a little more distance, and all a covering of about five inches of earth. The bulbs are also-valuable for forcing in the window or conservatory in the winter, like Hyacinths, Crocus, etc., and special directions for their management here, are given elsewhere.

\section{TUBEROSE (Tender Bulb).}

This is a bulbous plant, far less commonly grown than its merits deserve, and producing many beautiful pure white, wax-like, sweet-scented, double flowers, on long, upright stalks. The only difficulty in the way of this flower being generally cultivated, is, that unless the tubers are started early, in artificial heat, our seasons in the North are not sufficiently long for it to flower in the open ground. Unlike the Gladiolus, Tigridia, and others, the bulbs also do not produce new bulbs each year for flowering the next. It is true that small bulblets form freely around the old one, with each season's growth, but these must be cultivated one, two or more years before they will be sufficiently large for flowering. The first difficulty in the way of their culture named, may be overcome by starting the bulbs in pots, in a warm place, late in April and turning them into the garden soil the latter part of 
May. Should frost, in September, threaten to destroy the flowers before all are expanded, no plants are easier to take up than these, and the roots may be carefully lifted, potted and removed to the conservatory or a warm, light window, where they can finish blooming. Although the Tuberose requires considerable heat to flower well, growing bulbs may be transplanted, either in the spring or fall, with safety. If it is desired to secure new bulbs for flowering, the young bulblets should, in the fall or spring, be removed from the old bulbs and planted in a warm part of the garden, not earlier than the first of June, and then given clean culture until the first of October. This must be repeated each year with all that are desired for flowers, until they are strong enough to produce flowering shoots. The bulbs of this plant require, during the winter, to be kept in a dry condition, and where it is warm. The temperature should not fall far below $45^{\circ}$, or else they may receire injury, from the germ of the next season's flowering shoot decaying, although the external appearance would never indicate it. The Tuberose is susceptible of being managed to flower in winter by lieeping the bulbs dry and starting them at any time, or at intervals for succession up to August 1st; but they require a situation where the thermometer, in the night-time, will indicate at least $60^{\circ}$, and ten or fifteen degrees higher during the day, otherwise any attempt to force them must prove fruitless.

\section{TRITOMA UVARIA-RED-Hot Poker (nearly Hardy Perennial).}

This beautiful garden plant throws up, in September, numerous strong flower stems four feet in height, which are each surmounted with a spike of red and yellow flowers of exceedingly striking appearance. Although the Tritoma is nearly hardy in this latitude, it is better to take up the plants in autumn and keep them in a cool cellar or cold-pit, covering the roots with earth or sand. Of the easiest culture, and they will thrive in any garden soil.

\section{VALLOTA PURPUREA (Tender Bulb).}

This is a superb summer flowering bulb for pot culture, and also suitable for bedding. It is easily grown, and in August throws up its flowering shoots a foot or more high, each of which is surmounted by five to eight lily-like flowers, of a brilliant scarlet color. During its season of growth the plant should be 
abundantly watered, and cxposed to the sun as much as possible. In October water should be gradually withheld, allowing the roots to become fully dry by November, in which condition they should be kept in any dry place, away from the frost, until March, when they may by applying water be started into growth again for another season of flowering.

\section{VERBENA (Annual or Greenhouse Perennial, 33, 45, 80).}

The Verbena is in every respect a desirable bedding plant, but of little use for pot culture. In the open air it is a rapid grower, an abundant bloomer, and the flowers in the varieties embrace colors and shades, varied without end almost, and exceedingly bright and attractive; indeed there is not a dull color to be found among them. Verbenas set out in May require but a warn shower to start them into rapid growth, and the plants will, in the hot weather of June, assume a srreading form, and from then on be continually in bloom. By August the upright single stem plant that was set in May, will have extended to three feet across, and will at all times be covered with scores of beautiful, bright and in some varieties, fragrant flowers. Verbenas will thrive in any soil, but, without exception, it should be in a good state of fertility. I would particularly caution inexperienced growers against planting too close in the beds; three feet is near enough, Do not grow them on the same spot too often, as they do much better on fresh soil. After the plant has made some growth, the stems should be pegged down to the ground with hair-pins, or little sticks like matches, four inches long: crossed over them. The Verbena is most generally increased from cuttings, although it can be easily raised from seed. The advantage of adopting the former method is, that the splendid named varieties can be maintained pure beyond a doubt from year to year, while it can never be known exactly what colors will come from the seed. Seed grown Verbenas also lack the fine form of the selecter. named varieties, each of which is likely to equal the best that could be selected from among thousands grown from seed. In the winter, stock plants require a cool, light, airy situation, on which account it is a difficult matter to keep up healthy ones in a window. Where it is desired to kcep orer stock it is far better to start with young plants that were propagated from cuttings, in September, than to take up and keep over the old plants. Propagation for bedding in the spring 


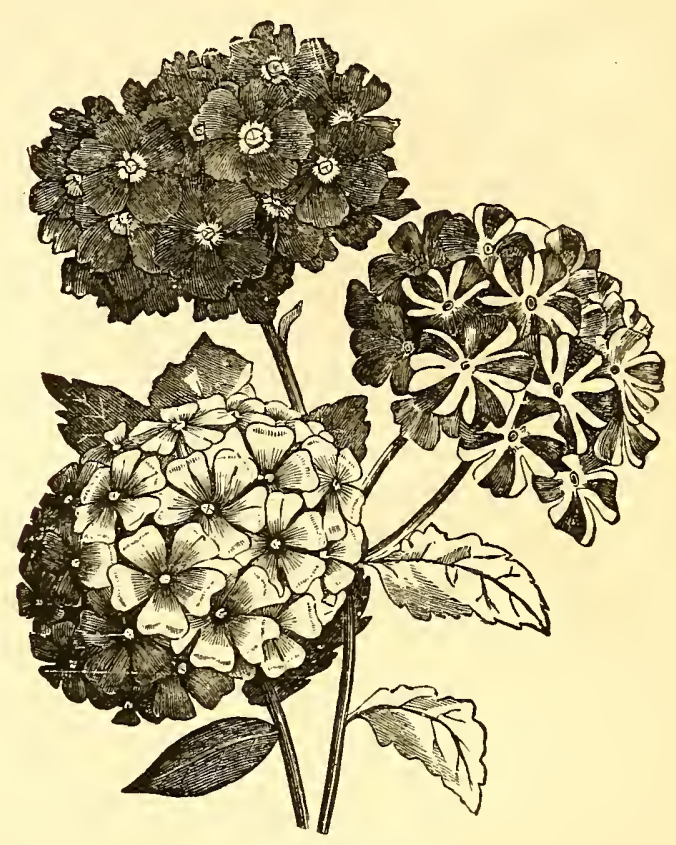

Verbenas.

may be done at any time from January until April, but the young plants should be given as much light and air as possible. To grow seedlings, sow in February, March or April, provide plenty of light and air, and never allow them to be crowded. Verbenas, if weil hardened, will bear some freezing without its killing them.

Verbena Montana (Hardy Verbena). - This is a pretty, freegrowing hardy plant, for the garden. The flowers are similar in form to the tender varieties; of a bright rose color, changing to lilac, and are produced in great profusion all summer. The plant is of low spreading habit, and very handsome when covered with bloom.

VERONICA (Half-Hardy Perennial, 30, 45, 75).

A class of plants blooming during the fall months, that are well adapted for bedding and pot culture. The flowers are borne on spikes from three to five inches in length, running through the various shades of purple, rose, lilac and white, and are attractive. The plants succeed in any soil, and when growing in the garden may be taken up and preserved in a cold-pit during winter 


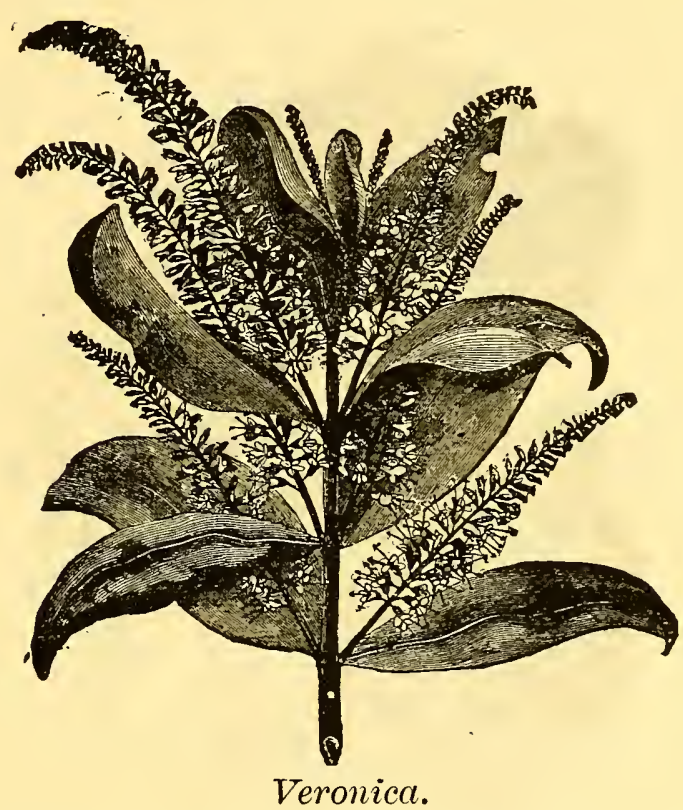

or may be kept in a cool part of the conservatory. There is t handsome variegated variety. which is highly attractive, either as a pot, basket or vase plant, or for bedding.

\section{VIBURNUM, SNOWBALL (Hardy Shrub).}

The common and well known Snowball shrub is a strong, hardy yrower, covered when in bloom with large balls of pure white Howers, really resembling balls of snow, but much pleasanter for snowballing purposes than real snow.

$V$. plicatum-This is a new variety introduced from Japan and is said to be superior to the old sort, being of dwarfer growth.

VIRGINIAN STOCK (Hardy Annual).

This beautiful little annual is a native of the shores of the Mediterranean. The seeds may be sown directly where the plants are wanted, early or at any time in the spring. The plants grow six inches high, and embrace in the respective varieties, red, white and rose colored flowers. The flowers are small and distinct; are produced in great profusion on erect stems well above the plant, from early in the season until after frosts. Useful for massing and in ribbon beds, and may also be grown as an edging plant. The plants to flower well should stand not closer than three or four inches apart. 


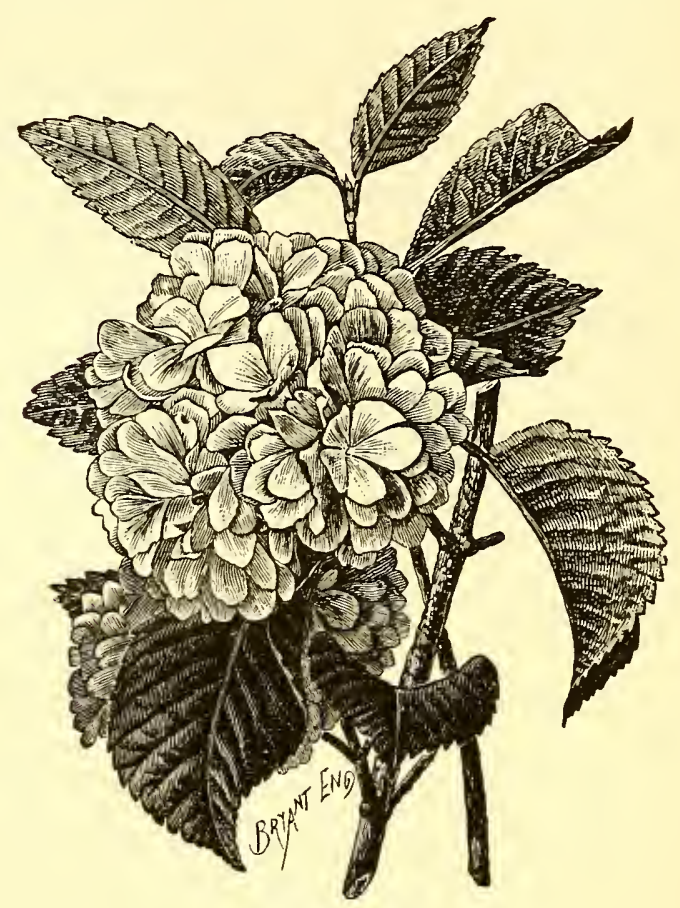

Snowball.

VIOLET (Hardy Perennial).

Famous spring flowering plants, very highly esteemed for their earliness, and the rich refreshing fragrance of the flowers, which include shades of color from violet to white in the different sorts. There are double and single varieties, the former being most highly prized, although they lack somewhat in hardiness. These are forced extensively for winter flowers, in all the large cities where a good demand for cut flowers exist. Plants designed for this purpose, are grown in the open ground during the summer, at a foot apart each way. In August these are gone over, and the runners which start into growth about this time are removed by pinching them close to the plants. This operation is repeated every few weeks, and in October the plants are taken up and potted, or if to be forced in the conservatory they may be planted directly in the beds. The plants will not bear close confinement, and a crop of flowers can only be expected where the plants are kept cool (32, $45,75^{\circ}$ ) and treated to an abundance of fresh air. The double 
varieties may be wintered with entire safety in a cold-pit, or by receiving protection in the open ground. Out of doors for permanent, all the violets delight in cool places, and a little shade. Propagate by division and cuttings.

V. Belle de Chatenay-New double white Violet. The flowers are pure white, most delicately perfumed; of immense size, and very double.

$V$. Double Blue-Light blue.

V. King of Violets-Large and double, indigo shaded with violet.

V. Lackawana-Single dark blue, very fragrant, fine for forcing.

$V$. Marie Louise-Dark blue flowers, larger than the Neapolitan.

$V$. Princess Louise-Double white.

$V$. Queen of Whites-Fine double white, very fragrant.

$V$. White Czar-Producing very large single flowers, sweetly scented. Flowers said to be larger than any other known in this class; strong growth and free flowering.

V. Swanley White-In this we have that great desideratum, a prire white Violet, which is never tinged with pink or purple under any conditions. It will be equally valuable as the purple variety Marie Louise, from which it is a sport, for forcing, as its flowers are the same size and are as freely produced as in that variety. Exquisitely fragrant. The Swanley White will be a novel feature in bridal bouquets and other fine floral work.

WALL FLOWER_Cherianthus Cheiri (Half Hardy Perennial).

This is a well-known plant, of the easiest culture from seed, and suitable for pot or garden culture. It commences flowering in the spring of the second season after sowing; during the preceding winter it should be kept in the cellar, cold-pit, or cool part of the conservatory. There are handsome double and single flowers, very fragrant, with orange and yellow colors predominating, and these shaded with red, brown or violet.

\section{WAX PLANT. (See Hoya). \\ WEIGELA ROSEA (Hardy Shrub).}

This is one of the most useful hardy shrubs for borders, etc. It is very ornamental when in flower during June and July. The 
flowers, which are produced in great abundance, are of a rose color. There is a Variegated Leaved variety which is very handsome, and a number of other fine kinds.

\section{WISTARIA-CHINESE Glycine (Hardy Climber).}

One of the most popular hardy vines, growing rapidly, climbing to a height of fifty feet or more, and when in bloom presenting a truly magnificent appearance.

$W$. Sinensis-The favorite, producing thousands of rich clusters or pendulous racemes of delicate violet-blue blossoms, richly perfumed.

W. Sinensis alba-A white variety of the above.

\section{XERANTHEMUM (Hardy Annual).}

A class of everlasting flowers, possessing much merit for drying for winter decoration. There are white and several shades of light purple flowers, which are double and borne on long substantial stems that retain their strength with drying. The plants are robust and easily grown from seed, which starts readily and may be sown in heat or where the plants are wanted.

\section{YUCCA FILAMENTOSA-Aday's NeEdLe (Hardy Perennial).}

A tropical-looking plant, with long narrow leaves that remain green the entire year. It throws up a strong flower-stem in summer, three to four feet high, bearing a large spike of creamy. white, bell-shaped flowers, which retain their beauty a long time.

\section{ZINNIA, DOUBLE (Half-Hardy Annual).}

The improved Double Zinnia of the present day is emphatically one of the most valuable annuals that can be grown, and deserving of a place in every flower garden. The plant is robust, freegrowing and exceedingly prolific of bloom, and may be easily raised from seed sown under glass, transplanting the plants when small, or the seed may be sown in the open ground, as soon as danger from frost is over. The flowers from good seed are of a beautiful form and texture, parfectly double in the best sorts, and afford white, scarlet, yellow, purple, salmon, violet and other colors in the different varieties. They begin to appear when the plants are very young, retain their attractiveness for a long time, 
and increase in number and beauty until hard frosts. While the flowers of the Zinnia, like those of many other choice doub!e seed-grown plants, will not invariably come double, yet enough may be depended upon to produce a large percentage of double blossoms from the best strains of seed. Let the plants be set six or seven inches apart, in rows twenty inches apart, and then as they come in flower thin out the poorest, and thus retain plenty of those of superior quality. This thinning must be done with caution, and several flowers should be allowed to form on a plant before deciding whether to pull it up or not, for plants which will in season produce the most double flowers, frequently show their first ones only partially double. The Zinnia will thrive in any good garden soil.

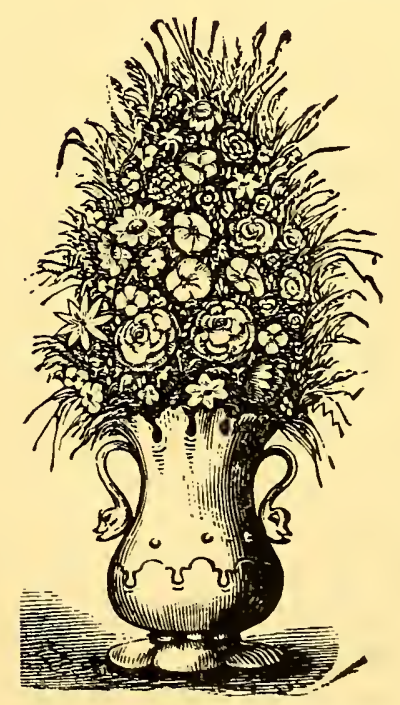




\section{THE FLORICUITURAL OPERATIONS OF THE YEAR ARRANGED BY WEEKS.}

The successful cultivation of plants and flowers depends largely on the performance of all the work connected therewith, at the right times, and some kind of a reminder of the various operations as they should occur, is serviceable to cultivators and especially to those who can devote but a small portion of their time to floriculture. The following will be found an arrangement of the various operations of the florist during the year, into fifty-two parts, which are respectively adapted to the fiftytwo weeks of a year. It is most perfect in its application, to latitudes between $42^{\circ}$ and $43^{\circ}$, and persons living north and south of this should calculate somewhat upon the difference between their own latitude and this one in making use of the arrangement.

In dividing a year into fifty-two weekly parts, each week for the sake of convenience may begin on the same day that the first week beginning with January 1 commences on: thus, January 1 falling on Wednesday, so January 8, January 15, and all the dates given below will fall on Wednesday, and so of any other day of the week. The only exception to this is after February 29 , during a leap-year, and here the difference one day is so slight as to be of little consequence.

The matter under each weekly head is designed for the week commencing at the date given. Although nearly all the operations named may with safety be performed either at a time preceding or following the week under which they appear, those printed in italics are of general interest at the season in which they are given, without reference to the particular week they may be under.

The following abbreviations are made use of : W for Window; Con. for Conservatory; O. A. for Open Air; C. P. for Cold-Pit; W. F. for Winter Flowering. 


\section{JANUARY 1-FiRST WEEK.}

Read in the preceding pages all about the required temperature, adaptability and culture of each plant included in the collection. Pay strict attention to airing when the weather is mild, watering, destroying insects, etc., in the Con., W. and C. P.-See Dec. 17 and Oct. 15. Give Callas, hardy forcing bulbs, etc., (see list Oct. 8) plenty of water. Fuchsias at rest may be started. Repair at once any glass happening to get broken.

\section{JANUARY 8-SECOND WEEK.}

Give plants in $W$. extra protection during severe nights. Study and decide early what improvements it would be desirable to mare about the grounds; also to what extent you will engage in, or increase upon floriculture during the coming year. Ascertain the number of plants, etc., required, and govern subsequent propagations, the procuring of plants, seeds, etc., accordingly.

\section{JANUARY 15-THIRD WEEK.}

Continue to bring in kinds named under Oct. 8, and Roses, etc., under Oct. 29. Tie up Hyacinths and other flowering plants. Keep Pelargoniums near the light. Syringe and wash plants, etc. see Nov. 26. See that dormant Canna and other tubers, etc., named under Oct. 8, are not suffering from any cause.

\section{JANUARY 22-FOURTH WEEK.}

Seeds under Feb. 19 may be sown, for early. As bulbs pass out of flower, cut away the flower stalks. Keep the earth in the pots mellow at the top.-See Dec. 17.

\section{JANUARY 29-FIFTH WEEK.}

Make hot-bed sash, etc. - see Dec. 10. Study to improve plants by pruning. Encourage W. F. Roses, etc., by occasionally applying liquid manure.

\section{February 5-Sixth WeEK.}

February is the month for propagating from cuttings, all kirds of common soft-wooded plants in the W. and Con. for adornment during the coming year, and nearly everything will now strike readily, therefore, as fast as suitable growth is afforded make cuttings and propagate. After Poinsettias have flowered, rest them. Provide seedling Plants named under Aug. 20, and Oct. 29, with an abundance of pot room, air, and light, and they will grow rapidly.

\section{February 12-Seventh WeEk.}

Continue to bring in for forcing, kinds named under Oct. 8 , and Roses, etc., under Oct. 29. Start Chrysanthemums to propagute from. Provide an abundance of manure outside for future use. 
February 19-Eighth Week.

Seeds of Pansy, Verbena, Salvia Splendens, Petunia, Stock, Sweet Alyssum, Mimulus, Maurandia, Ice Plant, Sensitive Plant, Delphinium, Dianthus, Antirrhinum may now be sown to secure strong plants for spring and summer flowering. As the season advances plants will need more water, and should have an increase of air; be ever on guard against insects-see Oct. 15, Dec. 17. Have clean pots and good soil on hand for newly-started plants.

\section{February 26-NINTH WEEK.}

See that implements, vases, etc., for summer use are in repair. Give all cuttings close attention. Perfect plans as alluded to under Jan. 8. Water abundantly all plants that are being forced. Give the Fernery daily attention-see Dec. 24. See that climbers of all kinds have suitable support.

\section{March 5-Tenth Week.}

See that a proper quantity of stock is coming on, either by propagation or otherwise. Propagation from cuttings should still go on for spring plants, and Chrysanthemums, Eupatoriums, Stevias, Roses, Carnations, Violets, Libonia, Laurestinus, Jasminums, W. F. Fuchsias, Cytisus, Chorozema, Abutilons, etc., for W. F. be struck. Pinch back the shoots of newly started plants to induce a stocky growth. Pot cuttings as soon as possible after they are roted. Dormant Lemon Verbenas, Richardias, Gesneras, Mimulus, and the like, may be started to grow. Out door work, such as grading, trenching, etc., should be commenced as early as the soil can be worked, but beware of digging stiff, loamy soil when it is wet.

\section{March 12-Eleventh WeEK.}

Kinds named under Oct. 8, and Roses, etc., under Oct. 29, may still be brought in. Provide pot plants with all the room needed for developing good forms now that they are growing fast. See "As the Season Advances," etc., Feb. 19, also Oct. 15 and Dec. 17.

\section{MarCh 19-Twelfth WeEK.}

From the time Camellias start into growth until antumn they require to be shaded from the sun; will also need more water, frequent syringing and may be pruned if desirable. Attend to airing Ferneries, see Dec. 24. Hot-beds may be made for general purposes. If Anemone Hortensis tubers hare been kept over, plant at first opportunity. Double white Primroses may be propagated by cuttings or division.

\section{MARCH 26-THIRTEENTH WEEK.}

Seeds of Gomphrena, Cobœa, Amaranthus, Celosia, Ipomœa, Thunbergia, Canary Pird Flower, Canna, etc., may be sown in heat. Hot-beds should be very carefully aired, watered and protected; allow for the admittance of a little air during the night time 
when the weather is mild. Lilies may be started in pots. Oleanders, Oranges and Lemons, Cactus, Pomegranates, Hydrangeas, may be started into new growth; repotting if needed. Calceolarias, Cinerarias, Pelargoniums, may be treated to liquid manure occasionally. Give cutting close attention; pot off when slightly rooted. Bedding and other plants in pots will do well in a good hot-bed. Push out-door work as the season will allow. A good share of the protection applied to beds, plants, etc., in the fall should be removed if not yet done. Sodding may be done as soon as the ground is settled.

\section{APRIL 2-FOURTEENTH WEEK.}

Cuttings may still be made of Verbenas, Petunias, Achyranthes, Coleus, Salvias, Heliotropes, Fuchsias, German Ivy, etc., for summer decoration, and the kinds named under March 5th for W. F. Seeds of Acroclinum, Aster, Balsam, Browalia, Cacalia, Celosia, Helichrysum, Helipterum, Japanese Maize, Marigold, Petunia; Ricinus, Phlox Drummondii, Portulaca, Scabiosa, Stocks of all kinds, Tropæolum, Wall Flower, Xeranthemum, Double Zinnia, and those named under Feb. 19 may be sown in heat. If the soil is dry Hardy Perennials may be taken up, divided and reset, as required. and Lilies be planted.

\section{APRIL 9-FIFTEENTH WeEK.}

Not much fire heat is likely to be needed after this date in the Con.--see "As the Season Advances," etc, under Feb. 19. Dahlias, Caladiums, Cannas, Amaryllis, Vallota, and similar things, may be started in heat. As the soil becomes fit, Candytuft, Sweet Pea, Convolvulus minor, Mignonette, Clarkia, Sweet Alyssum, Briza, Coix Lachryma, Lupinus, may be sown in the O. A. Overhaul plants remaining in the C. P. and give almost full exposure to the air.

\section{APRIL 16-SIXTEENTH WEEK.}

Keep watci of the seed-beds, watering when necessary, removing weeds, and thinning and transplanting plants that stand too close. Watch for and destroy all insects in the W., Con., etc., as with warm weather they multiply rapidly-see Dec. 1\% If W. plants can be set outdoors during a warm shower they will be benefited. Early hanging baskets may be planted. Sow lawns, if ready. Divide and reset edgings of Statice. Plant out Tritomas, etc. Secure plenty of loamy turf, manure, refuse hops, etc., for potting soil.

\section{APRIL 23-SEVENTEENTH WEEK.}

Start Tuberose bulbs in a warm place. Pot up and shade young Double White Primroses. Cold-frames may be sown with seeds named under April 2, etc. Hot-beds may still be sown. If they have been well aired, Carnations, Pinks, Violets, for W. F., etc., also Veronicas, Penstemons, and Pansies, may be planted out. Make a planting of Gladiolus, and continue doing so at intervals of ten days or two weeks, until June 15. 


\section{APKIL 30-EighteEnTH WEEK.}

Give an abundance of air to all plants; attend to pinching back such as need it. All plants will need close attention now as regards watering, lest they suffer from drying out-see Feb. 19 and Dec. 1\%. See "Keep watch of Seed-beds, etc., April 16. Iow the lawn as soon as a little growth of grass has been made; repeat every two weeks or oftener, during the season.

\section{MaY 7-NineteEnTH WEeK.}

If well-hardened, Roses, Verbenas, and the hardiest annuals and other plants may be set out. See "Transplanting." Seeds may be sown in the O. A. of Animated Oats, Amaranthus, Amobium, Antirrhinum, Aster, Browalia, Cacalia, Calendula, Calliopsis, Campanula, Agrostemma, Clarkia, Morning Glory, Erysimum, Escholtzia, Godetia, Grasses, Gypsophila, Helianthus, Felichrysum, Leptosiphon, Nemophila, Pansy, Petunia, Phlox Drummondii, Poppy, Portulaca, Salpiglossis, Scabiosa, Ten-week Stock, Tropæolum, Virginian Stock, Xeranthemum, Double Zinnia besides those named under Aug. 13. The ventilators of the Con. may be kept open almost constantly. See that no Red-Spider affect Roses, Fuchsias, etc. This is a very small insect appearing on the under-side of leaves, in large numbers, and causing them to turn brown and finally to drop-see May 21. Cut away flower stems of bulbs out of bloom, but let the leaves grow.

\section{May 14-Twentieth WeEK.}

The planting out of all but the most tender plants may go on. Plant out Dahlia tubers. Sow seeds of Solanum in pots, for autumn and winter decoration, and in the open air tender annuals, such as Balsam, Calandrina, Celosia, Helipterum, Japanese Maize, Marigold and Mirabilis. Keep a lookout for Rose Sau-flies-see "Insects Injurious to Roses," page 117.

\section{MAY 21-TWENTY-FIRST WEEK.}

The glass of the Con. may be shaded, except over Noisette and other Roses. These should be syringed frequently, as also should Camellias, Fuchsias and other plants kept in during summer. To create moisture for preventing attachs of Red Spider, water should also at all times be freely used on the walks and about the Con. The ventilators should be kept open, Azaleas may be repotted and moved out; also Agaves, Caladiums, Dracenas and other ornamental pot plants, designed for the lawn, etc. WinterHowering Roses, Bouvardia, Jasminums, Poinsettias, and those named March 5, to be grown in pots during summer, should be moved to the $\mathrm{O}$. A. and carefully plunged in soil or other substance to prevent their drying out; each one should be placed on a stone, pot-sherd or slate, to prevent angle worms entering through the hole below. House plants may be moved to summer quarters. Vases, hanging baskets, etc., may be put out, and new ones still be planted. Fuchsias, Geraniums, Ageratums, Cupheas, 
Petunias, Heliotropes, etc., make handsome pot plants for fall blooming if propagated now, and kept pinched back for eight weeks. Plant out Bouvardia, started Dahlias, Coleus. also Tigridia, Amaryllis, Vallota, and sow Ricinus, Acroclinium, Rhodanthe, Ipomoea and other tender seeds. If not yet done, W. F. Fuchsias should be given a rest.

\section{MaY 28-TWENTY-SECOND WEEK.}

Tropæolums and Heliotropes, for W. F., may be propagated; also a general collection of such things as will be useful for winter decoration, including plants with ornamental foliage, and for Ferneries, also Ivies, and the freest-growing plants named under March 5. New lawns yet to be sown, should be seeded with as little delay as possible. Any of the seeds named under May 7-14, etc., may still be sown in the O. A. Be prepared to destroy Rose Slugs as they appear-See June 18, also July 9.

\section{JUNE 4-TWFNTY-THIRD WEEK.}

Planting of Geraniums, Verbenas, and all started bedding plants is still in order. Set out young Tuberose bulblets. Callas should be given a rest of several months when done flowering. Keep Double White Primroses in shade and give plenty of space.

June 11-Twenty-Fourth WEEK.

Pinch back Carnations, Bouvardia, and other W. F. plants that require it. After all plants for out-doors have been moved from the Con. it should be thoroughly cleaned for the summer. Wash empty pots. Watch for and destroy Chafers on Rose bushes.

\section{JUNE 18-TWENTY-FIFTH WEEK.}

Peg down Verbenas and other trailing bedding plants. See "Summer Culture," "Watering Plants," etc.," "Removal of Matured Flowers." Mow the lawn frequently. Maintain neatness in all parts of the grounds. Water hanging baskets, vases, pot plants, etc., abundantly. Syringe and use water freely in the Con., not neglecting Camellias. Provide Sweet Pea, Morning Glory, and all other climbers with support, as needed.

\section{JUNE 25-TWENTY-SIXTH WEEK.}

Repot, if necessary, Roses, and other W. F. plants named and alluded to under May 21, and keep well watered and plunged. Propagation of plants named and alluded to under May 28 may still go on. As strong young shoots of Perennicils, Roses, Shrubs, etc., are formed, layering may be done.

\section{July 2-Twenty-SeVENTH WeEK.}

Any building or improvement of Conservatories which is contemplated, also repairing of glass, etc, should be done, to have them ready for plants in Sept. and Oct. Sweet Alyssum, Tenweek Stock, Arignonette, and the other hinds named under Aug. 20, may be sown for $W . F$. Candytuft, Mignonette. Phlox, Erisymum, may be sown in O. A. or frames for late blooming. 
July 9-TWENTY-EIGHTH WEEK.

Keep edgings clipped, and cut the edges of grass borders occasionally. Allow no weeds to grow either in the walks or beds.

\section{JULY 16-TWENTY-NINTH WEEK.}

Layering of Carnations, Pinks, Roses, etc., should receive attention where suitable growth is afforded-see June 11 and 18.

\section{JULY 23-THIRTIETH WEEK.}

Should the season prove dry, Dahlias, Carnations, newly-plant ed trees, etc., will be benefited by mulching. Plants alluded to under May 28 may still be propagated. Seeds of the kinds named under August 13 and 20 may be sown thus early.

\section{JULY 30-ThIRTY-FIRST WEEK.}

Pinch and use the knife freely on monthly Roses and all rapidgrowing plants-see "Pruning." For potting soil, see April 16. After they are done flowering give Pelargoniums a rest. For 'Rust on Roses"- see page 118.

\section{August 6-ThIRTY-SECOND WEeK.}

Callas may be started to grow. Keep flowering Dahlias, Gladiolus, Lilies, etc., tied to stakes. The re-potting of Oleanders, etc., named under March 26, is seasonable, after they have made a growth. Carnations, for early winter flowers should receive their last heading back.

\section{AUGUST 13-THIRTY-THIRD WEEK.}

Winter-flowering Fuchsias may be started. Propagation of Geraniums and other plants alluded to under Sept. 10 may be begun. As they require it re-pot W. F. plants named and alluded to under May 21. Sow Seeds of Pansy, Hollyhock, Delphinum, Dianthus, Aquilegia, Canterbury Bells, Digitalis, Lychnis, Myosotis, Perennial Poppy, Lobelia Cardinalis, Antirrhinum, and all other Perennials and Biennials-see June 18, also July 11.

\section{AUGust 20-Thirty-Fourth WeEk.}

Sow for winter and spring decoration, Calceolaria, Cineraria, Coboea Scandens, Cyclamen, Primula, Smilax, Ten-Week Stock. For drying everlastings gather before fully expanded, tie in small bunches, and hang in the shade. In gathering seed, save that only from the best flowers.

\section{AUGUST 27-ThIRTY-FIFTH WeEK.}

Provide pots, potting soil, fuel, etc. Lilium Candidum may now be reset. Layering may still be kept up.

\section{SEPTEMBER 3-ThIRTY-SIXTH WeEK.}

Giv Fuchsias rest as they cease to flower. Remove runners, and cut back W. F. Violets-see July 2. 


\section{SEPTEMBER 10-ThiRTY-SEVENTH WeEK.}

Bouvardias and others of the more tender plants for winter decoration also Tuberoses not yet done flowering, may be taken up and potted. Propagation of a general stock of tender plants should be enguged in, which are to be increased during the fall and winter for spring and later use. Those named under October 1 may be deferred until then. Repot such W. F. plants named and alluded to under May 21 as require it.

\section{SEPTEMBer 17-ThiRTY-eighth WeEK.}

Hardy bulbs named under Oct. 8 may be planted in the O. A. or started for forcing. Be on your guard against frosts, and protect for a week or two longer, or take in, all $W$. $F$. plants, for the window or conservatory. Vases, hanging baskets and the showy pot plants named under May 21, may be left out longer by carefully protecting in cool and frosty nights.

\section{SEPTEMBER 24-ThIRTY-NINTH WEEK.}

See "Treatment of Plants designed for W. F.," also Roses. Pelargoniums may be cut back and started into growth. Give cuttings close attention daily, and see "Keep watch of seed-beds," etc.. April 16. Lift Carnations, Violets and other plants of a similar degree of hardiness, that are designed for winter flowering. Propagation should continue to go on with all tender plants. A little fire heat may be needed on cool, frosty nights. -See Oct. 15. The bulbs under Oct. 8, may be planted.

\section{OCTOBER 1-ForTIETH WeEK.}

Ferneries for winter adornment may be planted. Petunias, Centaureas, Carnations, Pinks, can be propagated better now than earlier; Verbenas strike well yet. Chrysanthemums may be stimulated with liquid manure. Pot cuttings, soon as they are rooted; thin out, transplant or pot any seedlings which may require it. Sow, for early plants next year, Clarkia, Calliopsis, Candytuft, Erysimum, Mignonette, Nemophila, Perennial and Sweet Pea, Larkspur.

\section{OCTOBER 8-FORTY-FIRST WEEK.}

Now is the time for planting in the O. A., or starting in pots, etc., for forcing, the hardy bulbs of Hyacinth, Tulip, Crocus, Narcissus, Jonquil, Lilium Longiflorum, Iris, Crown Imperial, Snowdrop, etc. After sharp frosts, take up, dry and store away for winter, Canna, Caladium, Dahlia, Amaryllis, Gladiolus, Tigridia, and Tuberose, bulbs, etc. Commence drying off Vallota.

\section{OCTOBER 15-FORTY-SECOND WEEK.}

Give plants in the Con., W. and the C. P., an abundance of air daily as long as the weather will admit, and also some later all during the winter. By no chance allow a higher temperature to exust at night than would be suitable in the daytime, neither strive 
to keep ashigh a degree in cloudy weather as in clear; never subject plants of any kind, and especially Roses, to strong drafts of air; open ventilators in the Con. on the side away from the wind in cold weather. Secure Lemon Verbena plants. Haul, manure, sand, etc., under shelter for winter use. See "Taking Up Plants in the Fall." On Insects, Watering, etc.-See Dec. 17.

\section{OCTOBER 22-FORTY-THIRD WEEK.}

Take up Feverfews, Penstemons, Veronicas, for stock plants. Oleanders and other hard-wooded plants named under March 26, may be placed in winter quarters. Water Callas abundantly.

\section{OCTOBER 29-ForTY-FOURTH WEEK.}

Sweet Alyssum, Mignonette, Ten week Stock, Maurandia, Browalia, etc., may be sown for winter and spring decoration. Young plants of Carnation, Chrysanthemum, Stevia, Eupatorium, Pink, Violet, that are too small for flowering, may be kept safely during winter at a night temperature of $40^{\circ}$ to $45^{\circ}$. Roses, Deutzias, Dicentras, Lily of the Valley, Pinks, Daisies, Violets, Astilbe Japonica, for winter and spring forcing, may be taken up, potted and stored in the C. P. or cellar. In taking them in from the C. P., etc., during winter, never commence forcing too rapidly; the same with hardy bulbs.

\section{Noveyber 5-ForTY-FIFTH WEEK.}

Hardy bulbs named under Oct. 8, may be planted in the O. A., as long as the ground remains open, and be started for forcing tuo months yet. Fall struck cuttings and seedling plants in small pots should be shifted as required. Be very particular not to allow the seedlings, named under Aug. 20, to become pot-bound.

\section{NoveMrBeR 12-ForTY-SIXTH WeEK.}

At this season the grounds should be cleaned up generally; vases, etc., secured; rubbish and dead plants removed; manure applied; beds worked over, etc. The earliest started bulbs, for forcing, named under Oct. 8 may be brought in. On the care of Ferneries, see page 51 and under Dec. 24.

\section{Noveyber 19-ForTY-SEVEnTH WeEK.}

Protect, by laying down or otherwise, Roses, Shrubs, etc., before the winter sets in severely; mulch the roots for a good distance around. For airing, temperature, etc., of the Con. and $W$. , see Oct. 15 . For watering plants, destroying insects, etc., see Dec. 17.

\section{NovfMBer 26-ForTY-EIGHTH WeEK.}

Improve plants by pinching and pruning. Wash the foliage of Ivies, Wax Plant, C'amellias and other house plants occasionally, and syringe Roses in the Con. frequently. Cuttings of such plants as stock appears short of should be made at first opportunity. See "Removal of Matured Flowers," page 31. 


\section{DeceMBeR 3-ForTY-NINTH WeEK.}

As soon as the ground is frozen, a dressing of straw or hay should be applied to beds of fall-planted hardy bulbs. Pansies, and other fall-grown seedlings. Top-dress the lawn with wellrotted manure if the soil has become impoverished. Chrysanthemums, after flowering should be cut down and moved to the cellar, under Con. staging or some other similar place. See that Tuberose bulbs are stored in a warm place; also that all bulbs, seeds, tubers, etc., are secure and safe from frost, mice, etc.

\section{DECEMBER 10-FifTIETH WEeK.}

Give extra protection to plants in the $W$. in severe cold nights. Bring in, for forcing, kinds named under Oct. 8 and Roses, etc., under Oct. 29. During the leisure of winter make hot-bed sash, mats, rustic work, trellises, etc.

\section{DECEMBER 17-FIFTY-FIRST WEEK.}

Keep the earth mellow in pots, and the pots clean. Should the soilbecome hard, remove the top and replace with fresh earth. Guard strictly against and destroy all insects. If a plant becomes infested, never allow it to stand among.clean ones. In the Con. fumigate with tobacco frequently as a preventive. Aim to water all plantsjust enough and no more. In the winter, as a rule, never water except in the forenoon. Provide plants with stakes whenever they are required. On airing Con. and W. see Oct. 15.

\section{DECEMBER 24-FIFTY-SECOND WEEK.}

Pay attention to propagating such plavis as are wanted large or early, or of which stock is scarce. Air the Femery a little daily, remove decayed leaves or flouers, and if uater is needed apply it moderately, without fear of harm. As the different Eupatoriums and Stevias pass out of flower, cut down to induce a new growth from which to propagate. 






$$
\text { (3. }
$$

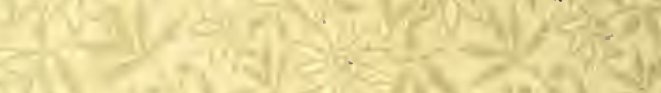

$+4$ 


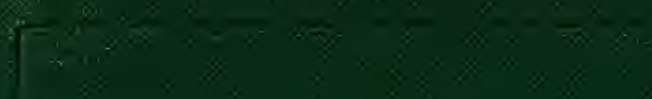

